\title{
Cretaceous to Cenozoic thermo-tectonic evolution and provenance analysis of the basement and some sedimentary successions northeast of the Songliao Basin, NE China
}

\author{
Dissertation \\ zur Erlangung des mathematisch-naturwissenschaftlichen Doktorgrades \\ "Doctor rerum naturalium" \\ der Georg-August-Universität Göttingen \\ im Promotionsprogramm Geowissenschaften / Geographie \\ der Georg-August University School of Science (GAUSS)
}

vorgelegt von

Jianping Zhou

aus Zibo, China

Göttingen 2020 



\section{$\underline{\text { Betreuungsausschuss }}$}

Dr. István Dunkl, Abteilung Sedimentologie, Geowissenschaftliches Zentrum, GeorgAugust-Universität Göttingen

Prof. Dr. Hilmar von Eynatten, Abteilung Sedimentologie, Geowissenschaftliches Zentrum, Georg-August-Universität Göttingen

\section{Mitglieder der Prüfungskommission}

Referent: Prof. Dr. Hilmar von Eynatten, Abteilung Sedimentologie, Geowissenschaftliches Zentrum, Georg-August-Universität Göttingen

Korreferent: Prof. Dr. Jonas Kley, Abteilung Strukturgeologie, Geowissenschaftliches Zentrum, Georg-August-Universität Göttingen

\section{Weitere Mitglieder der Prüfungskommission}

Dr. István Dunkl, Abteilung Sedimentologie, Geowissenschaftliches Zentrum, GeorgAugust-Universität Göttingen

Dr. Volker Karius, Abteilung Sedimentologie, Geowissenschaftliches Zentrum, GeorgAugust-Universität Göttingen

Prof. Dr. Hans Ruppert, Abteilung Sedimentologie, Geowissenschaftliches Zentrum, GeorgAugust-Universität Göttingen

Dr. Klaus Wemmer, Abteilung Isotopengeologie, Geowissenschaftliches Zentrum, GeorgAugust-Universität Göttingen

Tag der mündlichen Prüfung: 29.01.2021 
Cretaceous to Cenozoic thermo-tectonic evolution and provenance analysis of the basement and some sedimentary successions northeast of the Songliao Basin, NE China

Hiermit erkläre ich an Eides statt, die vorliegende Arbeit selbstständig angefertigt zu haben und dabei keine anderen als die von mir angegebenen Quellen und Hilfsmittel benutzt zu haben. Ferner erkläre ich, dass ich nicht anderweitig versucht habe, eine Dissertation einzureichen.

Göttingen, den 20. Dezember 2020

Jianping Zhou 


\section{Table of Contents}

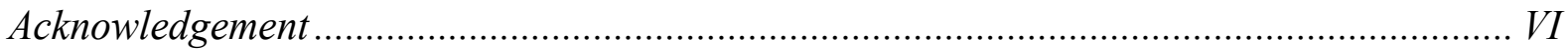

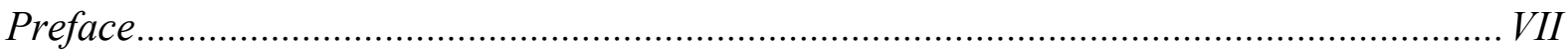

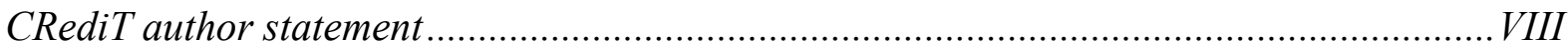

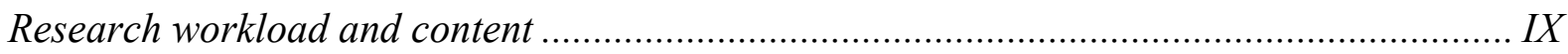

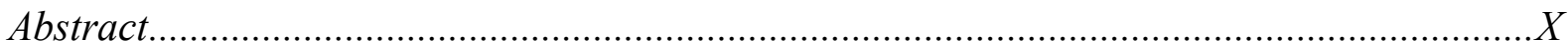

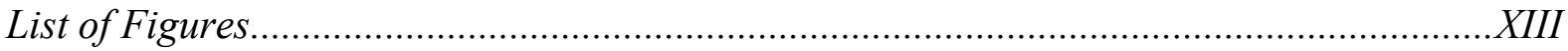

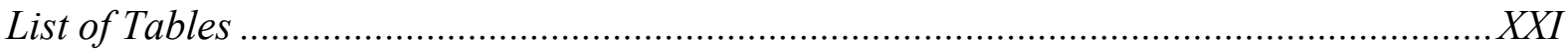

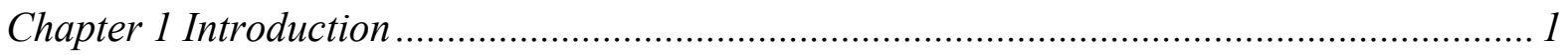

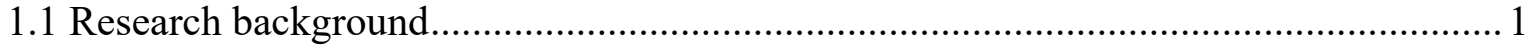

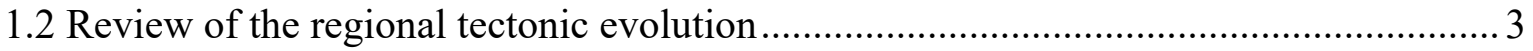

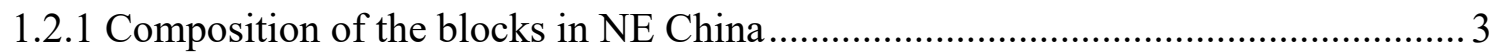

1.2.2 Paleozoic basement amalgamation period in NE China......................................... 4

1.2.3 The closure of the Mongol-Okhotsk ocean and the influence of Paleo Pacific plate subduction on NE China in the Mesozoic-Cenozoic...................................................... 7

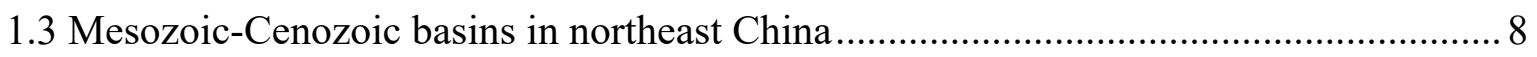

1.4 Low-temperature thermochronology studies in northeast China .............................. 10

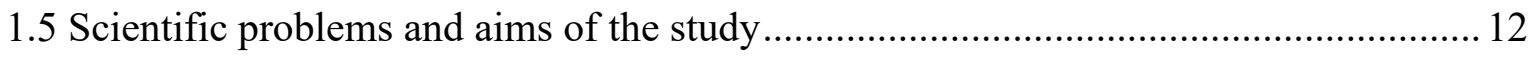

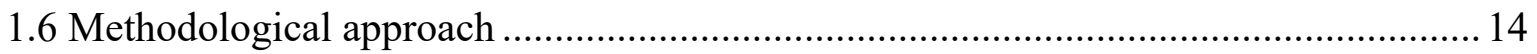

Chapter 2 Manuscript I: Late Cretaceous-Tertiary tectonic inversion of northeastern Asian continental margin: insight from the low temperature thermochronology in NE China ........ 16

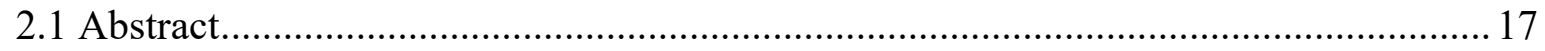

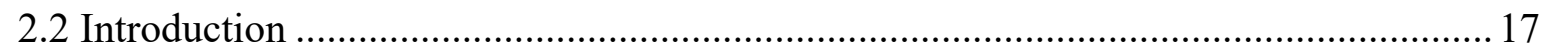

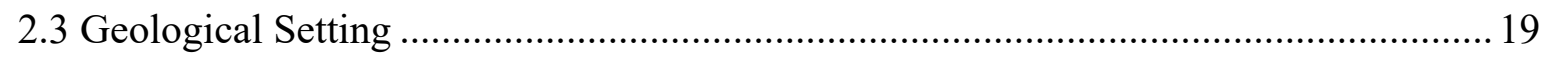

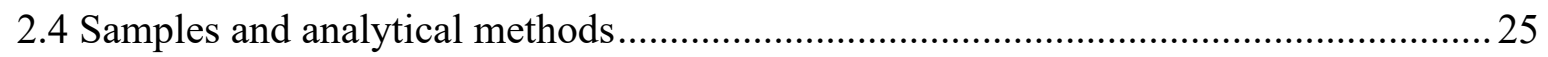

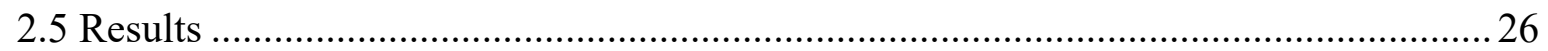

2.6 Tandem modelling of the thermal and burial history to the east of the Songliao basin 40 
2.8 Conclusions

Acknowledgments

Chapter 3 Manuscript II: Miocene age of the Huanan basalt lava flow (NE China) inferred by reset of zircon (U-Th) /He thermochronometer in the underlying sand

3.1 Abstract.

3.2 Introduction

3.3 Geological setting.

3.4 Sample and analytical methods

3.5 Results

3.6 Discussion. 66

3.7 Conclusion .74

Acknowledgements .75

Chapter 4 Manuscript III: Does U-Pb signatures of river sediment represent the age distributions in the catchments? A study of variegated catchments along the eastern border of the Songliao Basin, NE China.

4.1 Abstract

4.2 Introduction .78

4.3 Bedrock geology of NE China ....... 80

4.4 Samples and geological review of the sampled rivers' catchments 81

4.5 Analytical methods 84

4.6 Results .84

4.7 Discussion. 87

4.8 Conclusion 102

Acknowledgements 103

Chapter 5 Summary 104

Bibliography 108 


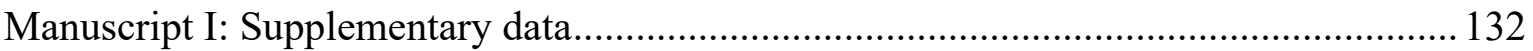

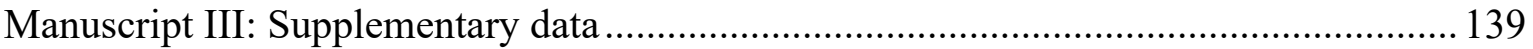


Cretaceous to Cenozoic thermo-tectonic evolution and provenance analysis of the basement and some sedimentary successions northeast of the Songliao Basin, NE China

\section{Acknowledgement}

First of all, I would like to thank all members of the Department of Sedimentology and Environmental Geology. It was a pleasure to work with such an excellent team in a friendly, positive and familiar atmosphere. My special gratitude goes to my supervisors Dr. István Dunk1 and Prof. Dr. Hilmar von Eynatten for the possibility of doing research together, science talks, discussions on many ideas during the whole time of my thesis. They also teach me a lot about ethics and how to be a professional geologist. The experimental chances, adequate funding provided by them are important guarantees for the completion of my study. My special gratitude goes to Prof. Yongjiang Liu for his endless trust, professional guidance and financial support throughout my postgraduate study period. Thanks to Prof. Dr. Weimin Li for his instructions and help during the fieldwork and thesis writing.

Special thanks to my wife Duozi Li and my lovely daughter Anqi for never-ending support, love and joy.

Many thanks for a lot of help in the lab to Judit Dunklné Nagy, Irina Ottenbacher, Cornelia Friedrich, Dr. Keno Lüsdorf, Dr. Volker Karius, Dr. Mathias Hueck, Dr. Róbert Arató, Anna Wolf and the workshop of the GZG. Many thanks to Zhaoxu Chen for his endless help during the fieldwork. Many thanks for much support in the department to Ines Ringel. Her super warm heart helping both in work and daily life lighted my study and life in Germany. Many thanks to Dr. Ingo Hache and Caren for their help at anytime, anywhere.

Finally, I wish to thank my friends and family for constant encouragement and emotional support during the past four years of my PhD project. 


\section{Preface}

This cumulative doctoral thesis is composed of 5 chapters. The first chapter presents a short introduction to the main issues of the thesis and outlines the motivation and main objectives. The following chapters 2 to 4 are manuscripts, which have been published in or submitted to international peer-reviewed journals. The last chapter is a short synopsis, highlighting the most important results of the study.

List of articles included in this thesis:

Zhou, J., Dunkl, I., Liu, Y., Li, W., von Eynatten, H. (2020, published online). Late Cretaceous-Tertiary tectonic inversion of northeastern Asian continental margin: Insight from the low temperature thermochronology in NE China. Gondwana Research. (https://doi.org/10.1016/j.gr.2020.05.017).

Zhou, J., Dunkl, I., Liu, Y., Li, W., Wolf, A., von Eynatten, H. (2020). Miocene age of the Huanan basalt lava flow (NE China) inferred by reset of zircon (U-Th)/He thermochronometer in the underlying sand. Geological Journal, 55(11), 7443-7457.

Zhou, J., Dunkl, I., Liu, Y., Li, W., von Eynatten, H. (submitted to Sedimentary Geology in 12/2020). Does zircon U-Pb signatures of river sediment represent the age distributions in the catchments? A study of variegated catchments along the eastern border of the Songliao Basin, NE China. 
Cretaceous to Cenozoic thermo-tectonic evolution and provenance analysis of the basement and some sedimentary successions northeast of the Songliao Basin, NE China

\section{CRediT author statement}

This $\mathrm{PhD}$ research was funded by the Geoscience Center of the University of Göttingen and the China Scholarship Council (2016094678). All analytical work has been performed at the Geoscience Center Göttingen. Further support was provided by the National Key R\&D Program of China (Grant No. 2017YFC0601300-01), Qingdao Leading innovation talents (19-3-2-19-zhc), and Taishan Scholars (ts20190918).

Topic 1: Late Cretaceous-Tertiary tectonic inversion of northeastern Asian continental margin: Insight from the low temperature thermochronology in NE China.

István Dunkl, Yongjiang Liu, Weimin Li and I designed and participated in the field trip in NE China for field observation, description and sampling in 2017. István Dunkl and I designed the second field trip in NE China. Zhaoxu Chen and I participated in the second field trip aiming at complementary field observation, description and sampling in 2018. Under the supervision of István Dunkl, I was responsible for the heavy mineral concentrates, (U-Th)/He and fissiontrack analyses. Yongjiang Liu provided vitrinite reflectance data. István Dunkl conducted the $\mathrm{U}-\mathrm{Pb}$ dating. István Dunkl instructed me on the data interpretation as well as basin and timetemperature modelling. As the main author, I wrote a first draft of the manuscript which was carefully discussed, reviewed and edited by both supervisors Hilmar von Eynatten and István Dunkl.

Topic 2: Miocene age of the Huanan basalt lava flow (NE China) inferred by reset of zircon $(U-T h) / H e$ thermochronometer in the underlying sand.

István Dunkl, Yongjiang Liu, Weimin Li and I designed and participated in field observation, description and sampling in 2017. Under the supervision of István Dunkl, I was responsible for the heavy mineral concentrates and (U-Th)/He analyses. Anna Wolf conducted the Raman spectroscopy analyses. István Dunkl instructed me on the data interpretation. As the main author, I wrote a first draft of the manuscript which was carefully discussed, reviewed and edited by both supervisors Hilmar von Eynatten and István Dunkl.

Topic 3: Does zircon U-Pb signatures of river sediment represent the age distributions in the catchments? A study of variegated catchments along the eastern border of the Songliao Basin, NE China. 
István Dunkl, Yongjiang Liu, Weimin Li and I designed and participated in field observation, description and sampling in 2017. Under the supervision of István Dunkl, I was responsible for the heavy mineral concentrates and sample preparation for $\mathrm{U}-\mathrm{Pb}$ dating. István Dunkl conducted the $\mathrm{U}-\mathrm{Pb}$ dating, and instructed me on the data interpretation. As the main author, I wrote a first draft of the manuscript which was carefully discussed, reviewed and edited by both supervisors Hilmar von Eynatten and István Dunkl.

\section{Research workload and content}

Work completed during the $\mathrm{PhD}$ study was as follows:

(1) Two fieldtrips: work included planning, field observation, description and sampling. The working area is situated in eastern NE China between the city of Changchun and the Amur river. There were 104 field points recorded and more than 80 rock samples were collected.

(2) Separation of accessory minerals was performed on 79 samples.

(3) Apatite (U-Th)/He dating of 39 samples, zircon (U-Th)/He dating of 9 samples, apatite fission-track dating of 14 samples, zircon $\mathrm{U}-\mathrm{Pb}$ dating of 9 samples and zircon Raman spectroscopy of 4 samples were performed at the Geoscience Center of the University of Göttingen.

(4) Attended $16^{\text {th }}$ International Conference on Thermochronology (Thermo 2018), published one abstract, gave one poster presentation; attended the GeoUtrecht 2020 Conference, published one abstract, gave one oral presentation.

(5) Two SCI papers published and 1 SCI paper submitted. 


\section{Abstract}

The major aim of this $\mathrm{PhD}$ thesis is to explore the post-Early Mesozoic thermo-tectonic evolution and provenance analysis of the area of satellite basins to the east of the Songliao basin in NE China, covering a huge area, over 200,000 $\mathrm{km}^{2}$. Comparing with the Songliao basin, the thermo-tectonic evolution of the basins and basement highs separating them is still less understood. Therefore, an integrated evaluation of the thermal history of the basement highs and the basin remnants was firstly performed using low-T thermochronology and burial/thermal modelling based on vitrinite reflectance data. The studied Mesozoic sedimentary formations and the basement are penetrated and partly covered by Cenozoic mafic volcanic rocks. As supplementary research to the regional thermal evolution study, a case study was performed on the thermally influenced substrate of a basalt lava flow. Raman spectroscopy and zircon (U-Th)/He thermochronology were applied to detect the thermal effect of the lava flow and determine the eruption age. Detrital zircon $\mathrm{U}-\mathrm{Pb}$ age distributions from modern sands provide useful insights to detect, verify or re-classify the ages of the zircon-bearing units in the catchments. Moreover, combining the modern age data with a regional compilation of ages from the basement units and some Mesozoic sedimentary formations allows for refining the Cretaceous provenance history of the region. Finally, the inferred provenance evolution is checked against the thermo-tectonic evolution. Sand samples from five modern rivers whose catchments drain most of the currently elevated basement blocks of eastern NE China were investigated with the detrital zircon $\mathrm{U}-\mathrm{Pb}$ geochronology method. The Cretaceous supply's temporal change is well discussed by carefully considering multiple influencing factors to the modern sediments' provenance analysis and referring to the well-studied igneous basement units. The supposed regional geological evolution model is mutually verified with our regional thermo-tectonic evolution.

After a short introduction to the subject (Chapter 1), the new data from the study area is presented and discussed in Chapters 2 to 4. In Chapter 2, apatite and zircon (U-Th)/He and apatite fission-track results from most basement highs in eastern NE China are presented. The low-T thermochronometers show mostly Late Cretaceous - early Paleogene apparent ages, younger than the onset of the Early Cretaceous burial in the Songliao and related satellite basins. These age constraints are in harmony with the thermal modelling of vitrinite reflectance data from the basins, which indicates that the maximum burial depth occurred in mid-Cretaceous. The following primary basin inversion leads to erosion from ca. $110 \mathrm{ca} .40 \mathrm{Ma}$. The modelling 
indicated that in the Jiamusi Uplift, the central part experienced deeper erosion than the marginal areas. Combining the above modelling results, we suggest a single united downwarped basin which formed in the Early Cretaceous and covered the currently elevated western Zhangguangcai Range and eastern Mishan Uplift at the time of its maximum extent. The Late Cretaceous - Paleogene exhumation of the Jiamusi Uplift gradually destroyed the formerly continuous, 1.6 to $4.8 \mathrm{~km}$ thick sedimentary cover. Only isolated, deeply eroded basin remnants have been preserved.

Chapter 3 focuses on the dating of young mafic lava with an unconventional method. Mafic lavas of the Cenozoic age are widely distributed in NE China and received much attention as an important part of the Circum-Pacific volcanic belt. We present new zircon (U-Th)/He ages obtained on the thermally overprinted sands directly underlying basaltic lava. This thermochronometer is insensitive to weathering and cannot be biased by, e.g., excess argon; thus, it can accurately express the age of the lava flow's thermal effect. As a regional cooling age reference, three granite samples were dated from basement units away from the basalt lavas at different distances. The reference granite samples revealed well-defined Cretaceous (U$\mathrm{Th}$ )/He-ages, while 20 zircon crystals from the sand below the basalt lava revealed a prominent Miocene $(\mathrm{U}-\mathrm{Th}) / \mathrm{He}$ age component of $9.33 \pm 0.24 \mathrm{Ma}$. Raman spectroscopy of these zircon crystals supports their thermally overprinted character. We infer that the sand sample has experienced a significant thermal overprint by the overlying basalt lava, leading to most of the detrital zircon crystals' thermal reset. The obtained age is thus interpreted as the eruption age of the basalt lava. The dating results provide strict constraints on the thermal influence of the regional volcanic units on reconstructing the study area's thermo-tectonic evolution history.

Chapter 4 provides detrital zircon $\mathrm{U}-\mathrm{Pb}$ data from modern sand samples of five rivers draining catchments of variable size $\left(\sim 500\right.$ to $\left.\sim 40.000 \mathrm{~km}^{2}\right)$, dominated by Carboniferous to Jurassic granitoids, Proterozoic to Early Paleozoic siliciclastic (meta-)sediments, and/or Jurassic to Cenozoic volcanic rocks from the Lesser Xing'an-Zhangguangcai Range and the Jiamusi block. Our results show low consistency between the age spectra and the potential source units' areas in the catchment. A part of the differences can be explained by variation in fertility and sediment yield among the source units. Additionally, we detected a consequent mismatch between the obtained and expected ages. It can be explained only by re-considering some igneous suites' emplacement ages and assuming that some metasedimentary units have much younger depositional ages. Although the proportion of the identified age components is highly 
different from the areal proportions of the igneous suites in the catchments, the mean ages of the age components in the modern sand samples and the age components isolated from the compiled U-Pb ages of the former basement studies show excellent agreement. By including the zircon $\mathrm{U}-\mathrm{Pb}$ age patterns of the studied catchments and the region-wide compilation of the basement ages, it is possible to refine the Cretaceous provenance of the Songliao Basin and its strongly inverted eastern satellite basins. In the Early Cretaceous, the Songliao Basin mainly received sediment from the Great Xing'an Range, North China Craton, and Zhangguangcai Range. The Lesser Xing'an Range and Jiamusi block provided minor or no sediment as these currently exhumed basement areas were buried at the time. In the early Late Cretaceous, the Jiamusi block became the primary sediment provider for the eastern satellite basins.

To conclude, the low-temperature thermochronology studies on the currently exposed basement areas in eastern NE China area revealed that late Early Cretaceous to Late Cretaceous continuous subsidence primarily led to the reset of the thermochronometers from the basement highs and basin sediments; the volcanic thermal influence was minor or negligible. Using the detrital zircon $\mathrm{U}-\mathrm{Pb}$ data from this study, both the thermal-tectonic evolution model and the temporal change in Cretaceous sediment provide evidence for the forming of a huge Early Cretaceous united down-warped basin that covered most of the current eastern satellite basins and basement highs in the eastern NE China area. From ca. 110 to $40 \mathrm{Ma}$, the exhumation of the Jiamusi Uplift has gradually destroyed the formerly continuous sedimentary cover, and only basin remnants have been preserved. By the end of the major exhumation in the Eocene, both the major uplift areas and the basin remnants developed towards a slow uplift and erosion stage which continued until recent times. 


\section{List of Figures}

Figure 1.1: (a) Schematic tectonic map of Asia indicating the position of the study area (modified after Kröner et al., 2014; Liu et al., 2017). (b) Map of major terranes of NE China and adjacent areas (after Zhou et al., 2009; Liu et al., 2017).

Figure 1.2: (a) Schematic tectonic map of Asia indicating the position of the study area (modified after Li, 2006; Safonova et al., 2009, 2011; Kröner et al., 2014; Liu et al., 2016). (b) Digital elevation map of NE China, showing the major basins by green, and the borders of tectonic blocks (after Zhou et al., 2009; Liu et al., 2017). The base digital elevation model is from the U.S. Geological Survey (2017).

Figure 1.3: The outline of the Jiamusi-Mongolia Block (after Liu et al., 2017). 5

Figure 1.4: A cartoon showing the possible Late Triassic amalgamations of the micro blocks along the NE Asian margin (after Zhou et al., 2013; Li et al., 2020). CAOB = Central Asian Orogenic Belt; $J B=$ Bureya-Jiamusi-Khanka block; EB=Erguna block; XB=Xing'an block; $S X B=$ Songliao-Xilinhot block; $Q B=$ Qaidam block; TB= Turpan terrance; TMB= TuvaMongol block; Suo= Japan Suo metamorphic belt; $C Y=$ Changchun-Yanji metamorphic belt; $H L=$ Heilongjiang metamorphic belt.

Figure 1.5: Compilation of the stratigraphy of the basins in NE China (after Zhang et al., 2010, 2012; Qie, 2009; Gao, 2010). Circled numbers indicate the major basing filling sedimentary and volcanic formations: 1 - Didao, 2 - Chengzihe, 3 - Muling, 4 - Dongshan and 5 - Houshigou. Zig-zag line: erosional unconformity.

Figure 1.6: Compilation of the formerly published low-T thermochronological data of the study area (the ages are in Ma; after Yang et al., 1995; Fang et al., 2005; Xiang et al., 2007; Fang et al., 2008; Li et al. 2011a, b; and Chen, 2016; Cheng et al., 2018; Song et al., 2018)....... 11

Figure 1.7: Simplified geological map of the study area (modified after Ren et al., 2013).... 13

Figure 2.1: (a) Schematic tectonic map of Asia indicating the position of the Songliao basin (modified after Li, 2006; Safonova et al., 2009, 2011; Kröner et al., 2014; Liu, et al., 2016).

(b) Digital elevation map of NE China, showing the major basins by green, and the bordering faults of tectonic blocks (after Zhou et al., 2009; Liu et al., 2017). Red line: fault; black dashed 
Cretaceous to Cenozoic thermo-tectonic evolution and provenance analysis of the basement and some sedimentary successions northeast of the Songliao Basin, NE China

line: suture zone; gray dashed line: national boundary. The rectangle represents the study area that covers most of the east NE China, see details in Figure 2. The shadowed areas represent the major uplifts, and collectively referred to the Jiamusi Uplift. The base digital elevation model from the G.S. Geological Survey (2017) .18

Figure 2.2: Geological map of the study area and the locations of the thermochronological samples indicated by stars (map is simplified after Ren et al., 2013). The digital elevation model is taken from the U.S. Geological Survey (2017).

Figure 2.3: Compilation of the stratigraphy of the basins in NE China (after Zhang et al., 2010, 2012; Qie, 2009; Gao, 2010). Roman numbers along with basin names refer to the numbering in Fig. 1b. Circled numbers indicate the major basing filling sedimentary and volcanic formations: 1 - Didao, 2 - Chengzihe, 3 - Muling, 4 - Dongshan and 5 - Houshigou. Zig-zag line: erosional unconformity.

Figure 2.4: Compilation of subsidence trends in the Songliao basin (Wang et al. 2016) and some representative wells of the eastern satellite basins between 150 and $60 \mathrm{Ma}$. The question marks indicate the unknown termination of the burial-exhumation histories of the studied boreholes. No younger stratigraphical information is available from these sites; see discussion in the text. 24

Figure 2.5: Map of low-T thermochronological data of the study area. The uncertainties and other analytical details are listed in Tables 2.2 and 2.3. The compilation of the formerly published AFT results is from Li et al. (2011a, b) and Chen (2016). The compilation of the formerly published igneous rock zircon $\mathrm{U}-\mathrm{Pb}$ age results is from Wu et al. (2011), Yu et al. (2012, 2013), Bi et al. (2014), Yang et al. (2014), Wang et al. (2016) and Dong et al. (2017).

Figure 2.6: Overview of the available down-hole vitrinite reflectance values and the burialexhumation modelling results performed by PetroMod software on selected boreholes of the eastern basin group. The good match of the calculated and measured Ro\% data indicates the reliability of the modelling results. The presented burial curves are only a selection of the burial scenarios that yielded good match to the measured vitrinite reflectance data. The total eroded thickness and the paleo heat flow are used as variables for the modelling of different 
burial scenarios, see text for details. K1d, Early Cretaceous Didao formation; K1c, Early Cretaceous Chengzihe formation; K1m, Early Cretaceous Muling formation; Klds, Early Cretaceous Dongshan formation; K2, Upper Cretaceous; Pg, Paleogene; N, Neogene. For the legend of the simplified geological map see Figure 2.5.

Figure 2.7: Results of the time-temperature modelling of the exhumed basement areas northeast of the Songliao Basin. The input data were the apatite fission track ages and track length distributions, the apatite and zircon (U-Th)/He ages, the actinide contents and dimensions of the dated crystals (AFT: apatite fission track; AHe or ZHe: apatite or zircon (UTh)/He). For each model, 100,000 random paths were generated or the modeling procedure was stopped after 100 good paths. GOF: goodness of fit between the modelled and measured results. The numbers of good (red, GOF>0.5) and acceptable (green, GOF>0.05) paths are indicated on the plots. Blue paths denote the weighted mean paths of the good models. Black paths denote the best-fit paths for the models shown. 45

Figure 2.8: Overview of the PetroMod (Schlumberger) modelling results of the basement areas. For the legend of the simplified geological map, see Figure 5. In the burial plots of each modelled well the gray parts represent the accumulation-removal history of the missing cover sequences. All five plots reveal the situation where the residual error has a minimum value; see details in text. K1, Lower Cretaceous; K2, Upper Cretaceous; Pg, Paleogene; N, Neogene.

Figure 2.9: Residual error plots showing the interrelation of the paleo-heat flow and thickness of missing sequences (eroded thickness) for the five wells where the burial history was modelled. The values on the isolines represent the sum of the residual error (SRE) between the modelled vitrinite reflectance data and the measured ones. The isolines on the plots were generated by the Surfer software according to the five PetroMod modelling runs assuming different heat flow-burial combinations. The white band represents the smallest SRE. For the legend of the simplified geological map, see Figure 2.5.

Figure 2.10: Estimation of the thickness of the missing sequences (eroded thickness) and the paleo-heat flow at the time of sedimentary cover for five selected basement sample sites. The residual error plots were generated by a combined modelling using PetroMod (Schlumberger) and HeFTy (Ketcham, 2005) software assuming different thickness and heat flow values as input data. The lines of the different thermochronological parameters indicate a kind of 
Cretaceous to Cenozoic thermo-tectonic evolution and provenance analysis of the basement and some sedimentary successions northeast of the Songliao Basin, NE China

threshold of acceptance and the lighter colored side indicates the better match of the modelled values and the measured values. The white belts represent the best fit conditions, when the burial and heat flow interplay resulted in thermal histories that generated low-T thermochronological data close to the measured ones. AHe, ZHe: apatite or zircon $(U-T h) / H e$ age, AFT: apatite fission track age, MTL: mean confined horizontal track lengths in the apatite crystals. For the legend of the simplified geological map, see Figure 2.5. 50

Figure 2.11: Compilation of the thickness of the missing sequences calculated for the basement highs and basin areas. The numbers represent the eroded thickness in $\mathrm{km}$. The numbers in rectangles were determined by modelling of low-T thermochronological data and express the total removed thickness (sedimentary pile + some erosion of the basement). The numbers in ellipses are the modelling results based on vitrinite reflectance down-hole trends and they express the thickness of the post-Early Cretaceous burial. The assumed paleo-heat flow is 60 $\mathrm{mW} / \mathrm{m}^{2}$, that corresponds to the bulk average value of the region, see text for details. The estimated thickness of the removed sedimentary formations in the central Songliao basin is taken from Lu et al. (2005), Liu et al. (2013) and Wang et al. (2016). For the legend of the simplified geological map see Figure 2.5.

Figure 3.1: (a) Simplified geological map of NE China, modified after Ren et al. (2013) and HBGMR (1993). The occurrences of basalt volcanoes and their age (in Ma) are taken from Fan, Sun, Li, and Wang (2006), Fan et al. (2011), Fan, Zhao, Sui, Li, and Wu (2012), Liu (1987), Liu, Chen, Zhong, Lin, and Wang (2017), Liu et al. (2017), Qiu, Liao, and Liu (1991), and Zhang, Xu, Ge, and Ma (2006). The digital elevation model is from the U.S. Geological Survey, 2017. The two faults marked with (1) and (2) are the Jiamusi-Yitong and DunhuaMishan faults, respectively, and belong to the eastward extension of the Tan-Lu Fault Zone in NE China. Dashed box indicates position of Figure 2. (b) Schematic tectonic map of North Asia (modified after Liu, Chen, et al., 2017; Liu, Li, et al., 2017) 59

Figure 3.2: Simplified geological map of the study area, modified after HBGMR (1993). The digital elevation model is taken from the U.S. Geological Survey, 2017. Pt, Palaeoproterozoic strata; J, Jurassic strata; K1, lower Cretaceous strata; N1, Miocene strata; Q2-3, Middle to Upper Quaternary strata; Q4, Holocene strata; $\gamma$ : Permian granite; $\beta$ : Cenozoic basalt; yellow star: sample locations in this article and the measured (U-Th)/He age; black star: zircon $U_{-}$ 
Pb age of granitoids (Dong et al., 2017); Solid black lines: faults; dotted black lines: unconformities.

Figure 3.3: Photographs illustrating the basalt lava outcrop and its base close to Qunli village. Thickness of the lava flow in the upper left photo is 2-3 meter. 62

Figure 3.4: Microphotographs of the dated zircon crystals along with the effective $U$ concentration (eU, where e $U$ is calculated as $U+0.235 *$ Th; Gastil et al., 1967) and the (UTh)/He age.

Figure 3.5: Cumulative diagram of zircon (U-Th)/He ages obtained on 20 single crystals from the sand sample (JB40; $2 \sigma$ error bars). 68

Figure 3.6: Effective U concentration (eU) vs. zircon (U-Th)/He ages plot for the sand sample JB40 and the three granitoid samples. Each symbol represents a single dated zircon crystal.

Figure 3.7: Kernel density plot of the measured zircon $(U-T h) / H e$ ages and the best fitted model between the measured ages and calculated ages. Grey curve: kernel density plot of the 20 measured zircon crystals (calculated by DensityPlotter, Vermeesch, 2012); cycles: single zircon crystals; inset shows cumulative plot of ZHe ages; horizontal line in the insert: the real measured single detrital zircon crystals' He-ages; curve in the insert: the best fit line between the real data and the calculated model; $K-S$ test: the Kolmogorov-Smirnov test (method after Press, Flannery, Teukolsky, \& Vetterling, 1996); RMS: the goodness of fit between the calculated model and the measured data, the lower the value the better (method after Cserepes, 1989); bins in the insert: the error of the model.

Figure 3.8: Plot of Raman shift versus the full width at half-maximum of the $v_{3}\left(\mathrm{SiO}_{4}\right)$ vibration (FWHM) for the sand sample JB40 and the three granitoid samples.

Figure 3.9: Age and major rock types of the ten Cenozoic volcanic formations in Northeast China (modified after Liu, 1988). Green bar indicates the age of the basalt eruption dated by the JB40 sample of this study. 74

Figure 4.1: (a) Schematic tectonic map of Asia indicating the position of the study area (modified after Li, 2006; Safonova et al., 2009, 2011; Kröner et al., 2014; Liu, et al., 2017). 
EB, Erguna block; SXB, Songliao-Xilinhot block; XB, Xing'an block; BJKB, Bureya-JiamusiKhanka block. (b) Geological map of the study area including the locations of the river sand samples indicated by yellow stars. The contours of the sampled catchments are indicated by white lines. JB, Jiamusi block. Detailed geological map of each sampled tributary sees in Fig. 2. The map base is simplified after Ren et al. (2013) and the digital elevation model is taken from the U.S. Geological Survey (2017) .79

Figure 4.2: Geological maps of the sampled catchments (the geological units are simplified after JBGMR, 1988; HBGMR, 1993; IMBGMR, 1991). The digital elevation model is from the U.S. Geological Survey (2017). 82

Figure 4.3: Detrital zircon U-Pb age spectra obtained on the river sand samples from NE China. The plots present binned age histograms, kernel density estimation curves and the age components identified by the Density Plotter software (Vermeesch, 2012). The age scales of the plots are different; $n=$ number of $U-P b$ data with 90-110\% concordance. The discrete single ages which are not included in the age component calculation are excluded from the percentage calculation. 86

Figure 4.4: $U$-Pb ages versus $T h / U$ ratios of detrital zircons from the five sand samples of the studied catchments. The dashed line marks $T h / U$ ratio of 0.1 .

Figure 4.5: Comparison of the areal proportions of the different units in the catchments and the proportions of the obtained detrital zircon U-Pb ages. (a) Pre-Quaternary geological units, without the Cenozoic basalts, (b) proportions of the modelled age components, and (c) proportions of the single-grain zircon $\mathrm{U}-\mathrm{Pb}$ ages assigned to the chronostratigraphic periods after Cohen et al. (2019). Arrows related to \#1 to \#15 indicate possible zircon provenance as discussed in the text; numbers marked in black label represent units of the catchments that are not detected in the detrital zircon $U-P b$ age spectra.

Figure 4.6: Comparison of the mean zirconium contents with 1 s standard errors of the granitoid rocks from the study area, considering their emplacement ages. References provided in supplementary datafile in Appendix A3. ZGC: Zhangguangcai Range area; LXR: Lesser Xing'an Range area; JB: Jiamusi block. 93 
Figure 4.7: Comparison of the detrital zircon U-Pb age spectra of the modern river sediments (blue symbols) with the compilation of the published bedrock $U$-Pb ages of the tectonic blocks that host the catchments (yellow symbols; see sources of data in Appendix Table A2). The gray tables at the right show the age components identified by the DensityPlotter software (Vermeesch, 2012).

Figure 4.8: Pie-diagrams showing the simplified age spectra of the new detrital zircon U-Pb ages in the river sand samples, the compiled zircon $U$-Pb ages of the igneous rocks of the exposed basement highs (with black rim), and the compiled detrital age spectra determined in the Cretaceous siliciclastic formations (with white rim; data after Wu et al., 2002, 2003, 2004a,b, 2011, Chen et al., 2009; Ge et al., 2005, 2007; Xu et al., 2008, 2012, 2013; Y. B. Zhang et al., 2005; L. Zhang et al., 2009; Y. L. Zhang et al., 2008, 2010; Yu et al., 2012; Wang, 2017; Sun et al., 2004, 2005, 2013; Wang et al., 2016; Zhou et al., 2005, 2015; Sui et al., 2006, 2007; Miao, 2003; Miao et al., 2004; Liu et al., 2008, 2009; Meng, et al., 2011; Wilde et al., 1997, 2000, 2003; Shi et al., 2003, 2004; She et al., 2012; Cui et al., 2013; Yang et al., 2014, 2015, 2016; Bi et al., 2014, 2016; Dong et al., 2016, 2017; Ge et al., 2018, Ma et al., 2019; Gao et al., 2007; Guo et al., 2016; Wei et al., 2012; Yu et al., 2012. See sources of data in Appendix Table 2). Simplified geological map is after Wu et al. (2011). Black dots indicate the locations of the igneous basement samples. Compilation of detrital zircon U-Pb ages from Cretaceous sediments: A: southern Songliao Basin; B: middle Songliao Basin; C: Early Cretaceous in Hegang Basin; D: Late Cretaceous in Hegang Basin; E: Early Cretaceous in Sanjiang Basin; F: Late Cretaceous in Sanjiang Basin; G: Boli Basin. 98

Figure 4.9: Compilation of zircon U-Pb ages from the five modern sand samples of this study (A), from igneous rocks of the basement highs of NE China (B) and from Upper (C) and Lower Cretaceous (D) siliciclastic formations of the basins (see sources of data in Appendix Table A2). Note that the data of the basement reflect mean ages of rock samples, not individual grain ages. Blue belts in A-D represent the durations of the three major magmatic periods (TriassicJurassic, Permo-Carboniferous and Early Paleozoic) of the region. Green belts in $C$ and D indicate the sedimentation ages. S. Songliao: South Songliao Basin; C. Songliao: Central Songliao Basin. 100

Figure 4.10: General arrows reveal the temporal change in the Cretaceous sediment supply of the study area. Green and blue arrows: sediment supplies from different areas in Early and 
Late Cretaceous times, respectively. The width of the arrows symbolizes the proportion of the sediment yield.

Appendix Figure 2.1: Radial plots generated from the AFT single-grain ages of 14 basement samples.

Appendix Figure 2.2: Distribution of confined horizontal fission track lengths measured in apatite of the basement samples.

Appendix Figure 2. 3: Concordia plot of laser ablation ICPMS zircon U-Pb data obtained on sample JB27.

Appendix Figure 4.1: Wetherill zircon U-Pb concordia plots from the modern sediments in this study.

Appendix Figure 4.2: Compilation of cited igneous rocks' mean zircon U-Pb ages, Cretaceous sediments distributions and sampled detrital zircon river sand sample in this study results shown as pie charts representing age population. Simplified geological map is after Wu et al. (2011). Black dots indicate the cited igneous rock samples' locations. Red dots indicate the cited Cretaceous sediment samples' locations. A, compilation of detrital zircon U-Pb ages from Cretaceous sediments of southern Songliao Basin; $B$, detrital zircon U-Pb ages from the middle Songliao Basin; $C$, detrital zircon U-Pb ages from eastern Basins. Igneous rocks' mean zircon U-Pb ages and Cretaceous sediments' detrital zircon U-Pb ages are after the same citations shown in Figure 4.6. 


\section{List of Tables}

Table 2.1: Geographical coordinates and petrography of the studied samples

Table 2.2: Apatite fission track results obtained on the basement samples from the NE margin of the Songliao basin.

Table 2.3: Apatite and zircon $(U-T h) / H e$ results obtained on the basement samples from the NE margin of the Songliao basin.

Table 3.1: Zircon (U-Th)/He results obtained on the sand and granite samples in this study.

Table 3.2: The v3(SiO4) Raman band of the zircon samples investigated. 70

Table 4.1: Geographical coordinates of the sampling sites, area and composition of the catchments.

Appendix Table 2.1: Vitrinite reflectance values used for the thermal / subsidence modelling.

Appendix Table 2.2: U-Pb data obtained on samples JB27 and JB28

Appendix Table 4.1: Zircon U-Pb data obtained on the modern sand samples from NE China 141

Appendix Table 4.2: Cited Igneous rock Zircon U-Pb ages 165 Appendix Table 4.3: Cited whole-rock geochemistry zirconium contents from igneous rock units 179 



\section{Chapter 1 Introduction}

\subsection{Research background}

Northeastern China is tectonically located in the area surrounded by the Siberian Craton to the north, the North China Craton (NCC) to the south, and the western Pacific plate to the east, composing the main part of the eastern segment of the Central Asia Orogenic belt (CAOB) (Eizenhöfer et al., 2014; Jahn et al., 2000; Sengör et al., 1993, 1996; Windley et al., 2007; Xiao et al., 2009; see Figure 1.1). The tectonic evolution of the area was closely related to the PaleoAsian Ocean and Paleo-Pacific Ocean regimes during the Paleozoic-Early Mesozoic (Li, 2006; Windley et al., 2007; Li et al., 2009, 2013; Han et al., 2012) and related to the western Pacific Ocean and Mongol-Okhotsk Ocean regimes during and after the Mesozoic (e.g., Donskaya et al., 2013; Xu et al., 2013). Since the Late Paleozoic, it has undergone long-term plate subduction and continent-arc and/or microcontinent-continent collisions before the ultimate collision between the North China-Mongolian Block and the Siberian Craton (e.g., Sengör et al., 1993; Van der Voo et al., 1999; Jia et al., 2004; Li, 2006). Consequently, widespread Phanerozoic granitoids were formed in NE China and along the northern margin of North China Craton (e.g., Wu et al., 2002, 2003, 2005, 2011; Jahn et al., 2001; Meng, 2003). Since the Mesozoic, its evolution is strongly influenced by the closure of the Mongolia-Okhotsk Ocean in the north and the northwestward subduction of the Paleo-Pacific Plate in the east (Meng, 2003; Safonova et al., 2009; Li et al., 2012; Zhang et al., 2012; Xu et al., 2013). With the lithosphere thinning during the Late Jurassic to Early Cretaceous and this stage's Paleo-Pacific plate's fast subduction below the Eurasia continent, intense Mesozoic-Cenozoic tectonic activities led to the northeastern extension of the major Tanlu fault that formed the JiamusiYitong and Dunhua-Mishan faults (Jia and Zheng, 2010; Sun et al., 2010; Figure 1.2b), the development of a series of multi-stage sedimentary basins, exhumation of a metamorphic core complex (Davis et al., 2002; Lin et al., 2008) and widespread magmatism (Zhang et al., 2000; Zhou and Li, 2000; Wang et al., 2006). The unique geotectonic location and complex geological evolution history make this area one of the hotspots studied by geologists to understand the NE Asian tectonic evolution and its regime transition from the Paleozoic to Mesozoic. 

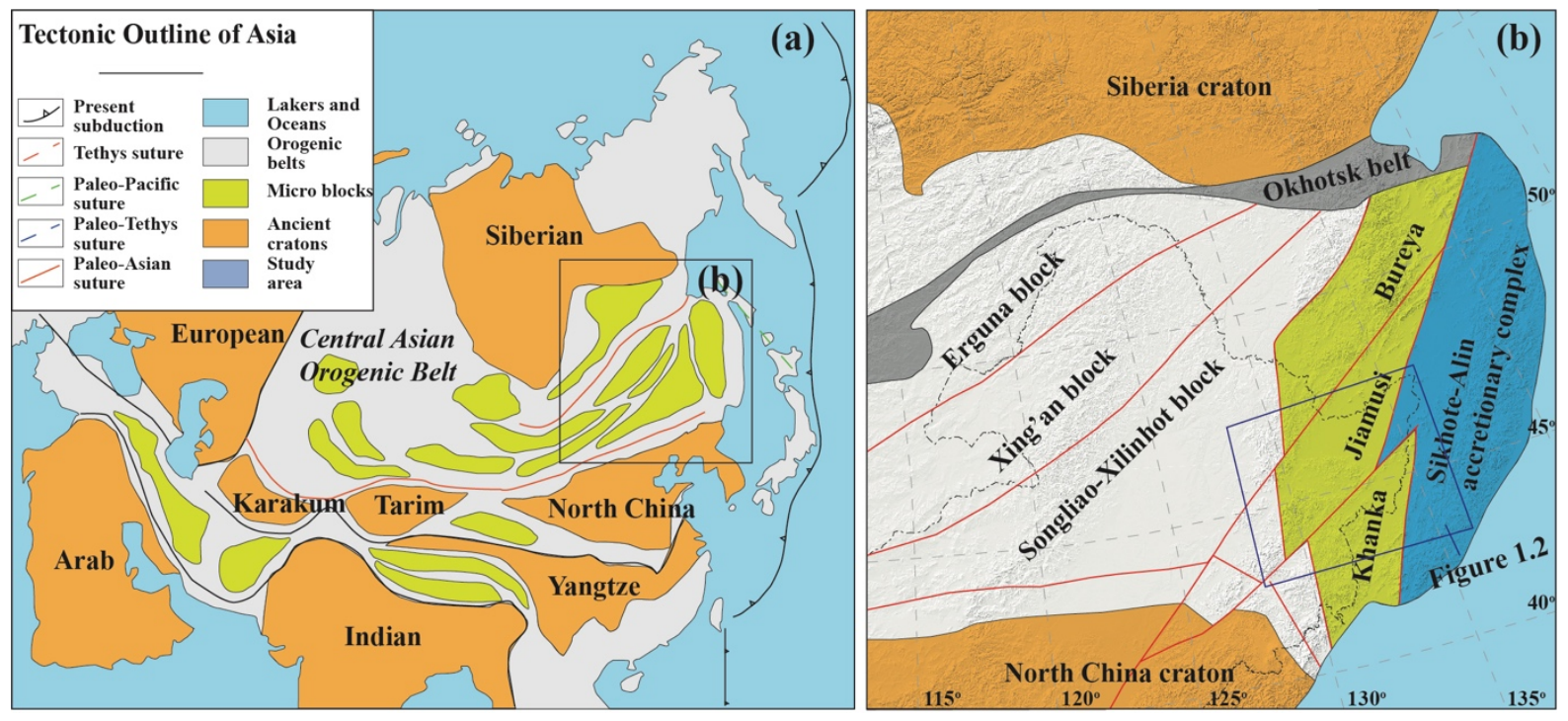

Figure 1.1: (a) Schematic tectonic map of Asia indicating the position of the study area (modified after Kröner et al., 2014; Liu et al., 2017). (b) Map of major terranes of NE China and adjacent areas (after Zhou et al., 2009; Liu et al., 2017).

Since the Mesozoic, accompanied by the intense Mesozoic-Cenozoic tectonic activities, NE China gradually developed one of the largest lacustrine basin systems in the world, including the large Songliao basin and a series of smaller basins east and north-east from the major depression (Tian et al., 1992; Ren et al., 2002; Meng et al., 2003). It is one of the regions with abundant petroleum, natural gas, and coal resources in China, providing plenty of essential information to understand the tectonic evolution of NE China. The oil-rich Cretaceous Songliao basin with the size of ca. $260,000 \mathrm{~km}^{2}$ is in the focus of petroleum exploration since the first oil discovery in 1959. The geophysical exploration gradually revealed the tectonic development of the Songliao basin (e.g., Wang et al., 2016a). However, with the superimposition development of multi-stage basins, most of the eastern satellite basins areas have complicated geological conditions, dense vegetation coverage, late-stage deformation, transformation, etc. The level of knowledge on the evolution of the smaller basin groups to the east of the Songliao basin is still insufficient. Previous studies of sedimentary strata and structural features in these basins mainly rely on drill core and geophysical data, especially seismic profiles. Multi-method studies, including thermochronology to reconstruct the east of the Songliao basin area's thermal history, are scarce. 

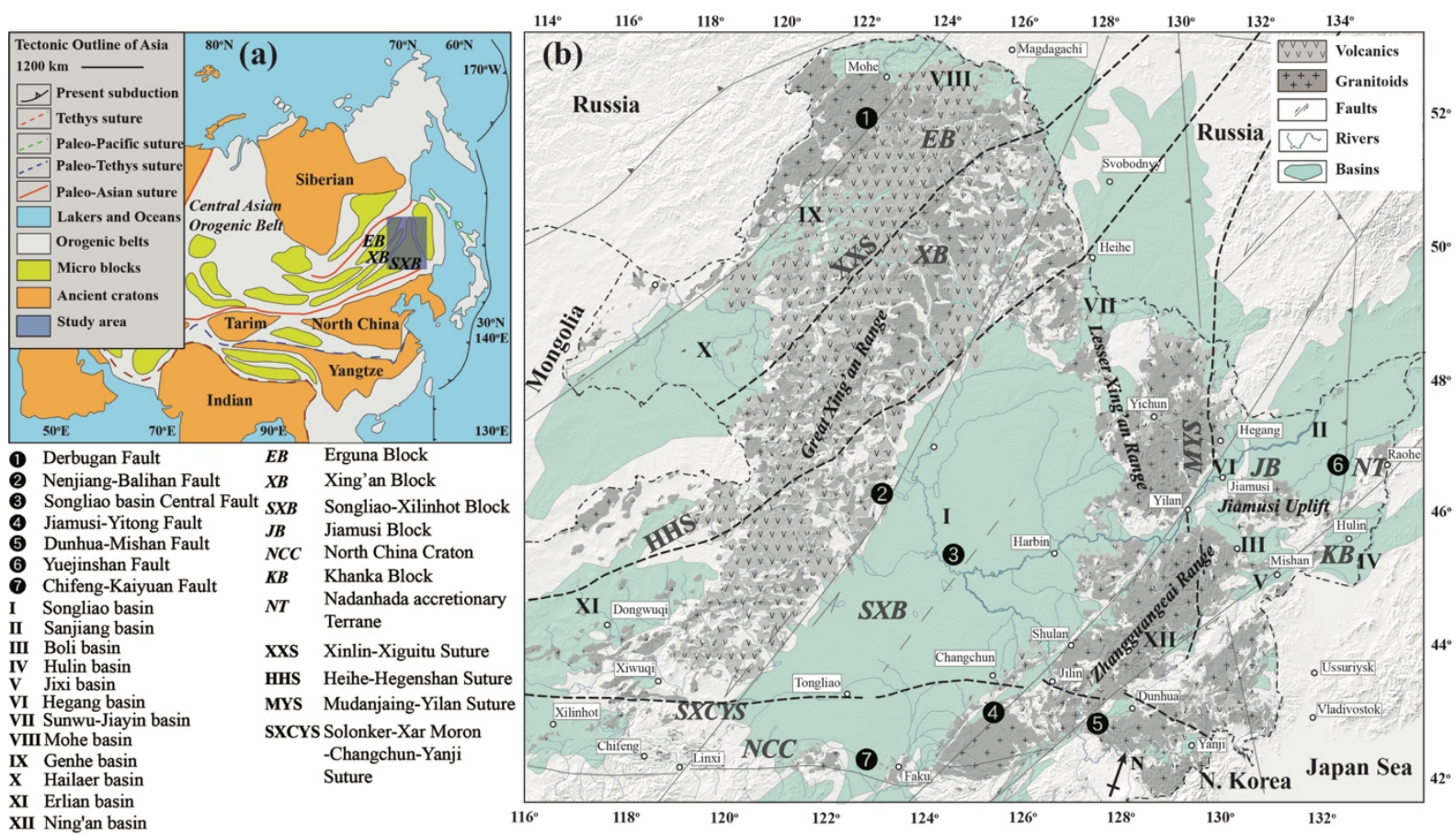

Figure 1.2: (a) Schematic tectonic map of Asia indicating the position of the study area (modified after Li, 2006; Safonova et al., 2009, 2011; Kröner et al., 2014; Liu et al., 2016). (b) Digital elevation map of NE China, showing the major basins by green, and the borders of tectonic blocks (after Zhou et al., 2009; Liu et al., 2017). The base digital elevation model is from the U.S. Geological Survey (2017).

This $\mathrm{PhD}$ thesis focused on the satellite basins and their associated basement areas, intending to explore the post-Early Mesozoic thermo-tectonic evolution and provenance analysis of the eastern Songliao basin in NE China. Therefore, an integrated evaluation of the thermal history of both the basement highs and the basin remnants was performed using low-T thermochronology and burial/thermal modelling based on vitrinite reflectance data, respectively. The detrital zircon $\mathrm{U}-\mathrm{Pb}$ dating on the modern river sand studies are further aimed to reveal the temporal change in the Cretaceous sediment supply of the Songliao basin and its strongly inverted eastern satellite basins, which is expected to verify with our regional thermaltectonic evolution model.

\subsection{Review of the regional tectonic evolution}

\subsubsection{Composition of the blocks in NE China}

The area of NE China mainly contains the Erguna block (EB), Xing'an block (XB), SongliaoXilinhot block (SXB), Bureya-Jiamusi-Khanka block and Sikhote-Alin accretionary complex (Figures 1.1, 1.2). The Erguna block, Xing'an block and Songliao-Xilinhot block, belonging 
to the western NE China area, were separated by Xinlin-Xiguitu suture zone and HegenshanHeihe suture zone in turn. The Buruaya-Jiamusi-Khanka block and the Nadanhada accretionary terrane were separated from west to east by the Mudanjiang suture zone, Jiamusi-Yitong fault, Dunhua-Mishan fault and Yuejinshan fault (Figure 1.2). The Okhotsk belt in the north recorded the closure of the Mongol-Okhotsk Ocean which was located between the Siberia craton and the combined North China block during the Late Paleozoic-Mesozoic (Figure 1.1b; Zorin, 1999; Parfenov et al., 2001). The Solonker-Xar Moron-Changchun-Yanji suture zone in the south is generally believed as the south boundary of the CAOB. In that case, the majority of the eastern CAOB should be a broad collision-amalgamation belt between the Siberia craton and North China craton (Figures 1.1, 1.2; Wilde, 2015).

\subsubsection{Paleozoic basement amalgamation period in NE China}

In the Paleozoic, the micro-blocks in the NE China gradually amalgamated as one united block. Ge et al. (2005) reported 494 to $480 \mathrm{Ma}$ zircon U-Pb age of the post-orogenic A-type granite in the Erguna block (EB) that implied that the Erguna block was already connected Xing'an block (XB) in the Early Paleozoic. Liu et al. (2017) carried out a provenance study of the Early Carboniferous and Early Devonian sandstones in southeast EB by detrital zircon $\mathrm{U}-\mathrm{Pb}$ dating and Hf isotope methods, and got $>780 \mathrm{Ma}, \sim 540 \mathrm{Ma}, \sim 500 \mathrm{Ma}, \sim 450-480 \mathrm{Ma}$ age peaks in both sandstones and additional $\sim 360 \mathrm{Ma}$ age peak only in the Early Carboniferous sandstone. These age groups and their Hf isotopic data suggest that the EB and XB had been connected before deposition of the Early Devonian sandstones (Han et al., 2015).

Zhang et al. (2006) revealed the consistency of the $\mathrm{Nd}$ model ages (1.2 Ga to $500 \mathrm{Ma}$ ) between the $\mathrm{XB}$ and the Songliao-Xilinhot block $(\mathrm{SXB})$ and considering the deep reflection seismic data, suggested a united Xing'an-Songliao block. Two subduction-related magmatic arc belts (i.e., $\sim 480-420 \mathrm{Ma}$ and $\sim 360-330 \mathrm{Ma}$ ) were identified along the eastern margin of the XB, suggesting ca. $150 \mathrm{Myr}$. -long time episodic subduction/collision between the XB and SXB (e.g., Ge et al., 2007; Guo et al., 2009; Wu et al., 2015; Shi et al., 2015; Feng et al., 2015a). After the magmatic arc (360-330 Ma) along the eastern margin, the widely distributed magmatic activities with the ages of 320-290 Ma occurred within the XB and the adjacent areas, suggesting the final syn- and post-collision along with the HHS (e.g., Wu et al., 2011; Wang et al., 2013; Feng et al., 2015b); the XB was finally amalgamated with SXB along with the HHS in the late Early Carboniferous-early Late Carboniferous (Liu et al., 2017). 
Meng et al. (2010) reported a significant 551-489 Ma detrital zircon U-Pb age group from the Early Devonian sedimentary units in the east segment of the Songliao-Xilinhot block that was consistent with the age of the Mashan complex and the Early Paleozoic granitoids in the Jiamusi block indicating the SXB and the JB were already connected in the Early Devonian. Wang et al. $(2008,2009)$ also recognized the coeval and correlated Early Devonian strata in both on the SXB and JB suggesting that the formation of the united Jiamusi-Mongolia block was probably already took place in the Early Paleozoic (Figure 1.3). During the late Paleozoic to early Mesozoic, the Jiamusi-Mongolia block amalgamated with the North China craton along the Solonker-Xar Moron Changchun-Yanji suture zone (Liu et al., 2010, 2017; Zhou et al., 2013).

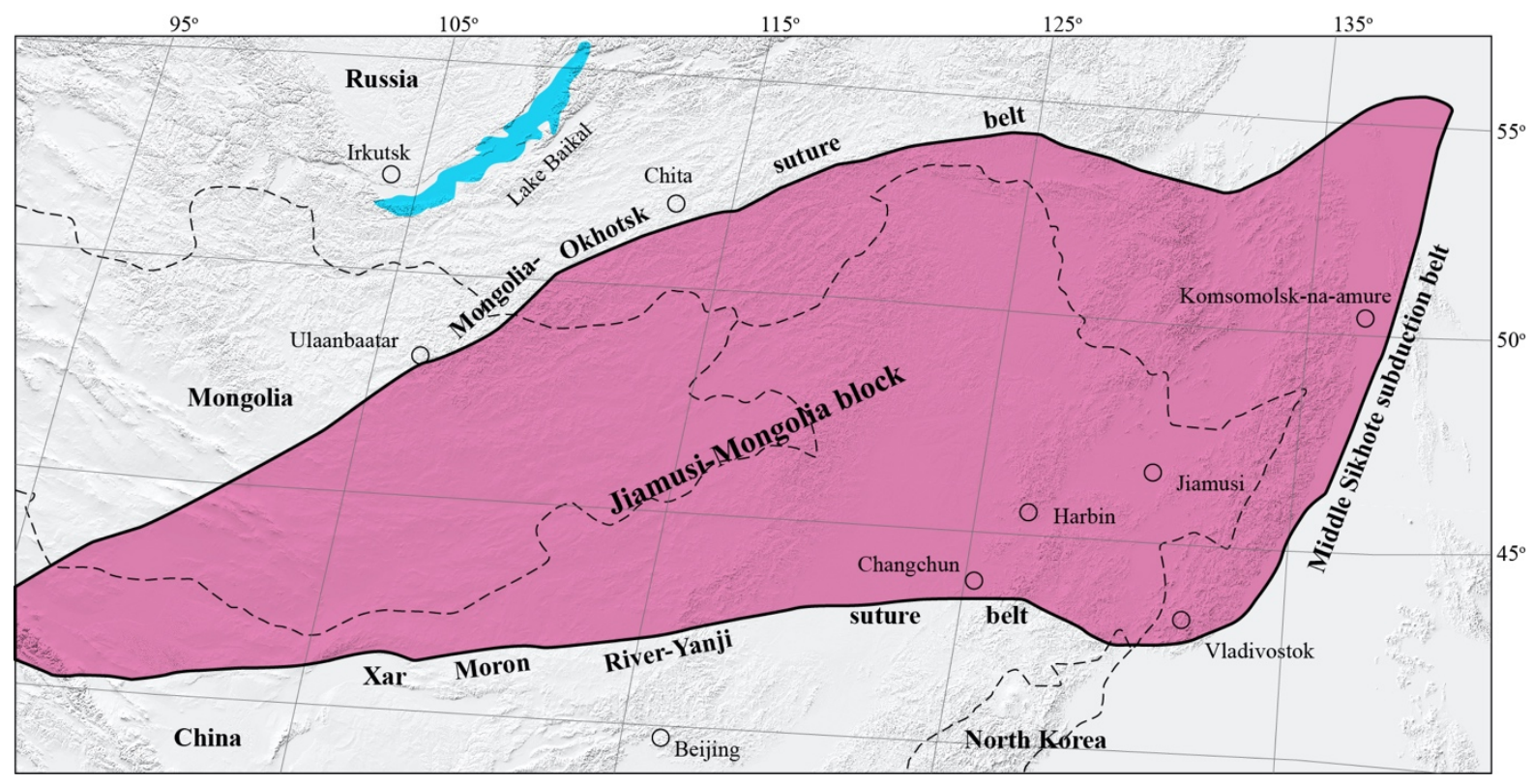

Figure 1.3: The outline of the Jiamusi-Mongolia Block (after Liu et al., 2017).

Xu et al. $(2012,2019)$ revealed SN distributed 250-210 Ma bimodal volcanic rocks at the east segment of SXB, indicating an extensional environment and suggesting a rifting event between the JB and SXB in the Early Triassic. Zhou et al. (2009) and Wang et al. (2016b) reported 275 Ma tholeiite and 255-210 Ma OIB or E-MORB type basalts in the Heilongjiang complex from the JB that are considered to have formed in a continental rift environment. This indicates separation of the JB from the Jiamusi-Mongolia block in the Late Paleozoic and development of the Mudanjiang Ocean between the JB and the Jiamusi-Mongolia block. The youngest detrital zircon $\mathrm{U}-\mathrm{Pb}$ age group (213-199 Ma) in the Heilongjiang complex also revealed the oceanic basin's existence between the SXB and JB during the Late Triassic-Early Jurassic (Zhou et al., 2009; Li et al., 2011a). The formation of blueschists in the Heilongjiang complex 
recorded another subduction-collision process between the JB and SXB. Its polysilicon muscovite ${ }^{40} \mathrm{Ar} /{ }^{39} \mathrm{Ar}$ age limited the time of its peak metamorphic or the following tectonic exhumation, revealing the final re-docking with the SXB occurred in the Jurassic (185-145 Ma; Wu et al., 2007; Li et al., 2009, 2010; Zhao and Zhang, 2011; Zhu et al., 2017; Ge et al., 2017). This westward drift of the combined Bureya-Jiamusi-Khanka blocks resulted from the onset of Pacific plate subduction (Figure 1.4) in the Late Triassic-Jurassic (Wu et al., 2007).

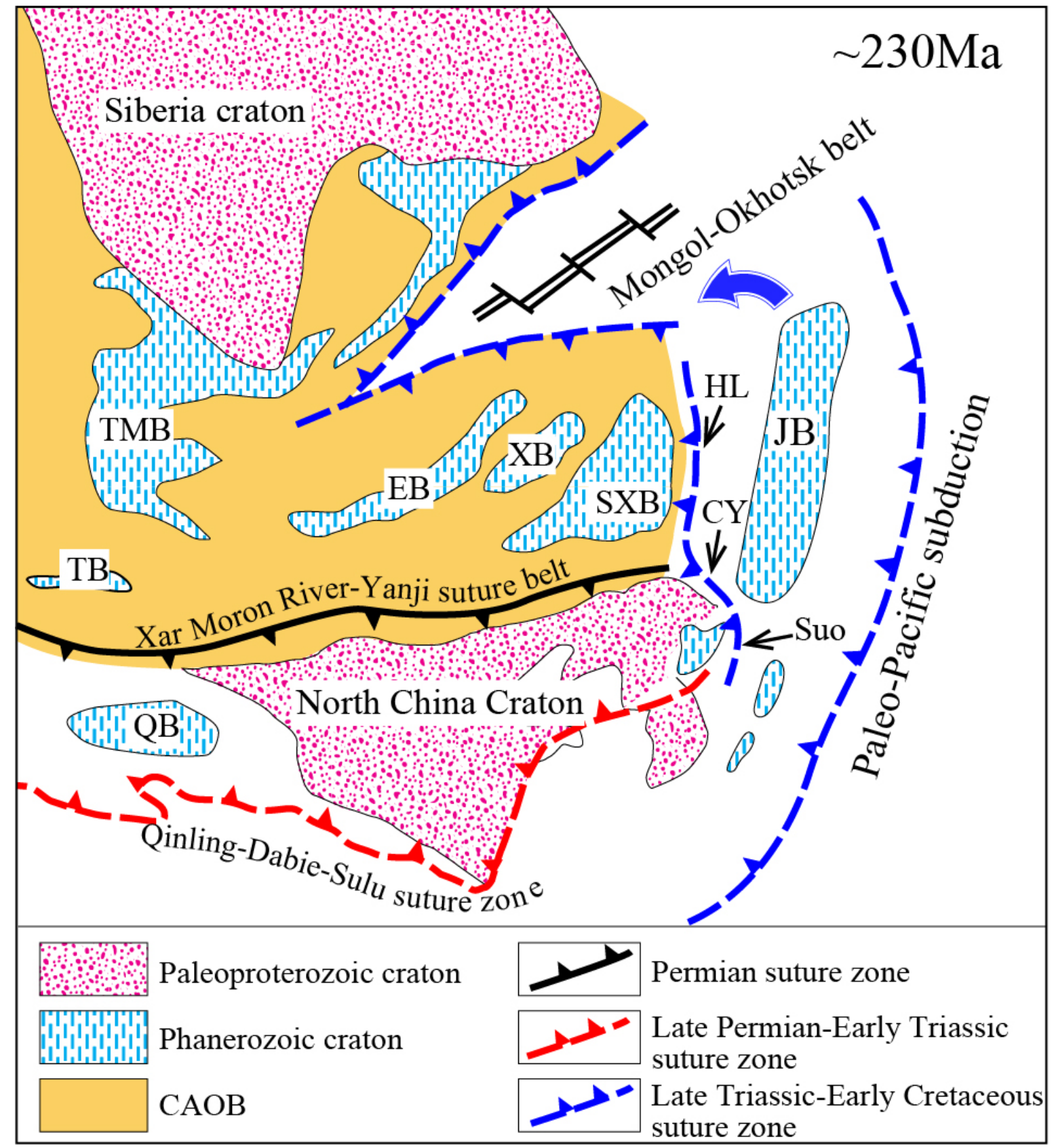

Figure 1.4: A cartoon showing the possible Late Triassic amalgamations of the micro blocks along the NE Asian margin (after Zhou et al., 2013; Li et al., 2020). CAOB = Central Asian Orogenic Belt; JB = Bureya-JiamusiKhanka block; EB=Erguna block; XB=Xing'an block; $S X B=$ Songliao-Xilinhot block; $Q B=$ Qaidam block; TB= 
Introduction

Turpan terrance; $T M B=$ Tuva-Mongol block; Suo= Japan Suo metamorphic belt; $C Y=$ Changchun-Yanji metamorphic belt; $H L=$ Heilongjiang metamorphic belt.

\subsubsection{The closure of the Mongol-Okhotsk ocean and the influence of Paleo Pacific plate subduction on NE China in the Mesozoic-Cenozoic.}

Since the Mesozoic, the NE China area was mainly influenced by the orogeny triggered by the closure of the Mongol-Okhotsk Ocean in the north and the Paleo Pacific plate subduction in the east (Figure 1.4; Meng, 2003; Safonova et al., 2009; Li et al., 2012; Zhang et al., 2012; Xu et al., 2013). The Mongol-Okhotsk Ocean existed in the Late Paleozoic to Early Mesozoic between Siberian craton and the Jiamusi-Mongolia block (Safonova et al., 2009; Huang et al., 2016). The geophysical data revealed the Mongol-Okhotsk ocean plate's northward subduction in the Mesozoic (Zorin et al., 2002). Evidence of the possibility of its southward subduction was also confirmed by seismic tomography (Van der Woo et al., 1999) and igneous rock record (Xu et al., 2013). The Mongol-Okhotsk Ocean's closure was mainly followed by a scissor-like movement from west to east (Figure 1.4; Donskaya et al., 2013; Huang et al., 2016). The western part closed at the Early-Middle Jurassic according to magmatic, sedimentary and basin evolution evidences (Fan et al., 2013; Meng, 2003; Wang et al., 2006), while the eastern part was closed until the Late Jurassic-Early Cretaceous (Pei et al., 2011; Huang et al., 2016).

The Paleo-Pacific plate's subduction beneath the eastern Eurasian continental margin generally started at the late Late Triassic-Early Jurassic (Yu et al., 2012; Xu et al., 2013) and gradually dominated NE China's tectonic evolution (Xu et al., 2013). With the Late Jurassic-Early Cretaceous fast subduction of the Paleo-Pacific Plate below the Eurasian continental plate (Maruyama et al., 1997), the NE China area experienced extension. Further, it led to the formation of a series of rift basins in NE China (e.g., Ren et al., 2002), the exhumation of a metamorphic core complex (e.g., Davis et al., 2002) and the continuing magmatism events (e.g., Wang et al., 2006; Zhang et al., 2018).

In the early Late Cretaceous (ca. $90 \mathrm{Ma}$ ), with the Paleo-Pacific plate considerably changed its subduction direction from NNW to WNW at high rates $(23.5 \mathrm{~cm} / \mathrm{yr}$; Engebretson et al., 1985; Maruyama et al., 1997), the approx. NW-ward subduction direction almost at a right angle with the approx. NE-ward eastern Eurasian continental margin put east NE China and its adjacent area under dextral compressional shear (Sun et al., 2010). In the Korean Peninsula, southwestern Japan and Russia's far east appeared plenty of subduction-related igneous rocks (e.g., Nakajima et al., 1990; Kinoshita, 1995; Sato et al., 2002). The Early Cretaceous rift basins 
in NE China experienced compression, folding and erosion (e.g., Song et al., 2014; Zhang et al., 2015; Chen, 2017).

Since the early Cenozoic the roll-back of the subducting Pacific Ocean plate has triggered the extension of the eastern Eurasian continental margin (Maruyama et al., 1997). It developed plenty of northeast-southwest oriented rift valleys, i.e., the Japan sea, Bohai bay, Donghai basin and Baikal rift valley, forming the typical West pacific-type trench-arc-basin system (Maruyama et al., 1997; Ren et al., 2002).

\subsection{Mesozoic-Cenozoic basins in northeast China}

Due to the extremely wide extent and their dominance on the region the development Mesozoic-Cenozoic basins need special attention. The amalgamated Jiamusi block and the Songliao-Xilinhot block form the basement of the Meso-Cenozoic basins in NE China (Zhang et al., 2011; Liu et al., 2017). The Mesozoic-Cenozoic basins and mountain ranges in NE China generally follow SW-NE trends, controlled by the primary NE trending strike-slip fault structures (Figure 1.2). The Great Xing'an Range (GXR) borders the Songliao basin in the west, the Lesser Xing'an Range (LXR) in the north, and Zhangguangcai Range (ZGC) and JiamusiYitong Fault in the east. Northeast of the Songliao Basin, in between the Jiamusi-Yitong strikeslip fault and the Dunhua-Mishan fault further SE, a series of NE-SW oriented MesozoicCenozoic rift basins developed, such as the Sanjiang basin, Hulin basin, Boli basin, Jixi basin and Hegang basin (see numbers II to VI in Figure 1.2). They all have remained as residual basins and are mainly separated by the major uplift zone named as Jiamusi Uplift (Figure 1.2). The basin group to the east of the Songliao basin is filled mainly by Mesozoic-Cenozoic siliciclastic and volcanic formations (Figure 1.5). While in the central part of the Songliao basin, the depositional record remained intact and the subsidence is interrupted by only a minor mid' Cretaceous inversion event, the burial record of the eastern basin group terminates in Early or Late Cretaceous due to the intense removal of the younger strata. In these basins the marginal facies of the sediment fill are missing (Cao et al., 2003; Wen et al., 2008a). Jurassic shallow marine to continental formations were documented only in the Sanjiang basin (Sha et al., 2003, 2009; Zhang et al., 2012). Mostly continental Lower Cretaceous sedimentary formations occur in the study area with thicknesses varying from $2.2 \mathrm{~km}$ to $5.0 \mathrm{~km}$. The upper part of the Lower Cretaceous sequence contains volcaniclastic sediments indicating multiple volcanic events. Remarkable that the Lower Cretaceous strata in the different basins can be well correlated 
(Figure 1.5). Starting from the early Late Cretaceous, tectonic inversion events lead to the partly or entirely removal of the Upper Cretaceous sediments in the eastern basin group. The preserved Upper Cretaceous continental sediments are mostly cover the Lower Cretaceous formations unconformably, and their thicknesses vary from $1.2 \mathrm{~km}$ to $3.0 \mathrm{~km}$. The Paleogene sediments are only partly recorded in the eastern basin group with continental facies. Only between the Jiamusi-Yitong fault and the Dunhua-Mishan fault zone, the Yilan-Yitong basin and Ning'an basin contain relatively complete Paleogene sedimentary successions. The Neogene continental sediments are widely distributed in the study area with thickness from 0.1 $\mathrm{km}$ to $0.7 \mathrm{~km}$.

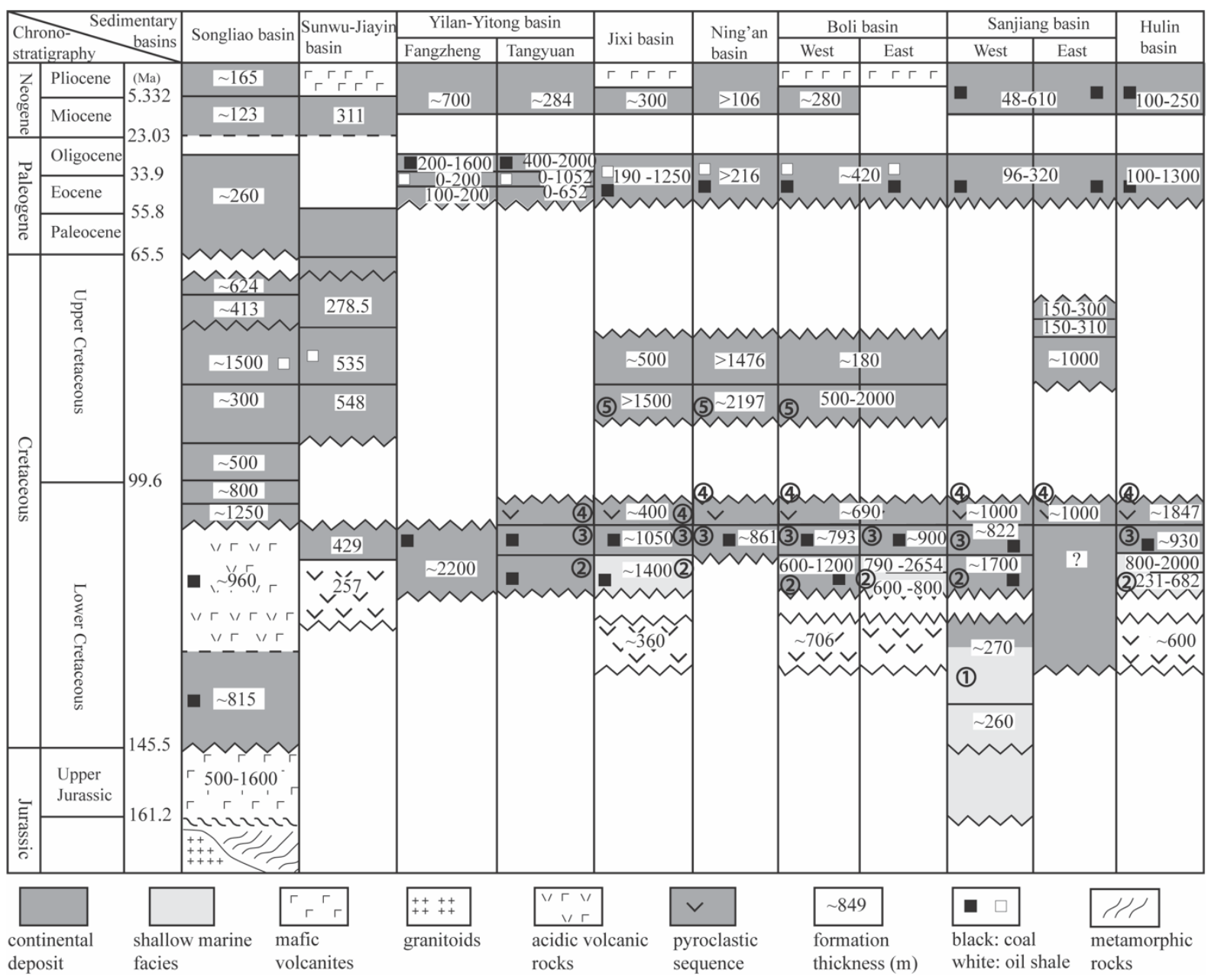

Figure 1.5: Compilation of the stratigraphy of the basins in NE China (after Zhang et al., 2010, 2012; Qie, 2009; Gao, 2010). Circled numbers indicate the major basing filling sedimentary and volcanic formations: 1 - Didao, 2 - Chengzihe, 3 - Muling, 4 - Dongshan and 5 - Houshigou. Zig-zag line: erosional unconformity.

The provenance studies of the eastern basin groups in east NE China are mainly focused on the late Mesozoic formations. Wang et al. (2007) indicated that in Early Cretaceous the sediment supply of the Hulin basin was mainly the Nadanhada Terrane in the north. Wang (2007) 
revealed the western Sanjiang basin mainly received sediment from southwestern and northeastern source regions in the Late Jurassic-Early Cretaceous. While Wang et al. (2007) further indicated the western Sanjiang basin's provenance is mainly from the southern side of the basin in Late Jurassic, and the Early Cretaceous provenance is mainly from the southeastern side. Sun et al. (2014) indicated that the LXR and JB were the major sources of the Early Cretaceous sediments in the Hegang basin, but the provenance from LXR is not detected in the Late Cretaceous. Wang et al. (2006), Wen et al. (2008a) and Liu et al. (2010) analyzed the Cretaceous provenance in the basins around the Jiamusi Uplift and suggested the Lesser Xing'an range and Zhangguangcai Range as sources of the Lower Cretaceous Chengzihe and Muling formations. Wen et al. (2008) further indicated the Lesser Xing'an Range, Zhangguangcai Range and Jiamusi Uplift should supply the Upper Cretaceous Houshigou formation. These studies suggested the presence of one united basin at the current Jiamusi Uplift area. The later exhumed Jiamusi Uplift gradually destroyed the prototype basin, and only isolated basin remnants have been preserved. Cenozoic provenance data from the study area are still rare but with multiply views. Wang et al. (2007) suggested the Tangyuan fault depression's Paleogene sediments have derived mainly from the northwest and southeast. While Wang (2007) preferred three major source areas, they are along the western, northeastern and eastern sides. In general, the Cenozoic basin's provenance is mainly dominated by local uplifts, triggered by faults (Li et al., 2002; Chen et al., 2010; Sun et al., 2010; Zhao, 2011).

\subsection{Low-temperature thermochronology studies in northeast China}

For the identification, dating and quantification of exhumation events affecting the topmost part of the crust and the inversion in sedimentary basins, the most useful and most widely applied tool is the low-temperature thermochronology like apatite/zircon fission tracks and (UTh)/He. Numerous studies have applied apatite and zircon fission track (AFT, ZFT) thermochronology in the Songliao basin (Figure 1.6). They revealed that the central depression of the Songliao basin reached the maximum burial depth and highest paleotemperature at the end of the Cretaceous, followed by an east to west migrating erosional event (Yang et al., 1995; Huang et al., 1999; Fang et al., 2005; Xiang et al., 2007; Song, 2010). Cheng et al. (2018) further suggested that the southern Songliao basin experienced two distinct, compression and extension related uplift events with rapid cooling during the late Mesozoic-Cenozoic. Li et al. (2011b) detected by AFT and ZFT thermochronology that the northern Great Xing'an range, the western bordering basement high of the Songliao basin has experienced rapid cooling 
between 90 and $57 \mathrm{Ma}$. For the northern boundary of the Songliao basin, Li et al. (2011c) concluded that the granites from the Lesser Xing'an range experienced cooling from 95 to 65 Ma.

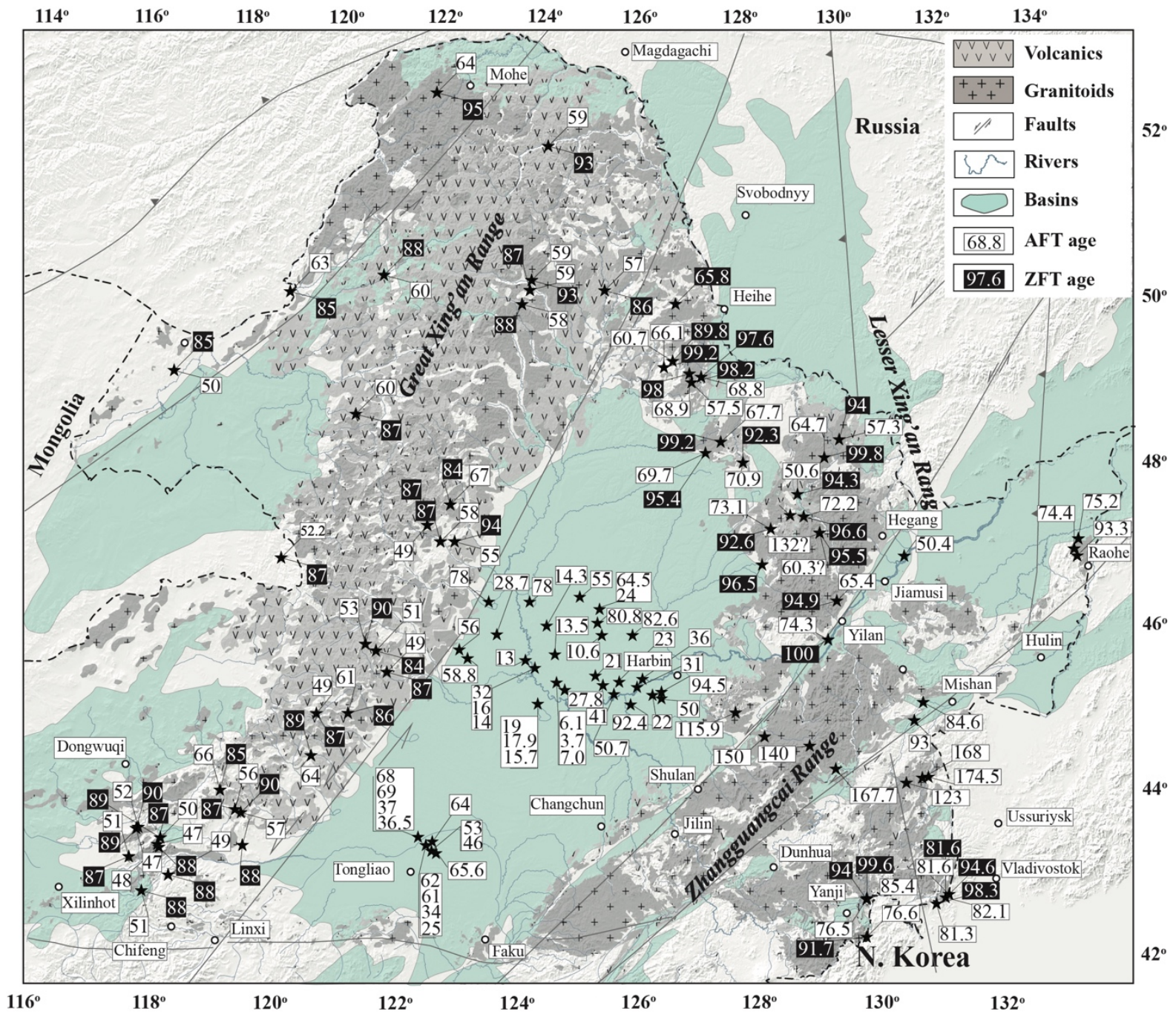

Figure 1.6: Compilation of the formerly published low-T thermochronological data of the study area (the ages are in Ma; after Yang et al., 1995; Fang et al., 2005; Xiang et al., 2007; Fang et al., 2008; Li et al. 2011a, b; and Chen, 2016; Cheng et al., 2018; Song et al., 2018).

Low-temperature thermochronological studies in the eastern basin group are still insufficient. For the eastern segment of the Songliao basin, Fang et al. (2008) recognized by ZFT a thrust event that happened after $62 \mathrm{Ma}$ in the Lesser Xing'an Range, and two thrust events that happened after 116 and $80 \mathrm{Ma}$ in the west Jiamusi uplifted area. Chen (2016) analyzed both granite and sandstone samples from two large scale, roughly E-W trending sections by AFT and revealed different cooling and exhumation processes. The Lesser Xing'an range and 
Zhangguangcai range were uplifted in the Early Jurassic and the whole eastern Songliao basin area experienced regional exhumation and denudation in the Late Cretaceous.

\subsection{Scientific problems and aims of the study}

During the field studies, we observed a large variety of Cretaceous sedimentary remnants on basement highs, which suggested a widespread late- or post-Cretaceous basin inversion east of the Songliao basin. There are also widespread Mesozoic-Cenozoic volcanic rocks, which may have also some impact on the thermal evolution of the basins and basements (Figure 1.7). Both the low-temperature thermochronometers and the maturation of the organic matter record the last thermal event and the cooling after it, thus their sensitivity make them key methods for studying the development of the thermal evolution during the inversion affecting the area east of the Songliao basin.

On the other hand, the Songliao Basin, its eastern "satellite" basins and the associated sedimentsupplying basement highs form an excellent natural laboratory for detrital zircon $\mathrm{U}-\mathrm{Pb}$ studies as the currently exhumed basement areas are composed mostly of zircon-bearing igneous formations having highly variable emplacement ages. This contrast in the sources generates highly informative detrital age patterns. With the widespread and still growing application of detrital zircon geochronology in sedimentary provenance analysis, the use of existing geological data, such as regional geological maps to trace provenance, is common. However, for some regions, such as densely-vegetated or poorly/not accessible areas, especially when tracking large-scale provenance, the results may be misleading due to large uncertainties in the geological maps and non-representative sampling of the region. 


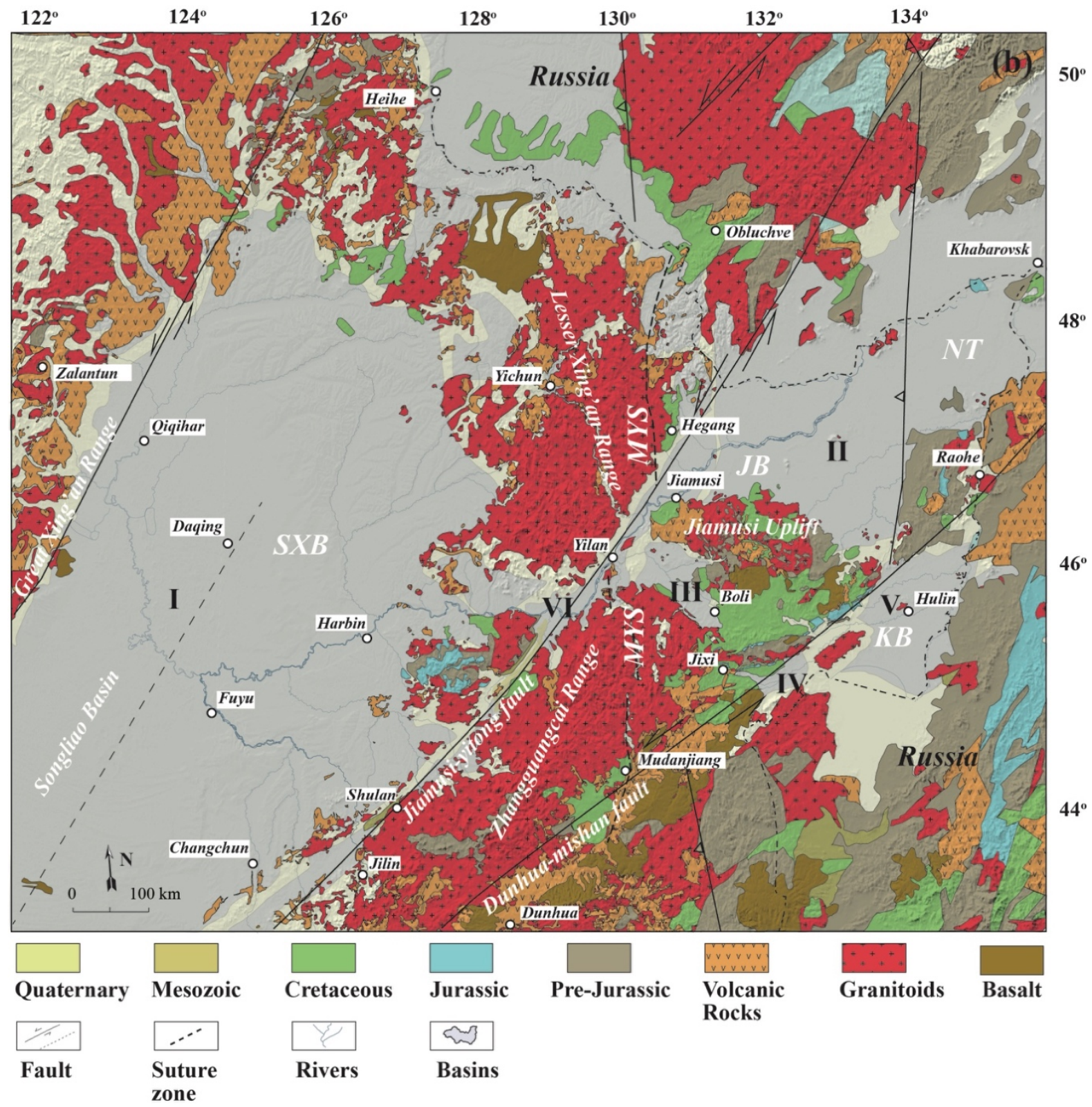

Figure 1.7: Simplified geological map of the study area (modified after Ren et al., 2013).

Another approach to evaluate detrital age spectra can be the comparison to the age distribution compiled from all available geochronological data from the basement. Such a comparison is mostly biased by the uneven sampling of the basement and the different sediment yield of individual tributaries and/or geological units. Modern river sand studies frequently analyze catchments that include highly rugged mountains and low relief areas, like Himalayan rivers or the Amazon (e.g., Mapes, 2009; Guo et al., 2020). In the case of such sediments, the interpretation of the detrital age spectra is encumbered by two factors acting at poorly known magnitudes: the sediment yield (relief \& erodibility) and the zircon yield (fertility; e.g., Dickinson, 2008; Malusà et al., 2016). In NE China, the relief in the Lesser Xing'an Range 
(LXR), Zhangguangcai Range (ZGC) and the western Jiamusi block (JB), situated along the eastern border of Songliao Basin in NE China, is moderate and can be considered as catchmentwide relatively uniform, thus one could expect an aerial balanced sediment yield.

For this thesis, a whole range of magmatic rocks was investigated by low-temperature thermochronology and geochronology, and this dataset was completed by vitrinite reflectance data from the Cretaceous sediments. I also identified the detrital zircon U-Pb age populations from modern river sands with variable compositions of the catchment areas, in order to achieve the following primary scientific goals:

1) To clarify whether the Neogene-Quaternary basalt lavas have influenced the regional ZHe cooling age pattern or they have only local contact-related thermal influence.

2) To reveal the thermal evolution of basement highs and the basins remnants. To construct a coherent pattern for the entire region that was affected by burial and partial exhumation by the integrated evaluation of the thermal histories of the structural blocks obtained by different methods.

3) To evaluate the impact of the inferred thermo-tectonic evolution on the geodynamic evolution in NE China.

4) To address how accurately and proportionally the detrital zircon age spectra of modern river sediments reflect the Paleozoic-Cenozoic, igneous, metamorphic and sedimentary formations of the catchments.

5) To reveal the relationships among the detrital zircon $\mathrm{U}-\mathrm{Pb}$ age patterns from the modern river sediments, the basement units of the specific catchments and the wider area and the available detrital ages from Cretaceous sediments in NE China.

6) To constrain the temporal change in the Cretaceous sediment supply of the Songliao Basin and its strongly inverted eastern satellite basins and check this evolution against the thermo-tectonic evolution developed under (2) and (3).

\subsection{Methodological approach}

Previous thermochronological studies used only a single method and revealed simplified thermal evolution models for the eastern part of NE China. In this PhD thesis, therefore, multimethod low-temperature thermochronology analysis including apatite fission-track (AFT), apatite (U-Th)/He (AHe), and zircon (U-Th)/He (ZHe) were conducted in order to obtain more details of the thermal histories and a denser information on the pattern of exhumation of the area. Additionally, organic maturation data (Ro\%) (collected from the literature and reports) 
were re-evaluated and beyond the basement highs the thermal history of the basin areas were also modelled in order to constrain the distribution of the Late Cretaceous-Tertiary tectonic inversion, quantify the thickness of the former burial and the temporal development of basin inversion, affecting an area over $200,000 \mathrm{~km}^{2}$ in NE China. What's more, the volcanic rock's thermal influence on its surrounding sediment and igneous rock units is also concerned. Using zircon (U-Th)/He thermochronology and Raman spectroscopy, I detected the eruption age of young basaltic lava. The granitoid basement in the region does not shows the Neogene age of the basalt volcanism. This part of the study includes only one thermally overprinted sample, but its consequence is relevant for the regional thermo-tectonic evaluations; I conclude that regional $\mathrm{ZHe}$ ages reflect the exhumation history and the young lavas have only local effect, like Blondes et al. (2007) quantified it in a former study. Lastly, modern river sediments whose catchments drain most of the current elevated basement areas of eastern NE China were detected with the detrital zircon U-Pb geochronology method. The Cretaceous supply's temporal change is expected to be well discussed by carefully considering multiple influencing factors to the modern sediments' provenance analysis and referring to the well-studied igneous basement units.

The research content is as follows: Chapter 2 elucidated the thermal history of the basement highs bordering the sub-basins with a multi-method approach including vitrinite reflectance Ro values, apatite fission-track, and apatite/zircon helium thermochronology from an area of ca. $100,000 \mathrm{~km}^{2}$ covering the eastern part of the NE China basin system broadly. Thermal modelling is performed to quantify the former burial's thickness and the temporal development of basin inversion. Chapter 3 discussed the basaltic lava's thermal influence on its surrounding rocks. Zircon (U-Th)/He and Raman spectroscopy were inferred to test the zircon thermal reset degree obtained on the thermally overprinted sands directly underlying basaltic lava and granitic rocks far away from the basaltic lavas with different distances. Chapter 4 focuses on modern river sands draining catchments of variable size to test the correlation between the area proportion and age spectra, summarizing the available zircon $\mathrm{U}-\mathrm{Pb}$ ages of the igneous rock and detrital zircon $\mathrm{U}-\mathrm{Pb}$ ages from the Cretaceous sediment to make the comparison and discussion. Chapter 5 summarizes the $\mathrm{PhD}$ thesis and highlights the major conclusions. 
Cretaceous-Cenozoic thermo-tectonic evolution and provenance analysis of the basement and some sedimentary successions northeast of the Songliao Basin, NE China

\section{Chapter 2 Manuscript I: Late Cretaceous-Tertiary tectonic inversion of northeastern Asian continental margin: insight from the low temperature thermochronology in NE China}

The following second article combines vitrinite reflectance value Ro, apatite helium, apatite fission track, zircon helium and zircon U-Pb geochronology analysis to reveal the Post Early Cretaceous thermal evolution in NE China. This paper is published 2020 in Gondwana research, Doi: 10.1016/j.gr.2020.05.017

Jianping Zhou ${ }^{1}$, István Dunk1 ${ }^{1}$, Yongjiang $\mathrm{Liu}^{2},{ }^{3}$, Weimin $\mathrm{Li}^{4}$, Hilmar von Eynatten ${ }^{1}$

1 University of Göttingen, Geoscience Center, Sedimentology and Environmental Geology, Goldschmidtstrasse 3, Göttingen, D-37077, Germany

2 Key Lab of Submarine Geoscience and Prospecting Techniques, MOE, Institute for Advanced Ocean Study, College of Marine Geosciences, Ocean University of China, Qingdao, 266100, China.

3 Laboratory for Marine Mineral Resources, Qingdao National Laboratory for Marine Science and Technology, Qingdao, 266237, China.

4 College of Earth Sciences, Jilin University, Jianshe Str. 2199, Changchun 130061, Jilin, China

Short title: The Late Cretaceous-Tertiary tectonic inversion of NE China Keywords: thermochronology, modelling, basement, inversion, NE China 


\subsection{Abstract}

We studied a less understood area of basins and basement horsts to the east of the Songliao basin, NE China. An integrated evaluation of the thermal history of both the basement highs and the basin remnants was performed using low-T thermochronology and burial/thermal modelling based on vitrinite reflectance data. We present new apatite and zircon (U-Th)/He and apatite fission track results from an area of ca. 100,000 $\mathrm{km}^{2}$ covering largely the eastern part of the satellite basin system in order to elucidate the post Jurassic thermal history of the basement highs bordering the sub-basins. The low-T thermochronometers show mostly Late Cretaceous - early Paleogene apparent ages, younger than the Early Cretaceous sedimentary record in the related satellite basins. These age constraints are in harmony with the thermal modelling of vitrinite reflectance data from the basins, which indicates that the maximum burial depth occurred in mid-Cretaceous. The following major basin inversion leads to erosion from ca. 110 ca. $40 \mathrm{Ma}$. The modelling indicated that in the Jiamusi Uplift the central part experienced deeper erosion than marginal areas. Combining the above modelling results, we suggest a single united down-warped basin that formed in the Early Cretaceous, and covered the currently elevated western Zhangguangcai Range and eastern Mishan Uplift at the time of its maximum extent. The Late Cretaceous - Paleogene exhumation of the Jiamusi Uplift, gradually destroyed the formerly continuous, 1.6 to $4.8 \mathrm{~km}$ thick sedimentary cover and only basin remnants have preserved.

\subsection{Introduction}

Northeast China owns one of the largest lacustrine basin systems in the world, including the large Songliao basin and a series of smaller basins east and north-east from the major depression. The oil rich Cretaceous Songliao basin with the size of ca. $260,000 \mathrm{~km}^{2}$ is in the focus of petroleum exploration since the first oil discovery in 1959. The geophysical exploration gradually revealed the tectonic development of the Songliao basin (e.g., Wang et al., 2016a). However, the level of knowledge on the evolution of the group of smaller basins to the east of the Songliao basin is still insufficient. The Mesozoic-Cenozoic rift basin system includes sixteen basins larger than $200 \mathrm{~km}^{2}$ and five basins larger than $3000 \mathrm{~km}^{2}$ (Figure 2.1). In the 20th century, accompanied by coal mining, the study of the eastern basin group was focused mainly on the characterization and basic stratigraphic subdivision of the sedimentary sequences filling the basins. In recent years, with the increasing requirements for oil and gas, 
even the medium and small basins received more attention, which has promoted in-depth studies of the tectonic framework, stratigraphic correlation and thermal evolution of the basin groups to the east of the Songliao basin. The current distribution pattern of the basin group east of the Songliao basin is dominated by the major Huanan Uplift and the Mishan Uplift (Figure 2.1). These uplift areas are also called Jiamusi Uplift and the surrounding basins (Sanjiang basin, Boli basin, Hulin basin and Jixi basin) are mainly located on the Jiamusi Block (JB; see Figure 2.1).
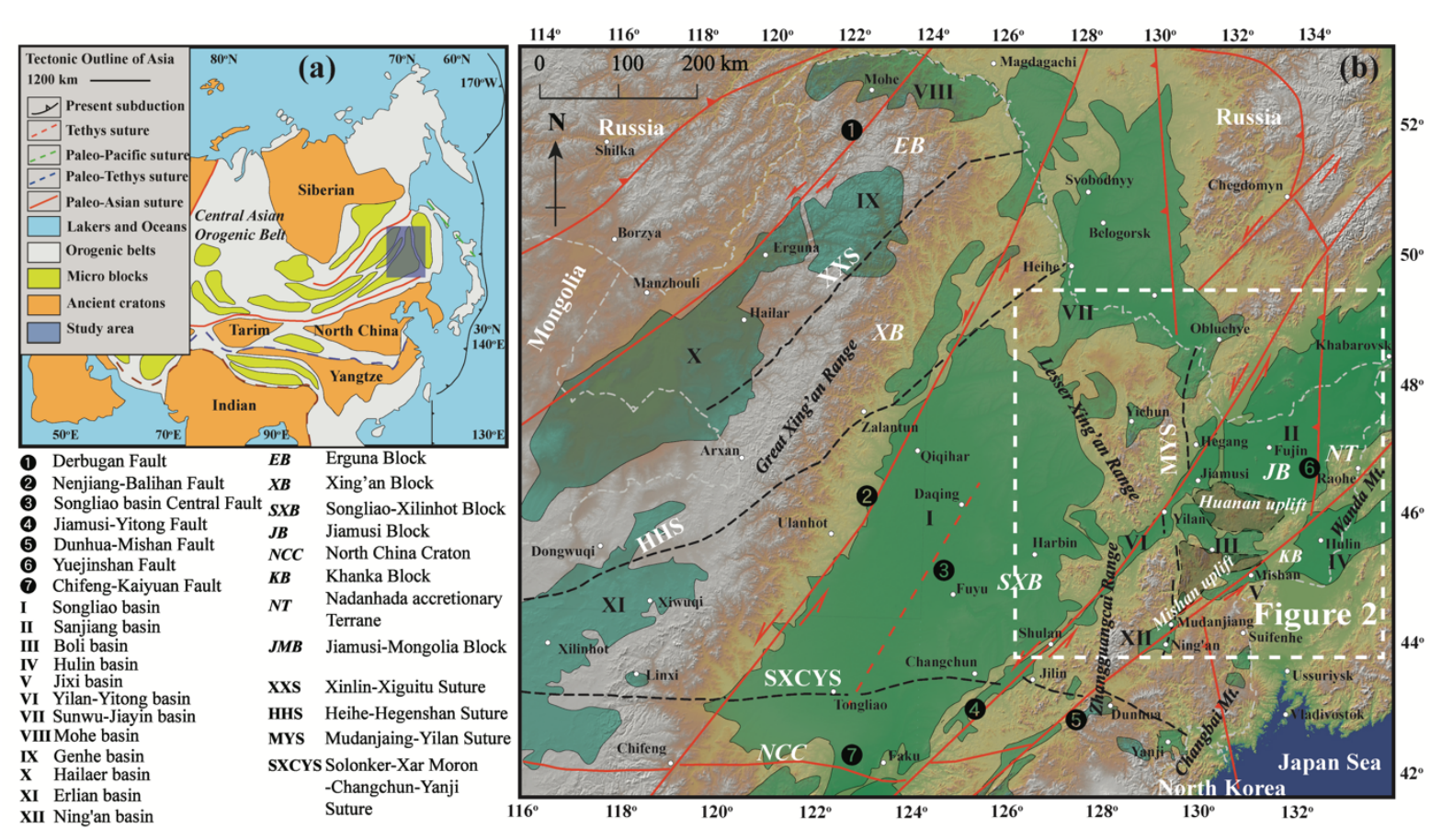

Figure 2.1: (a) Schematic tectonic map of Asia indicating the position of the Songliao basin (modified after Li, 2006; Safonova et al., 2009, 2011; Kröner et al., 2014; Liu, et al., 2016). (b) Digital elevation map of NE China, showing the major basins by green, and the bordering faults of tectonic blocks (after Zhou et al., 2009; Liu et al., 2017). Red line: fault; black dashed line: suture zone; gray dashed line: national boundary. The rectangle represents the study area that covers most of the east NE China, see details in Figure 2. The shadowed areas represent the major uplifts, and collectively referred to the Jiamusi Uplift. The base digital elevation model is from the U.S. Geological Survey (2017).

The tectonic evolution of NE China is still intensely debated (e.g., BGMRHP, 1993; Liu et al., 1994; Tang et al., 1995; Tian et al., 1993; Zhang et al., 1999), especially the exhumation age and mechanism of the Jiamusi Uplift. One concept suggests that the Jiamusi Uplift belongs to a long-term uplifting area since the Paleozoic. In the late Indo-Chinese epoch (ca. 250-205 Ma) the peri-Pacific continental margin was tectonically activated by block faulting and a series of Mesozoic-Cenozoic rift basins (BGMRHP, 1993). Another opinion argues for multiple uplift 
events (Wen et al., 2011), and the current roughly E-W trending basin-bordering system has developed in the late Early Cretaceous-Late Cretaceous (Han et al., 2008; Wen et al., 2008a, b).

The eastern basin group is considered as extensional rift basins by Tang et al. (1995), Liu et al. (2000), Cao et al. (2003), Zhang et al. (2004, 2005) and Cheng et al. (2006). Other authors assume a single united continental margin depression-type basin that has formed in the early Cretaceous and, thereafter, experienced intense transformation by a series of eastwards thrusts between the major Jiamusi-Yitong fault and the Dunhua-Mishan fault in the late Early Cretaceous to Late Cretaceous (Wen et al., 2008a, b; Zhou et al., 2009; Zhang et al., 2010). Previous studies of sedimentary strata and structural features in these basins mainly rely on drillcore and geophysical data, especially seismic profiles. Multi-method studies including thermochronology to reconstruct the thermal history of the Jiamusi Uplift area are scarce.

For the identification, dating and quantification of inversion events affecting sedimentary basins low-temperature thermochronological methods are most useful and widely applied tools. Previous thermochronological studies used a single method only and revealed simplified thermal evolution models for the eastern part of NE China. In this contribution, we focus on the low-temperature thermal history of the satellite basins and the exhumed basement highs to the east of the Songliao basin. We apply a multi-method approach including organic maturation data (Ro\%), apatite fission track (AFT), apatite (U-Th)/He (AHe) and zircon (U-Th)/He (ZHe) thermochronology in order to constrain the distribution of the Late Cretaceous-Tertiary tectonic inversion of the east NE China area, quantify the thickness of the former burial and the temporal development of basin inversion, affecting an area over100,000 $\mathrm{km}^{2}$.

\subsection{Geological Setting}

NE China is situated in the eastern segment of the Central Asian Orogenic Belt (CAOB), the world's largest accretionary orogen, lying between the Siberian Craton to the north, and the North China Craton to the south (Eizenhöfer et al., 2014; Jahn et al., 2000; Sengör et al., 1993, 1996; Windley et al., 2007; Xiao et al., 2009; see Figure 2.1). Since the Phanerozoic, this area experienced superposition and transformation from the Paleo-Asian Ocean tectonic domain to the circum-Pacific tectonic domain. During the Paleozoic and the early Mesozoic, under the control of the Paleo-Asian Ocean tectonic domain, NE China experienced multi stage amalgamation of several microcontinents and finally formed one united block (i.e., Wang et al., 2008; Liu et al., 2017). Since the Mesozoic, its evolution is strongly influenced by the 
closure of the Mongolia-Okhotsk Ocean in the north and the northwestward subduction of the Paleo-Pacific Plate in the east (Meng, 2003; Safonova et al., 2009; Li et al., 2012; Zhang et al., 2012; Xu et al., 2013). Intense Mesozoic-Cenozoic tectonic activities led to the northeast extension of major Tanlu fault that formed the Jiamusi-Yitong fault and Dunhua-Mishan fault, the development a series of multistage sedimentary basins (Tian et al., 1992; Ren et al., 2002; Meng et al., 2003), exhumation of a metamorphic core complex (Davis et al., 2002; Lin et al., 2008; Liu et al., 2017) and magmatism (Zhang et al., 2000; Zhou and Li, 2000; Wang et al., 2006).

The Mesozoic-Cenozoic basins and mountain ranges in NE China generally follow SW-NE trends, controlled by the main NE trending strike-slip fault structures (Figures 2.1, 2.2), and consistent with the direction of the western Pacific continental marginal trench-arc-basin system. The Songliao basin is surrounded by the Great Xing'an Range and Nenjiang-Balihan Fault in the west, the Lesser Xing'an Range in the north and Zhangguangcai Range and Jiamusi-Yitong Fault in the east. Northeast of the Songliao Basin, in between the JiamusiYitong strike-slip fault and the Dunhua-Mishan fault further SE, a series of NE-SW oriented Mesozoic-Cenozoic rift basins developed, such as the Sanjiang basin, Hulin basin, Boli basin, Yilan-Yitong basin and Jixi basin (see numbers II to VI in Figure 2.1b). They all have remained as residual basins and are mainly separated by two major uplift zones named as the Huanan uplift and Mishan Uplift (Figure 2.1b).

Several major faults in the study area deeply influenced the formation and evolution of the Meso-Cenozoic basins including the NE trend Jiamusi-Yitong fault, Dunhua-Mishan fault; near SN trend Mudanjiang fault and Yuejinshan fault (Figure 2.1). Especially the NE trending faults, as the north extension of the major Tancheng-Lushan fault, greatly reactivated and extension during the Cretaceous-Cenozoic was believed to control the subsidence and exhumation of rift basins to the east of the Songliao basin (Zhang et al., 2005; Xie et al., 2009; Sun et al., 2010). 


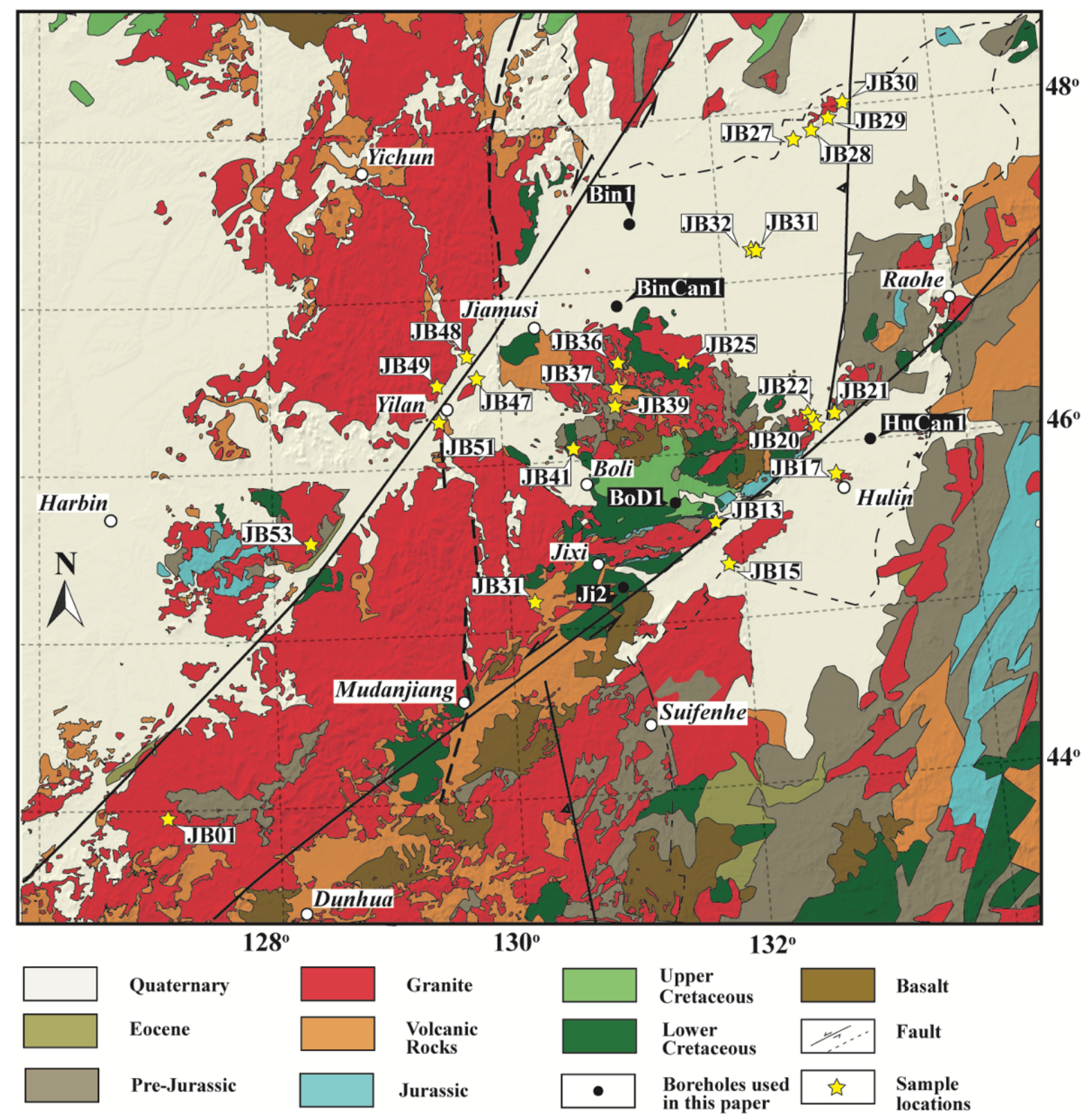

Figure 2.2: Geological map of the study area and the locations of the thermochronological samples indicated by stars (map is simplified after Ren et al., 2013). The digital elevation model is taken from the U.S. Geological Survey (2017).

With the final amalgamation between the Jiamusi block and the Songliao-Xilinhot block in the Paleozoic-early Mesozoic, the united block composed the basement of the Meso-Cenozoic basins in NE China (Zhang et al., 2011; Liu et al., 2017; Figure 2.1). The basin group to the east of the Songliao basin is filled mainly by Mesozoic-Cenozoic siliciclastic and volcanic formations (Figure 2.3). While in the central part of the Songliao basin the depositional record remained intact and the subsidence is interrupted by only a minor mid' Cretaceous inversion event, the burial record of the eastern basin group terminates in Early or Late Cretaceous due 
to the intense removal of the strata during the intense denudation events (Figure 2.4). In these basins the marginal facies of the sedimentary sequences are missing (Cao et al., 2003, Wen et al., 2008a). Jurassic shallow marine to continental formations were documented only in the Sanjiang basin (Sha et al., 2003, 2009; Zhang et al., 2012). In the Lower Cretaceous, mostly continental sediments occur in the study area with thicknesses varying from $2.2 \mathrm{~km}$ to $5.0 \mathrm{~km}$. The upper part of the Lower Cretaceous sequence contains volcaniclastic sediments indicating multiple volcanic events. Remarkable that the Lower Cretaceous strata in the different basins can be well correlated (Figure 2.3). Starting from the early Late Cretaceous, tectonic inversion events leads to the partly or fully removal of the Upper Cretaceous sediments in the eastern basin group. The preserved Upper Cretaceous continental sediments are mostly overlying unconformably the Lower Cretaceous formations and their thickness vary from $1.2 \mathrm{~km}$ to 3.0 $\mathrm{km}$. The Paleogene sediments are only partly recorded in the eastern basin group with continental facies. Only within the Jiamusi-Yitong fault and the Dunhua-Mishan fault zone, the basins like the Yilan-Y itong basin and Ning' an basin contain relatively complete Paleogene sedimentary succession The Neogene continental sediments are widely distributed in the study area with thickness from $0.1 \mathrm{~km}$ to $0.7 \mathrm{~km}$. 
I. Late Cretaceous-Tertiary tectonic inversion of northeastern Asian continental margin: insight from the low temperature thermochronology in NE China

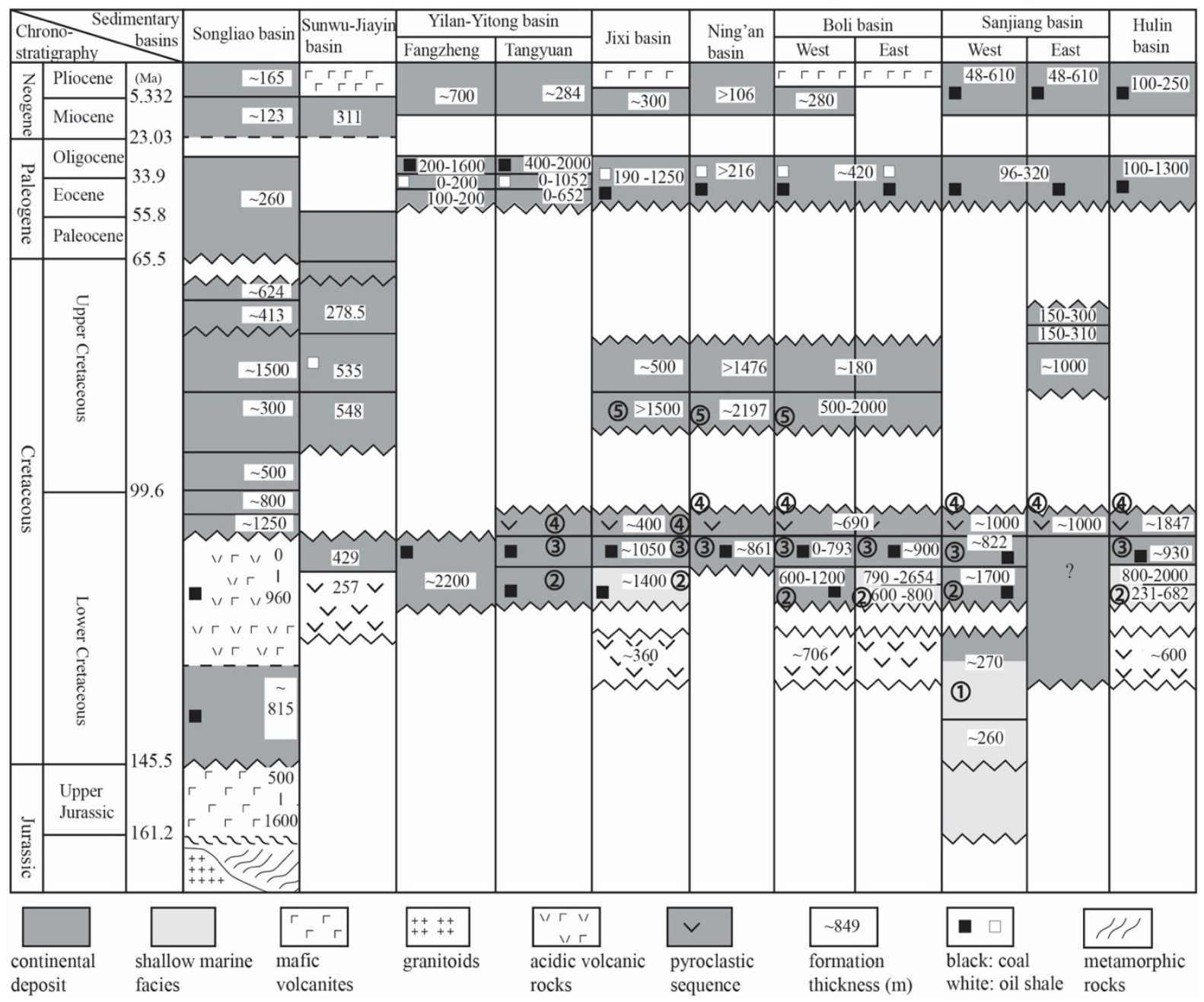

Figure 2.3: Compilation of the stratigraphy of the basins in NE China (after Zhang et al., 2010, 2012; Qie, 2009; Gao, 2010). Roman numbers along with basin names refer to the numbering in Fig. 1b. Circled numbers indicate the major basing filling sedimentary and volcanic formations: 1 - Didao, 2 - Chengzihe, 3 - Muling, 4 - Dongshan and 5 - Houshigou. Zig-zag line: erosional unconformity.

\section{Previous thermochronological studies}

Numerous studies applied apatite and zircon fission track (AFT, ZFT) thermochronology in the Songliao basin. They revealed that the central depression of the Songliao basin reached the maximum burial depth and highest paleotemperature at the end of the Cretaceous, followed by an east to west migrating erosional event (Yang et al., 1995; Huang et al., 1999; Fang et al., 2005; Xiang et al., 2007; Song, 2010). Cheng et al. (2018) further suggested that the southern Songliao basin experienced two distinct, compression and extension related uplift events with rapid cooling during the late Mesozoic- Cenozoic. Li et al. (2011a) detected by AFT and ZFT thermochronology that the northern Great Xing'an range - the western bordering basement high of the Songliao basin - experienced rapid cooling between 90 and $57 \mathrm{Ma}$. For the northern 
boundary of the Songliao basin, Li et al. (2011b) concluded that the granites from the Lesser Xing'an range experienced cooling from 95 to $65 \mathrm{Ma}$.

Low-temperature thermochronological studies in the eastern basin group are still insufficient. For the eastern segment of the Songliao basin, Fang et al. (2008) recognized by ZFT a thrust event that happened after $62 \mathrm{Ma}$ in the Lesser Xing'an Range, and two thrust events that happened after 116 and $80 \mathrm{Ma}$ in the Huanan uplifted area. Chen (2016) analyzed both granite and sandstone samples from two large scale, roughly E-W trending sections by AFT and revealed different cooling and exhumation processes. The Lesser Xing'an range and Zhangguangcai range were uplifted in the Early Jurassic and the whole eastern Songliao basin area experienced regional compressive extraction and denudation in the Late Cretaceous (Figure 2.5).

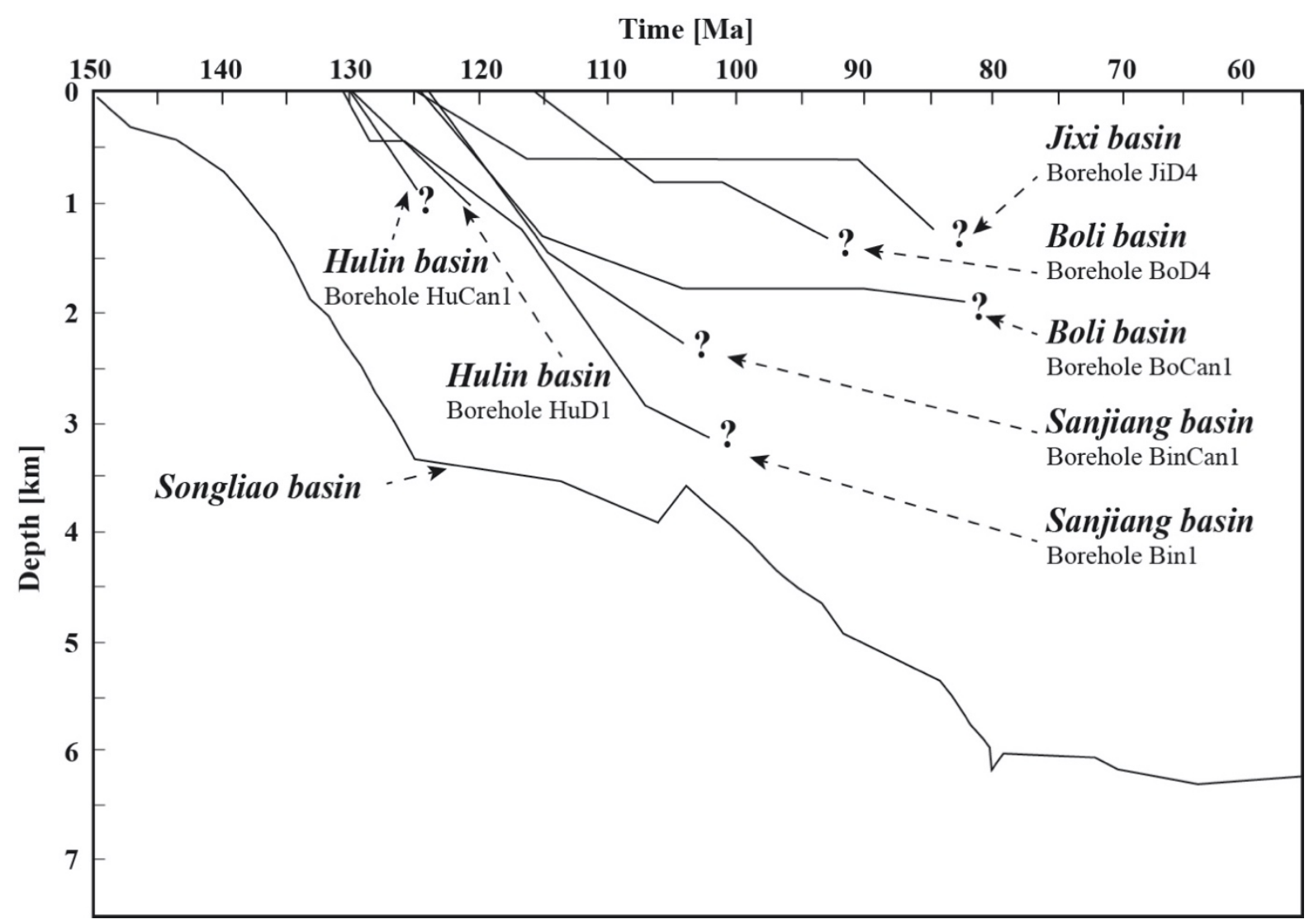

Figure 2.4: Compilation of subsidence trends in the Songliao basin (Wang et al. 2016) and some representative wells of the eastern satellite basins between 150 and $60 \mathrm{Ma}$. The question marks indicate the unknown termination of the burial-exhumation histories of the studied boreholes. No younger stratigraphical information is available from these sites; see discussion in the text. 


\subsection{Samples and analytical methods}

Granitoid, volcanic and siliciclastic samples were collected from basement and Mesozoic sedimentary outcrops at the northeastern margin of the Songliao basin (Figure 2.2). The majority of the twenty-three samples was collected from intrusions or dikes of Early Paleozoic to Late Mesozoic age, and two more volcanic rocks were collected for extra zircon $\mathrm{U}-\mathrm{Pb}$ dating (Table1). None of the 12 sandstone samples contain accessory apatite grains, presumably due to the acid pore fluids from omnipresent coal seams of the studied sections. Thus, unfortunately it was not possible to perform low-T thermochronology on the sedimentary successions. Depending on the amount and quality of the accessory minerals, twenty-five samples were selected from the igneous formations for apatite (U-Th)/He dating, eight samples for zircon $(\mathrm{U}-\mathrm{Th}) / \mathrm{He}$ dating, fourteen samples for apatite fission track analysis, and two samples for zircon $\mathrm{U}-\mathrm{Pb}$ dating.

The heavy mineral concentrates were generated from ca. $5 \mathrm{~kg}$ samples by the physical separation methods like crushing, wet-sieving, gravity separation by shaking table and Napoly-tungstate heavy liquid, and by Frantz magnetic separator. For AFT dating the apatite crystals were embedded in epoxy resin mounts and polished. Etching the apatite crystals by $5.5 \% \mathrm{HNO}_{3}$ at $21{ }^{\circ} \mathrm{C}$ for $20 \mathrm{~s}$ revealed the spontaneous tracks. The mounts were then covered by low-U muscovite plates and irradiated in the thermal neutron facility of the reactor of Oregon State University, USA. After the irradiation, each muscovite was etched by $40 \% \mathrm{HF}$ for $30 \mathrm{~min}$ to reveal the induced fission tracks. The AFT ages were calculated by the zeta method (Hurford and Green, 1983) using the TRACKEY software (Dunkl, 2002). The zeta value was determined to $322.3 \pm 16.9$ by the Fish Canyon Tuff and Durango age standards.

For (U-Th)/He dating the crystals were hand-picked under stereo and polarizing microscopes. The selected crystals are all euhedral and free of cracks and inclusions. Length, prismatic length and width of the selected crystals were measured and recorded by microphotographs for correcting the alpha-ejection (Farley et al., 1996). The crystals were placed in platinum capsules for helium extraction, and the released gas was purified by an SAES Ti-Zr getter and the remaining inert gas measured in a Hidden triple-filter quadrupole mass spectrometer equipped with a positive ion-counting detector. After spiking with known amount of ${ }^{230} \mathrm{Th}$ and ${ }^{233} \mathrm{U}$ solutions, the degassed apatite crystals were dissolved in $4 \% \mathrm{HNO}_{3}$ and the zircon crystals in $48 \% \mathrm{HF}$ and $65 \% \mathrm{HNO}_{3}$ in a pressurized Teflon bombs at the temperature of $220{ }^{\circ} \mathrm{C}$ for five days. The amount of actinide elements was measured by the isotope dilution method and the 
Sm and the major matrix elements of the crystals $(\mathrm{Ca}, \mathrm{P}$ and $\mathrm{Zr}$ ) by external calibration using an iCAP-Q ICPMS. The (U-Th)/He ages were calculated by the Taylor Expansion Method.

Laser ablation ICP-MS zircon U-Pb geochronology of two volcanic rocks were also conducted at the GÖochron Laboratories of the Geoscience Center, University of Göttingen, Germany. The detailed experimental procedures can be found in Dunkl et al. (2019).

\subsection{Results}

The zircon (U-Th)/He ages obtained on the basements are presented in Table 3 and projected on the study area (Figure 2.5). The ZHe ages range from the Valanginian to the Coniacian and all are younger than the emplacement ages of the sampled igneous formations (Table 1). The AFT ages obtained on fourteen basement samples are presented in Table 2 and projected on the basement outcrops of the study area (Figure 2.5). In the samples 18 to 26 grains were counted, except for the sample JB20, which had a poorish apatite yield. The central AFT ages range from early Cretaceous to early Eocene $(120.9 \pm 7.6$ to $53.8 \pm 4.3 \mathrm{Ma})$, are on average younger than the ZHe ages, and all ages are younger than the emplacement ages of the host formations. Most of the samples have relatively low uranium concentrations and therefore low spontaneous track densities and consequently a relative wide spread of single grain ages, but all of sample passed the $\chi 2$-test (see radial plots in Appendix Figure 1). The mean track length (MTL) of each sample varies from 12.2 to $14.3 \mu \mathrm{m}$ (Appendix Figure 2.2).

Twenty-five samples were dated by the AHe method, using 4 to 5 grains per sample (Table 3, Figure 2.5). With a few exceptions the apatite (U-Th)/He ages are younger than the ZHe and AFT ages measured in the same samples. Sample JB48 gave three single grain AHe ages between 71.0 and $97.8 \mathrm{Ma}$ with a mean age of $86.7 \mathrm{Ma}$, which is much older than its AFT central age of 60.5 Ma. Six single grain AHe ages from sample JB51 are between 74.5 and 95.0 Ma with a mean age of $83.9 \pm 3.3 \mathrm{Ma}$, which is also much older than its corresponding AFT central age of 59.5 Ma. Fitzgerald et al. (2006) and Spiegel et al. (2009) have shown that a part of the "too old" AHe ages can be explained by helium implantation into low eU apatite crystals from neighboring U-Th rich minerals or the inapplicable Ft correction due to strong zonation of the alpha-emitting elements. In our case, the apatite crystals from both samples with old AHe ages revealed strong fission track zoning. Thus, for samples JB48 and JB51 the uncorrected AHe ages were used (52.9 \pm 5.9 and 50.9 $\pm 1.4 \mathrm{Ma}$, respectively). 
The single-grain apatite helium ages have little intrasample variation. Mean apatite helium ages of all the basement samples range from 43 to $106.4 \mathrm{Ma}$, and most uncertainties (1s) are within $5 \%$, with only two samples surpassing $6 \%$. The apatite crystal sizes and the eU contents have a relatively large variation (equivalent sphere radii are between 32 and $81 \mu \mathrm{m}$, the eU content is ranging from 6.2 to $166.4 \mathrm{ppm})$. There is no detectable correlation between the AHe ages and other parameters, such as crystal size, altitude, eU content or geographic position.

Zircon $\mathrm{U}-\mathrm{Pb}$ ages were determined on two volcanic rock samples collected from the northern margin of the Jiamusi uplift (Appendix Table 2 and Appendix Figures 2.3 and 2.4). From the andesite sample JB27 15 euhedral zircon crystals were measured and revealed a zircon U-Pb concordia age of $94.3 \pm 0.6 \mathrm{Ma}$. Sample JB28 was collected from a dacite dyke and revealed a U-Pb TuffZirc age of $99.1 \pm 0.4$ (calculated by Isoplot software; Ludwig, 2012). 
Cretaceous-Cenozoic thermo-tectonic evolution and provenance analysis of the basement and some sedimentary successions northeast of the Songliao Basin, NE China

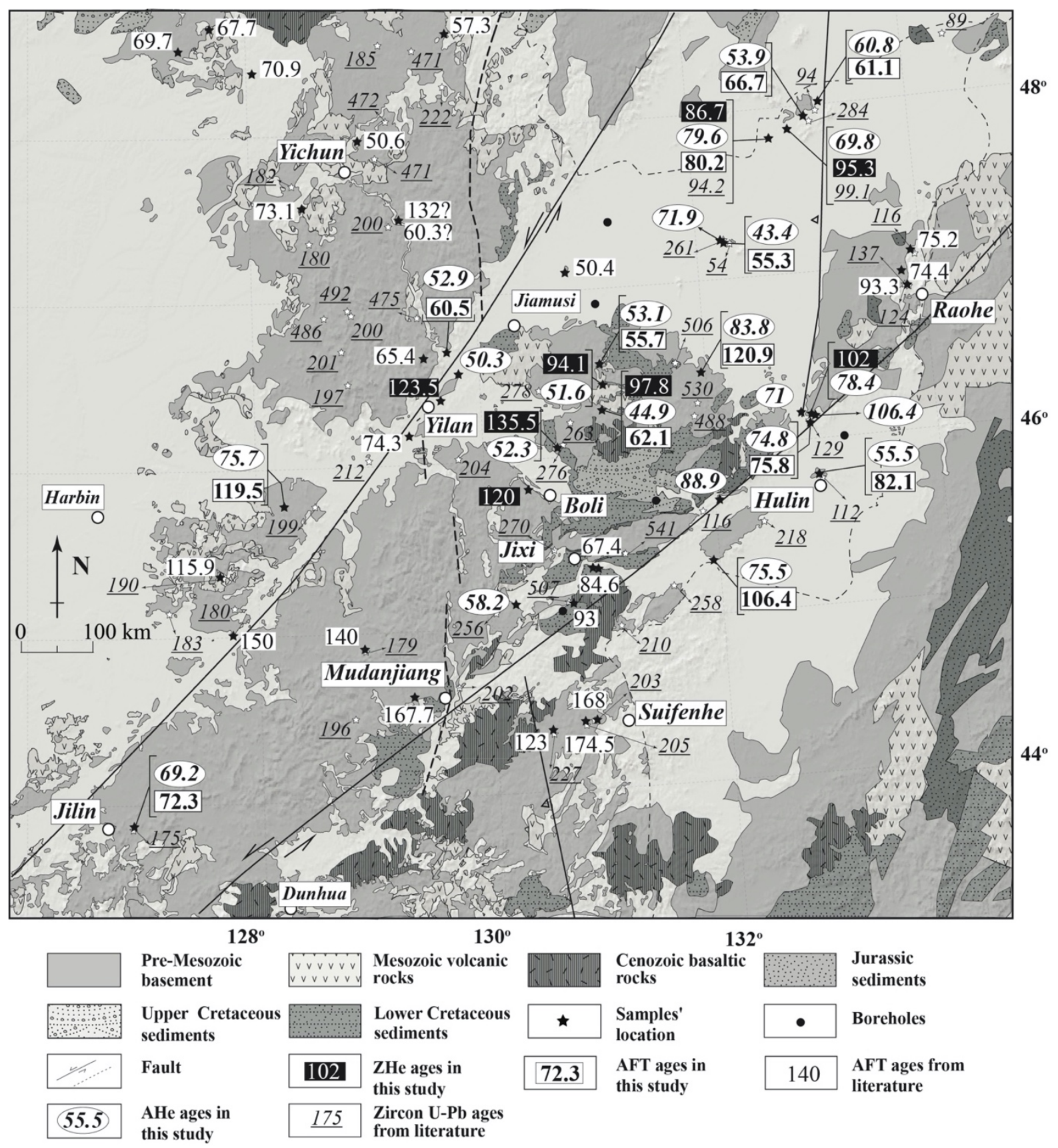

Figure 2.5: Map of low-T thermochronological data of the study area. The uncertainties and other analytical details are listed in Tables 2.2 and 2.3. The compilation of the formerly published AFT results is from Li et al. (2011a, b) and Chen (2016). The compilation of the formerly published igneous rock zircon U-Pb age results is from Wu et al. (2011), Yu et al. (2012, 2013), Bi et al. (2014), Yang et al. (2014), Wang et al. (2016) and Dong et al. (2017). 


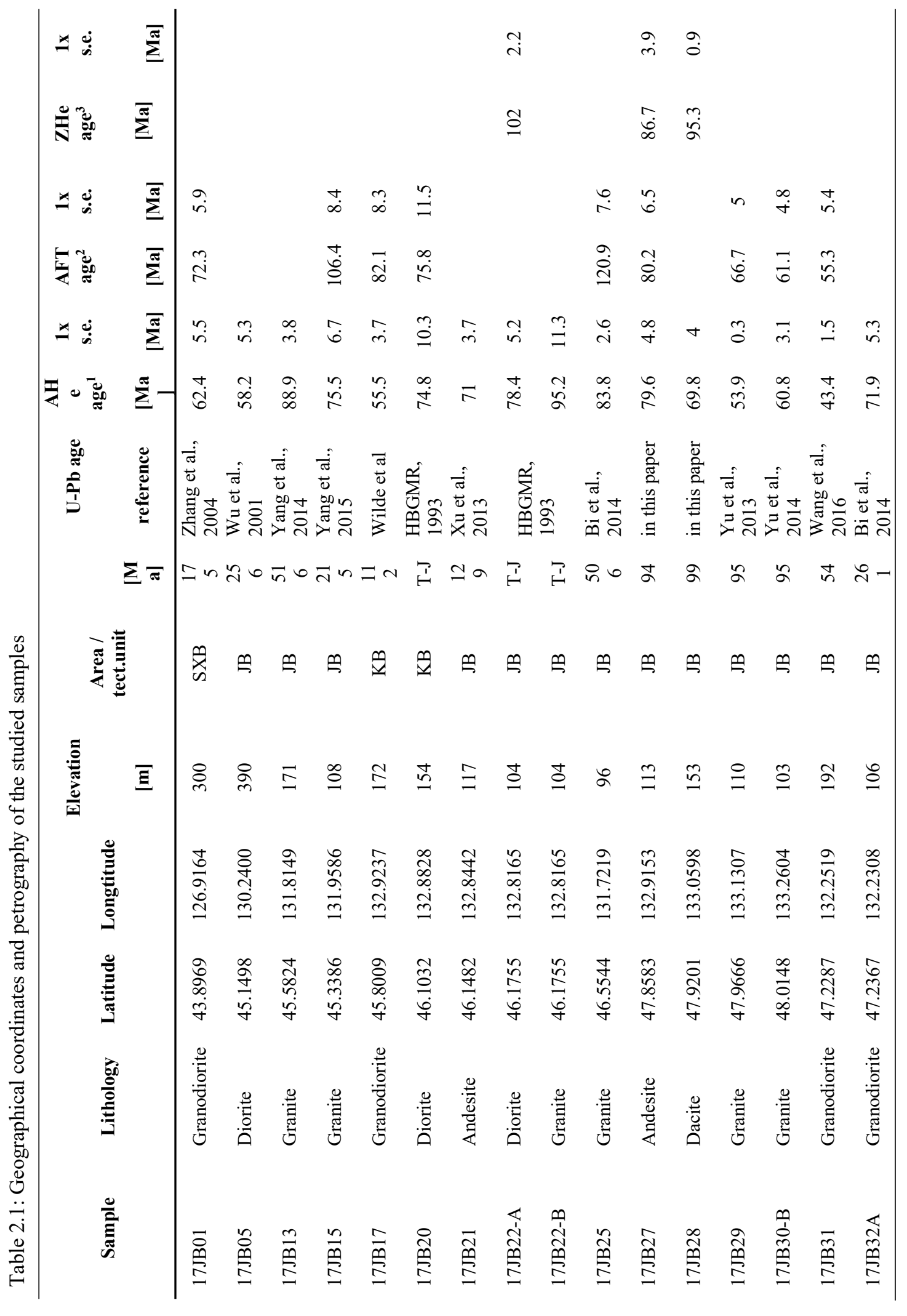



successions northeast of the Songliao Basin, NE China

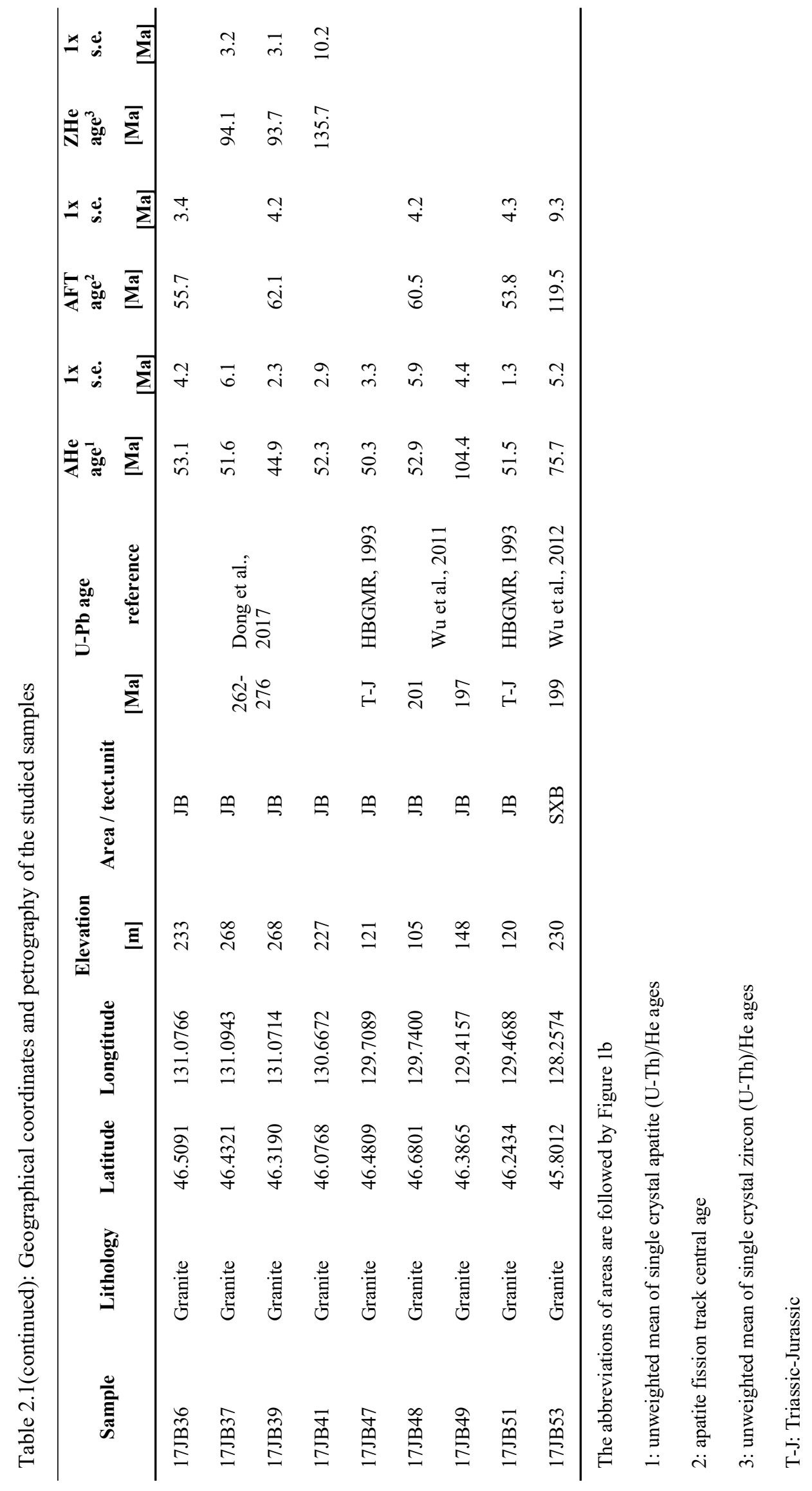




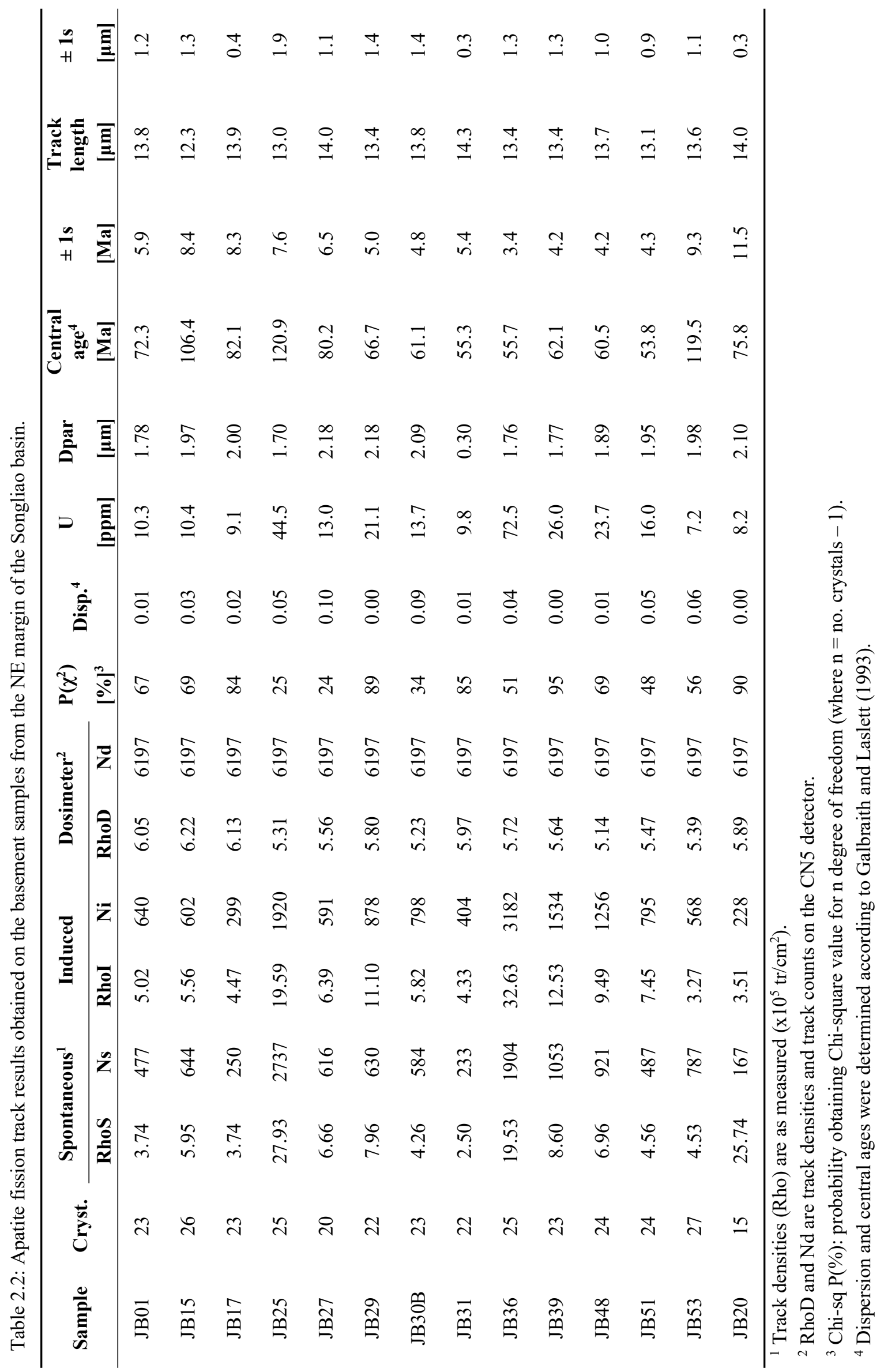




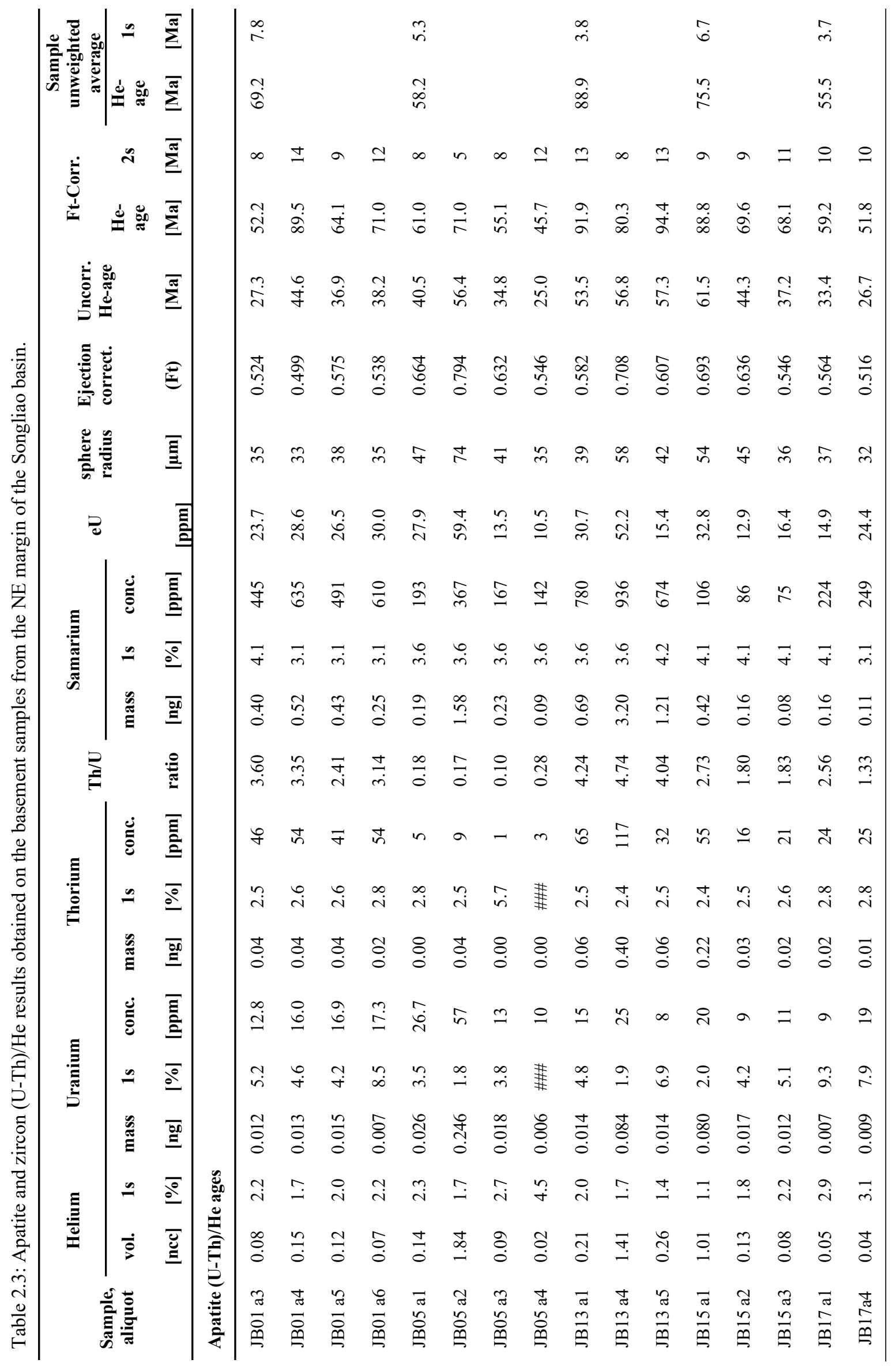




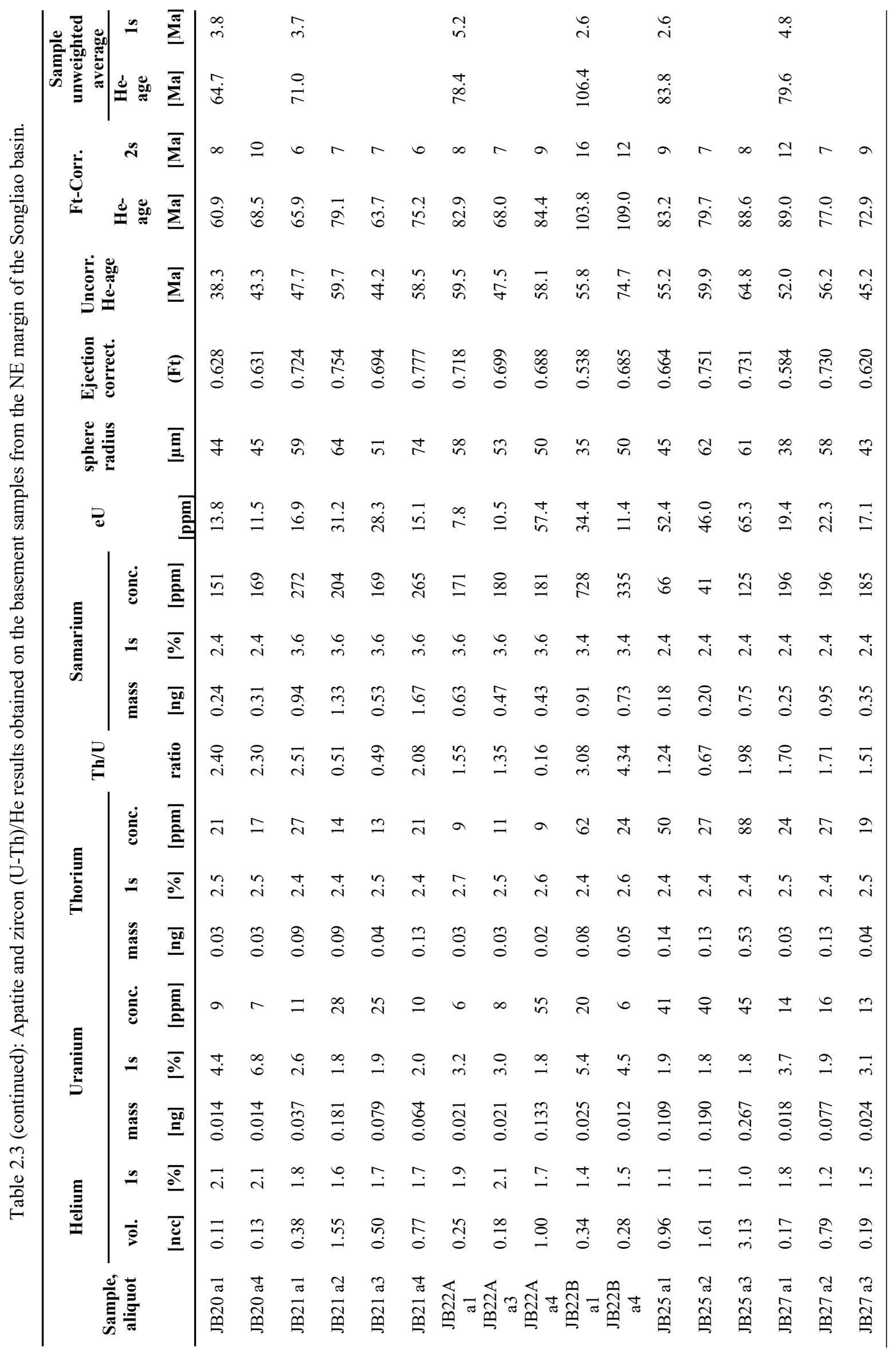




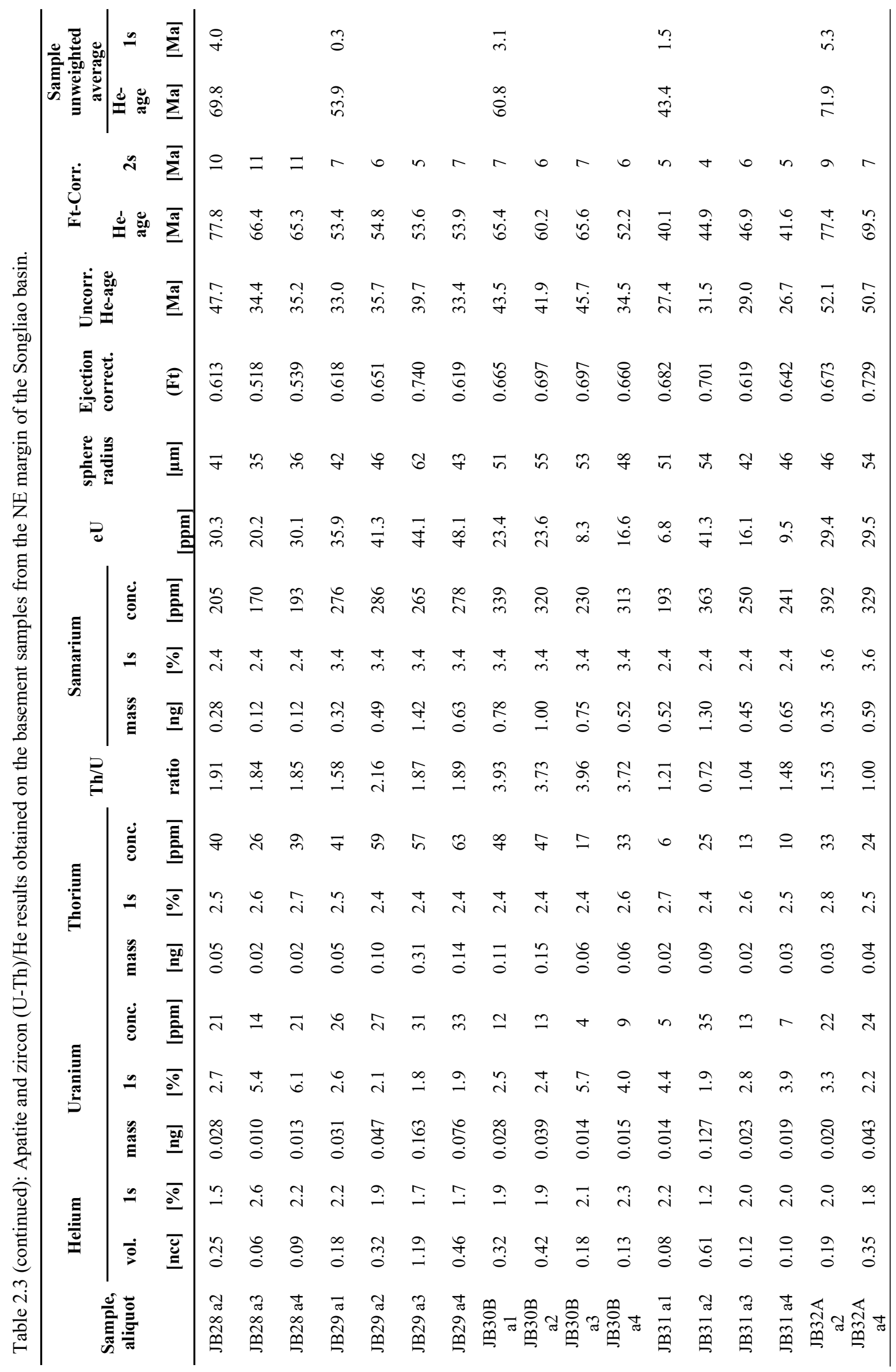




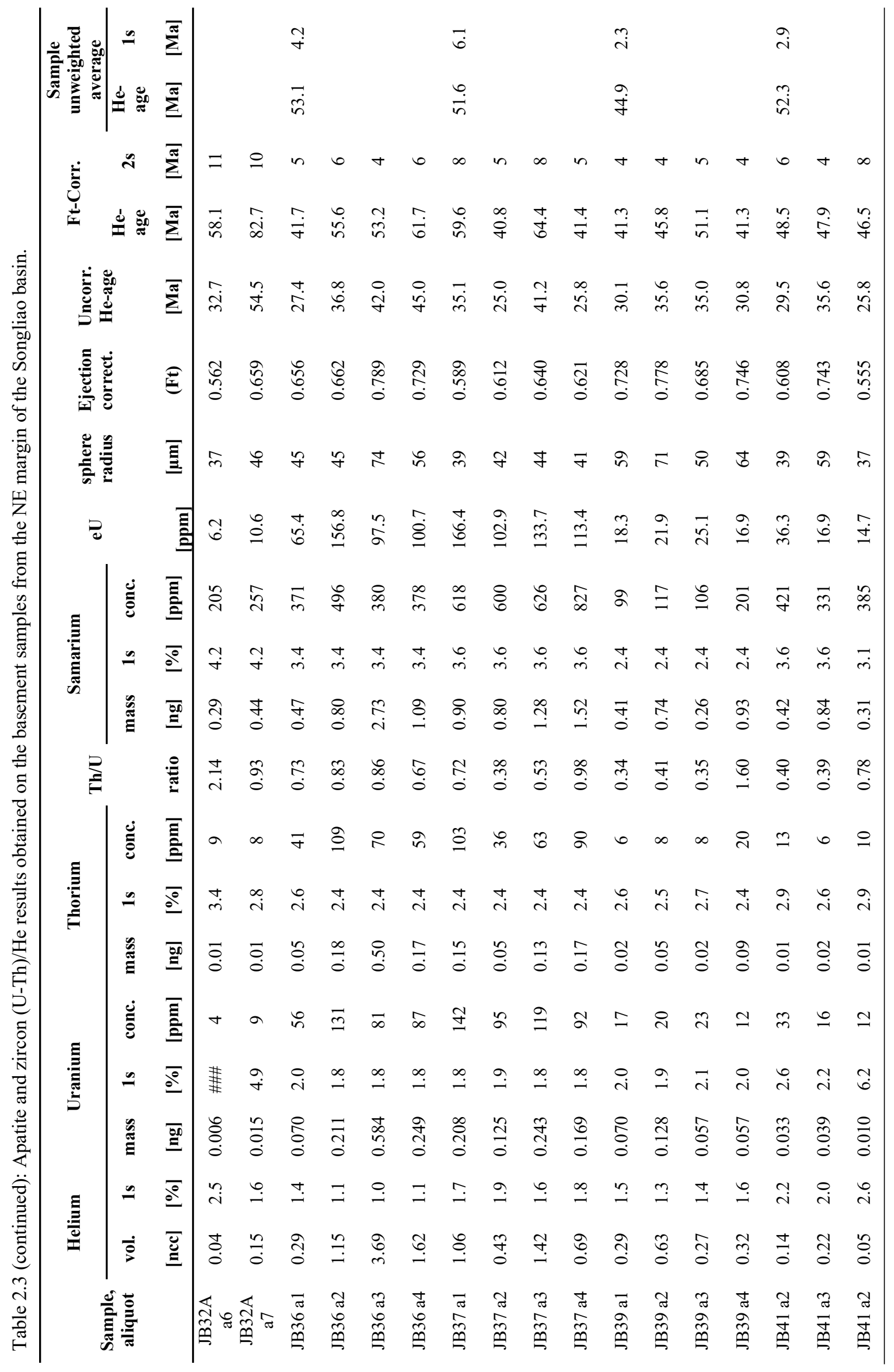




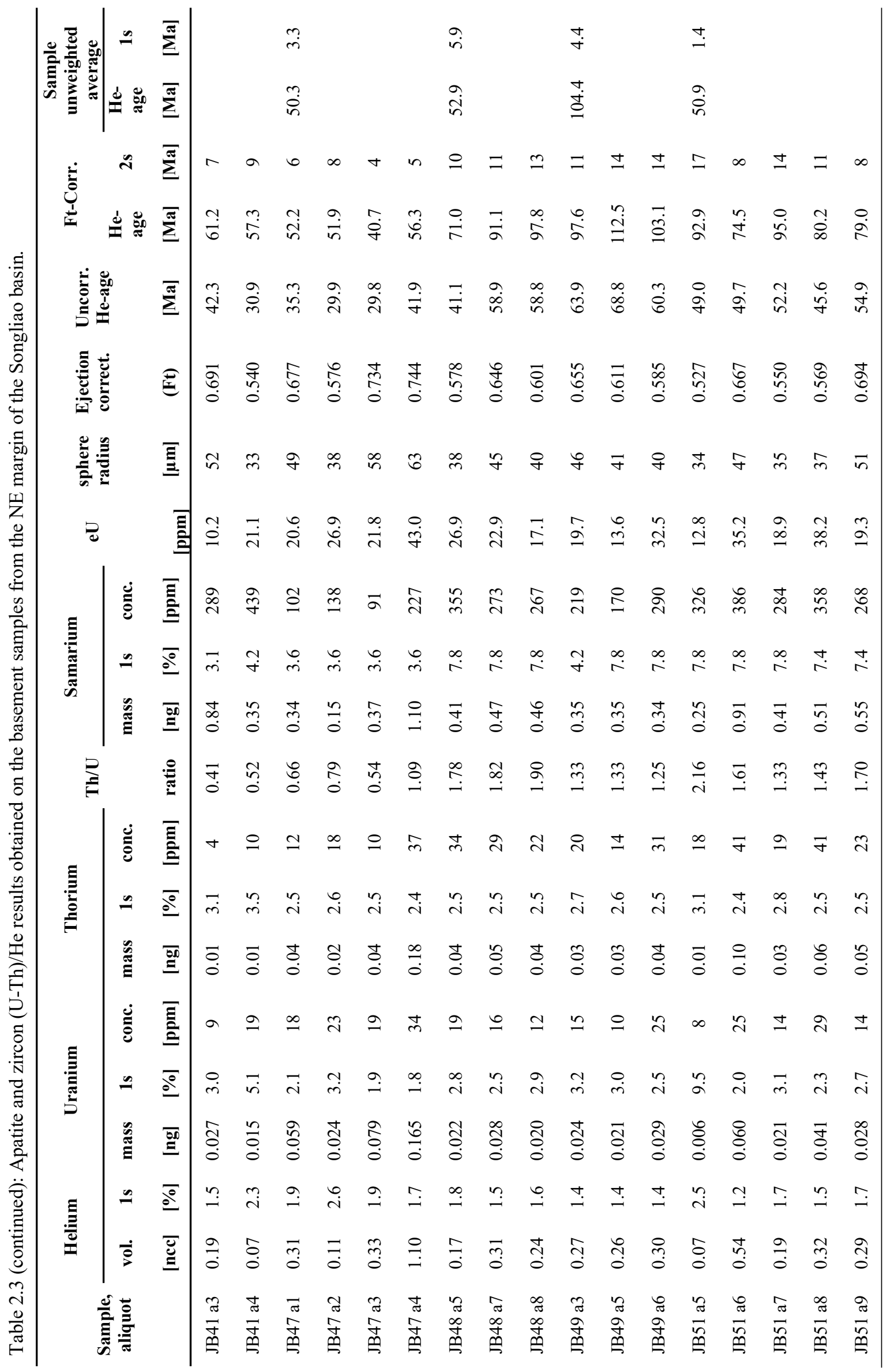




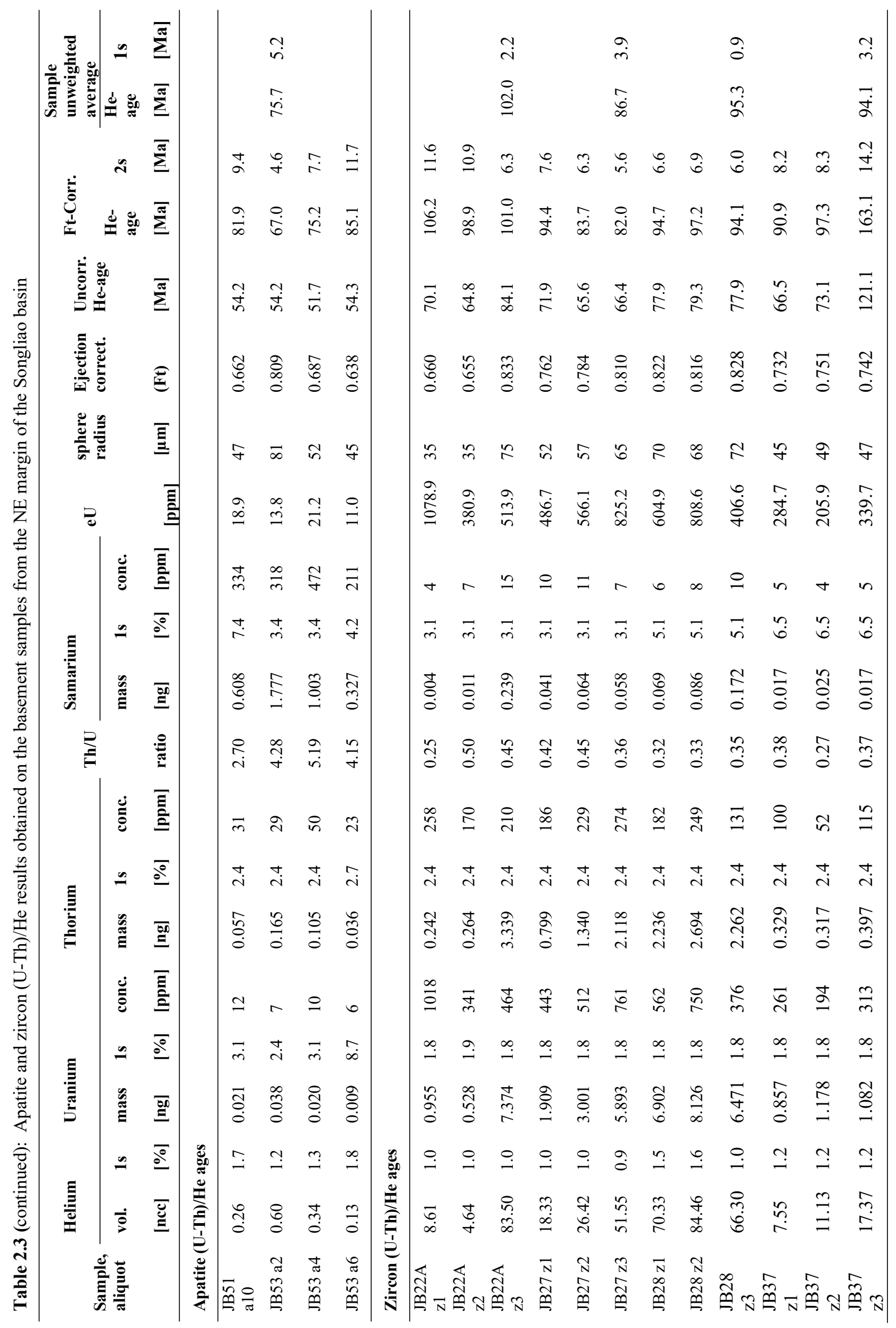




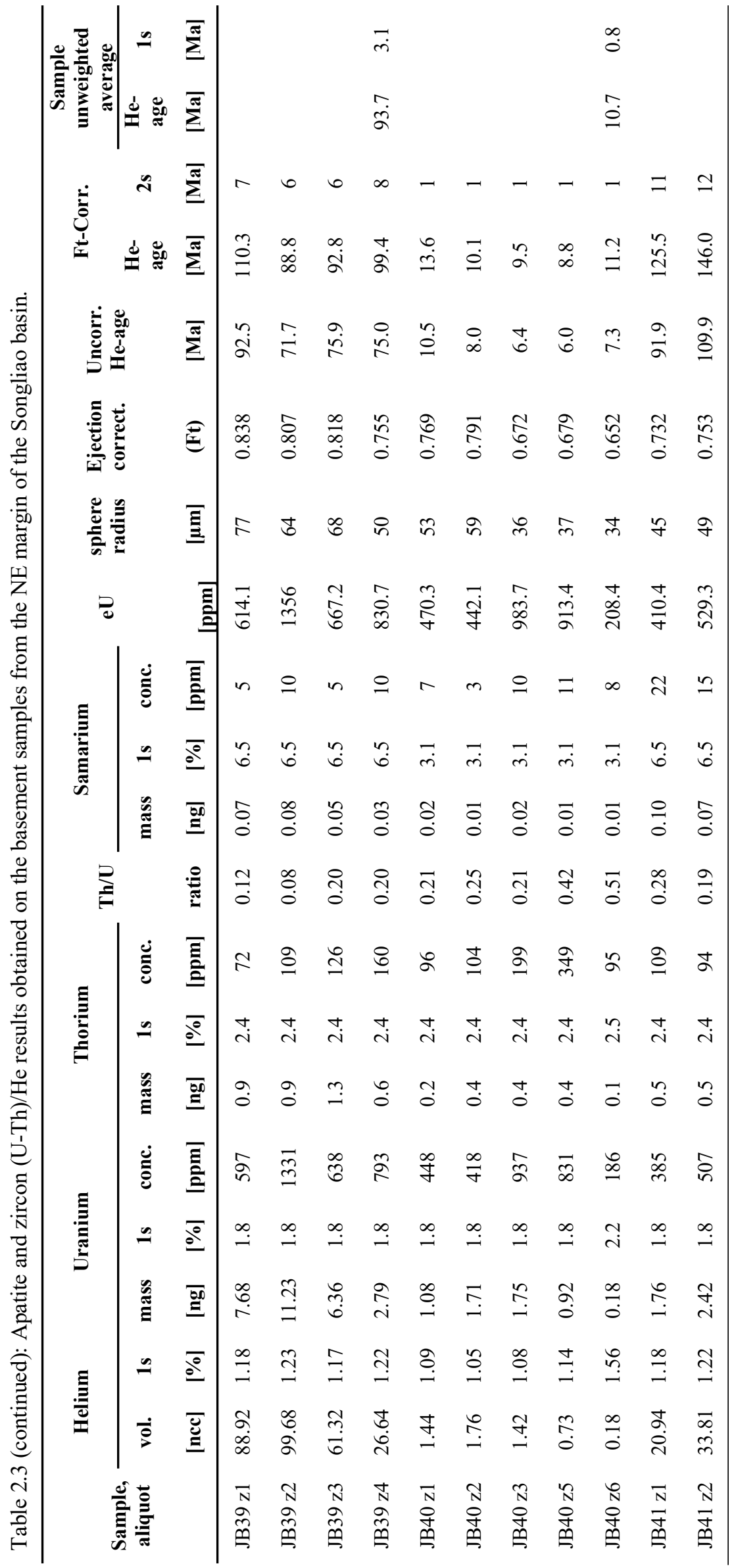




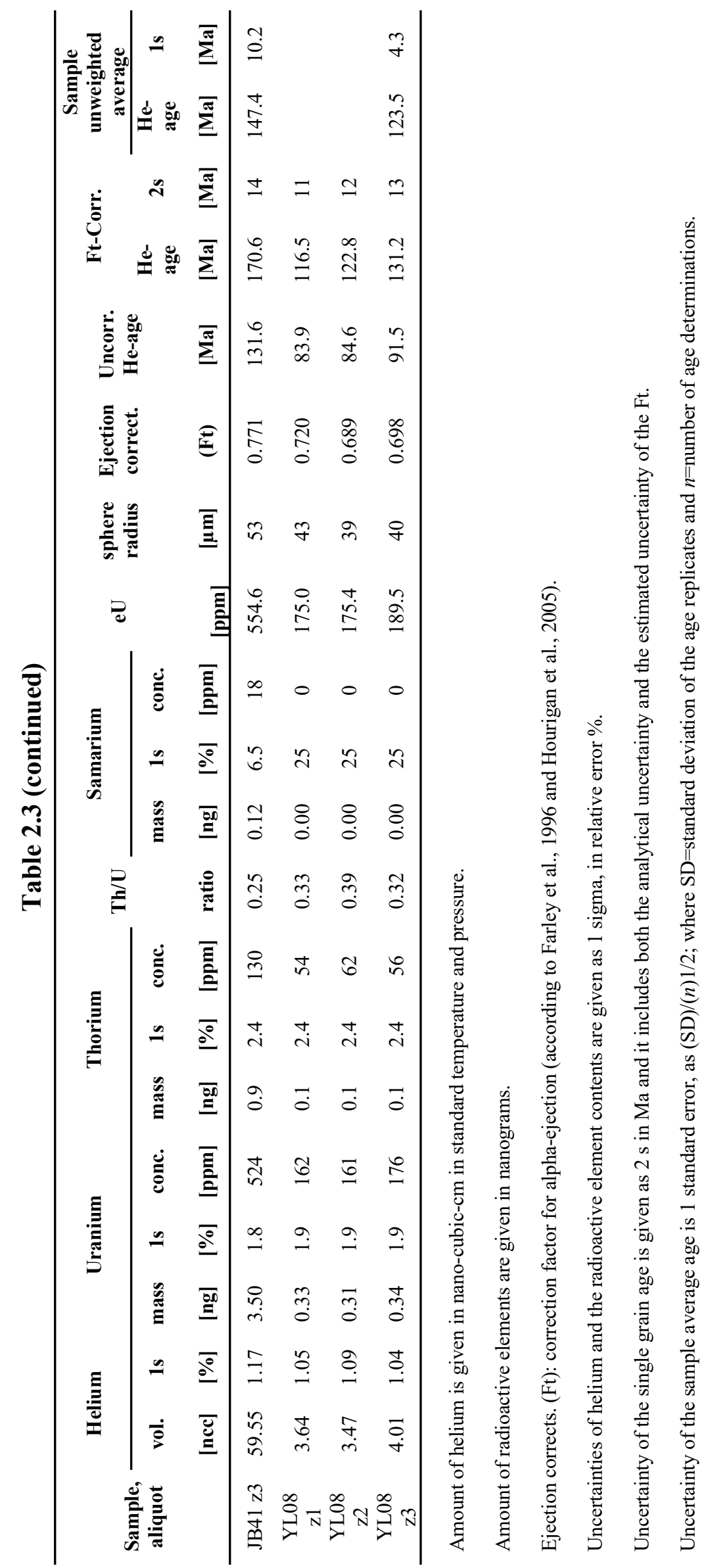




\subsection{Tandem modelling of the thermal and burial history to the east of the Songliao basin}

In the study area, in a wide zone of basement highs east of the Songliao basin, small remnants of the former Cretaceous sedimentary cover are preserved (Figure 2.2). These isolated, sometimes tiny Cretaceous basin remnants indicate a former much wider extent of Cretaceous basin fill and also widespread basin inversion events. In order to reconstruct the post-Jurassic thermal history of this region, a series of one-dimensional subsidence/thermal modelling was performed on the basement areas (relying on the ZHe, AFT, and AHe thermochronometers) and also on the basin remnants relying on the available vitrinite reflectance data. Our modelling is thus based on both subsidence analysis of the basin areas and thermal modelling on the basement highs and has been performed in four main steps.

In the first step the PetroMod software (Schlumberger Inc.) is used for the modelling of the subsidence history of selected wells, which contain proper stratigraphical and vitrinite reflectance information and represent specific sub-basins. In the second step the AFT, AHe and ZHe data obtained on the basement samples are used for thermal modeling by the software HeFTy v.1.8.3 (Ketcham, 2005). For the modeling of AFT, AHe and ZHe ages the Ketcham et al. (2007), Farley et al. (2000) and Reiners et al. (2004) algorithms were used, respectively. In the third step PetroMod modeling was used for the basement highs in order to reconstruct the burial-exhumation history of these formerly sediment-covered regions. This modelling considered the thermochronological age constraints, and the stratigraphic evidence from the sedimentation histories of the adjacent basins. The variables at this modeling stage were the paleo heat flow (assumed in a range of $40-80 \mathrm{~mW} / \mathrm{m}^{2}$ ), the thickness of the removed sedimentary sequences and the timing of the removal. Each tested burial thickness and heat flow setting generated a time-temperature curve, which serves as input for the calculation of the modelled AFT, AHe and ZHe ages and for the modelled MTL value. In the final step, all modelled results were compared to the measured results. The absolute residual error (RE) was used to express the "goodness" of the individual modelling runs. The equation is followed by $\mathrm{RE}=\mid$ Modelled results - Measured results $\mid$

For the borehole data, the modelled and measured Ro\% values were compared and generated the $\mathrm{RE}_{\mathrm{x}}$ which is followed by

$\mathrm{RE}_{\mathrm{x}}=$ Modelled Ro\% value in depth $\mathrm{x}$ - Measured Ro\% value in depth $\mathrm{x}$ The sum of the $R E_{x}$ values ( $S R E=\mid$ sum $R E_{x} \mid$ ) was determined on samples with different depths and it was used to quantify the match of the modelling of organic maturation data. The calculated RE of the basement samples and SRE of the boreholes with their corresponding 
different burial thickness and heat flow value were plotted on contour maps by the software Surfer (Golden Software Inc.) and then overlapped with each other to similarity of each methods' smallest RE or SRE value trending band.

\section{First step: modelling of the subsidence and exhumation history of the basins}

Comparing with the well-studied Songliao basin, the eastern basin group has received less attention up to now. The Ro\% measurements have partly low quality or the wells are represented by too low number of analyses to quantify accurately the downhole trend of organic maturation. In this study, we selected five wells with relatively high-quality organic maturation data from the Sanjiang basin, Boli basin, Hulin basin and Jixi basin for the thermal modelling (the Ro\% data are shown in Appendix Table 1; borehole locations are shown in Figure 2.2; data from Daqing oil company). The vitrinite reflectance data and the modelling results are shown in Figure 2.6.

The stratigraphic age and the thickness of the preserved sedimentary successions in the basin fill are the input data for the reconstruction of the thermal history, while the paleo heat flow as well as the thickness, the stratigraphic age and the time of removal of the eroded successions are the variables. The paleo water depth and the sediment-water boundary temperature have negligible influence on the modelling results; we kept them constant as the Lower Cretaceous formations are mainly shallow marine to continental deposits (He et al., 2008, 2009; Figure 2.3). In the study area thickness and age of deposition of the basin filling sedimentary formations are well known (i.e., Sun et al., 2000; Sha, 2002; Ren et al., 2005), however, very few heat flow data are available from the region. In the entire eastern NE China area only five measurements have been reported on the current heat flow, and the values vary from 35 to 70 $\mathrm{mW} / \mathrm{m}^{2}$ (Han, 1998; Jiang et al., 2016). For the modelling, the heat flow is treated as a variable ranging from 40 to $80 \mathrm{~mW} / \mathrm{m}^{2}$ in eight intervals with a step of $5 \mathrm{~mW} / \mathrm{m}^{2}$. To simplify the modelling procedure and to reduce the number of variables the heat flow was considered constant over time. The organic maturation and its downhole trend are the most important input data for the thermal modelling of the burial history. In this study, the collected Ro\% values were determined mostly in the Lower Cretaceous formations, and usually the younger sequences are underrepresented (except the borehole HuCan1, where Paleogene Ro\% values are also available; Figure 2.6, Appendix Table 1). The measured Ro\%-depth plots indicate that most of the Ro\% values have relatively linear relationship with depth. The Ro\% trends extrapolated until the surface yield intersection values between 0.4 and $1.5 \%$, and these values 
are always higher than the initial reflectance of the vitrinite implying denudation of former post-Early Cretaceous cover sequences. Depending on the heat flow settings and the variable assumptions on eroded thickness, some of the best-fit curves are shown in Figure 6 . Furthermore, when approaching the best-fit situation, the highest burial temperature of each borehole is roughly constant and appeared in the late Early Cretaceous to Late Cretaceous (approx. 110 to $70 \mathrm{Ma}$ ). The calculated maximum paleo burial temperatures in the deepest part of the basin fill are ca. $240{ }^{\circ} \mathrm{C}$ for borehole Bin 1, ca. $200^{\circ} \mathrm{C}$ for boreholes BinCan1, HuCan1 and $\mathrm{BoD} 1$ and ca. $135^{\circ} \mathrm{C}$ for borehole Ji2 (Figure 2.6). The modelled maximum paleo burial temperatures can be further used for the basement modelling in the second step.

Different heat flow value and eroded thickness combinations can result in good fit to the measured organic maturation data. In order to visualize the interdependence of these variables and to plot the field of scenarios with proper calculated VR data the Surfer software was used, and the sum of residual error isolines were computed by the Kriging method (Figure 2.9). All of the five boreholes revealed similar, negative correlation between the heat flow and erosion thickness. However, the position of the "acceptance belt" is different in the basins. For instance, a given heat flow value of $60 \mathrm{~mW} / \mathrm{m}^{2}$ and the corresponding "acceptance belt" indicates ca. 4.5 $\mathrm{km}$ eroded thickness in Binl well, while the same constraints indicate only ca. $1.6 \mathrm{~km}$ eroded in Ji2 well. Thus, we can conclude that the different regions experienced highly different postEarly Cretaceous burial and subsequent erosion. 


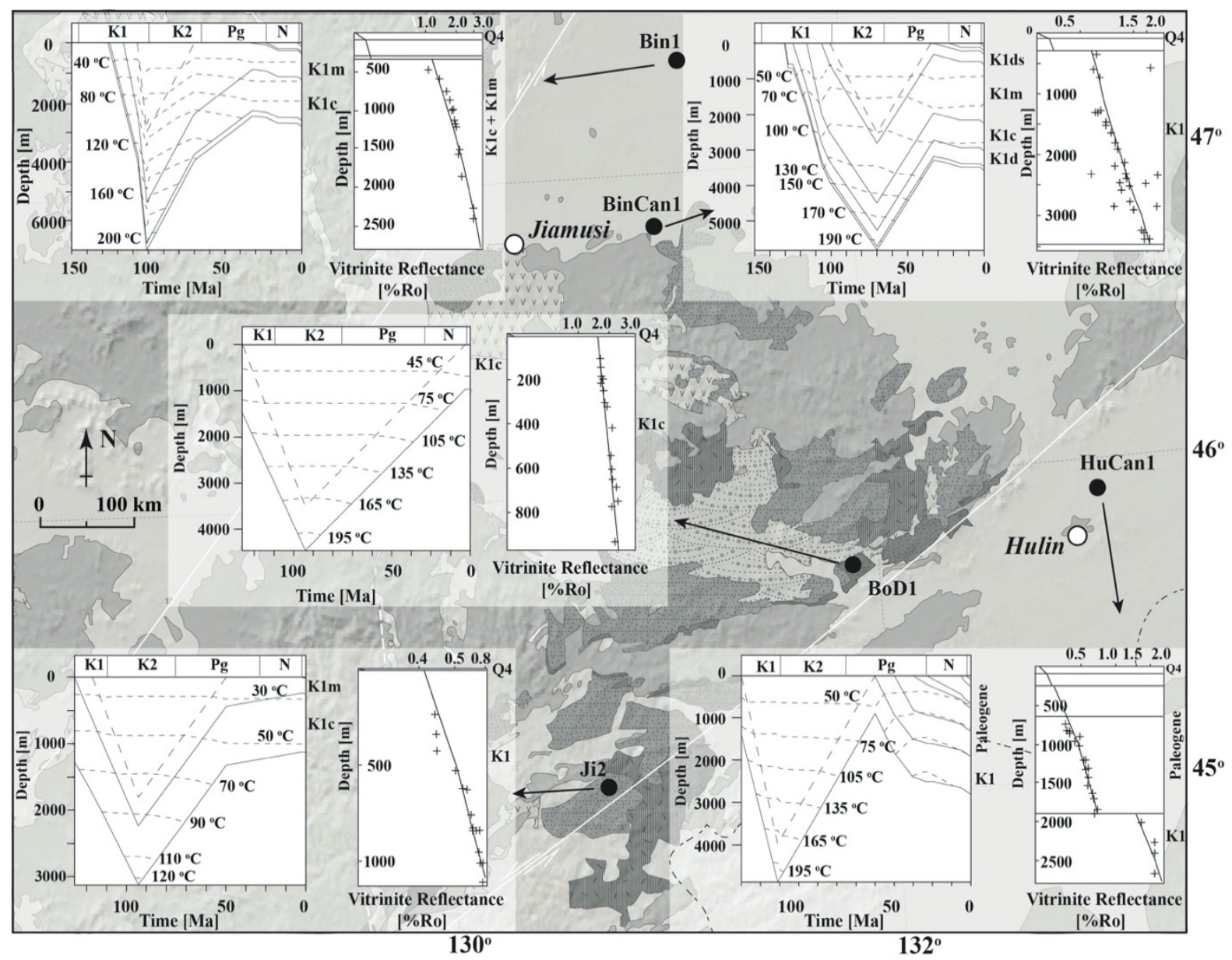

Figure 2.6: Overview of the available down-hole vitrinite reflectance values and the burial-exhumation modelling results performed by PetroMod software on selected boreholes of the eastern basin group. The good match of the calculated and measured Ro\% data indicates the reliability of the modelling results. The presented burial curves are only a selection of the burial scenarios that yielded good match to the measured vitrinite reflectance data. The total eroded thickness and the paleo heat flow are used as variables for the modelling of different burial scenarios, see text for details. K1d, Early Cretaceous Didao formation; K1c, Early Cretaceous Chengzihe formation; K1m, Early Cretaceous Muling formation; K1ds, Early Cretaceous Dongshan formation; K2, Upper Cretaceous; Pg, Paleogene; N, Neogene. For the legend of the simplified geological map see Figure 2.5.

\section{Second step: The time-temperature modelling of the basement samples}

The time interval was set between 200 and 0 Ma to perform the thermal modelling. Using the HeFTy software (Ketcham, 2005) random time - temperature paths were tested and the calculated apparent low-T ages and track length distributions were compared with the measured data. The modelled results were then categorized as good or acceptable according to the goodness of fit parameter (Ketcham, 2005). Twelve samples dated by the AFT, AHe and/or ZHe methods were chosen for the thermal modelling. Mostly both FT and helium ages were 
considered, except for samples JB28 and JB41 where only AHe and ZHe data are available. Beyond the low-T age constraints the emplacement ages of the intrusions in the basement, the age of the beginning of sedimentation in the adjacent basins and the organic maturation-based maximum paleo temperatures (as derived from step 1) were considered. The formation of the basement took place between Cambrian and early Mesozoic - according to the zircon U-Pb geochronology of the granitoids (Bi et al., 2013; Yu et al., 2013; Yang et al., 2014; Dong et al., 2017). The emplacement ages of the basement samples are considerably older than their $\mathrm{ZHe}$, AFT and AHe ages. For basement samples with $>200$ Ma emplacement age the first timetemperature constraint was set to $190 \pm 10 \mathrm{Ma}$ and $15-200^{\circ} \mathrm{C}$. For the basement samples with $<200 \mathrm{Ma}$ emplacement ages, the first constraint was set slightly later than the crystallization age and the temperature was set at $>110^{\circ} \mathrm{C}$ which is higher than the apatite fission track partial annealing zone. For the following constraints the samples were separated into two groups. Samples taken from the surface (JB01, JB27, JB28, JB29 and JB30b) were only given a final constraint with the annual mean temperature of $10 \pm 5^{\circ} \mathrm{C}$ at $0 \mathrm{Ma}$. These samples are located at the northern and southern margins of the Jiamusi Uplift. The rest of the basement samples (JB25, JB36, JB39, JB41 and JB48) were collected from the neighborhood of unconformably onlapping Mesozoic sediment remnants, and this indicates that these basement blocks experienced a near surface temperature in the Late Jurassic - Early Cretaceous. The near surface t-T (time-temperature) constraints for these four samples were placed at 130-115 Ma and 20 \pm $5{ }^{\circ} \mathrm{C}$. The samples JB15 and JB53 were close to the Upper Jurassic-Lower Cretaceous sediment remnants which suggest a first near surface t-T constraint at $140 \pm 10 \mathrm{Ma}$ and $20 \pm 5{ }^{\circ} \mathrm{C}$ (the sedimentation ages are after HBGMR, 1993). The results of the basin modelling from the first step indicate a Late Cretaceous maximum burial temperature of ca. $200{ }^{\circ} \mathrm{C}$ in the southwestern part of the Sanjiang basin and the eastern Boli basin (Figure 6). This temperature was taken as potential maximum value for the modelling of the basement area and thus $\mathrm{t}-\mathrm{T}$ constraints of $200{ }^{\circ} \mathrm{C}$ and 110-80 Ma were applied for samples JB36, 39, 41 and 48 (Figure 2.7). 
I. Late Cretaceous-Tertiary tectonic inversion of northeastern Asian continental margin: insight from the low temperature thermochronology in NE China
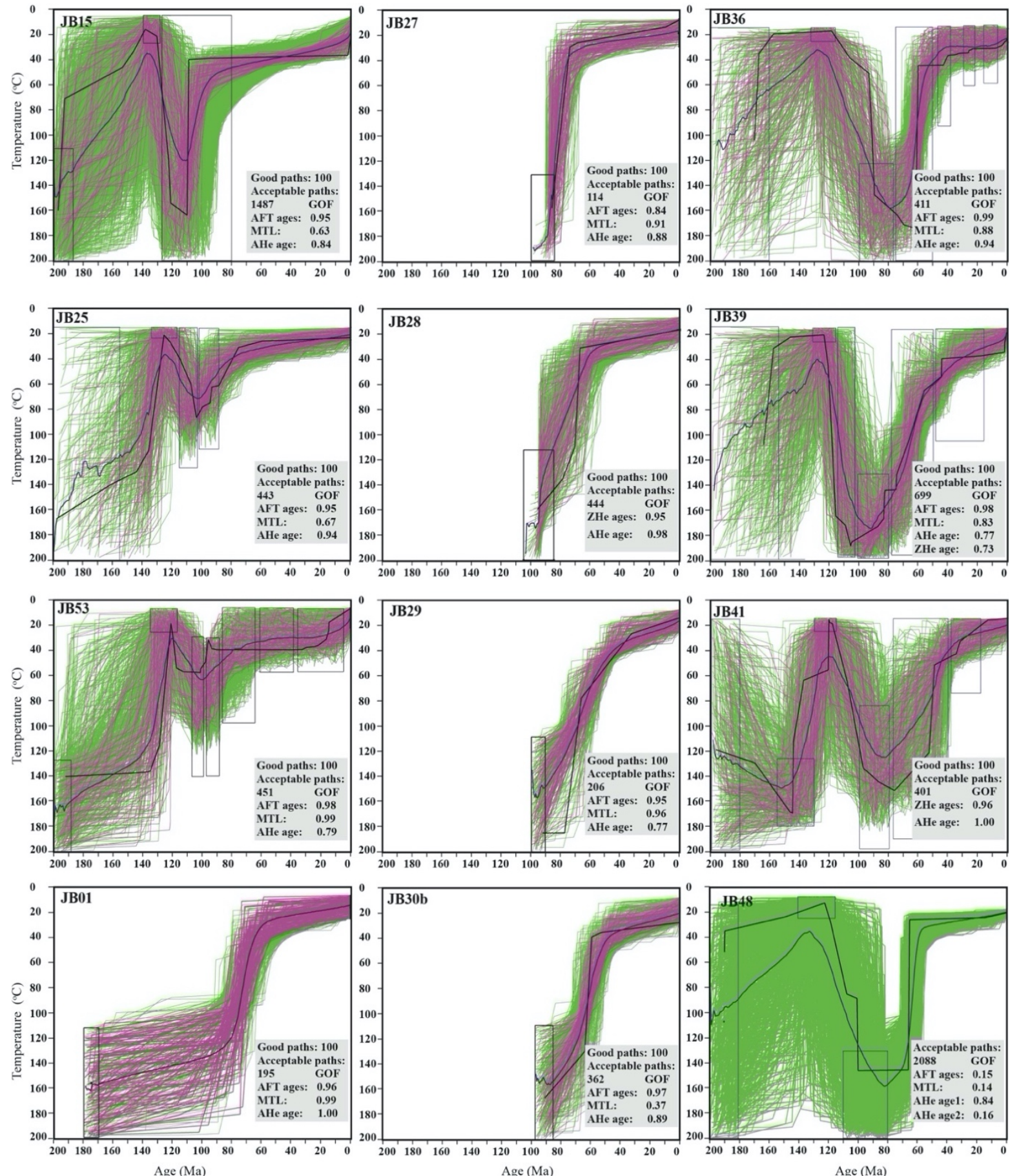

Figure 2.7: Results of the time-temperature modelling of the exhumed basement areas northeast of the Songliao Basin. The input data were the apatite fission track ages and track length distributions, the apatite and zircon (UTh)/He ages, the actinide contents and dimensions of the dated crystals (AFT: apatite fission track; AHe or ZHe: apatite or zircon (U-Th)/He). For each model, 100,000 random paths were generated or the modeling procedure was stopped after 100 good paths. GOF: goodness of fit between the modelled and measured results. The numbers of good (red, GOF >0.5) and acceptable (green, GOF >0.05) paths are indicated on the plots. Blue paths denote the weighted mean paths of the good models. Black paths denote the best-fit paths for the models shown. 
The resulting models show different cooling patterns from different areas of the Jiamusi Uplift. Except for the poorly constrained pre-Early Cretaceous thermal history, which only revealed an approximate cooling process until the Early Cretaceous, the post-Early Cretaceous thermal history is well constrained. Starting from 110-100 Ma, samples JB15, JB25 and JB53 from the eastern and western margins of the Jiamusi Uplift first cooled below $40{ }^{\circ} \mathrm{C}$ with high cooling rates (2.6 and $\left.1.2^{\circ} \mathrm{C} / \mathrm{Myr}\right)$ until ca. $90-80 \mathrm{Ma}$. This is followed by a long-lasting period of much slower cooling (0.3-0.5 $\left.{ }^{\circ} \mathrm{C} / \mathrm{Myr}\right)$ until present. The samples JB15 and JB25 from the east exhumed earlier and experienced more post-Early Cretaceous erosion than the sample from the western margin. The samples from the middle part of the Jiamusi Uplift (samples JB25, JB36, JB39, JB41 and JB48) revealed a slightly later exhumation than the eastern and western margins. The early cooling rates between 90-80 and 60-40 Ma were high (ca. 2.4-5.4 ${ }^{\circ} \mathrm{C} / \mathrm{Myr}$ ). After this period the cooling rates were considerably lower, ca. $0.1-0.7{ }^{\circ} \mathrm{C} / \mathrm{Myr}$ (Figure 2.7).

Third step: modelling the heat flow and burial thickness over the re-exhumed basement areas

The modelling of the thermal evolution of the formerly buried and re-exhumed basement areas needs assumptions on the following characteristics of the cover sequences: (1) the lithology of the eroded sedimentary cover (2) the thickness of the burial, (3) the paleo heat flow, (4) the onset of burial and (5) the onset of removal of the cover sequence.

(1) and (2): Lithology and stratigraphy of the cover sequences

The widely distributed Lower Cretaceous sediment remnants on the basement highs show similarities to the contemporaneous strata in the surrounding basins (Zhou et al., 2009). We thus assume similar sedimentary sequences covering formerly the basements. For the sake of simplicity, we applied the petrophysical parameters of siltstone for the entire cover sequence. The eroded thicknesses and the remaining sedimentary thicknesses from the satellite basins were considered as potential total burial of the basement highs.

(3) Paleo heat flow

The HeFTy modelling of basement samples indicates a generally similar, rapid heating and cooling process from the late Early Cretaceous to Eocene. The potential reasons of this overprint could be the burial heating by the covering younger successions and its interplay with the Late Cretaceous volcanic activity. Xu et al (2013) mentioned that the major volcanic activity occurred between 131 and $106 \mathrm{Ma}$ in the study area, thus the eruption ages in the Songliao basin and its immediate surroundings are older than most of the measured apatite and zircon low-T ages (Figure 2.5). It is remarkable that two new U-Pb ages of 99 and $94 \mathrm{Ma}$ were 
measured on volcanic rock samples JB27 and JB28 collected along the Amur river at the northern border of the study area (Figure 2.2, Appendix Figures 2.3 and 2.4). These data highlight that the igneous activity lasted longer in the northernmost part of the basin system, but the remote position of this dated younger volcanism makes a thermal influence on the southern areas highly unlikely.

The Early Cretaceous igneous activity-triggered high heat flow likely decreased soon after the cessation of the volcanism in the major part of the eastern basins, i.e. before $100 \mathrm{Ma}$. This means that the post-volcanic burial has determined the climax of the thermal history in the eastern basin group and in the currently exhumed basement highs, except for the northernmost part. That is why high heat flow periods were not considered for the modelling of the low-T ages that are considerably younger than the volcanic activity and the heat flow was treated to be constant over time. In order to be consistent with the PetroMod modelling of the basins the heat flow values for the basement modelling runs were set between 40 and $80 \mathrm{~mW} / \mathrm{m}^{2}$ in eight steps of $5 \mathrm{~mW} / \mathrm{m}^{2}$.

(4) Onset of burial and (5) onset of removal of the cover sequence

According to the sedimentary record the onset of burial for the modelling was set to the beginning of Late Jurassic or to Early Cretaceous. The onset of removal of the cover sequence was defined by the inflection points identified on the average mean thermal history paths yielded by the HeFTy modelling (Figure 2.8). 


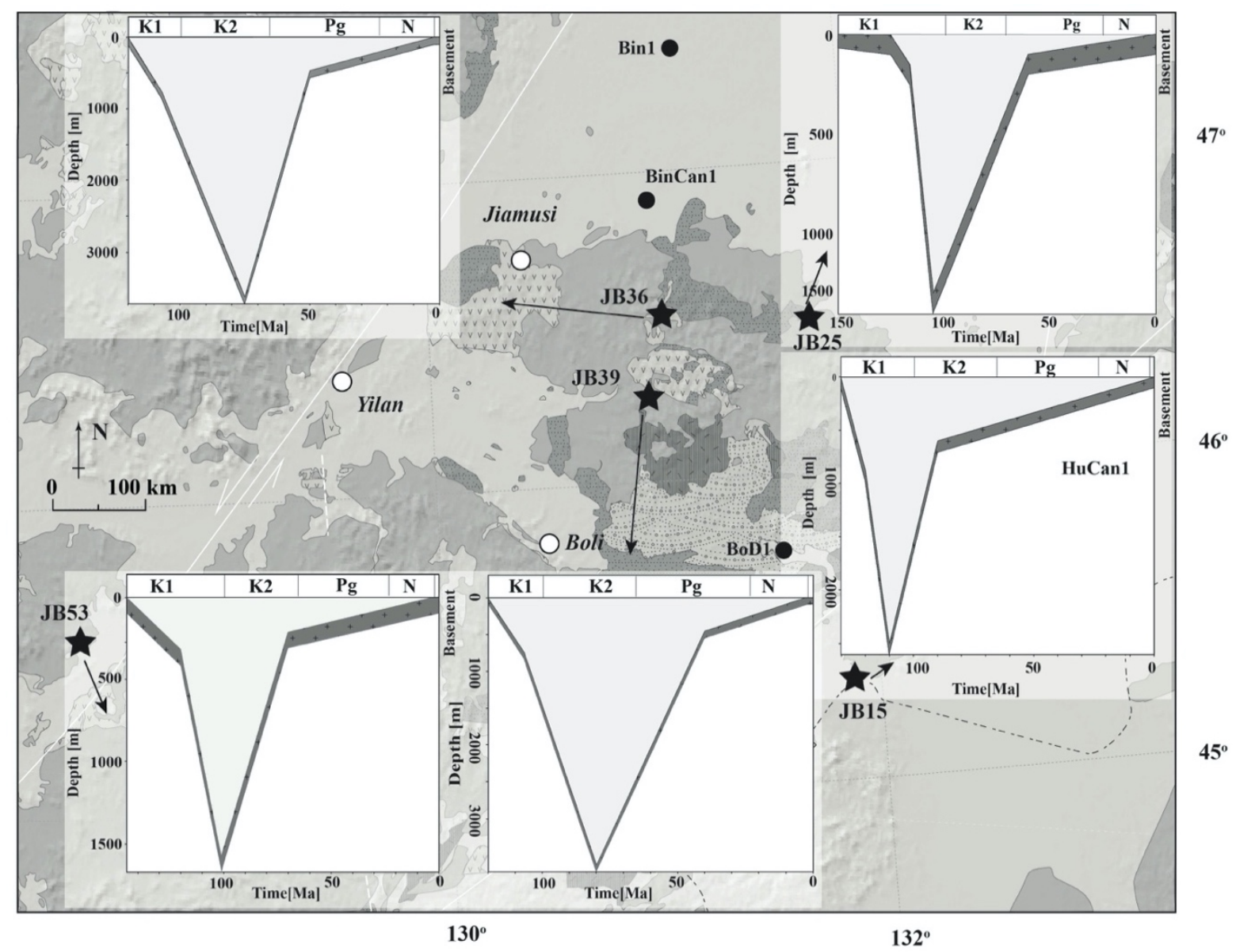

Figure 2.8: Overview of the PetroMod (Schlumberger) modelling results of the basement areas. For the legend of the simplified geological map, see Figure 5. In the burial plots of each modelled well the gray parts represent the accumulation-removal history of the missing cover sequences. All five plots reveal the situation where the residual error has a minimum value; see details in text. K1, Lower Cretaceous; K2, Upper Cretaceous; Pg, Paleogene; N, Neogene.

\section{The results of the thermal modelling of basement areas}

The modelling results obtained on basement samples are shown in Figure 2.10. The interdependence (negative correlation) of the burial thickness and the paleo heat flow is well reflected on all residual error plots. The width of the "acceptance belt" is variable; e.g., in case of samples JB53 and JB15 the different criteria used for the acceptance belt yield a coherent pattern, while in case of sample JB39 the acceptance threshold lines are less coherent and thus the compiled "acceptance belt" is wider, less determined. Similar to results obtained on the basins, the former burial thickness of the currently exhumed basement highs was variable (Figure 10). See e.g., the intersection of the $60 \mathrm{~mW} / \mathrm{m}^{2}$ heat flow value and the white "acceptance belt" in case of northern samples. The former indicates the maximum burial is 
between 2.5 and $4.8 \mathrm{~km}$, while in the southern samples the corresponding thickness of the paleo-cover is around $1.7 \mathrm{~km}$ (Figures 2.10, 2.11).

The usage the heat flow value of $60 \mathrm{~mW} / \mathrm{m}^{2}$ is a reliable approximation as Han (1998) and Jiang et al. (2016) have determined this value as an average value of the whole NE China. However, it is remarkable that heat flow data from the region are very rare.

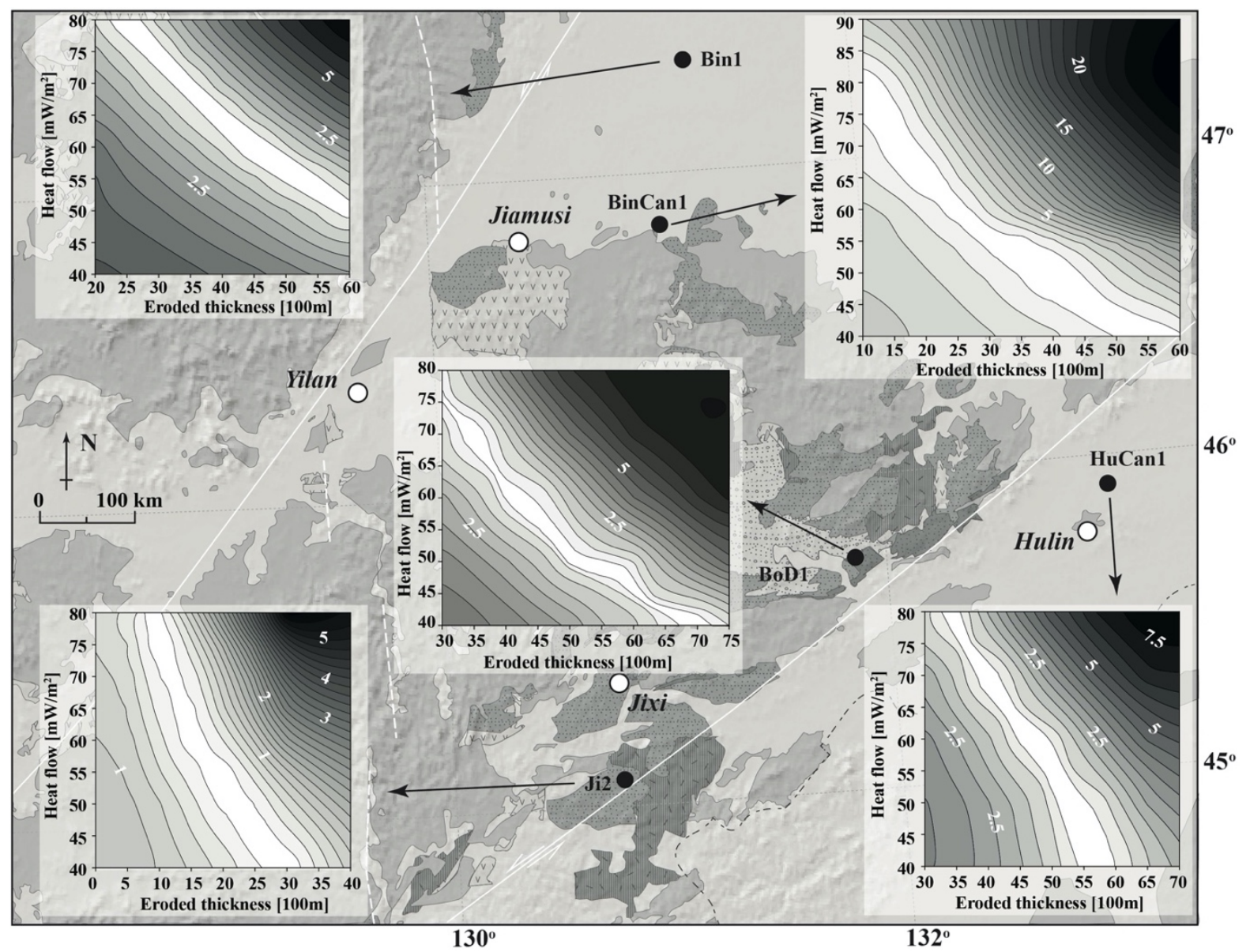

Figure 2.9: Residual error plots showing the interrelation of the paleo-heat flow and thickness of missing sequences (eroded thickness) for the five wells where the burial history was modelled. The values on the isolines represent the sum of the residual error (SRE) between the modelled vitrinite reflectance data and the measured ones. The isolines on the plots were generated by the Surfer software according to the five PetroMod modelling runs assuming different heat flow-burial combinations. The white band represents the smallest SRE. For the legend of the simplified geological map, see Figure 2.5. 
Cretaceous-Cenozoic thermo-tectonic evolution and provenance analysis of the basement and some sedimentary successions northeast of the Songliao Basin, NE China

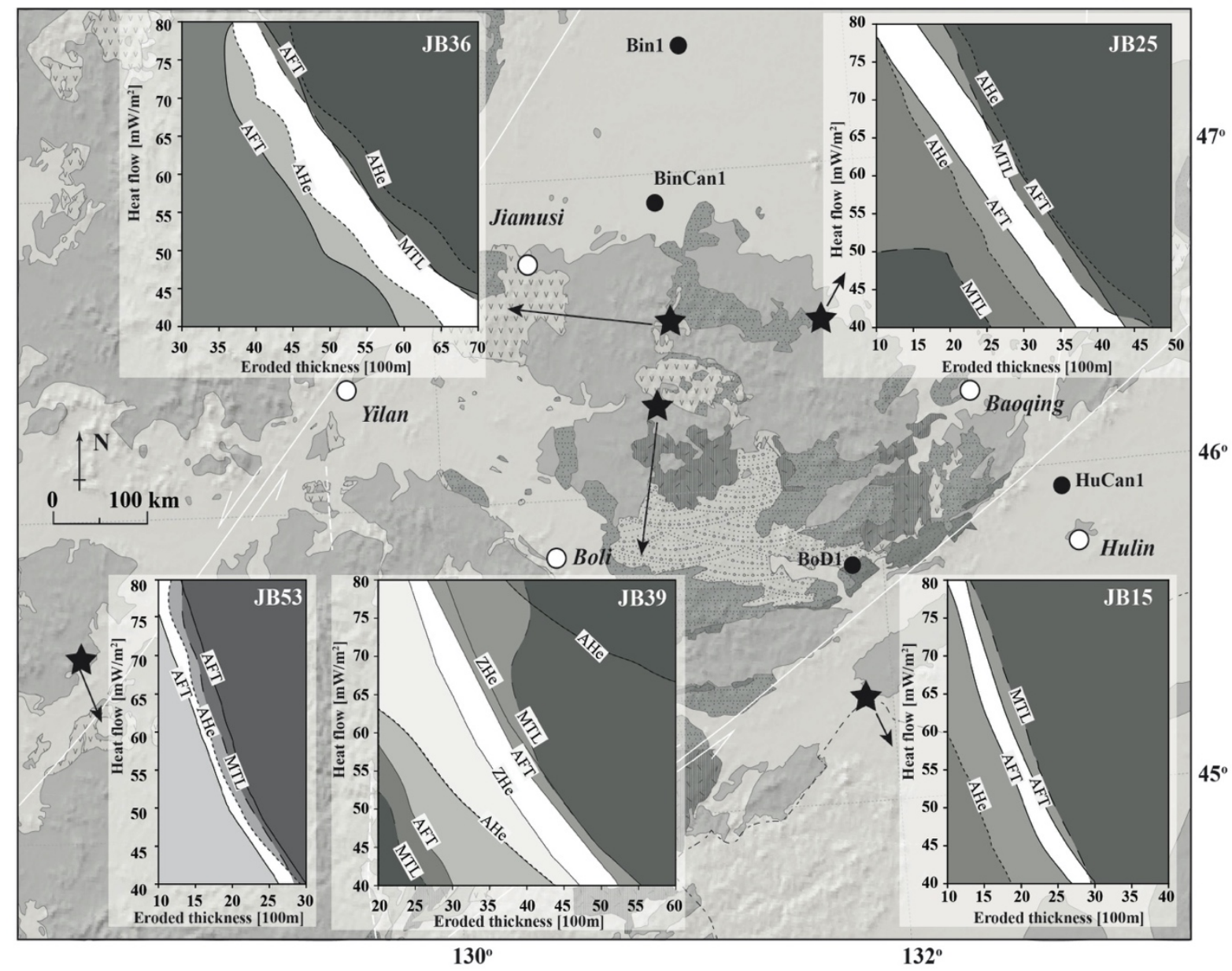

Figure 2.10: Estimation of the thickness of the missing sequences (eroded thickness) and the paleo-heat flow at the time of sedimentary cover for five selected basement sample sites. The residual error plots were generated by a combined modelling using PetroMod (Schlumberger) and HeFTy (Ketcham, 2005) software assuming different thickness and heat flow values as input data. The lines of the different thermochronological parameters indicate a kind of threshold of acceptance and the lighter colored side indicates the better match of the modelled values and the measured values. The white belts represent the best fit conditions, when the burial and heat flow interplay resulted in thermal histories that generated low-T thermochronological data close to the measured ones. AHe, ZHe: apatite or zircon (U-Th)/He age, AFT: apatite fission track age, MTL: mean confined horizontal track lengths in the apatite crystals. For the legend of the simplified geological map, see Figure 2.5.

\subsection{Discussion}

Post Jurassic thermal history reconstruction of the east NE China area

The stratigraphical record and the modelled thermal histories of the basement highs yielded two exhumation periods in the study area, the first between ca. $200 \mathrm{Ma}$ and ca. $130 \mathrm{Ma}$ and the second between ca. 110-90 Ma and ca. 60-40 Ma. The first exhumation is poorly constrained. Former studies have indicated that the Jiamusi Block (JB) and Songliao-Xilinhot Block (SXB) 
have completed their amalgamation in the Late Jurassic (ca. $160 \mathrm{Ma}$ ), which lead to the rapid exhumation alongside the major Mudanjiang-Yilan suture zone, (MYS, see Figure 1; Zhou et al., 2009a, Li et al., 2010, Zhao and Zhang, 2010, Liu et al., 2017). With the final amalgamation of JB and SXB, during the Late Jurassic-Early Cretaceous, the area was covered by marinecontinental alternating sedimentation (He et al., 2009, Zhou et al., 2009). The very similar Early Cretaceous stratigraphy in the satellite basins indicate a, regional cover sequence that covered uniformly the basement highs and the surrounding remnant basins including the Jixi basin, Boli basin, Sanjiang basin and Hulin basin. At this stage, the continuous subsidence and sedimentation has gradually increased the burial heat which led to the reset of the zircon and apatite thermochronometers in the basement units.

Uplift, basin inversion and erosive removal of the basin fill has started between 110 and $80 \mathrm{Ma}$ and continued until the Eocene in the eastern NE China area. The eastern margin of the Jiamusi Uplift (east Mishan Uplift and east Huanan Uplift) experienced slightly earlier exhumation (starting from 110-105 Ma) and more erosion than the western margin of the uplift area (Zhangguangcai Range). Among the exhumed areas, the west Huanan Uplift experienced most erosion. Furthermore, a narrow NE-SW belt between the Jiamusi-Yitong fault and the DunhuaMishan fault revealed a nearly consistent exhumation starting at ca. 90-80 Ma that matched with the cessation of the fast-cooling period for both east and west sides of the Jiamusi uplift margin area (Figure 2.7). The difference in the exhumation times might be controlled by the Jiamusi-Yitong fault and Dunhua-Mishan fault systems.

The eastern satellite basins overall experienced thicker post-Early Cretaceous burial and deeper erosion than the Songliao basin (Figure 11). The total thickness of the missing sequence is variable for the different areas. We assume that the currently elevated western Zhangguangcai Range and eastern Mishan Uplift were also covered by Late Cretaceous sedimentary formations, and that these blocks probably formed the margin of the basin system at the time of its maximum extent. Continuing from ca. 110 to $40 \mathrm{Ma}$, the exhumation of the Jiamusi Uplift gradually destroyed the formerly continuous sedimentary cover and only the distributed, sometimes tiny basin remnants have preserved part of it. Since the end of the major exhumation in the Eocene, both the main uplift areas and the basin remnants experienced slow uplift and slow erosion leading to the relatively low-relief, hilly landscape today. Only in some restricted 
areas subsidence and sediment accumulation took place in Paleogene times.

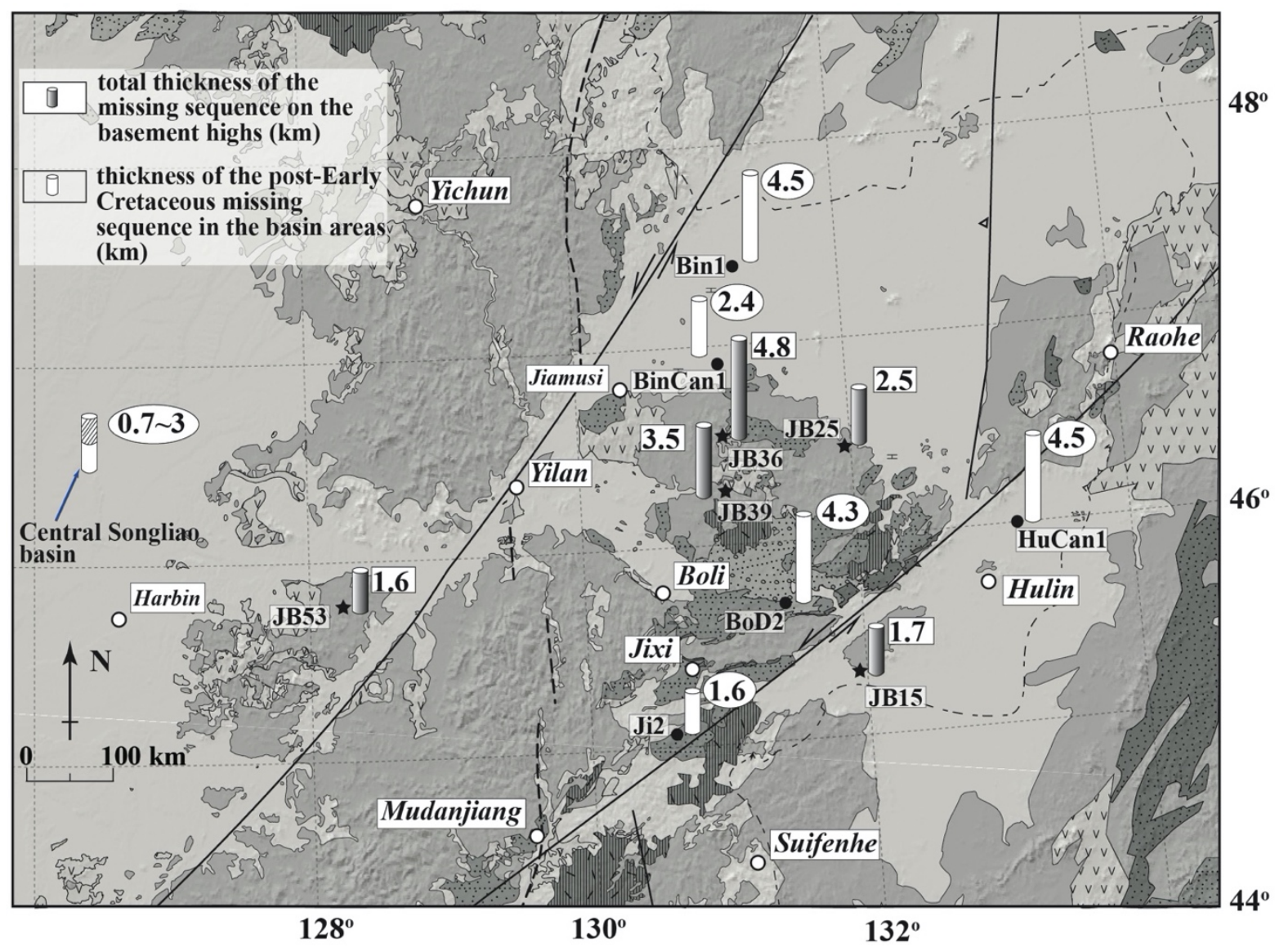

Figure 2.11: Compilation of the thickness of the missing sequences calculated for the basement highs and basin areas. The numbers represent the eroded thickness in $\mathrm{km}$. The numbers in rectangles were determined by modelling of low-T thermochronological data and express the total removed thickness (sedimentary pile + some erosion of the basement). The numbers in ellipses are the modelling results based on vitrinite reflectance downhole trends and they express the thickness of the post-Early Cretaceous burial. The assumed paleo-heat flow is $60 \mathrm{~mW} / \mathrm{m}^{2}$, that corresponds to the bulk average value of the region, see text for details. The estimated thickness of the removed sedimentary formations in the central Songliao basin is taken from Lu et al. (2005), Liu et al. (2013) and Wang et al. (2016). For the legend of the simplified geological map see Figure 2.5.

\section{Geodynamic implications}

The modelling results of this study revealed a widespread and significant exhumation phase that affecting the eastern part of NE China, starting from the late Early Cretaceous - early Late Cretaceous (ca. 110-80 Ma). This large scaled transformation of the tectonic environment corresponds to the regional NW-SE compressional events at the northeastern continental margin of Asia in the Late Cretaceous (Ratschbacher et al., 2003; Stepashko, 2006, 2008; Yang, 2013). Yang. (2013) mentioned that the Okhotomorsk continental block, currently residing 
below the Okhotsk Sea in Northeast Asia, following the west subduction of the Paleo-Pacific plate, collided with Yangtze Block at ca. 100 Ma. The collision caused the regional NW-SE compression and orogenic uplift in East Asia which could be related to the earlier exhumation on both east and west margin of the major Jiamusi uplift. The plate motion study of the PaleoPacific plate (Izanagi-Kula) indicated that, in the early Late Cretaceous (ca. $90 \mathrm{Ma}$ ), the movement direction of the plate greatly changed from NNW to WNW with high rates $(23.5$ cm/a; Engebretson et al., 1985; Maruyama et al., 1997). The near NW subduction direction almost at right angle with the near NE ward east Eurasia continental margin put the east NE China into dextral compressor shear environment (Sun et al., 2010) and probable further induced the long-lasting regional uplift in the study area.

The thermal modelling of the exhumed basement blocks in the east NE China indicates a significant reduction of the cooling rate in the Cenozoic, ca. 60-40 Ma. The transition to much slower exhumation might correspond to the slowing of the Pacific plate's subduction rate and the increasing subduction angle in the Eocene (Maruyama et al., 1997). The east Asia continental margin then experienced extensional tectonics, influenced by of the roll-back effect from the subduction of the Pacific plate (Ren et al., 2002). Triggered by this change, the Jiamusi-Yitong fault and Dunhua-Mishan fault started the dextral strike-slip extension activities that formed the narrow Yilan-Yitong basin and Ning'an basin filling with $3-5 \mathrm{~km}$ of Paleogene continental deposits. With the weakening of the extensional activity, the YilanYitong basin and Sanjiang basin developed into the Neogene and Quaternary depression sedimentation stage.

\subsection{Conclusions}

(1) New low-T thermochronological age constraints were determined by apatite FT and apatite and zircon (U-Th)/He methods on the basement highs separating the small basins situated NE of the Songliao basin in NE China. The apparent ages are mostly younger than the major subsidence period of the Early Cretaceous sedimentation in the adjacent basins.

(2) According to the thermal modelling the currently exhumed basement areas were covered by Cretaceous successions. The thickness of the missing sequences were calculated and assuming a reliable paleo-heat flow of $60 \mathrm{~mW} / \mathrm{m}^{2}$ the Mishan Uplift and the Zhangguangcai Range were covered by ca. 1.6-1.7 km sediment, while the central 
Jiamusi Uplift experienced considerably deeper burial: the calculated cover is varying from 2.5 to $4.8 \mathrm{~km}$.

(3) During the basin inversion the eastern Mishan Uplift and the western Zhangguangcai Range were exhumed first, between 110 and 100 Ma with cooling rates of 2.6 and 1.2 ${ }^{\circ} \mathrm{C} / \mathrm{Myr}$, respectively. Later the cooling rate has slowed down to $0.3-0.5^{\circ} \mathrm{C} / \mathrm{Myr}$. In the central Jiamusi Uplift the exhumation started slightly later, at ca. $90 \mathrm{Ma}$ and with higher cooling rates of ca. $2.4-5.4{ }^{\circ} \mathrm{C} / \mathrm{Myr}$, and continued until ca. $40 \mathrm{Ma}$.

(4) In the eastern satellite basins five representative boreholes were selected and the thermal history modelling is based on stratigraphic and vitrinite reflectance data. The thickness of the missing sequence that was removed mostly in Late Cretaceous time varies strongly. Assuming $60 \mathrm{~mW} / \mathrm{m}^{2}$ paleo-heat flow in the western Sanjiang basin the former burial was $2.4 \mathrm{~km}$ in the south and $4.5 \mathrm{~km}$ in the north. In the eastern Boli basin and northern Hulin basin, the models suggest similar thicknesses of the missing sequences: 4.3 and $4.5 \mathrm{~km}$, respectively. However, in the south the Jixi basin revealed a significantly smaller burial of ca. $1.6 \mathrm{~km}$.

(5) The calculated thicknesses of the missing sequences revealed a coherent, large-scale pattern, although different constraints and methods were applied for the basins and for the exhumed basement areas. In general, the eastern satellite basins experienced higher post-Early Cretaceous burial and subsequent erosion than the much larger Songliao basin to the west.

(6) According to the integrated burial/thermal modelling and combining with previous research results we postulate that the eastern basin group including the Jixi basin, Boli basin, Sanjiang basin and Hulin basin belonged to a single united huge down-warped basin in the eastern Asian continental margin. The current west Zhangguangcai Range and east Mishan Uplift were probably also involved in this united basin. From ca. 110 to $40 \mathrm{Ma}$, the exhumation of the Jiamusi Uplift has gradually destroyed the formerly continuous sedimentary cover and only basin remnants have been preserved. By the end of the major exhumation in the Eocene, both the major uplift area and the basin remnants came to the slow uplift and erosion stage until recent time. 


\section{Acknowledgments}

This research was funded by the Geoscience Center of the University of Göttingen and the China Scholarship Council (2016094678). All analytical work has been performed at the Geoscience Center Göttingen. Further support was provided by the National Key R\&D Program of China (Grant No. 2017YFC0601300-01), Qingdao Leading innovation talents (193-2-19-zhc) and Taishan Scholars (ts20190918). We are indebted to Judit Dunklné-Nagy and Duozi Li for their enthusiastic help in sample preparation and at the (U-Th)/He measurements. 
Cretaceous-Cenozoic thermo-tectonic evolution and provenance analysis of the basement and some sedimentary successions northeast of the Songliao Basin, NE China

\section{Chapter 3 Manuscript II: Miocene age of the Huanan basalt lava flow (NE China) inferred by reset of zircon (U-Th)/He thermochronometer in the underlying sand}

The following first case study revealing the approach to the case study of the volcanic influence area to the zircon (U-Th) /He system. This paper is published 2020 in Geological Journal, 2020; 55(11) 7443- 7457. https://doi.org/10.1002/gj.3877

Jianping Zhou ${ }^{1}$, István Dunkl ${ }^{1}$, Yongjiang $\mathrm{Liu}^{2}{ }^{3}$, Weimin $\mathrm{Li}^{4}$, Anna Wolf ${ }^{1}$, Hilmar von Eynatten $^{1}$

1 University of Göttingen, Geoscience Center, Sedimentology and Environmental Geology, Goldschmidtstrasse 3, Göttingen, D-37077, Germany

2 Key Lab of Submarine Geoscience and Prospecting Techniques, MOE, Institute for Advanced Ocean Study, College of Marine Geosciences, Ocean University of China, Qingdao, 266100, China.

3 Laboratory for Marine Mineral Resources, Qingdao National Laboratory for Marine Science and Technology, Qingdao, 266237, China.

4 College of Earth Sciences, Jilin University, Jianshe Str. 2199, Changchun 130061, Jilin, China

Short title: The basalt lava flow age inferred by reset of zircon (U-Th)/He thermochronometer in the underlying sand

Keywords: basalt lava, (U-Th)/He, zircon, geochronology, Miocene, Huanan 


\subsection{Abstract}

Mafic lavas of Cenozoic age are widely distributed in northeast China and received much attention as an important part of the Circum-Pacific volcanic belt. The age constraints for the volcanic activity were determined mostly by $\mathrm{K} / \mathrm{Ar}$ and $40 \mathrm{Ar} / 39 \mathrm{Ar}$ methods. We present zircon (U-Th)/He ages obtained on the thermally overprinted sands directly underlying a basaltic lava. This thermochronometer is insensitive to weathering and not biased by excess argon, thus it can express accurately the age of thermal effect of the lava flow. As a regional cooling age reference, three granite samples were dated from basement units that have not been thermally influenced by the basalt eruptions. The reference granite samples revealed well-defined Cretaceous (U-Th)/He-ages, while 20 zircon crystals from the sand below the basalt lava revealed a prominent Miocene $(\mathrm{U}-\mathrm{Th}) / \mathrm{He}$ age component of $9.33 \pm 0.24 \mathrm{Ma}$. Raman spectroscopy of these zircon crystals supports their thermally overprinted character. We infer that the sand sample has experienced significant thermal overprint by the overlying basalt lava leading to thermal reset of the majority of the detrital zircon crystals. The obtained age is thus interpreted as the eruption age of the basalt lava. The Huanan basalt flow thus belongs to volcanics of the Laoyeling episode in NE China.

\subsection{Introduction}

Mafic lavas of Cenozoic age are widely distributed in northeast China. Despite the small size of these occurrences, they represent an important part of the Circum-Pacific volcanic belt (Basu, Wang, Huang, Xie, \& Mitsunobu, 1991; Flower, Tamaki, \& Hoang, 1998; Zou, Fan, \& Yao, 2008; Xu et al., 2015). The age constraints of this volcanic activity were determined mostly by $\mathrm{K} / \mathrm{Ar}$ and ${ }^{40} \mathrm{Ar} /{ }^{39} \mathrm{Ar}$ methods and range from Miocene to Pleistocene except for some Late Cretaceous to Paleogene ages within and east of the Songliao Basin (Figure 1; Fan, Sui, Wang, Li, \& Sun, 2007; Hu et al., 1983; Liu, 1987; Liu, Chen, et al., 2017; Liu, Li, et al., 2017; Qiu et al., 2007; Wang et al., 1983; Zheng, Xu, \& Wang, 1999; Zhang et al., 2006).

In the last two decades, new geochronological techniques were introduced for dating young mafic eruptions such as the U-Th disequilibrium method (Zou, Zindler, Xu, \& Qi, 2000), indirect dating of volcanics from the surrounding fallout organic material deposits by the $14 \mathrm{C}$ method (Xu, Zhang, Qiu, Ge, \& Wu, 2012; Yin et al., 2012), fission track dating of volcanic glasses (Renne, 2000), and magnetite or zircon (U-Th)/He (ZHe) geo-thermochronology (e.g., Blackburn, Stockli, \& Walker, 2007; Blondes, Reiners, Edwards, \& Biscontini, 2007; Cooper, 
van Soest, \& Hodges, 2011; Farley, 2002). The modern 40Ar/39Ar approaches may yield precise ages of young volcanic rocks, but typically the age of young and/or low-K lava samples have high errors due to minor proportions of radiogenic Ar (Blondes et al., 2007; McDougall \& Harrison, 1999). The magnetite (U-Th)/He method is also introduced to date mafic volcanic rocks (Blackburn et al., 2007; Fanale \& Kulp, 1962). However, this mineral is not suitable for a wide range of applications due to its disadvantages. For example, (a) the Fe-oxide minerals in mafic volcanic formations have frequently irregu- lar external morphology, thus the ejection (FT) correction is hardly feasible and it would generate significant bias (Hernandez Goldstein, Stockli, Ketcham, \& Seman, 2014). (b) The interior of the magnetite grains in lavas are highly heterogeneous, often penetrated by ilmenite and haematite lamellae and they contain apatite inclusions. (c) The U content is usually very low. The studies for example, Fanale and Kulp (1962) and Blackburn et al. (2007) were dealing with pre- Cenozoic ages, with a few ppm or even sub-ppm uranium content. In the case of Miocene-Pliocene lavas the uncertainties would be much over the expectations for stratigraphical purposes. Furthermore, the Blackburn et al. (2007) study was made on kimberlites, which has atypical actinide contents and distributions. Zircon analysis has been proven a versatile tool for examining a wide range of geological processes because zircon crystals have a lot of important features for geochronology and thermochronology including high actinide concentrations, occurrence in variable lithologies and resistance to physical and chemical weathering (Reiners, 2005). Like many other minerals, zircon can also be dated by the (U-Th)/He method to reveal the low temperature (ca. $180-130$ $\left.{ }^{\circ} \mathrm{C}\right)$ thermal history (e.g., Farley, 2002; Reiners, Spell, Nicolescu, \& Zanetti, 2004). Comparing to the $\mathrm{K} / \mathrm{Ar}$ and $40 \mathrm{Ar} / 39 \mathrm{Ar}$ methods, zircon (U-Th)/ He method has the advantage of performing relatively rapidly on selected zircon crystals without neutron irradiation, and high accuracy on young volcanic rocks (Blondes et al., 2007). Even though mafic to intermediate volcanic rocks rarely contain zircon crystals, the strata below lava flows or the host rocks in contact with basaltic dykes, sills, or necks are often rich in zircon crystals. These zircons may become thermally reset upon significant heating (temperature and time) and the (U-Th)/He age obtained on these crystals then indicates cooling after the heating event. Assuming usual fast cooling of lava flows, this age should reflect the eruption age (Blondes et al., 2007; Cooper et al., 2011).

In this study, we report for first time zircon (U-Th)/He ages from a thermally overprinted basal layer of a lava flow from the Huanan region in NE China. Additionally, Raman spectroscopy 
was used to describe the crystalline state and confirm the thermal reset of the dated zircon crystals.

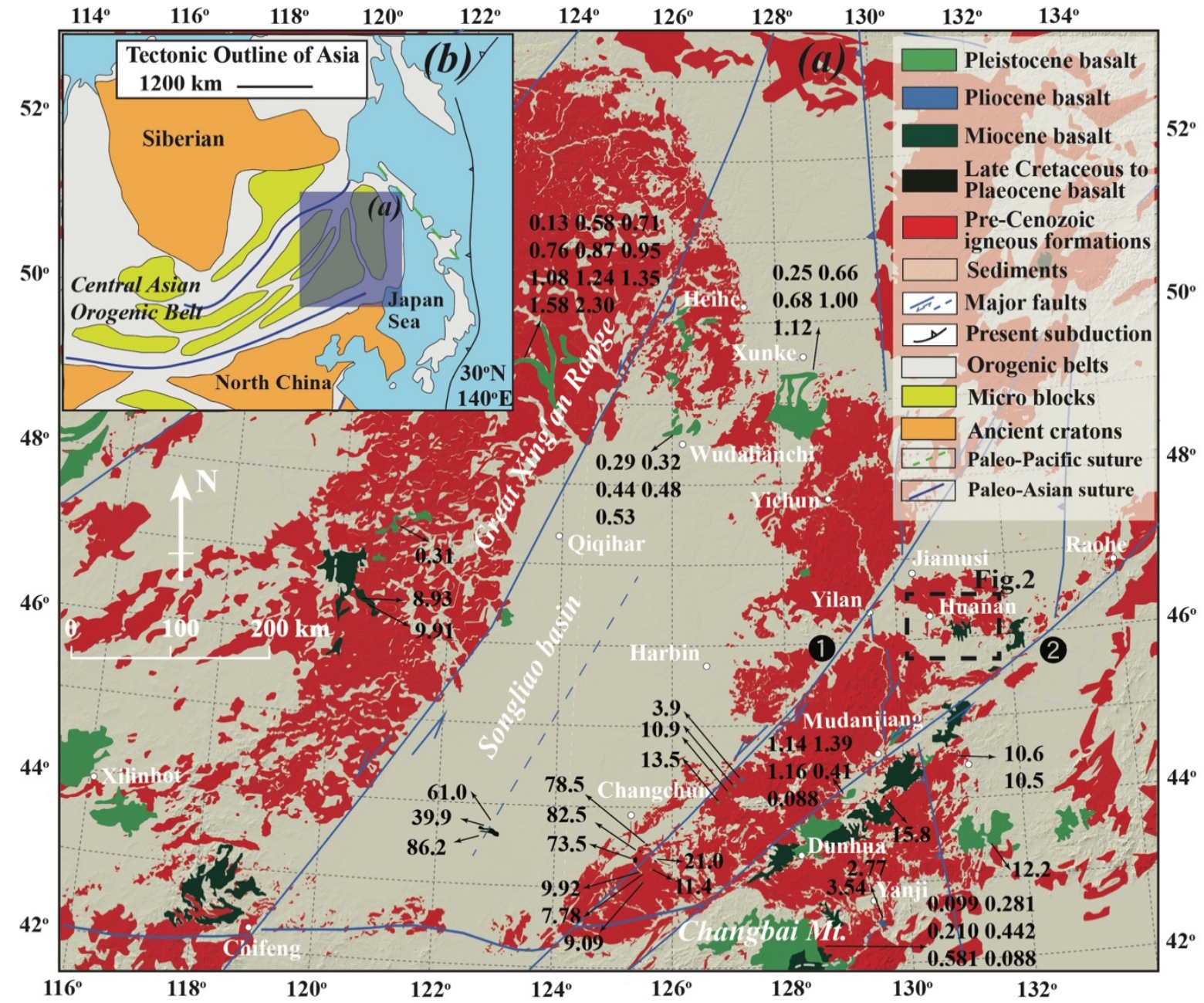

Figure 3.1: (a) Simplified geological map of NE China, modified after Ren et al. (2013) and HBGMR (1993). The occurrences of basalt volcanoes and their age (in Ma) are taken from Fan, Sun, Li, and Wang (2006), Fan et al. (2011), Fan, Zhao, Sui, Li, and Wu (2012), Liu (1987), Liu, Chen, Zhong, Lin, and Wang (2017), Liu et al. (2017), Qiu, Liao, and Liu (1991), and Zhang, Xu, Ge, and Ma (2006). The digital elevation model is from the U.S. Geological Survey, 2017. The two faults marked with (1) and (2) are the Jiamusi-Yitong and Dunhua-Mishan faults, respectively, and belong to the eastward extension of the Tan-Lu Fault Zone in NE China. Dashed box indicates position of Figure 2. (b) Schematic tectonic map of North Asia (modified after Liu, Chen, et al., 2017; Liu, Li, et al., 2017)

\subsection{Geological setting}

NE China is enclosed by the Siberian Block in the north, the North China Block in the south and the Pacific Plate in the east, tectonically situating in the eastern segment of the world's largest accretionary orogen, the Central Asian Orogenic Belt (CAOB) (Jahn et al., 2000; 
Sengör et al., 1993; Windley et al., 2007; Figure 3.1). This area was mainly dominated by the Paleo-Asian Ocean tectonic domain in the Pre-Mesozoic period, and strongly transformed by the circum-Pacific tectonic domain since the Mesozoic (Liu et al., 2010 and 2017). Since the Late Mesozoic a large continental rift system developed in NE China, related to the subduction of the Pacific plate and back-arc extension of the Japan Sea (Liu, 1988; Xu et al., 2015). This rift system includes the Songliao basin, Jiamusi - Yitong fault zone, Dunhua - Mishan fault zone and other adjacent basins (Figure 3.1). Contemporaneously about 690 volcanic cones and craters and 50,000 square kilometers of basaltic lavas with small amounts of alkali trachyte were formed in this area. The Cenozoic volcanism is mainly distributed alongside a series of NE to NNE oriented rift basins and adjacent mountain ranges and on both sides of the Songliao basin, but major volcanic activity occurred to the east (Liu, 1988, 1992; Figure 1). From west to east, the distribution of the volcanic rocks can be divided into several zones, these are the Great Xing'an Range, the Jiamusi - Yitong fault zone, the Dunhua - Mishan fault zone and the Changbai Mountains. The borehole data from the Songliao basin reveals over $1 \mathrm{~km}$ thick Paleogene basalt bodies of tholeiitic composition (Xu et al., 2015). The next volcanic activity peak period appeared in Neogene and mainly follows the Jiamusi - Yitong fault zone and Dunhua - Mishan fault zone. The youngest Quaternary volcanic rocks in NE China are distributed around the Songliao basin with major occurrences in the Great Xing'an Range and even more western areas, to the north of the Songliao Basin, and to the east in the Changbai Mountains, mostly east of Dunhua-Mishan fault zone (Liu, 1987, 1992, 1998; Qiu, 1991; Fan and Hooper, 1991; Fan et al., 1998, 1999, 2006, 2007, 2011, 2012; Zhang et al., 2000; Bai et al., 2005, 2008 and Zhao et al., 2008; Figure 3.1). The Cenozoic basalts in NE China are considered products of partial melting of the upper mantle, and mixing of depleted mantle and enriched mantle type I components (Zou et al., 2000, Zhou, 2006 and Xu et al., 2015).

Even though numerous geochronological studies have been published from many occurrences of mafic volcanic formations in NE China, high precision and weathering-insensitive geochronology such as zircon $\mathrm{U}-\mathrm{Pb}$ or $(\mathrm{U}-\mathrm{Th}) / \mathrm{He}$ dating has not yet been performed on the young volcanic formations of the Huanan area. Previous studies in this area mainly rely on constraints from lithostratigraphic and paleontological evidences (HBGMR.,1993). 


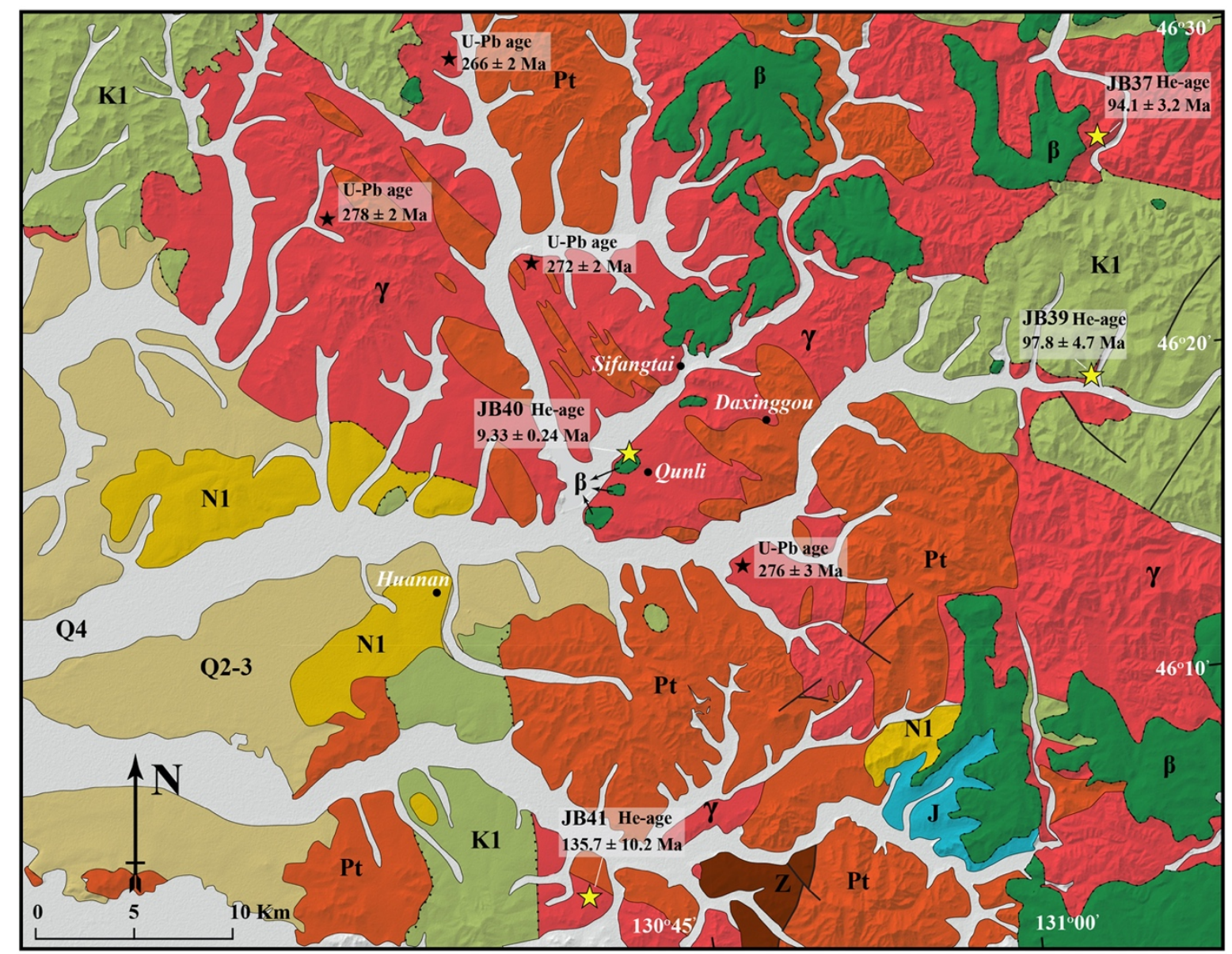

Figure 3.2: Simplified geological map of the study area, modified after HBGMR (1993). The digital elevation model is taken from the U.S. Geological Survey, 2017. Pt, Palaeoproterozoic strata; J, Jurassic strata; K1, lower Cretaceous strata; N1, Miocene strata; Q2-3, Middle to Upper Quaternary strata; Q4, Holocene strata; $\gamma$ : Permian granite; $\beta$ : Cenozoic basalt; yellow star: sample locations in this article and the measured $(U-T h) / H e$ age; black star: zircon U-Pb age of granitoids (Dong et al., 2017); Solid black lines: faults; dotted black lines: unconformities.

\subsection{Sample and analytical methods}

A sand sample (JB40) was collected in an active basalt quarry close to Qunli village (Figure 3.2; $\mathrm{N} 46.2983^{\circ}, \mathrm{E} 130.7182^{\circ}$ ). A $2-3 \mathrm{~m}$ thick horizontal lava flow is exposed along the excavation walls and the contact to the underlying sand is well preserved and accessible. In the surroundings of the quarry the sand forms only a few meters thick layer; this young, alluvial sediment covers the granitoid basement. The basal layer of the lava is amygdaloid, but the lava shows low degree of alteration. We collected a loose sand sample from the topmost $3-5 \mathrm{~cm}$, immediately below the base of the basalt lava (Figure 3.3). 


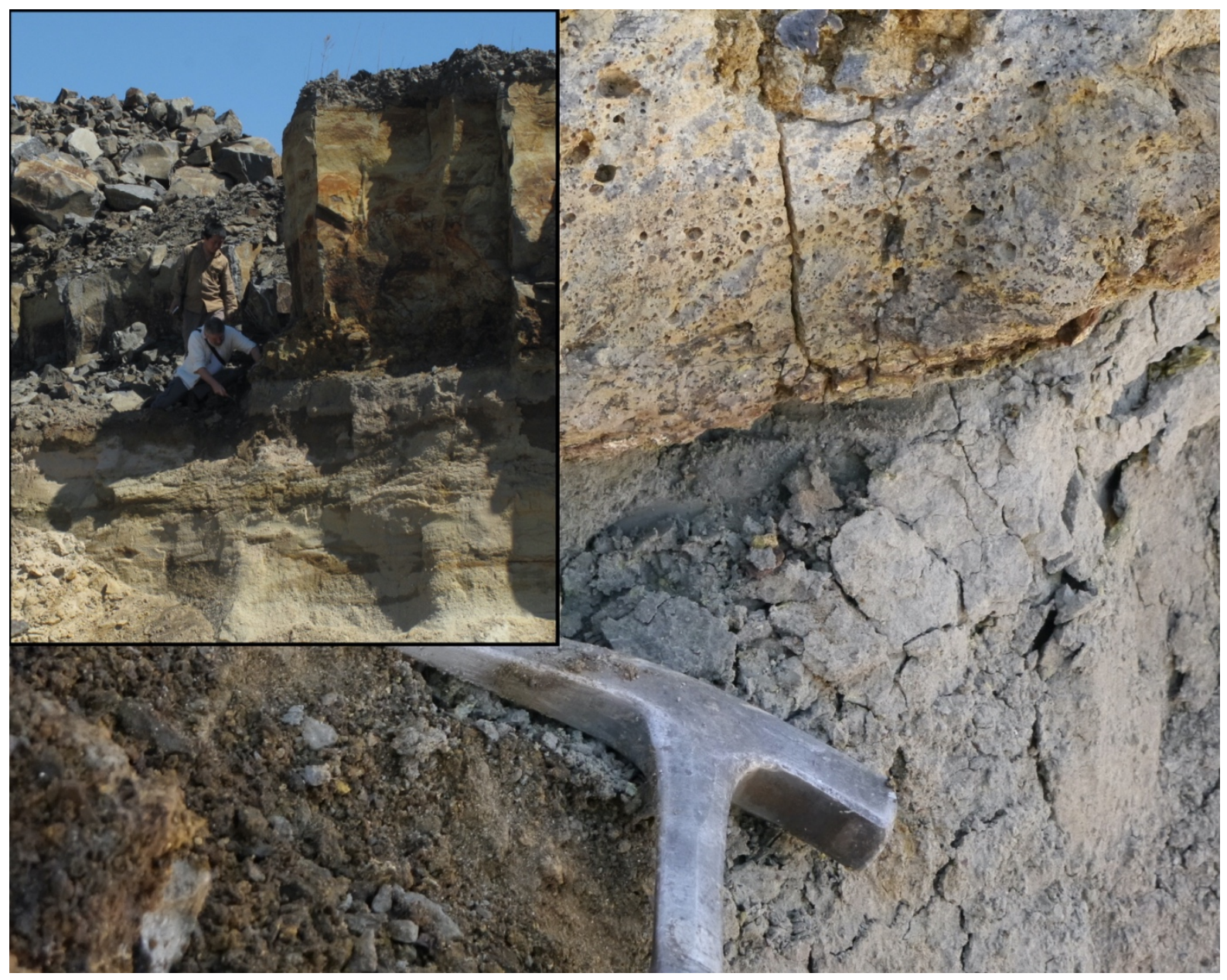

Figure 3.3: Photographs illustrating the basalt lava outcrop and its base close to Qunli village. Thickness of the lava flow in the upper left photo is 2-3 meter.

To discriminate the thermal influence imposed by the basalt lava to the underlying granite basement at the sampling position and the untouched area, three granite samples were collected for (U-Th)/ He dating from the wider area surrounding the basalt quarry (Figure 3.2; JB37,

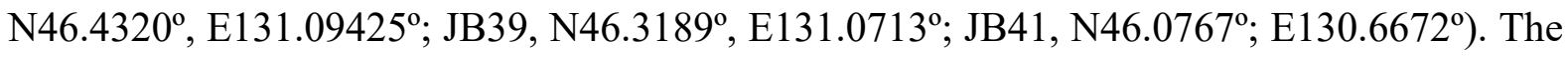
zircon grains were separated from the $63-125 \mu \mathrm{m}$ fraction by shaking table, gravity separation by Na-poly-tungstate, and magnetic separation.

The zircon crystals have variable shapes and colors, but they are mostly pinkish-brownish, transparent-translucent and euhedral to slightly rounded. (U-Th)/He analyses were performed at the GÖochron Laboratory of the Geoscience Center, University of Göttingen. Twenty-eight intact zircon crystals were selected by stereo and petrographic microscopes. The crystals were photographed and their dimensions (length, width and prismatic length) were used for alphaejection correction (Farley et al., 1996; Figure 3.4). The grains were wrapped in platinum capsules for helium extraction and heated with an infrared laser. The extracted gas was purified 
by an SAES Ti-Zr getter at $450^{\circ} \mathrm{C}$. The remaining inert gas was measured by a Hidden triplefilter quadrupole mass spectrometer equipped with a positive ion-counting detector.

Following degassing, the capsules were retrieved from the gas extraction line the zircon crystals were extracted from the capsules and spiked with calibrated 230Th and 233U solutions in $0.4 \mathrm{ml}$ teflon vials. The crystals were dissolved for five days at $220{ }^{\circ} \mathrm{C}$ in pressurized bombs using a mixture of double distilled $48 \% \mathrm{HF}$ and $65 \%$ HNO3. Each sample batch was prepared with a series of procedural blanks and spiked normals to check the purity and calibration of the reagents and spikes. Spiked solutions were analyzed by a Thermo iCAP Q ICP-MS. Procedural $\mathrm{U}$ and Th blanks by this method are usually very stable in a measurement session and below $1.5 \mathrm{pg}$. The ejection correction factors $(\mathrm{Ft})$ were determined for the single crystals by a modified algorithm of Farley et al. (1996) using an in-house spread sheet.

Raman spectroscopy was applied to all zircon samples to identify the thermal influence on the lattice of the zircon crystals as additional information to interpret the (U-Th)/He chronological data. Details of the laboratory procedure can be found in Lünsdorf and Lünsdorf (2016). The IFORS software was used to evaluate the Raman spectra. Fitted peak widths were corrected for the apparatus function after Irmer (1985) and Nasdala et al. (2001).

\subsection{Results}

\subsubsection{Zircon $(U-T h) / H e$ ages}

Twenty-eight euhedral or slightly rounded zircon crystals were dated (Figure 3.4 and Table 3.1). The crystal sizes with c-axis parallel and perpendicular dimensions range from 120 to 319 $\mu \mathrm{m}$ and 55 to $98 \mu \mathrm{m}$, respectively. The measured zircon crystals reveal radii ranging from 34 to $59 \mu \mathrm{m}$ and the effective uranium concentration (eU, where eU is calculated as [U ppm]+ $0.235 *$ [Th ppm]; Gordon Gastil et al., 1967) covers a wide range from $145 \mathrm{ppm}$ to $1883 \mathrm{ppm}$.

The Ft-corrected zircon ZHe ages of the dated crystals from the JB40 sand sample range from 5.7 Ma to 30.5 Ma (Figures 4, 5). Except for the youngest single zircon He age of 5.7 $\pm 0.5 \mathrm{Ma}$ and three older He-ages $>20 \mathrm{Ma}$, the ages reveal a tight distribution between 8.3 and 15.6 Ma. The Ft-corrected $\mathrm{ZHe}$ ages of the three granite samples from the region also reveal tight clustering with unweighted ZHe mean ages of $94.1 \pm 3.2 \mathrm{Ma}, 97.8 \pm 4.7 \mathrm{Ma}$ and $135.7 \pm 10.2$ Ma for samples JB37, JB39 and JB41, respectively (Table 3.1). ZHe ages show no correlation with eU concentrations (Figure 6) implying that the effect of radiation damage density on the measured apparent (U-Th)/He ages is negligible (e.g., Cook et al., 2013; Flowers et al., 2009; Reiners, 2005, Shuster et al., 2006).

\subsubsection{Raman spectra of the zircon crystals}



successions northeast of the Songliao Basin, NE China

ZHe ages are determined by the retentivity of He in zircon crystals, which is influenced by the alpha-damage inflicted in its crystalline lattice due to self-irradiation (e.g., Guenthner et al., 2013). Raman spectroscopy offers the opportunity to quantify the degree of metamictization in zircon crystals (Nasdala et al., 1995) selected for (U-Th)/He analysis. The accumulated alphadamage is estimated from the position and the width of the v3(SiO4) Raman band, the stretching vibration of the SiO4 tetrahedra about $1000 \mathrm{~cm}-1$ (Dawson et al., 1971). In our case, the four samples reveal distinct, narrow internal and external vibrational modes in the spectral range from 972.1 to $1010.5 \mathrm{~cm}-1$. All of the analyzed zircon crystals have tightly distributed full width at half-maximum (FWHM) values ranging from 3.4 to $9.0 \mathrm{~cm}-1$, with averages of $5.1 \mathrm{~cm}-1$ (JB40), $5.5 \mathrm{~cm}-1$ (JB37), $5.2 \mathrm{~cm}-1$ (JB39) and $6.8 \mathrm{~cm}-1$ (JB41), respectively (Table 3.2).

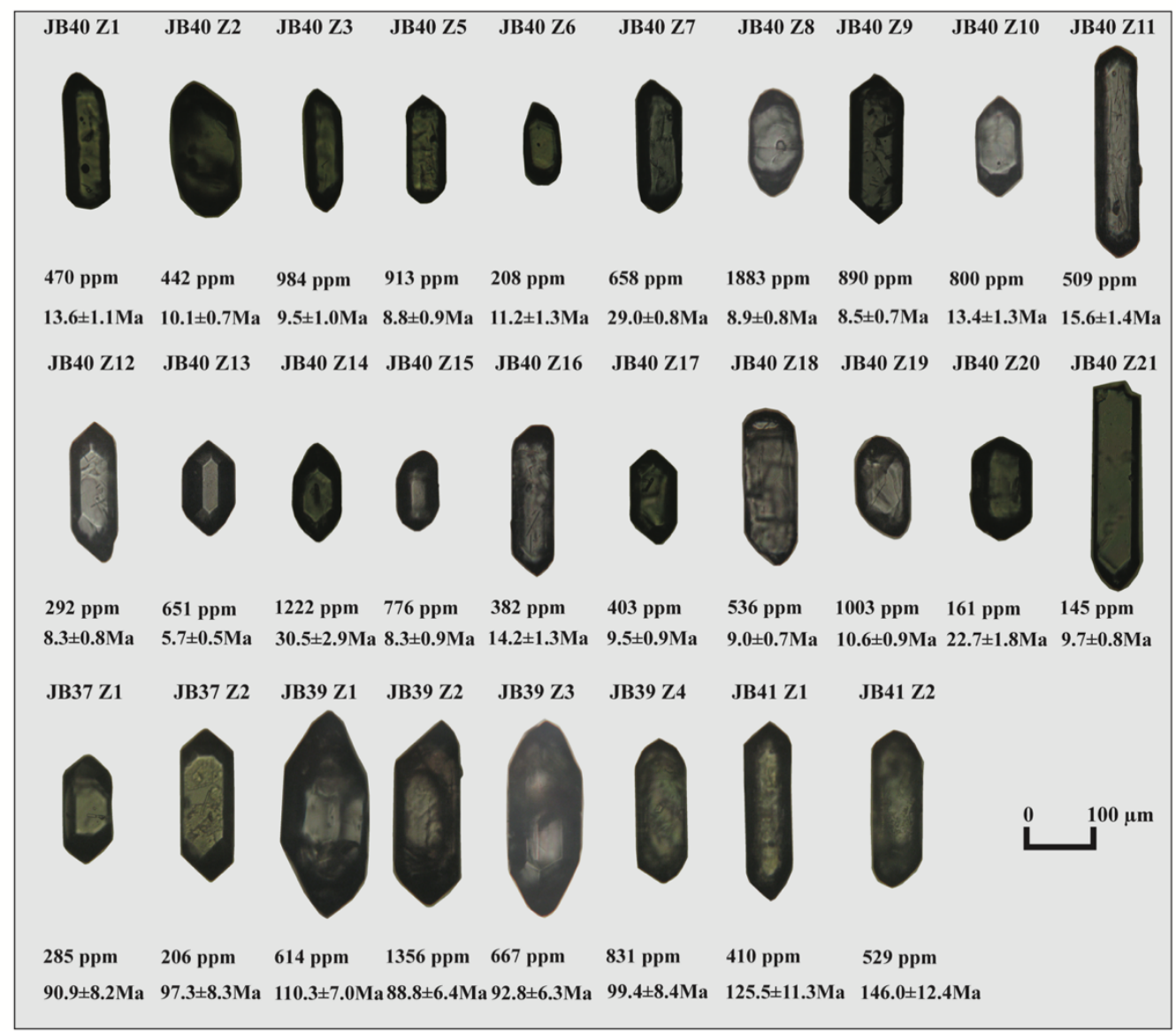

Figure 3.4: Microphotographs of the dated zircon crystals along with the effective $U$ concentration (eU, where eU is calculated as $U+0.235 *$ Th; Gastil et al., 1967) and the (U-Th)/He age. 


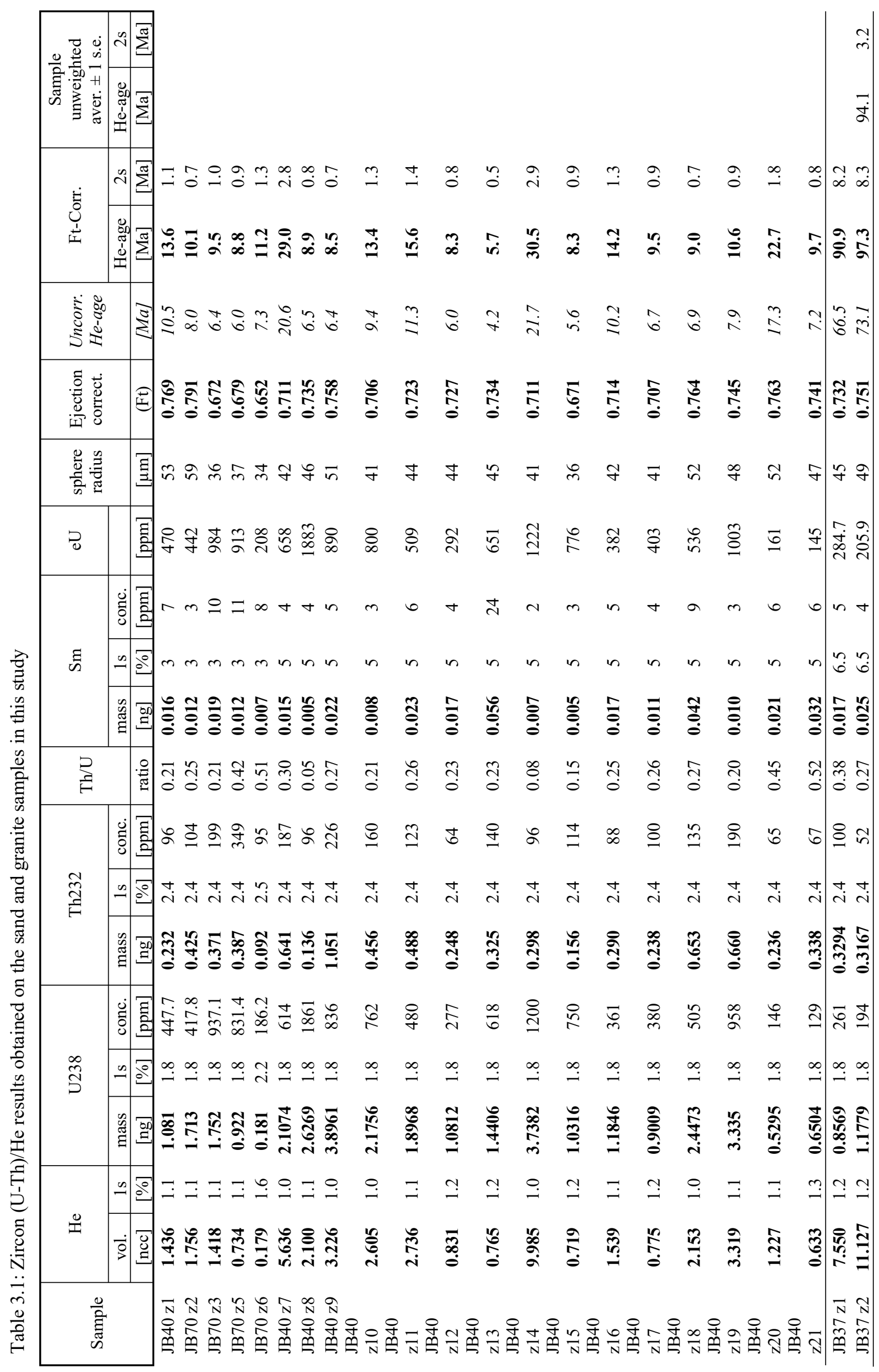


Cretaceous-Cenozoic thermo-tectonic evolution and provenance analysis of the basement and some sedimentary successions northeast of the Songliao Basin, NE China

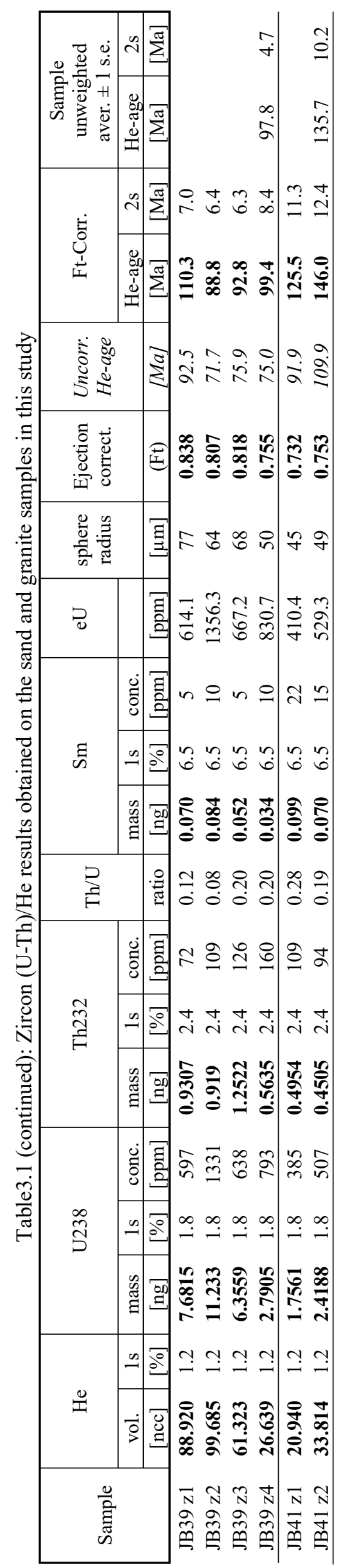




\subsection{Discussion}

\subsubsection{Identification of the principal age component of the single-crystal ZHe data}

Visualizing and interpreting the ages obtained on detrital zircon crystals forms a key part to unravel the corresponding geological questions in detrital zircon geochronological and thermochronological studies. The probability density plot (PDP) and the kernel density estimate (KDE) are the most used methods for visualizing detrital age distributions (Hurford et al., 1984; Silverman, 1986; Devroye, 1987; Vermeesch, 2012; von Eynatten and Dunkl, 2012). However, it has been pointed out that the PDP lacks any theoretical basis as a probability density estimator, although it may serve as a data visualization tool (Galbraith, 1998, 2010; Vermeesch, 2012).

The ZHe age distribution is visualized as KDE plot by the DensityPlotter v8.4 software (Figure 7; Vermeesch, 2012). The KDE age spectrum shows a typical left-hand asymmetry and the mean of the dominating (about 75\%) youngest age component is $9.33 \pm 0.24 \mathrm{Ma}$ (Figure 3.7). To further corroborate the result, we also use the SIMPLEX method (Cserepes, 1989) to perform a best-fit model to identify the age components by the Popshare software (Dunkl and Székely, 2002). This approach results in a similar best-fit model age at 9.2 $\pm 0.8 \mathrm{Ma}$.

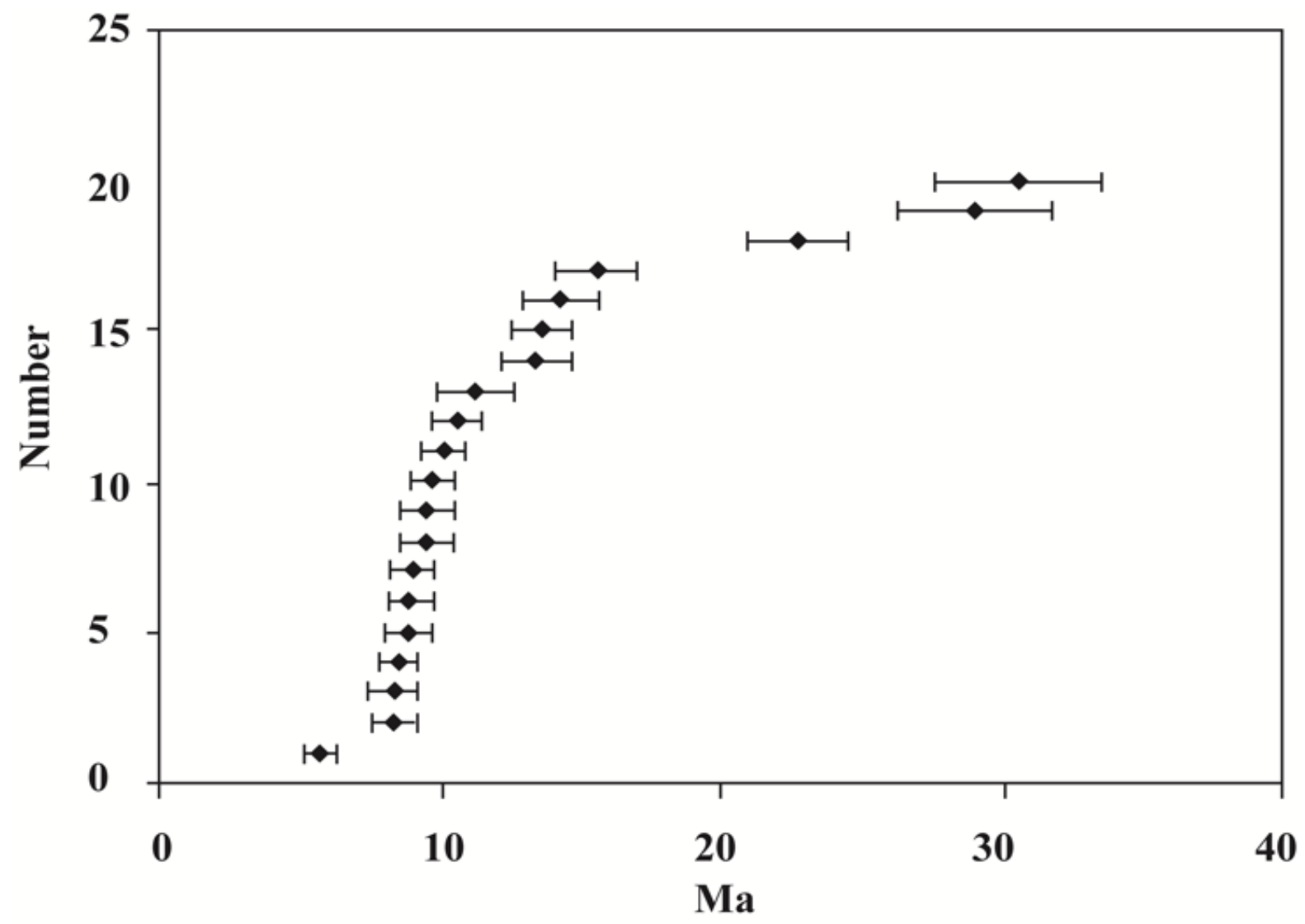


Cretaceous-Cenozoic thermo-tectonic evolution and provenance analysis of the basement and some sedimentary successions northeast of the Songliao Basin, NE China

Figure 3.5: Cumulative diagram of zircon (U-Th)/He ages obtained on 20 single crystals from the sand sample (JB40; $2 \sigma$ error bars).

\subsubsection{Zircon reset analysis}

In the study area, most of the basalt lava overlies the basement dominated by granitoid rocks. In our study site the lava covers alluvial sand. For the proper evaluation of the potential thermal overprint, we should first review the cooling age pattern of the basement that experienced no thermal overprint by young basalt eruptions. Zircon U-Pb studies indicate that the emplacement ages of the granitoid rocks in Huanan and its adjacent areas are Pre-Mesozoic, mostly Early to Middle Permian (Bi et al., 2014; Yang et al., 2015; Dong et al., 2017) (Figure 3.2). Lowtemperature thermochronology performed on basement samples far from basalt occurrences yield Early Cretaceous to early Late Cretaceous ZHe ages (136 to 94 Ma; Figures 3.2, 3.4; Table 1). These ages are considerably older than the ZHe age of sand sample from below the basalt lava. The zircons in the loose sand layer overlying the granitoid basement thus do not carry the regional cooling age signature, instead, their ZHe ages are mostly determined by the thermal effect of the basalt lava.

Zircon He diffusion experiments on pristine crystals reveal that the closure temperature of the $\mathrm{ZHe}$ thermochronometer is around $160-200 \mathrm{oC}$ in case of duration of the thermal overprint in the range of millions of years (Reiners et al., 2004). Even though the eruption temperature of the overlying basalt lava could be variable, the temperature of basaltic lavas is mostly above 950 oC (Francis, 1993). Blondes et al. (2007) presented calculations on the necessary time and temperature relations for reset of the $\mathrm{ZHe}$ thermochronometer in case of very short, shock-like thermal events like contact with lava. The laboratory derived He-in-zircon diffusion experiments indicated that partly or complete He loss in xenolithic zircon crystals should happen in magmatic entrainment or contact time of less than one hour (Blondes et al., 2007). The sample JB40 experienced proper temperature-time integral for complete reset as it situated close enough to the basalt lava and the heat of the basalt lava could lead to the full removal of the pre-eruption accumulated radiogenic helium from the majority of the zircon grains. 
II. Miocene age of the Huanan basalt lava flow (NE China) inferred by reset of zircon (U-Th) /He thermochronometer in the underlying sand

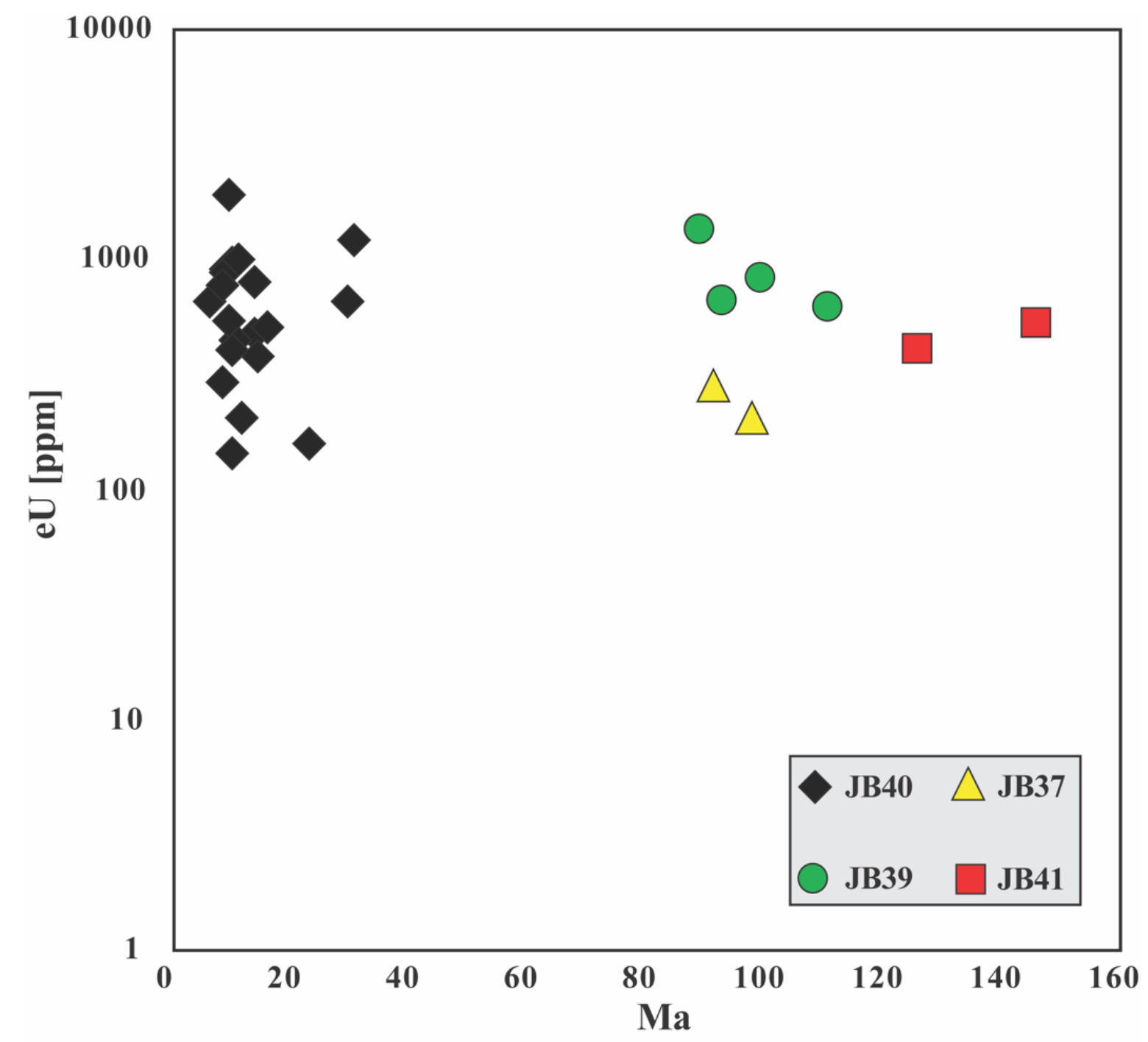

Figure 3.6: Effective U concentration (eU) vs. zircon (U-Th)/He ages plot for the sand sample JB40 and the three granitoid samples. Each symbol represents a single dated zircon crystal. 
Cretaceous-Cenozoic thermo-tectonic evolution and provenance analysis of the basement and some sedimentary successions northeast of the Songliao Basin, NE China

Table 3.2: The v3(SiO4) Raman band of the zircon samples investigated

\begin{tabular}{|c|c|c|c|c|c|c|c|c|c|c|c|c|}
\hline \multirow{2}{*}{$\begin{array}{c}\text { Samp } \\
\text { le }\end{array}$} & \multirow{2}{*}{ Aliquote } & \multirow{2}{*}{$\begin{array}{l}\text { scale } \\
\text { intensi } \\
\text { ty }\end{array}$} & \multirow{2}{*}{ shape } & \multirow{2}{*}{ area } & \multirow{2}{*}{$\begin{array}{c}\text { hwh } \\
\mathrm{m} \\
{\left[\mathrm{cm}^{-}\right.} \\
\left.{ }^{1}\right]\end{array}$} & \multirow{2}{*}{$\begin{array}{l}\text { center } \\
{\left[\mathrm{cm}^{-1}\right]}\end{array}$} & \multirow{2}{*}{$\begin{array}{l}\text { scale } \\
\text { intensi } \\
\text { ty }\end{array}$} & \multirow{2}{*}{ shape } & \multirow{2}{*}{ area } & \multirow{2}{*}{$\begin{array}{c}\text { hwhm } \\
{\left[\mathrm{cm}^{-1}\right]}\end{array}$} & \multirow{2}{*}{$\begin{array}{c}\text { corr } \\
\text { Fwhm }\end{array}$} & \multirow{2}{*}{$\begin{array}{c}\text { center } \\
{\left[\mathrm{cm}^{-1}\right]}\end{array}$} \\
\hline & & & & & & & & & & & & \\
\hline \multirow[t]{12}{*}{ JB40 } & P_00 & 13.4 & 0.9 & 636.0 & 3.1 & 976.2 & 91.8 & 0.8 & 4179.2 & 3.1 & 4.9 & 1009.3 \\
\hline & P_01 & 12.9 & 1.0 & 674.0 & 3.3 & 976.2 & 84.7 & 0.8 & 4141.7 & 3.3 & 5.5 & 1009.5 \\
\hline & P_02 & 12.9 & 1.0 & 738.4 & 3.7 & 976.2 & 90.3 & 0.8 & 4543.1 & 3.4 & 5.5 & 1009.3 \\
\hline & P_03 & 12.1 & 0.7 & 459.7 & 2.7 & 977.0 & 85.4 & 0.5 & 3145.4 & 2.7 & 3.9 & 1010.5 \\
\hline & P_04 & 8.1 & 1.0 & 312.9 & 2.4 & 977.4 & 45.6 & 0.5 & 1615.6 & 2.6 & 3.6 & 1010.5 \\
\hline & P_05 & 14.7 & 1.0 & 626.9 & 2.7 & 976.8 & 90.1 & 0.8 & 4189.7 & 3.2 & 5.1 & 1010.3 \\
\hline & P_12 & 11.6 & 1.0 & 608.3 & 3.4 & 975.7 & 76.9 & 0.8 & 3961.2 & 3.5 & 5.8 & 1008.9 \\
\hline & P_13 & 13.9 & 1.0 & 789.0 & 3.6 & 975.3 & 89.8 & 0.9 & 4969.8 & 3.7 & 6.3 & 1008.1 \\
\hline & P_14 & 10.0 & 0.9 & 641.5 & 4.2 & 975.5 & 67.5 & 1.0 & 4322.9 & 4.1 & 7.3 & 1008.3 \\
\hline & P_15 & 14.3 & 0.9 & 558.5 & 2.6 & 976.2 & 91.5 & 0.6 & 3845.7 & 3.0 & 4.6 & 1009.5 \\
\hline & P_16 & 7.7 & 1.0 & 364.7 & 3.0 & 976.1 & 48.8 & 0.4 & 1900.1 & 3.1 & 4.8 & 1009.9 \\
\hline & P_17 & 13.5 & 0.7 & 526.3 & 2.7 & 976.1 & 93.2 & 0.7 & 3828.2 & 2.9 & 4.4 & 1009.3 \\
\hline \multirow[t]{15}{*}{ JB41 } & P_21 & 13.0 & 0.9 & 563.8 & 2.9 & 975.3 & 92.7 & 0.8 & 4212.5 & 3.1 & 4.8 & 1008.7 \\
\hline & P_22 & 13.3 & 0.7 & 554.1 & 2.9 & 975.1 & 94.1 & 0.7 & 4279.8 & 3.1 & 5.0 & 1008.5 \\
\hline & P_23 & 13.6 & 0.8 & 610.7 & 3.0 & 975.3 & 94.0 & 0.8 & 4529.1 & 3.3 & 5.3 & 1008.3 \\
\hline & P_24 & 8.6 & 1.0 & 341.9 & 2.5 & 975.3 & 46.7 & 0.5 & 1933.9 & 3.1 & 4.9 & 1008.5 \\
\hline & P_25 & 6.5 & 0.6 & 319.5 & 3.5 & 974.7 & 41.7 & 0.5 & 1753.1 & 3.2 & 5.1 & 1008.1 \\
\hline & P_27 & 13.5 & 0.8 & 646.0 & 3.2 & 974.9 & 90.2 & 0.9 & 4971.5 & 3.7 & 6.2 & 1008.1 \\
\hline & P_28 & 13.1 & 0.8 & 553.8 & 2.8 & 974.9 & 88.2 & 0.7 & 4033.3 & 3.2 & 5.0 & 1007.7 \\
\hline & P_29 & 13.9 & 0.9 & 625.3 & 3.0 & 974.9 & 92.5 & 0.9 & 4778.0 & 3.4 & 5.6 & 1008.1 \\
\hline & P_30 & 5.0 & 1.0 & 380.5 & 5.0 & 972.7 & 39.1 & 1.0 & 2682.4 & 4.4 & 7.9 & 1004.4 \\
\hline & P_31 & 13.6 & 1.0 & 794.4 & 3.8 & 972.9 & 86.8 & 0.9 & 5506.9 & 4.1 & 7.3 & 1005.8 \\
\hline & P_33 & 48.5 & 0.9 & $\begin{array}{c}2227 . \\
0\end{array}$ & 3.0 & 974.9 & 75.4 & 0.8 & 3693.5 & 3.3 & 5.5 & 1007.9 \\
\hline & P_35 & 46.7 & 0.7 & $\begin{array}{c}1861 \\
4\end{array}$ & 2.8 & 974.7 & 61.1 & 1.0 & 3015.7 & 3.2 & 5.1 & 1007.7 \\
\hline & P_36 & 13.9 & 0.6 & 542.4 & 2.8 & 975.5 & 94.0 & 0.6 & 3838.0 & 2.9 & 4.4 & 1008.5 \\
\hline & P_37 & 14.6 & 0.8 & 679.1 & 3.1 & 975.1 & 93.1 & 0.8 & 4548.8 & 3.3 & 5.3 & 1008.3 \\
\hline & P_38 & 15.0 & 0.7 & 642.0 & 2.9 & 975.3 & 92.6 & 0.8 & 4196.5 & 3.1 & 4.9 & 1008.3 \\
\hline \multirow[t]{10}{*}{ JB37 } & P_45 & 13.2 & 1.0 & 772.1 & 3.8 & 974.7 & 92.3 & 0.9 & 5503.3 & 4.0 & 7.0 & 1007.9 \\
\hline & P_46 & 12.7 & 0.9 & 808.4 & 4.2 & 973.9 & 90.2 & 0.8 & 6147.7 & 4.6 & 8.4 & 1006.5 \\
\hline & P_47 & 13.0 & 1.0 & 866.0 & 4.3 & 973.7 & 93.8 & 0.8 & 6372.3 & 4.6 & 8.4 & 1006.4 \\
\hline & P_49 & 13.9 & 0.9 & 646.9 & 3.1 & 975.1 & 95.1 & 0.8 & 4783.9 & 3.4 & 5.7 & 1008.1 \\
\hline & P_50 & 13.3 & 0.9 & 610.0 & 3.0 & 974.3 & 92.8 & 0.8 & 4488.4 & 3.3 & 5.4 & 1007.1 \\
\hline & P_51 & 13.7 & 0.9 & 604.1 & 2.9 & 975.7 & 92.6 & 0.8 & 4302.7 & 3.2 & 5.1 & 1008.9 \\
\hline & P_52 & 13.3 & 0.7 & 527.0 & 2.8 & 975.3 & 94.1 & 0.7 & 4112.2 & 3.1 & 4.8 & 1008.5 \\
\hline & P_53 & 13.4 & 0.7 & 532.1 & 2.8 & 975.5 & 92.6 & 0.7 & 4023.2 & 3.1 & 4.8 & 1008.7 \\
\hline & P_54 & 12.3 & 0.6 & 480.8 & 2.8 & 975.7 & 92.3 & 0.7 & 3591.1 & 2.8 & 4.0 & 1008.9 \\
\hline & P_55 & 13.5 & 0.7 & 552.1 & 2.9 & 975.3 & 90.7 & 0.7 & 4065.7 & 3.1 & 4.9 & 1008.5 \\
\hline
\end{tabular}


II. Miocene age of the Huanan basalt lava flow (NE China) inferred by reset of zircon (U-Th) /He thermochronometer in the underlying sand

\begin{tabular}{|c|c|c|c|c|c|c|c|c|c|c|c|c|}
\hline & P_56 & 13.5 & 0.8 & 555.7 & 2.8 & 975.5 & 92.3 & 0.7 & 3984.2 & 3.0 & 4.6 & 1008.5 \\
\hline & P_57 & 13.2 & 0.9 & 640.5 & 3.2 & 975.1 & 96.7 & 0.8 & 4915.7 & 3.4 & 5.7 & 1008.1 \\
\hline & P_58 & 13.4 & 0.8 & 558.3 & 2.8 & 975.5 & 92.1 & 0.7 & 4142.0 & 3.1 & 4.9 & 1008.5 \\
\hline & P_59 & 13.7 & 0.8 & 547.8 & 2.7 & 975.1 & 95.7 & 0.7 & 4089.5 & 3.0 & 4.6 & 1008.3 \\
\hline & P_60 & 12.6 & 0.8 & 521.3 & 2.8 & 975.3 & 92.4 & 0.7 & 3779.4 & 2.9 & 4.3 & 1008.3 \\
\hline & P_63 & 12.7 & 1.0 & 574.1 & 2.9 & 975.3 & 91.0 & 0.6 & 3440.7 & 2.8 & 4.0 & 1008.7 \\
\hline & P_64 & 13.1 & 0.6 & 487.7 & 2.7 & 975.7 & 92.7 & 0.7 & 3721.2 & 2.9 & 4.2 & 1008.9 \\
\hline & P_65 & 13.5 & 0.7 & 566.8 & 2.9 & 975.1 & 94.5 & 0.7 & 4270.5 & 3.2 & 5.1 & 1008.3 \\
\hline & P_66 & 13.3 & 0.7 & 491.3 & 2.6 & 975.7 & 92.4 & 0.7 & 3723.4 & 2.9 & 4.3 & 1009.1 \\
\hline & P_68 & 12.8 & 0.6 & 438.3 & 2.5 & 975.7 & 93.9 & 0.6 & 3274.7 & 2.6 & 3.4 & 1008.9 \\
\hline \multirow[t]{12}{*}{ JB39 } & P_69 & 40.3 & 1.0 & $\begin{array}{c}2071 . \\
3\end{array}$ & 3.3 & 974.3 & 68.3 & 0.9 & 3608.7 & 3.5 & 5.8 & 1007.1 \\
\hline & P_72 & 69.6 & 1.0 & $\begin{array}{c}3654 . \\
7\end{array}$ & 3.4 & 974.1 & 68.9 & 1.0 & 3820.5 & 3.6 & 6.0 & 1006.9 \\
\hline & P_78 & 12.8 & 1.0 & 758.5 & 3.8 & 973.3 & 82.5 & 1.0 & 4764.4 & 3.7 & 6.4 & 1005.8 \\
\hline & P_ 80 & 13.0 & 1.0 & 674.3 & 3.4 & 973.9 & 86.7 & 0.9 & 4557.2 & 3.5 & 5.8 & 1006.7 \\
\hline & P_84 & 51.4 & 1.0 & $\begin{array}{c}3678 . \\
7\end{array}$ & 4.6 & 972.5 & 54.8 & 1.0 & 3892.7 & 4.6 & 8.3 & 1005.2 \\
\hline & P_85 & 58.1 & 1.0 & $\begin{array}{c}3584 . \\
6\end{array}$ & 4.0 & 973.1 & 57.3 & 1.0 & 3788.3 & 4.3 & 7.6 & 1005.6 \\
\hline & P_86 & 53.2 & 1.0 & $\begin{array}{c}3197 . \\
6\end{array}$ & 3.9 & 973.1 & 51.3 & 1.0 & 3400.9 & 4.3 & 7.7 & 1005.8 \\
\hline & P_87 & 12.8 & 0.8 & 686.9 & 3.6 & 972.9 & 91.0 & 0.9 & 5260.2 & 3.8 & 6.6 & 1005.6 \\
\hline & P_88 & 11.9 & 0.9 & 776.6 & 4.4 & 972.3 & 87.0 & 0.9 & 5882.4 & 4.4 & 7.9 & 1005.2 \\
\hline & P_89 & 11.8 & 0.8 & 693.9 & 4.0 & 972.7 & 90.3 & 0.9 & 5953.3 & 4.3 & 7.8 & 1005.2 \\
\hline & P_91 & 10.7 & 1.0 & 805.8 & 4.9 & 972.1 & 71.1 & 1.0 & 5414.3 & 4.9 & 9.0 & 1004.4 \\
\hline & P_92 & 13.4 & 1.0 & 789.8 & 3.8 & 973.7 & 87.9 & 0.8 & 5001.4 & 3.8 & 6.6 & 1006.2 \\
\hline
\end{tabular}

Abbreviation: FWHM, full width at half-maximum. HWHM, half

width at half maximum.

The Raman spectra of well-ordered zircon crystals show distinct, narrow vibrational modes in the spectral range from 200 to $1010 \mathrm{~cm}-1$. With increasing radiation damage, all of the main Raman bands of the zircon crystals decrease in intensity and become increasingly broader (Nasdala et al., 2001). The FWHM (the full width at half-maximum of the v3(SiO4) vibration) of the $v 3(\mathrm{SiO} 4)$ Raman band varies from $<3 \mathrm{~cm}-1$ in very well ordered $\mathrm{ZrSiO} 4$ to more than $30 \mathrm{~cm}-1$ in zircons of high amount of accumulated radiation damage. The position and the width of the $\sim 1000 \mathrm{~cm}-1$ peak typically show a well-developed correlation. However, for heattreated zircons Geisler et al. (2001) and Nasdala et al. (2002) have found some miscorrelation between the Raman bandwidths and positions. These annealed zircon crystals mostly plot above the peak position-peak width trend established for zircons derived from unheated or slowly cooled geological settings (Nasdala et al., 2001, 2002). In our case the Raman 
parameters obtained on sample JB40 plot somewhat off the trend constrained by the three granite samples reflecting the regional cooling history (Figure 3.8). This property of the lattice of the zircons from the sand sample below the lava flow supports their shock-like thermal reset. In summary, we can conclude that the detrital zircon crystals have been heated and their $\mathrm{ZHe}$ clock became fully reset at the contact with the basalt. The ZHe age of $9.33 \pm 0.24 \mathrm{Ma}$ of the sand sample is thus interpreted to represent the eruption age of the overlying basalt lava.

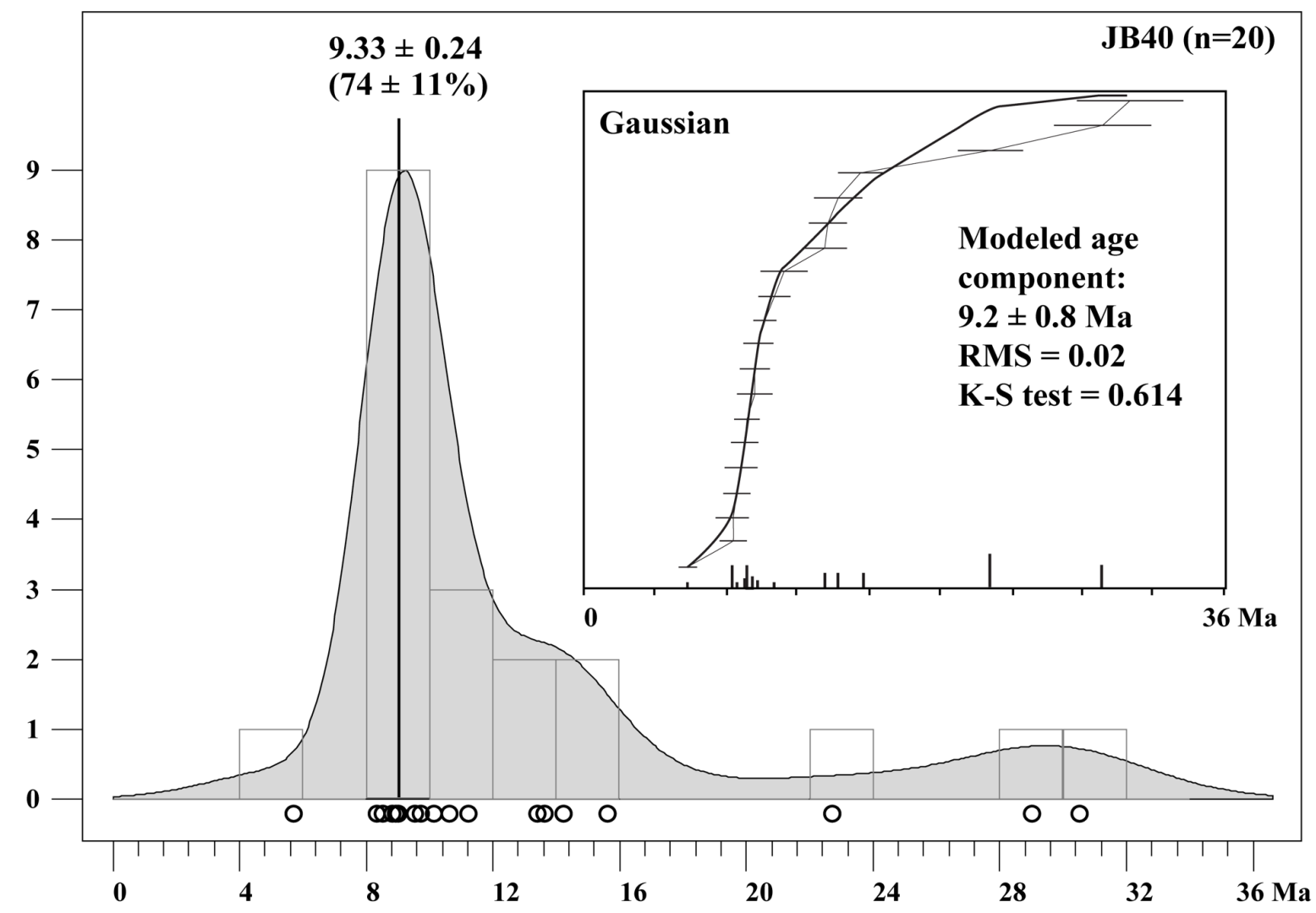

Figure 3.7: Kernel density plot of the measured zircon $(U-T h) / H e$ ages and the best fitted model between the measured ages and calculated ages. Grey curve: kernel density plot of the 20 measured zircon crystals (calculated by DensityPlotter, Vermeesch, 2012); cycles: single zircon crystals; inset shows cumulative plot of ZHe ages; horizontal line in the insert: the real measured single detrital zircon crystals' He-ages; curve in the insert: the best fit line between the real data and the calculated model; K-S test: the Kolmogorov-Smirnov test (method after Press, Flannery, Teukolsky, \& Vetterling, 1996); RMS: the goodness of fit between the calculated model and the measured data, the lower the value the better (method after Cserepes, 1989); bins in the insert: the error of the model. 


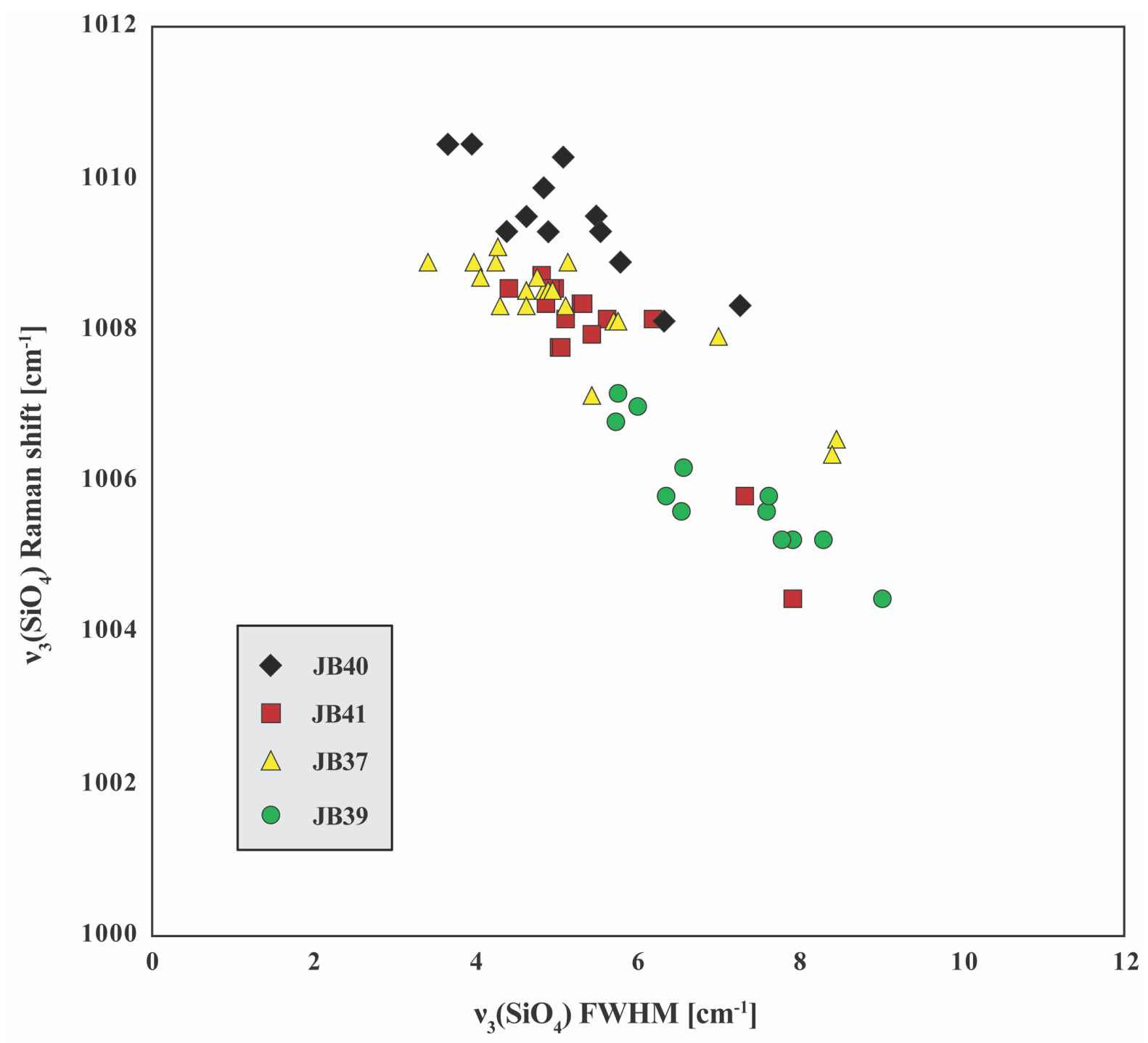

Figure 3.8: Plot of Raman shift versus the full width at half-maximum of the $v_{3}\left(\mathrm{SiO}_{4}\right)$ vibration (FWHM) for the sand sample JB40 and the three granitoid samples.

\subsubsection{Relation to other Miocene basalt lava occurrences}

Liu (1988) distinguished ten Cenozoic volcanic episodes in NE China, which are listed in Figure 9. According to the measured age, the Huanan basalt lava in this study belongs to the Laoyeling volcanic episode ( $\beta$ N13, 11-7 Ma), which is characterized by alkali olivine basalt, basanite, and basalt with ultramafic xenoliths. The magma of this volcanic episode mainly originated from partial melting of the upper mantle caused by extension of the East Asian continent, driven by the slab rollback of the Pacific plate's westward subduction (Xu et al., 2012, 2015). 
Cretaceous-Cenozoic thermo-tectonic evolution and provenance analysis of the basement and some sedimentary successions northeast of the Songliao Basin, NE China

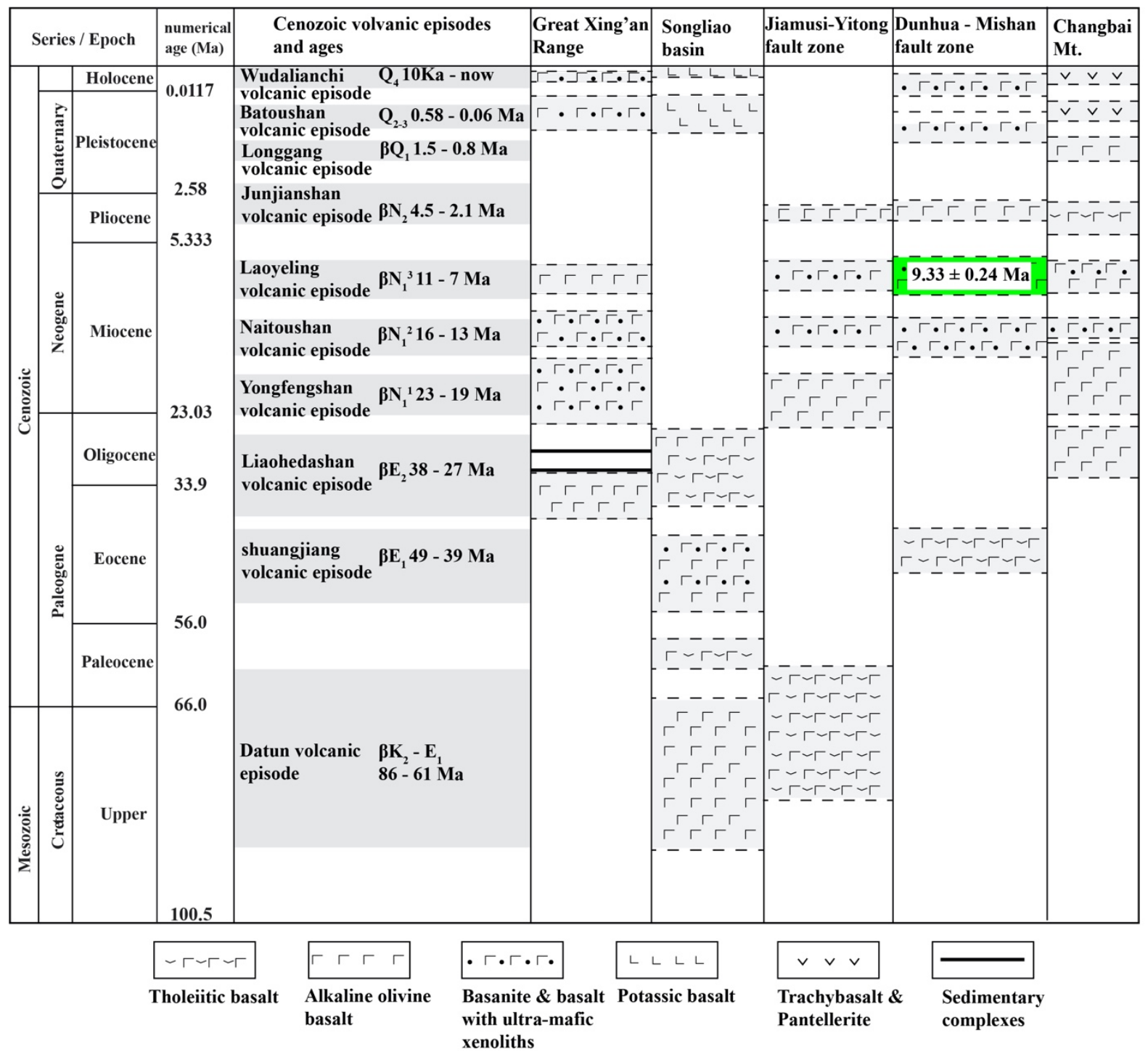

Figure 3.9: Age and major rock types of the ten Cenozoic volcanic formations in Northeast China (modified after Liu, 1988). Green bar indicates the age of the basalt eruption dated by the JB40 sample of this study.

\subsection{Conclusion}

1. (U-Th)/He dating of detrital zircon grains from a sand layer directly below a basalt lava flow in the Huanan region reveals a dominant age component of $9.33 \pm 0.24$ Ma. This implies, together with the Raman data that the reset of the ZHe thermochronometer was caused by the thermal effect of the basalt lava, which erupted at this time.

2. The result also implies that the basalt in the Huanan area belongs to the Laoyeling volcanic episode.

3. As a well-developed weathering insensitive geochronometer, the zircon (U-Th)/He method provides a fast and high accuracy dating tool for young, mafic volcanic rocks. 


\section{Acknowledgements}

This research was funded by the Geoscience Center of the University of Göttingen and the China Scholarship Council (2016094678). All analytical work has been performed at the Geoscience Center Göttingen. Further support was provided by the National Key R\&D Program of China (Grant No. 2017YFC0601300-01), Qingdao Leading innovation talents (193-2-19-zhc) and Taishan Scholars (ts20190918). We thank Dr. Keno Lünsdorf for his insight and advice at processing the zircon Raman spectra. We are indebted to Judit Dunklné-Nagy and Duozi Li for their enthusiastic help in sample preparation and at the (U-Th)/He measurements. 
III: Does U-Pb signatures of river sediment represent the age distributions in the catchments? A study of variegated catchments along the eastern border of the Songliao Basin, NE China

\section{Chapter 4 Manuscript III: Does U-Pb signatures of river sediment represent the age distributions in the catchments? A study of variegated catchments along the eastern border of the Songliao Basin, NE China}

The following third article compared the contrast between the proportions of the age components and the areal proportions of the source units, and revealed the temporal change in the Cretaceous sediment supply in NE China. This paper is submitted in 12/2020 in the Sedimentary Geology

Jianping Zhou ${ }^{1}$, István Dunk1 ${ }^{1}$, Yongjiang Liu$^{2,3}$, Weimin Li ${ }^{4}$, Hilmar von Eynatten ${ }^{1}$

1 University of Göttingen, Geoscience Center, Department of Sedimentology and Environmental Geology, Goldschmidtstrasse3, Göttingen, D-37077, Germany

2 Key Lab of Submarine Geoscience and Prospecting Techniques, MOE, Institute for Advanced Ocean Study, College of Marine Geosciences, Ocean University of China, Qingdao, 266100, China.

3 Laboratory for Marine Mineral Resources, Qingdao National Laboratory for Marine Science and Technology, Qingdao, 266237, China.

4 College of Earth Sciences, Jilin University, Jianshe Str. 2199, Changchun 130061, Jilin, China

Short title: Provenance analysis on modern river sediments with variable catchment sizes

Keywords: detrital zircon $\mathrm{U}-\mathrm{Pb}$, modern sediment, mineral fertility, provenance, NE China 


\subsection{Abstract}

We studied five modern river catchments of variable size $\left(\sim 500\right.$ to $\left.\sim 40.000 \mathrm{~km}^{2}\right)$, dominated by Carboniferous to Jurassic granitoids, Proterozoic to Early Paleozoic siliciclastic (meta)sediments and Jurassic to Cenozoic volcanic rocks in northeastern China. The Songliao Basin, its eastern "satellite" basins and the associated sediment-supplying basement highs form an excellent natural laboratory for detrital zircon $\mathrm{U}-\mathrm{Pb}$ studies as the currently exhumed basement areas are composed mostly of zircon-bearing igneous formations having highly variable emplacement ages. This contrast in the sources generates highly informative detrital age patterns. Our results show strong contrasts between the proportions of the zircon $\mathrm{U}-\mathrm{Pb}$ age components in the river sands and the areal proportions of the potential source units in the catchments. The limited range of zirconium content of the granitoids does not support high variations in zircon fertility between the magmatic suites having different emplacement ages. The detected mismatch between the obtained and the expected ages can be best explained by re-considering emplacement ages of some igneous suites of the region. We suggest that most of the granitoids mapped as Permo-Carboniferous are actually belonging to the Jurassic igneous suites. Some metasedimentary units with assumed Proterozoic protolith age have probably much younger, Paleozoic sedimentation age. Despite the proportional contrast between detrital age components and spatial coverage, the mean ages of the age components in the modern sand samples and the age components of the published basement $\mathrm{U}-\mathrm{Pb}$ data show excellent agreement. The zircon $\mathrm{U}-\mathrm{Pb}$ age distributions from modern sands thus provide useful hints to detect, verify or re-classify the ages of the zircon-bearing units in the catchment. This approach can be especially helpful at a reconnaissance prospecting on areas that are covered by imprecise large-scale geological maps only.

The detrital age distributions in modern sediments also serve diagnostic information for the provenance analysis of ancient sedimentary formations in the same areas, better than the simple map-based evaluation of the areal proportions of basement units. In our case, combining the zircon $\mathrm{U}-\mathrm{Pb}$ age patterns of the studied modern catchments and the region-wide compilation of the basement ages allows for refining the Cretaceous provenance history of the Songliao Basin and its strongly inverted eastern satellite basins. 
III: Does U-Pb signatures of river sediment represent the age distributions in the catchments? A study of variegated catchments along the eastern border of the Songliao Basin, NE China

\subsection{Introduction}

Zircon is an accessory mineral that forms mostly by crystallization in a variety of igneous lithologies ranging from gabbros of oceanic crust to sediment-derived acid-intermediate melts, and tectonic settings from subduction zones to continental rifts (Grimes et al., 2007; Lissenberg et al., 2009; Hopkinson et al., 2017; Spencer et al., 2017, 2018). The typically high U content and the low level of common $\mathrm{Pb}$ make zircon a robust geochronometer (Cherniak and Watson, 2001; Rubatto et al., 2001; Dickinson, 2008). Beyond dating igneous formations in order to unmix the "source to sink" process, detrital zircon U-Pb geochronology has been widely utilized in sedimentary provenance studies e.g., to approach the relationship between the orogenic belts and their associated basins (e.g., Gehrels et al., 1995; Fedo et al., 2003; Andersen, 2005; Dickinson and Gehrels, 2009; Cawood et al., 2012; Saylor et al., 2013). For the proper application of detrital zircon geochronology in sedimentary provenance analysis, the consideration of the regional geological information is crucial. A commonly used way at the interpretation of the obtained detrital ages is based on the evaluation of geological maps of the catchments. However, for some regions like densely vegetated or poorly accessible areas, especially when tracking large-scale provenance-, the results may be misleading due to large uncertainties in the geological maps and non-representative sampling of the region. Another way at the evaluation of the detrital age spectra can be the comparison to the age distribution compiled from the basement geochronological data. Such a comparison is also biased by the uneven sampling of the basement and also by the different sediment yield of the tributaries or geological units. Modern river sand studies frequently analyze catchments that include highly rugged mountains and low relief areas, like Himalayan rivers or the Amazon (e.g., Mapes, 2009; Guo et al., 2020). In the case of such sediments, the interpretation of the detrital age spectra is encumbered by two factors acting of even poorly known magnitudes: the sediment yield (relief \& erodibility) and the zircon yield (fertility; e.g., Dickinson, 2008; Malusà et al., 2016).

Our study focuses on the tributaries from the Lesser Xing'an Range (LXR), Zhangguangcai Range (ZGC), and the western Jiamusi block (JB), situated along the eastern border of Songliao Basin in NE China (Fig. 1). In the tested areas the relief is moderate and can be considered as catchment-wide uniform, thus we can expect an aerial balanced sediment yield. Additionally, as the region is dominated by granitoids and siliciclastic (meta-)sediments all eroded units are zircon-bearing. The currently exhumed basement formations have highly variable emplacement ages, and this contrast in the sources generates highly informative detrital age 
Cretaceous-Cenozoic thermo-tectonic evolution and provenance analysis of the basement and some sedimentary successions northeast of the Songliao Basin, NE China

patterns. That why this part of NE China seems to be an excellent natural laboratory for detrital zircon $\mathrm{U}-\mathrm{Pb}$ studies.

We identified the detrital zircon age populations in modern river sands from five different tributaries with variable compositions and catchment areas (Figures 4.1 and 4.2, Table 4.1). We use these data to address how accurately and proportionally reflect the detrital zircon age spectra of river sediments the Paleozoic-Cenozoic, igneous, metamorphic and sedimentary formations of the catchments.

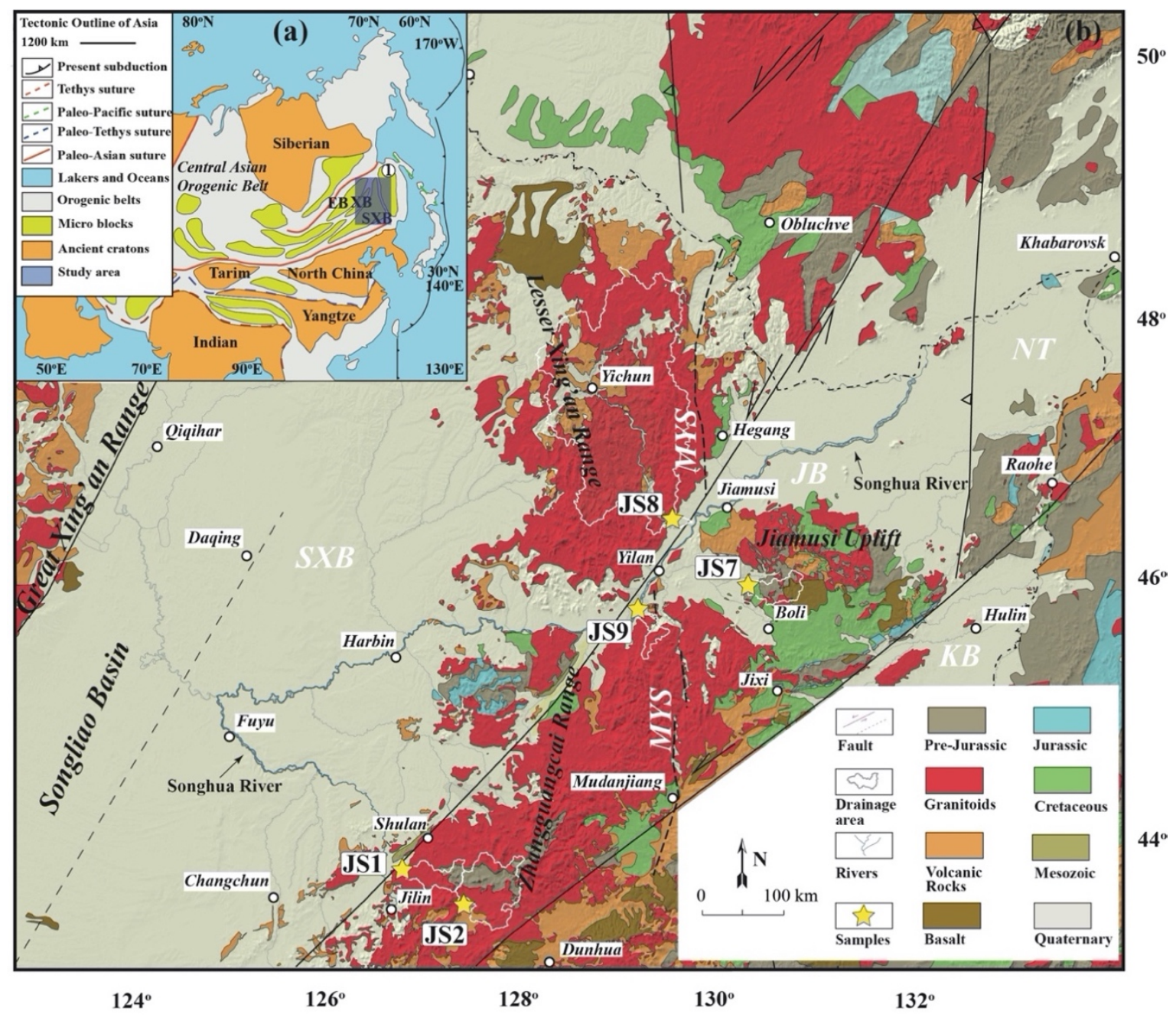

Figure 4.1: (a) Schematic tectonic map of Asia indicating the position of the study area (modified after Li, 2006; Safonova et al., 2009, 2011; Kröner et al., 2014; Liu, et al., 2017). EB, Erguna block; SXB, Songliao-Xilinhot block; XB, Xing'an block; BJKB, Bureya-Jiamusi-Khanka block. (b) Geological map of the study area including the locations of the river sand samples indicated by yellow stars. The contours of the sampled catchments are indicated by white lines. JB, Jiamusi block. Detailed geological map of each sampled tributary sees in Fig. 2. The map base is simplified after Ren et al. (2013) and the digital elevation model is taken from the U.S. Geological Survey (2017). 
III: Does U-Pb signatures of river sediment represent the age distributions in the catchments? A study of variegated catchments along the eastern border of the Songliao Basin, NE China

\subsection{Bedrock geology of NE China}

NE China consists of four major micro-continents of the eastern segment of the Central Asian Orogenic Belt, which is a large E-W trending accretionary orogen locating between the North China Craton and the Siberian Craton. This area experienced the most voluminous continental accretion of the world in Phanerozoic time (Sengör et al., 1993; Jahn et al., 2000; Windley et al., 2007; Eizenhöfer et al., 2014, Figure 4.1a). Located on easternmost Eurasia, NE China was successively dominated by the Paleo-Asian Ocean tectonic domain and the circum-Pacific tectonic domain since the Phanerozoic (e.g., Li, 2006; Windley et al., 2007).

From the Paleozoic to the early Mesozoic, several microcontinents in NE China gradually formed one united block after experiencing multi-stage amalgamation (e.g., Wang et al., 2008; Liu et al., 2017). Since the Mesozoic, this area was the linking part between the Siberian Craton, the North China Craton and the Paleo-Pacific Plate (Liu et al., 2017). The tectonic evolution of this area was jointly influenced by the northwestward subduction of the Paleo-Pacific Plate in the east and the closure of the Mongolia-Okhotsk Ocean in the north (e.g., Safonova et al., 2009, 2011; Xu et al., 2013). More stages of oceanic subduction and block amalgamation in the eastern segment of the Central Asian Orogenic Belt led NE China area exposed the Proterozoic-Paleozoic metamorphic basements and generated immense volumes of Phanerozoic granitic rocks (e.g., Wilde et al., 2010; Wu et al., 2011). The late-stage fast subduction of the Paleo-Pacific Plate below the Eurasian continental plate in the Late JurassicEarly Cretaceous (Maruyama et al., 1997) further led to a series of rift basins in NE China (e.g., Ren et al., 2002; Meng, 2003), the exhumation of a metamorphic core complex (e.g., Davis et al., 2002; Lin et al., 2008) and the continuing magmatic events (e.g., Wang et al., 2006; Zhang et al., 2018).

The regional geological surveys indicated widespread Paleozoic granitic rocks occupying most of the mountainous regions, such as the Lesser Xing'an Range in the north, the Great Xing'an Range in the west and the Zhangguangcai Range in the east (Figure 4.1; JBGMR, 1988; HBGMR, 1993; IMBGMR, 1991). Wu et al. (2001) further indicated that much of the basement underneath the Songliao Basin is composed of Paleozoic to Mesozoic granitic rocks and some Paleozoic sedimentary units. The majority emplacement ages of the granitoids in the Zhangguangcai Range is Jurassic, but some Paleozoic bodies were also detected. In contrast, in the Nadanhada Terrane from the eastern NE China, granitoids have slightly younger emplacement ages (around $115 \mathrm{Ma}$ ). The Great Xing'an Range in the west contains widespread Early Cretaceous (135-120 Ma) granitoids, and in the westernmost part of NE China, the 
granitoids of the Erguna Block were mainly emplaced in the Jurassic (190-160 Ma; Sun, 2013). However, more and more Paleoproterozoic-Early Paleozoic (meta-) intrusions are also reported in the study area in recent years; i.e., in the Erguna block, $\sim 1.8 \mathrm{Ga}$ granitic gneiss were reported by Tang et al. (2013). Sun et al. (2013) and Zhao et al. (2016) both revealed $\sim 927-737 \mathrm{Ma}$ intrusions. There is also a newly reported $\sim 890 \mathrm{Ma}$ granitic gneiss in the Songliao-Xilinhot block (Wang and Liu, 2014). East of the study area, in the Jiamusi block, 530 and 515 Ma old granitic magmatism has been recorded, that was associated with granulite/amphibolite facies metamorphism (e.g., Zhou et al., 2009; Wu et al., 2011; Sun et al., 2013). Later granitic magmatism took place in the Late Carboniferous- Permian (305-250 Ma) and between Late Triassic and Late Cretaceous (223-88 Ma; Liu et al., 2017; Bi et al., 2018; Tang et al., 2018). The sedimentary successions of NE China include Precambrian to Eocene carbonate and siliciclastic sequences that contain detrital zircon grains that yield several $\mathrm{U}-\mathrm{Pb}$ age clusters between 800 and 100 Ma (e.g., Sun et al., 2004; Zhang et al., 2004; Li et al., 2012; Zhou et al., 2019).

\subsection{Samples and geological review of the sampled rivers' catchments}

Five modern river sand samples were collected from different tributaries of the Songhua River (Figures 4.1 and 4.2). Sample JS1 was taken near the Huadan bridge, Jilin city, at the lower reaches of the Mangniu river that dewaters the southwestern part of the Zhangguangcai Range. JBGMR (1988) indicated that the area is dominated by Carboniferous-Jurassic granitoids and few Permian siliciclastic rocks (Fig. 2; see percentages in Table 1). Sun et al. (2005) and Wu et al. (2011) dated several Jurassic granitoid bodies exposed within the watershed and reported zircon $\mathrm{U}-\mathrm{Pb}$ ages varying from 190 to $173 \mathrm{Ma}$.

The southern Zhangguangcai Range is also represented by sample JS2, taken near Jiaohe city, at the lower reaches of the Jiaohe river with a medium-sized catchment area. According to JBGMR (1988) Carboniferous-Jurassic granitoids cover the majority of the catchment area. Permian siliciclastic rocks and few Triassic acid-intermediate volcanic rocks occupy a part of the upper catchment, and a few Late Jurassic to Cretaceous siliciclastic rocks are present downstream. Sun et al. (2005) and Wu et al. (2011) published zircon U-Pb ages of 190 and 216 Ma from two Jurassic granitoid bodies within the watershed.

Sample JS7 was taken near Wuyi village, at the lower reaches of the Qihuli river. The HBGMR (1993) map indicates for the catchment Proterozoic meta-sediments, Proterozoic granites, 
III: Does U-Pb signatures of river sediment represent the age distributions in the catchments? A study of variegated catchments along the eastern border of the Songliao Basin, NE China

basaltic lavas, minor occurrences of Jurassic granites, and Late Cretaceous and Cenozoic sediments (Table 4.1).

Sample JS8 was taken near Shuanghe village, at the lower reaches of the Tangwan river, dewatering the Lesser Xing'an Range, which forms the northern border of the Songliao Basin system. This sample represents the largest catchment, composed of a large area of PermoCarboniferous granitoids, some Jurassic granitoids, a few Proterozoic granitoids, some Jurassic-Cretaceous volcanic rocks, some Proterozoic-Devonian meta-sediments, and minor areas with Permian, Cretaceous, Cenozoic siliciclastic rocks (HBGMR, 1993). From the catchment area a lot of published zircon $\mathrm{U}-\mathrm{Pb}$ ages on granitoid bodies and dykes are available, varying from 515 to $102 \mathrm{Ma}$ (e.g., Wilde et al., 2003; Liu et al., 2008; Wu et al., 2011; Xu et al., 2013; Wang et al., 2016).

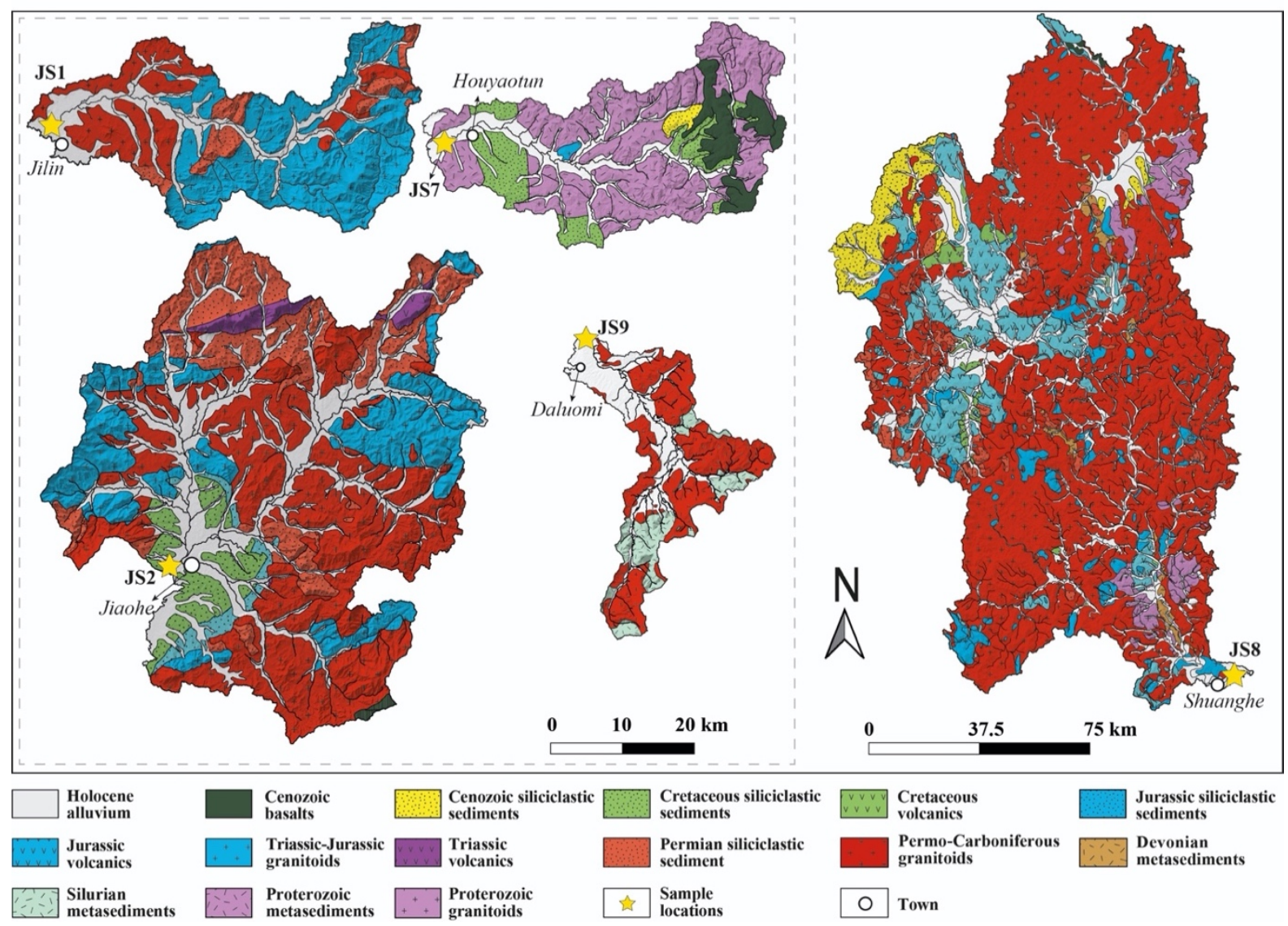

Figure 4.2: Geological maps of the sampled catchments (the geological units are simplified after JBGMR, 1988; HBGMR, 1993; IMBGMR, 1991). The digital elevation model is from the U.S. Geological Survey (2017).

Sample JS9 was collected in Daluomi county, at the lower reaches of the Xiaoluomi river that flows through the northern Zhangguangcai Range. This smallest catchment area includes 
Cretaceous-Cenozoic thermo-tectonic evolution and provenance analysis of the basement and some sedimentary successions northeast of the Songliao Basin, NE China

Permo-Carboniferous granitoids and Silurian meta-sediments with few acid-intermediate intrusions (HBGMR, 1993). Due to this region's dense vegetation and deep weathering, geochronological studies on the granitoids are still scarce. Wang et al. (2014) reported detrital zircon $\mathrm{U}-\mathrm{Pb}$ ages from schists and greywackes of the northern Zhangguangcai Range between 916 and $262 \mathrm{Ma}$ and interpreted the Zhangguangcai Range as a tectonic mélange.

Table 4.1: Geographical coordinates of the sampling sites, area and composition of the catchments.

\begin{tabular}{|c|c|c|c|c|c|}
\hline Sample code & JS1 & JS2 & JS7 & JS8 & JS9 \\
\hline River name & Mangniu & Jiaohe & Qihuli & Tangwang & Xiaoluomi \\
\hline Lithology & $\begin{array}{l}\text { Modern river } \\
\text { sand }\end{array}$ & $\begin{array}{l}\text { Modern river } \\
\text { sand }\end{array}$ & $\begin{array}{l}\text { Modern river } \\
\text { sand }\end{array}$ & $\begin{array}{l}\text { Modern river } \\
\text { sand }\end{array}$ & $\begin{array}{l}\text { Modern river } \\
\text { sand }\end{array}$ \\
\hline Location & Jilin & Jiaohe & Houyatun & Shuanghe & Daluomi \\
\hline Latitude & $43.9475367^{\circ} \mathrm{N}$ & $43.704345^{\circ} \mathrm{N}$ & $46.1485852^{\circ} \mathrm{N}$ & $46.6791387^{\circ} \mathrm{N}$ & $45.9682479^{\circ} \mathrm{N}$ \\
\hline Longtitude & $126.5482317^{\circ} \mathrm{E}$ & $127.3051417^{\circ} \mathrm{E}$ & $130.5948444^{\circ} \mathrm{E}$ & $129.7246004^{\circ} \mathrm{E}$ & $129.2487435^{\circ} \mathrm{E}$ \\
\hline $\begin{array}{l}\text { Total } \\
\text { catchment } \\
\text { area }\end{array}$ & 906 & 2884 & 873 & 41075 & 447 \\
\hline $\begin{array}{l}\text { Total } \\
\text { catchment } \\
\text { area (2) }\end{array}$ & 716 & 2230 & 620 & 34895 & 310 \\
\hline $\begin{array}{l}\text { Proterozoic } \\
\text { granitoid }\end{array}$ & & & 162 & 516 & \\
\hline $\begin{array}{l}\text { Proterozoic } \\
\text { meta- } \\
\text { sediment }\end{array}$ & & & 327 & 774 & 77 \\
\hline $\begin{array}{l}\text { Devonian } \\
\text { meta- } \\
\text { sediment }\end{array}$ & & & & 425 & \\
\hline C-P granitoid & 193 & 1038 & & 24683 & 233 \\
\hline $\begin{array}{l}\text { Permian } \\
\text { sediment }\end{array}$ & 78 & 443 & & 1109 & \\
\hline $\begin{array}{l}\text { Triassic } \\
\text { volcanic }\end{array}$ & & 58 & & & \\
\hline T-J granitoid & 445 & 510 & 5 & 1911 & \\
\hline $\begin{array}{l}\text { Jurassic } \\
\text { sediment }\end{array}$ & & 52 & & & \\
\hline $\begin{array}{l}\text { Jurassic } \\
\text { volcanic }\end{array}$ & & & & 3584 & \\
\hline
\end{tabular}


III: Does U-Pb signatures of river sediment represent the age distributions in the catchments? A study of variegated catchments along the eastern border of the Songliao Basin, NE China

\begin{tabular}{l|l|l|l|l|l}
\hline $\begin{array}{l}\text { Cretaceous } \\
\text { volcanic }\end{array}$ & & 129 & 114 & 240 & \\
\hline $\begin{array}{l}\text { Cretaceous } \\
\text { sediment }\end{array}$ & & 129 & 275 & \\
\hline $\begin{array}{l}\text { Neogene } \\
\text { sediment }\end{array}$ & & & 12 & 1380 & \\
\hline
\end{tabular}

Total catchment area (2), The total catchment area without Holocene alluvium and Eocene basalt

C-P, Carboniferous-Permian

T-J, Triassic-Jurassic

area is in $\mathrm{km}^{2}$

\subsection{Analytical methods}

All unconsolidated modern river sand samples were collected from sand bars; approximately $5 \mathrm{~kg}$ of bulk sediment samples were collected. Visual inspection showed that the overwhelming majority of sand grains were monomineralic quartz. The heavy mineral concentrates were generated by wet sieving, gravity separation using Na-polytungstate, and magnetic separation by Frantz magnetic separator. The details of the zircon U-Pb dating experimental procedure can be found in Dunkl et al. (2019). To localize homogeneous areas in the polished zircon crystals for the in-situ age determinations, we mapped them by cathodoluminescence images using a JEOL JXA 8900 electron microprobe at the Geoscience Center Göttingen. Zircon U$\mathrm{Pb}$ geochronology was conducted by laser ablation inductively coupled plasma mass spectrometry (LA-ICP-MS) at the GÖochron Laboratories of the Geoscience Center Göttingen. The measured $\mathrm{U}-\mathrm{Pb}$ age distributions are represented as binned histograms superposed by kernel density estimation curves (KDE; Vermeesch, 2012).

QGIS 3.14 (QGIS Development Team, 2020) software was used for digitizing the catchment areas and determining the major units' proportions according to the regional 1: 200,000 geological maps (JBGMR, 1988; HBGMR, 1993). The boundaries of the catchments were identified by the Seamless Shuttle Radar Topography Mission (SRTM) "Finished" 1 Arc Second digital elevation model (USGS, 2017). Quaternary alluvium and the Cenozoic basalt occurrences were excluded from the calculations of the source areas (Figure 4.2, Table 4.1).

\subsection{Results}

The results of the zircon $\mathrm{U}-\mathrm{Pb}$ analyses of the five sand samples are listed in Appendix Table A1 and shown in Figure 4.3. Between 129 and 161 single-grain in-situ analyses were performed per sample, and 96 to 122 of them were considered as concordant (90 to $110 \%$ of concordance). 
Most of the detrital zircons show oscillatory growth zoning and/or striped absorption pattern, as observed by $\mathrm{CL}$ images. $\mathrm{Th} / \mathrm{U}$ ratios are typically above 0.1 , indicating magmatic origin (Hoskin and Black, 2000; Figure 4.4). Only sample JS7 reveals a significant proportion of zircon grains with $\mathrm{Th} / \mathrm{U}$ ratios below 0.1 , restricted to pre-Carboniferous ages. The age components were identified and the kernel density plots were constructed using the DensityPlotter software (Vermeesch, 2012).

Samples JS1 and JS2 represent the southern Zhangguangcai Range. The Mangniu River zircons (JS1) are dominated by an Early Jurassic to Late Triassic age component (92\%), complemented by a small group of Late Archean to Early Proterozoic ages, while the neighboring Jiaohe River sample (JS2) yields almost exclusively Mesozoic ages with a dominant Early Jurassic (82\%) and a minor Middle Triassic age component. The Archean signal is missing here (Fig. 3). In the sample of the Xiaoluomi River representing the northern Zhangguangcai Range (JS9), the majority of the zircon U-Pb ages reflect Late Triassic and Early Jurassic age components (84\%), roughly similar to the southern catchments of the Range. However, a minor Cambrian to Ordovician age component is also present (Figure 4.3). Almost all zircons of the Zhangguangcai Range have $\mathrm{Th} / \mathrm{U}$ ratios $>0.1$ (Figure 4.4).

The zircon $\mathrm{U}-\mathrm{Pb}$ age distribution obtained on the sample from Qihuli River (JS7), draining part of the Jiamusi Uplift, is highly different from the samples of the Zhangguangcai Range. It is dominated by a Cambrian to Early Ordovician age component (57\%), followed by Late Permian to Early Triassic, Early Devonian, and Neoproterozoic age components (Figure 4.3). The first component shows a significant proportion (15 out of 61 ) of zircons with $\mathrm{Th} / \mathrm{U}$ ratios $<0.1$ (Figure 4.4).

The northernmost sample (JS8), whose catchment covers most of the Lesser Xing'an Range represents the largest studied catchment. The zircon age distribution is characterized by a dominant Late Triassic to Early Jurassic age component (59\%), followed by OrdovicianSilurian and Late Permian to Early Triassic age components. Only two single zircon ages are falling into the Cretaceous (Figure 4.3). 
III: Does U-Pb signatures of river sediment represent the age distributions in the catchments? A study of variegated catchments along the eastern border of the Songliao Basin, NE China
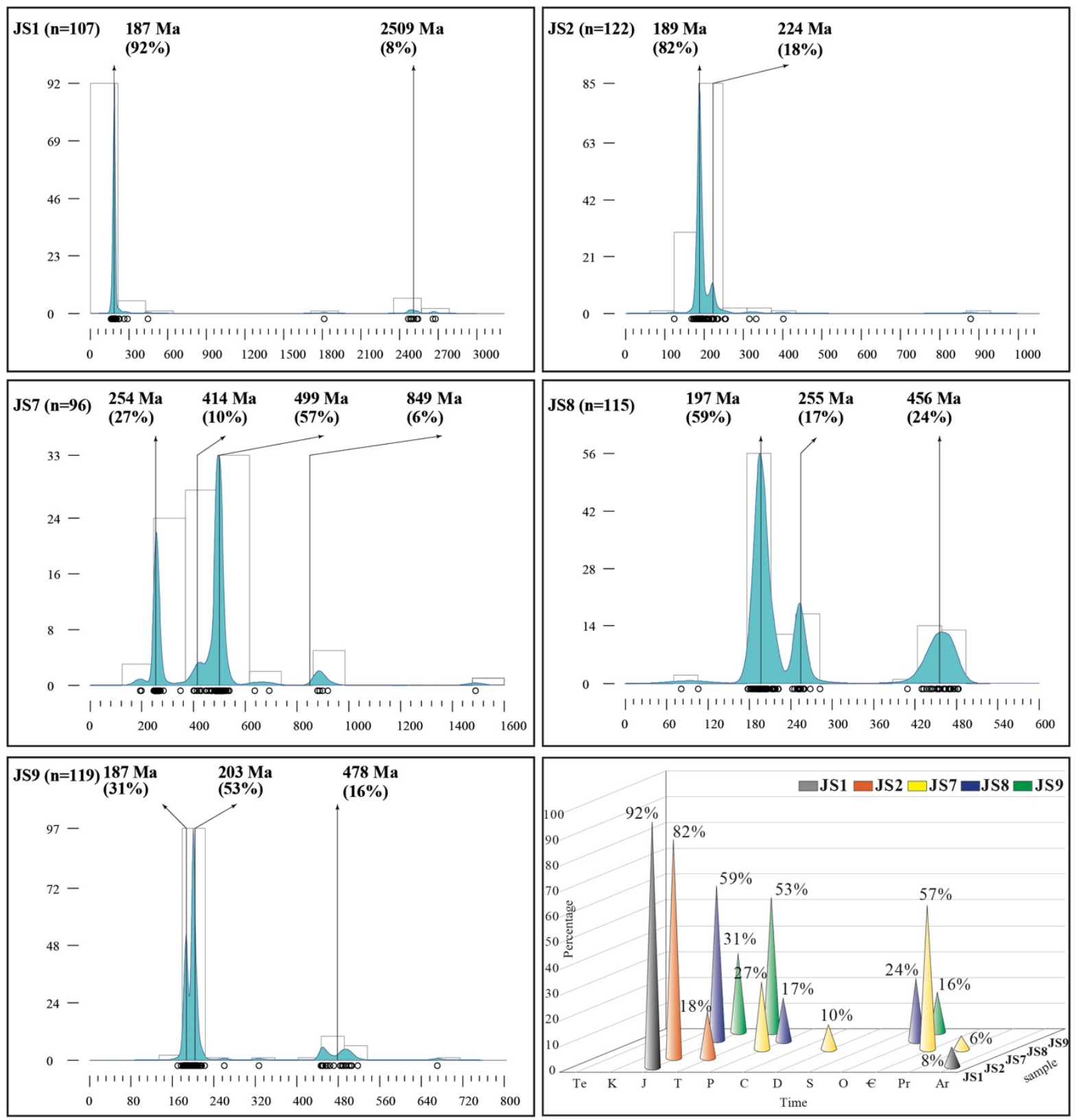

Figure 4.3: Detrital zircon U-Pb age spectra obtained on the river sand samples from NE China. The plots present binned age histograms, kernel density estimation curves and the age components identified by the Density Plotter software (Vermeesch, 2012). The age scales of the plots are different; $n=$ number of $U-P b$ data with 90-110\% concordance. The discrete single ages which are not included in the age component calculation are excluded from the percentage calculation. 


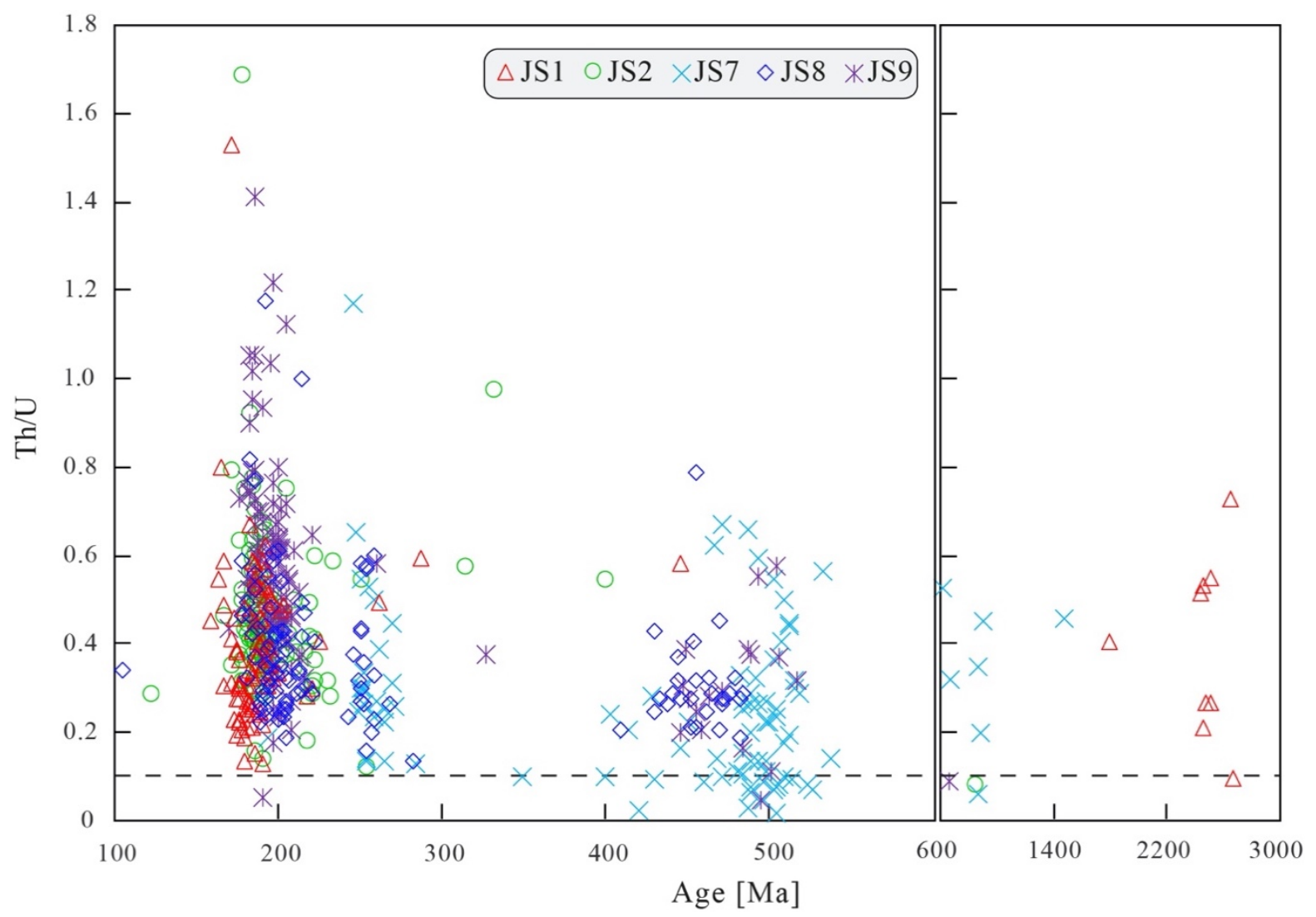

Figure 4.4: U-Pb ages versus Th/U ratios of detrital zircons from the five sand samples of the studied catchments. The dashed line marks Th/U ratio of 0.1.

\subsection{Discussion}

We evaluate the new detrital zircon U-Pb age distributions in three contexts: (1) their relation to the areal proportions of bedrock formations in the catchments as deduced from the published geological maps, (2) their relation to the available zircon $\mathrm{U}-\mathrm{Pb}$ ages determined in the basement units of the specific catchments as well as the broader area including all basement exposures in NE China, and (3) their relation to the available detrital ages from Cretaceous siliciclastic formations.

4.7.1 Comparison of the obtained U-Pb age spectra with the composition of the catchment areas

We use the regional geological survey results by HBGMR (1993) and JBRMR (1991) for comparison. Table 1 and Figure 4.2 show the areal proportions of the geological units in the catchments. Figure 4.5 visualizes the comparison of the proportions of the different units in the catchments and the zircon $\mathrm{U}-\mathrm{Pb}$ age spectra from the corresponding modern river sediments. 
III: Does U-Pb signatures of river sediment represent the age distributions in the catchments? A study of variegated catchments along the eastern border of the Songliao Basin, NE China

According to the available geological maps, the catchment of sample JS1 is dominated by Triassic-Jurassic and Permo-Carboniferous granitoids (62 and 27\%, respectively), complemented by $11 \%$ Permian siliciclastic rocks. In contrast, detrital zircon $\mathrm{U}-\mathrm{Pb}$ data reveal 92\% Jurassic and 8\% Archean ages. The arrows marked by \#1 to \#4 in Figure 4.5 represent the potential provenance of the detrital zircon grains from the different catchment units.

\#1: Derivation of Jurassic detrital zircons from Triassic-Jurassic granitoids. The minor overrepresentation may indicate a slightly higher zircon fertility of these igneous units. \#2: A part of the Precambrian zircons obtained in the detrital spectra $(b, c)$ may derive from inherited xenocrysts in the Triassic-Jurassic granitoids.

\#3: Another part of the Precambrian detrital zircons may derive from the Permian siliciclastic sedimentary rocks.

\#4: The Permo-Carboniferous granitoids are seriously under-represented in the detrital U-Pb age spectrum; only two Permian grains were detected. There are two possibilities to explain this contradiction between the exposed area and the detrital age proportions. (i) These granitoids contain only low amount of accessory zircon crystals. (ii) The granitoids indicated on the maps as Permo-Carboniferous have in fact Triassic-Jurassic emplacement ages. See discussion on these options below.

The catchment area of sample JS2 comprises 47\% Permo-Carboniferous granitoids, 23\% Triassic-Jurassic granitoids, 20\% Permian siliciclastic rocks, and some Cretaceous siliciclastic rocks and Triassic-Jurassic volcanic units. Similar to sample JS1, the determined detrital age distribution, which are dominated by Jurassic and Triassic ages (82\%), does not directly reflect the areal composition of the catchment (Figure 4.5).

\#5: The Cretaceous siliciclastic unit may contain zircons from the widespread Triassic-Jurassic igneous units. Note that traces of the regionally widespread Cretaceous volcanic rocks are hardly present in the modern sand sample. We detected a single Cretaceous $\mathrm{U}-\mathrm{Pb}$ age, although Wen et al. (2008), Zhang et al. (2012), and Sun et al. (2015) reported Cretaceous zircon ages from the Cretaceous sediments. This discrepancy might be explained by low zircon fertility of the Cretaceous igneous units, or the level of Cretaceous strata exposed in the catchment has minor volcanogenic components.

\#6: Both the Jurassic and Triassic age components can derive from the Mesozoic igneous units of the catchment.

\#7: Remarkable the lack of Permo-Carboniferous ages, as this age range is represented by only two grains. These formations indicated by the geological maps are seriously under- 
represented in the age spectrum, especially because Ju (2018) documented such ages from the Permian siliciclastic rocks. Here we confront the same problem like in case of the obtained unclear derivation relation $\# 4$.

The Qihulin River catchment (JS7) includes Proterozoic metamorphic rocks and granitoids (53 and $26 \%$ ), Cretaceous and Neogene siliciclastic rocks (18 and 2\%, respectively) and minor area of Triassic-Jurassic granitoids. The obtained detrital U-Pb age distribution again contrasts the areal composition of the catchment by the dominance of an early Paleozoic age component (57\%; Figure 4.5). The potential derivation of the age components from source units can be listed as:

\#8: The Cretaceous and Neogene siliciclastic rocks can deliver grains of all older age components detected in the sample (Proterozoic, Cambrian, Devonian, and PermoCarboniferous).

\#9: Proterozoic ages are present only by $7 \%$ despite the predominance $(\sim 80 \%)$ of Proterozoic rocks in the catchment. This might be caused by low zircon fertility of the Proterozoic units compared to the Cretaceous and Neogene clastic rocks. However, plenty of zircon $\mathrm{U}-\mathrm{Pb}$ studies on the metamorphic complex in the Southern Jiamusi block reported on 530-510 Ma granitoids which experienced granulite metamorphism between 510-490 Ma (Wilde et al., 2000, 2003; Zhou et al., 2010; Ren et al., 2012; Yang et al., 2014; Ge et al., 2016; Li et al., 2020). We should also consider the possibility that the metasedimentary units in the basement have actually younger, Paleozoic depositional ages, and constitute the sources of the Cambrian to Devonian U-Pb ages in the modern sand.

The sample JS8 from the Tangwang River represents the largest catchment in this study. The area includes predominantly Permo-Carboniferous granitoids (71\%), Proterozoic, Devonian, Permian, and Neogene siliciclastic rocks (12\%), Jurassic-Cretaceous volcano-sedimentary formations (10\%), and minor Triassic-Jurassic granitoids (5\%), minor areas of Proterozoic granitoids (2\%; Table 4.1). However, the measured $\mathrm{U}-\mathrm{Pb}$ age distribution reveals mostly Late Triassic to Early Jurassic ages (59\%) along with Late Permian to Early Triassic, and Cambrian to Silurian age components (Figure 4.5).

\#10: The Triassic-Jurassic and Cenozoic igneous and sedimentary units should contain Jurassic-Cretaceous zircons and recycled zircons from the pre-Mesozoic granitoids and (meta-)sedimentary units. The age spectrum reveals an obvious overproportion of the Late Triassic to Jurassic age component relative to the pre-Mesozoic rocks. 
III: Does U-Pb signatures of river sediment represent the age distributions in the catchments? A study of variegated catchments along the eastern border of the Songliao Basin, NE China

\#11: The Late Permian age component is likely derived from the widespread PermoCarboniferous granitoids and minor Permian siliciclastic rocks. The PermoCarboniferous units may also contribute to the Ordovician age component by inherited xenocrysts or detrital crystals. However, considering 71\% of Permo-Carboniferous granitoid and 3\% of Permian siliciclastic, the Permian age component is seriously underrepresented with $17 \%$ only. The recently published zircon $\mathrm{U}-\mathrm{Pb}$ ages from the basement ( $\mathrm{Wu}$ et al. 2011) allow for re-considering the emplacement age of some Paleozoic granitoid bodies to be Triassic-Jurassic (see also \#4 and \#7 and evaluation below).

\#12: The Ordovician age component may partly derive from the Devonian meta-sediments in the catchment.

\#13: The absence of ages from the Proterozoic meta-sediments and granitoids of the catchment is considered statistically insignificant, as they cover only $4 \%$ of the entire catchment. However, we cannot preclude that we face a stratigraphical age problem, i.e., the Proterozoic units are actually Paleozoic.

The Xiaoluomi River (sample JS9) drains the smallest catchment area exposing only PermoCarboniferous granitoids (75\%) and Silurian meta-sediments (25\%). In contrast, the detrital zircon U-Pb ages reveal Late Triassic-Early Jurassic (84\%), and Early Ordovician age components (Figures 4.3 and 4.5).

\#14: Despite Permo-Carboniferous granitoid dominance in the catchment maps, only 2 zircon grains yield such ages. Instead, $84 \%$ of the detrital U-Pb ages are Triassic and Jurassic. Mesozoic igneous units were reported for a few small andesite occurrences $(<1 \%$ of the catchment area) by Xu et al. (2013; $209 \pm 3$ and $214 \pm 3 \mathrm{Ma}$ ). This may suggest that Triassic-Jurassic igneous rocks are more widespread in the area, implying that most of the granitoids mapped as Paleozoic have actually Mesozoic emplacement ages (see \#4, $\# 7$ and \#11).

\#15: The Ordovician age component mostly likely originates from the $25 \%$ Silurian metasedimentary rocks. 


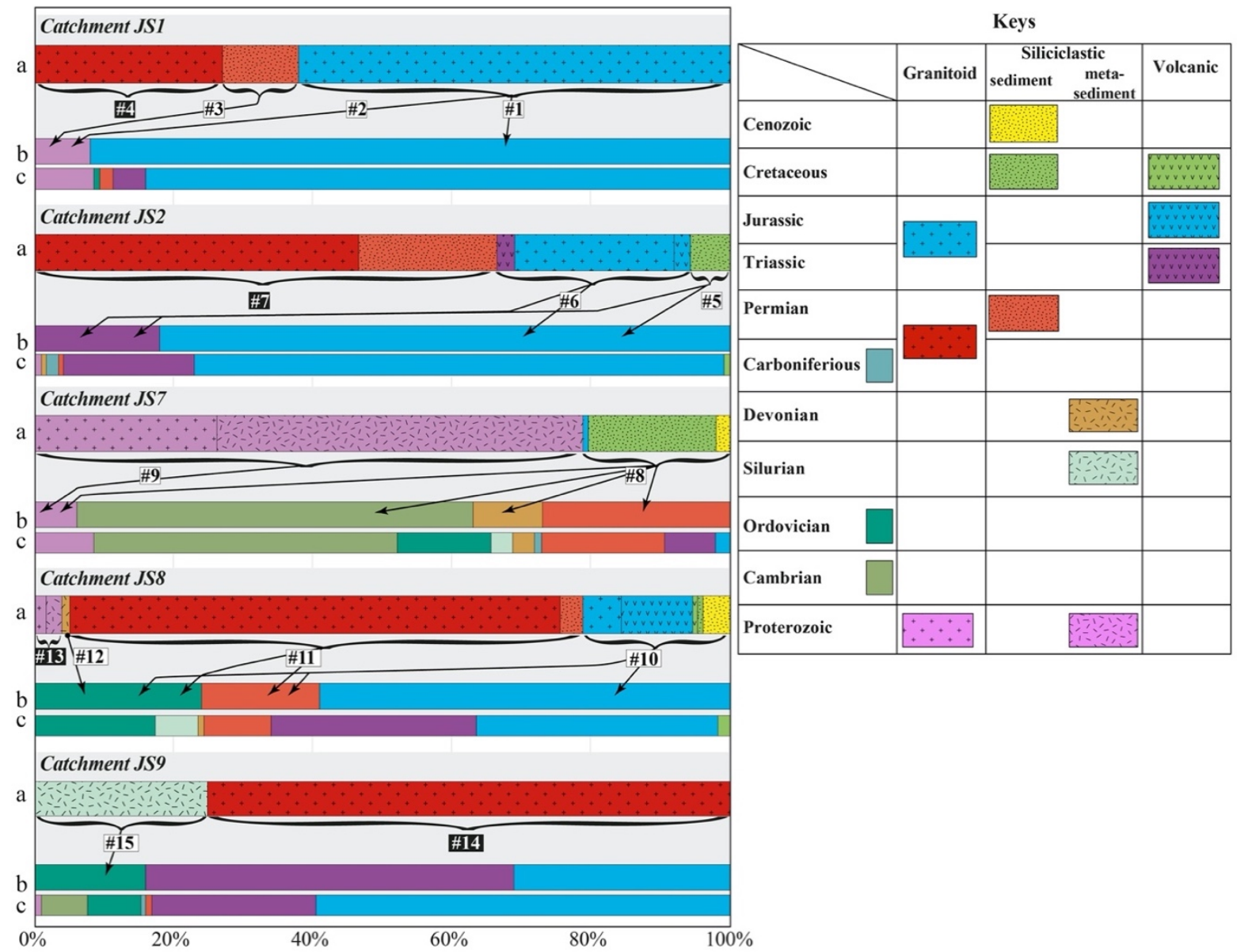

Figure 4.5: Comparison of the areal proportions of the different units in the catchments and the proportions of the obtained detrital zircon U-Pb ages. (a) Pre-Quaternary geological units, without the Cenozoic basalts, (b) proportions of the modelled age components, and (c) proportions of the single-grain zircon U-Pb ages assigned to the chronostratigraphic periods after Cohen et al. (2019). Arrows related to \#1 to \#15 indicate possible zircon provenance as discussed in the text; numbers marked in black label represent units of the catchments that are not detected in the detrital zircon U-Pb age spectra.

According to the geological maps, the Permo-Carboniferous magmatic suites constitute a significant areal proportion in four out of the five studied catchments. However, this age range is drastically underrepresented in the obtained detrital age spectra. The contrast can be assigned to (i) variable fertilities of the source units, or to (ii) serious problems in the geological maps regarding emplacement ages of the widespread igneous rock suites.

Let us investigate the first option. Dickinson (2008) reported that the zircon contents of granitoid rocks could vary with zirconium contents to a certain extent. The differential zircon fertility of granitoid rocks should be taken into account to estimate relative contributions from multiple bedrock sources. We collected the available whole-rock $\mathrm{Zr}$ concentrations from the granitoids of different types and ages of the study area (Figure 4.6). The $\mathrm{Zr}$ content shows 
variation between 5 and $785 \mathrm{ppm}$, but no systematic changes with respect to the emplacement ages. Specifically, the range of the zirconium content in the Permo-Carboniferous granitoids does not differ systematically from the other granitoids. Although the lowest $\mathrm{Zr}$ values appear in the Triassic to Jurassic basement of JB and GXR, zircons of these ages are predominant in most of the detrital age spectra. This indicates that the zircon fertility of granitoids exposed on the catchments cannot be the main reason for the detected inconsistency between the proportions of areas and the weights of age components.

The second opinion, implying that some of the granitoids and metasedimentary units have younger emplacement or depositional ages than indicated in the maps is thus more likely. This seems especially valid for the Permo-Carboniferous and Proterozoic units. Following the above discussion of samples JS1, 2, 8, and 9, at least parts of the granitoids mapped as PermoCarboniferous actually belong to the Jurassic igneous suites, and the metasedimentary units indicated as Proterozoic on the map are probably late Paleozoic or Mesozoic (sample JS7).

This result raises severe doubts on the applicability of the area ratios of the mapped lithological units for the prediction of detrital age distributions, even in cases where corrections for fertility and hydrodynamic effects can be applied (e.g., Mapes, 2009; Spencer et al., 2017). On the other hand, the obtained empirical age spectra reflect the presence and/or lack of specific magmatic and -more indirectly- sedimentary suites in the catchments. The new data thus allow for refined evaluation of the crustal growth processes of the region. They again hint at the lower contribution of the Permo-Carboniferous granitoids to the continental crust of the NE Songliao area. 


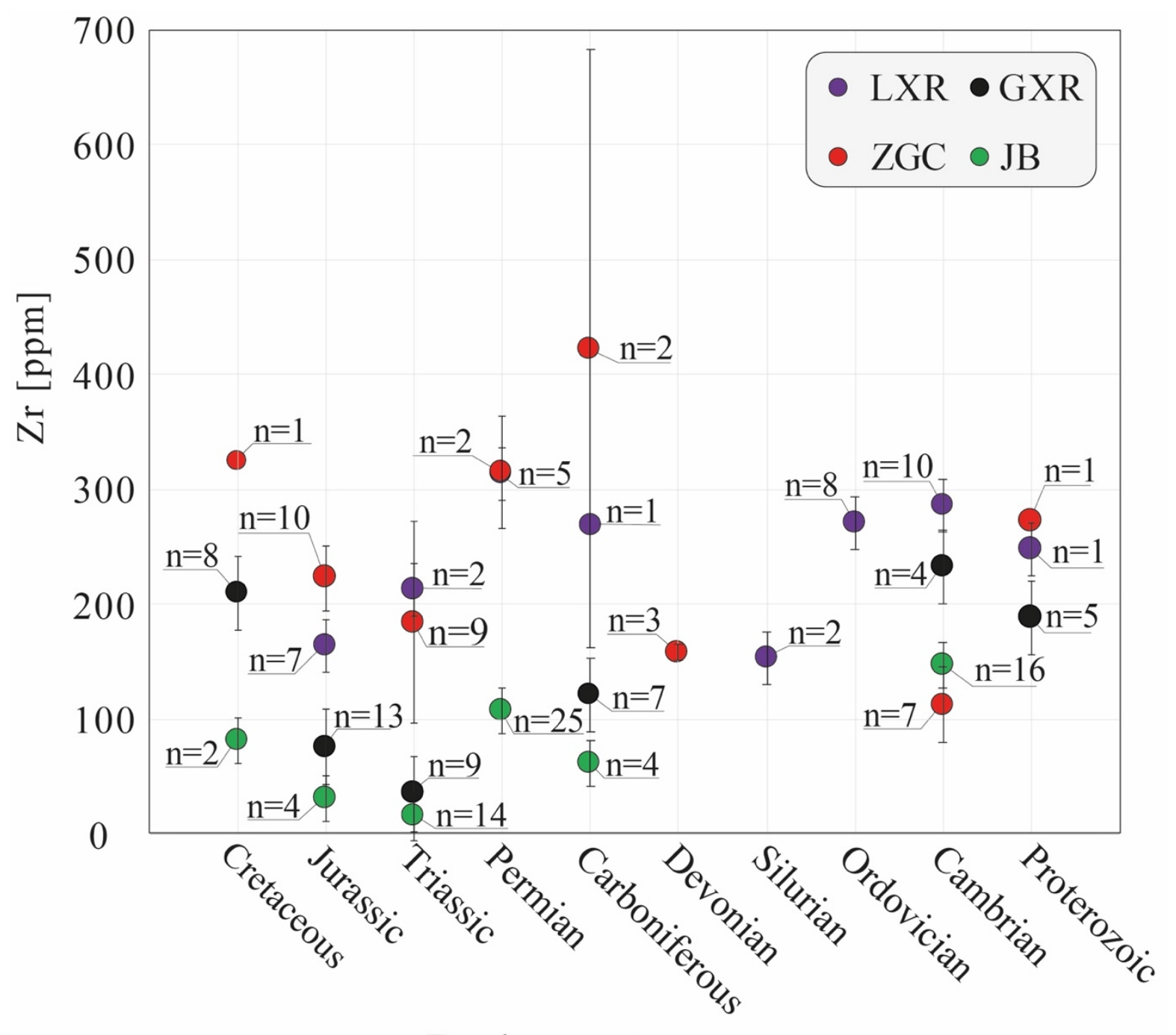

Emplacement age

Figure 4.6: Comparison of the mean zirconium contents with 1s standard errors of the granitoid rocks from the study area, considering their emplacement ages. References provided in supplementary datafile in Appendix A3. ZGC: Zhangguangcai Range area; LXR: Lesser Xing'an Range area; JB: Jiamusi block.

\subsubsection{Magmatic events reflected in the modern detrital zircon U-Pb age spectra}

We compare now the age components obtained in the modern sands with the $\mathrm{U}-\mathrm{Pb}$ age data from the basement formations. This assessment gives hints on the reliability of the identified age components - and throws light on what extent can we use them to resolve the Cretaceous provenance pattern (Section 7.3). A compilation of the formerly published zircon $\mathrm{U}-\mathrm{Pb}$ ages on granitoid and volcanic units of the exhumed basement highs is given in Figure 4.7 and Appendix Table A2, and the graphical comparison of bedrock and modern sediment ages are plotted on the map of the region (Figure 4.8b). Note that the basement reference data were generated according to different research concepts, mostly aiming to describe the 
petrographical, geochemical features of the units and their emplacement ages. We thus cannot expect that such sampling yields an unbiased representation of the region. Consequently, the goal of this section is rather to compare the mean ages of the characteristic age components identified in the basement units and the modern sediments than to address the quantification of the age components.

\subsubsection{Drainage areas in the Zhangguangcai Range}

Three tributaries (samples JS1, 2, and 9) drain different parts of the Zhangguangcai Range (ZGC; Figure 4.8). The Late Triassic-Early Jurassic ages that dominate their age spectra are consistent with the reported Triassic-Jurassic magmatic events in the Zhangguangcai Range (Sun et al., 2005; Wu et al., 2002; Wu et al., 2011). The mean ages of the identified age components are in excellent agreement (see table insets in Figure 4.7). In contrast with the Mesozoic zircon ages, the formerly identified Permo-Carboniferous granitoids of the area were not clearly revealed; only a very few grains yield such ages. Sample JS9 from the northern Zhangguangcai Range area contains a $\sim 478$ Ma age component that corresponds to the Early Paleozoic magmatic event in the northern Zhangguangcai Range; their mean ages are indistinguishable (Figure 4.7). The age component of $2500 \mathrm{Ma}$ in sample JS1 hints to the presence of Proterozoic units in the southern Zhangguangcai Range.

\subsubsection{Drainage areas in the Lesser Xing'an Range}

The age spectra of the Tangwang river sand (sample JS8) is dominated by a Triassic-Jurassic age component, with similar mean age to the widespread Late Triassic-Early Jurassic magmatic event in the Lesser Xing'an Range area (LXR, Figure 4.8; Wu et al., 2011). The Late Permian ages nicely correspond to the Late Paleozoic magmatic event recorded in the Lesser Xing'an Range (Meng et al., 2011; Wu et al., 2011; Wei et al., 2012). Recent studies have reported an early Paleozoic magmatic event ( 490-450 Ma) in the Lesser Xing'an Range (Liu et al., 2008; Wang et al., 2016; Wang, 2017), which is well reflected in the Late Ordovician detrital age component. The means of the three identified age components match well for all three igneous suites (Figures 4.6 and 4.8 and Appendix Fig. A2).

\subsubsection{Drainage areas in the Jiamusi block}

In the Qihuli river sands (sample JS7), the two dominating age groups show excellent match to the age distribution obtained on the units of the Jiamusi basement high (Figures 4.7 and 4.8 and Appendix Fig. A2). The emplacement ages of the Late Permian-Early Triassic magmatic event on the Jiamusi block and its surrounding area were determined by Zhou et al. (2009), 
Zhao (2011), Li et al. (2011), and Ge et al. (2016). The Cambrian-Early Devonian detrital ages can be associated with the Early Paleozoic magmatic event in the Jiamusi block and in the Zhangguangcai Range-Lesser Xing'an Range (Liu et al., 2008; Wu et al., 2011; Bi et al., 2014; Wang et al., 2016; Wang, 2017). Note that the detrital ages indicate a younger tail of this igneous suite that was not recognized in the bedrock analyses (Figure 4.7). The Neoproterozoic age component coincides with the newly found Neoproterozoic zircons (755-898 Ma) from the Mashan complex on the southern Jiamusi block by Yang et al. (2017, 2018), which suggest a Neoproterozoic magmatic event preserved in the region. It remains difficult to explain the lack of Cretaceous zircon $\mathrm{U}-\mathrm{Pb}$ ages in the modern sand sample, as the Cretaceous volcanic units are widespread in the Jiamusi block, and this age group is also well represented in the available bedrock age data which is similar to the ZGC (7.2.1), where the Lower Cretaceous age component is also lacking in the modern sediment. (Figure 4.7).

In summary, four river sand samples from the Zhangguangcai Range-Lesser Xing'an Range belt reveal the Jurassic-Triassic magmatic events, and the mean values of the detrital age components are very consistent with reported igneous ages in this region. On the other hand, the formerly considered widespread Permo-Carboniferous magmatic event appears only as a scattered weak signal in our four sand samples, suggesting a much smaller distribution of the late Paleozoic igneous suite in the area. Besides the lack of Permo-Carboniferous ages, the data suggest a widespread Early Paleozoic magmatic event in the LXR-ZGC. (Figures 4.7 and 4.8). The latter, although slightly older, is prominent in the Jiamusi Block as well and includes some metamorphic event as supported by low $\mathrm{Th} / \mathrm{U}$ ratios of the zircon grains (Figure 4.4). The age spectrum of sample JS7 further reports magmatic events at $\sim 849, \sim 414$, and $\sim 254 \mathrm{Ma}$, well consistent with detrital zircon U-Pb age studies on the Heilongjiang complex (Zhou et al., 2009; Li et al., 2010; Zhu et al., 2015, 2017). This implies that the catchment area belongs to the Heilongjiang accretionary complex (Li et al., 2020). 
III: Does U-Pb signatures of river sediment represent the age distributions in the catchments? A study of variegated catchments along the eastern border of the Songliao Basin, NE China

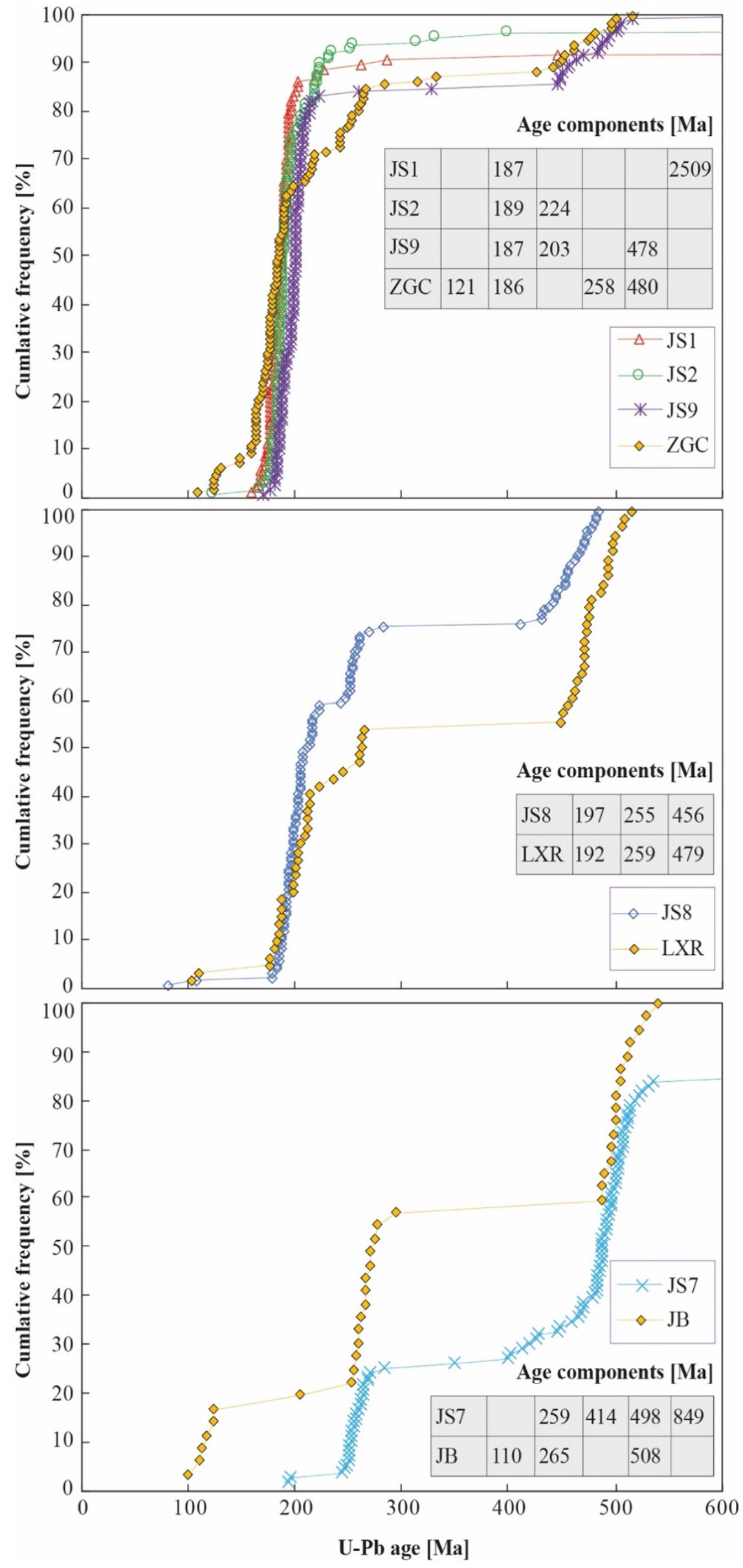


Cretaceous-Cenozoic thermo-tectonic evolution and provenance analysis of the basement and some sedimentary successions northeast of the Songliao Basin, NE China

Figure 4.7: Comparison of the detrital zircon U-Pb age spectra of the modern river sediments (blue symbols) with the compilation of the published bedrock $U-P b$ ages of the tectonic blocks that host the catchments (yellow symbols; see sources of data in Appendix Table A2). The gray tables at the right show the age components identified by the DensityPlotter software (Vermeesch, 2012).

\subsubsection{Comparison of the basement and modern river zircon U-Pb signatures with different}

\section{Cretaceous Basins}

Several studies have already been published on the provenance of the Cretaceous basin fill of the Songliao Basin, and the suggested sediment transport patterns have a common feature: it is assumed that the sediment was transported towards the basin from all directions, where mountainous regions are currently exposed (Himeno et al., 2001; Li et al., 2012; Zhao et a., 2013). Due to the different composition and age of the surrounding sediment source areas and the temporal variation in the development of the sediment deltas within the basin a very characteristic variation can be observed in the detrital zircon $\mathrm{U}-\mathrm{Pb}$ age spectra. Figures 4.6 and 4.9 present the compilation of the available single-grain ages obtained in the Cretaceous sediments in the southern and central parts of the Songliao Basin and in the eastern satellite basins (Sanjiang, Boli and Hegang Basins). Characteristic differences are visible in the detrital zircon $\mathrm{U}-\mathrm{Pb}$ age spectra of the Cretaceous sediments. These differences are in harmony with the age pattern of the basement - compiled from our river sand results and from the basement $\mathrm{U}-\mathrm{Pb}$ data (details in Appendix Fig. A2 and Appendix Table A2).

The Lower Cretaceous sediment samples from the southern Songliao Basin revealed a significant proportion of Paleoproterozoic ages, including age components of $1.8 \mathrm{Ga}$ and 2.5 Ga, which are typical for the North China Craton (Figure 4.9D; P. Li et al., 2009; H. Li et al., 2009; Yang et al., 2006). Our river sand sample JS1 from the southern Zhangguangcai Range also contains the $\sim 2.5 \mathrm{Ga}$ age component (Figure 4.9A), suggesting that the south Zhangguangcai Range could be a part of the Precambrian sediment sources feeding the southern Songliao Basin. On the contrary, the Lower Cretaceous sediments from the eastern satellite basins are almost free of Precambrian ages, which implies that the drainages of the North China Craton did not reach these eastern satellite basins. The scattered Early Paleozoic ages are subordinate in the detrital data in the Lower Cretaceous sediments compared to the basement area (especially JB and LXR; Figure 4.9B) and the modern sand (especially JS7 and JS8). They are more common in the northeastern satellite basins compared to Songliao basin 
III: Does U-Pb signatures of river sediment represent the age distributions in the catchments? A study of variegated catchments along the eastern border of the Songliao Basin, NE China

where they are almost absent. Thus, sediment from Early Paleozoic sources hardly reached the central and southern Songliao Basin.

The complexity of the Cretaceous sediment supplying paleo-river network is well indicated by the differences in the proportion of the Permo-Triassic age components (Figure 4.9). Although this component is among the most characteristic ones, it is hardly present in the Cretaceous samples of the central Songliao and Boli Basins. These two basins also share the presence of a Lower Cretaceous (ca. 150-100 Ma) age component, which is less common in the other Cretaceous sequences, and present only in the JB and GXR potential source areas.

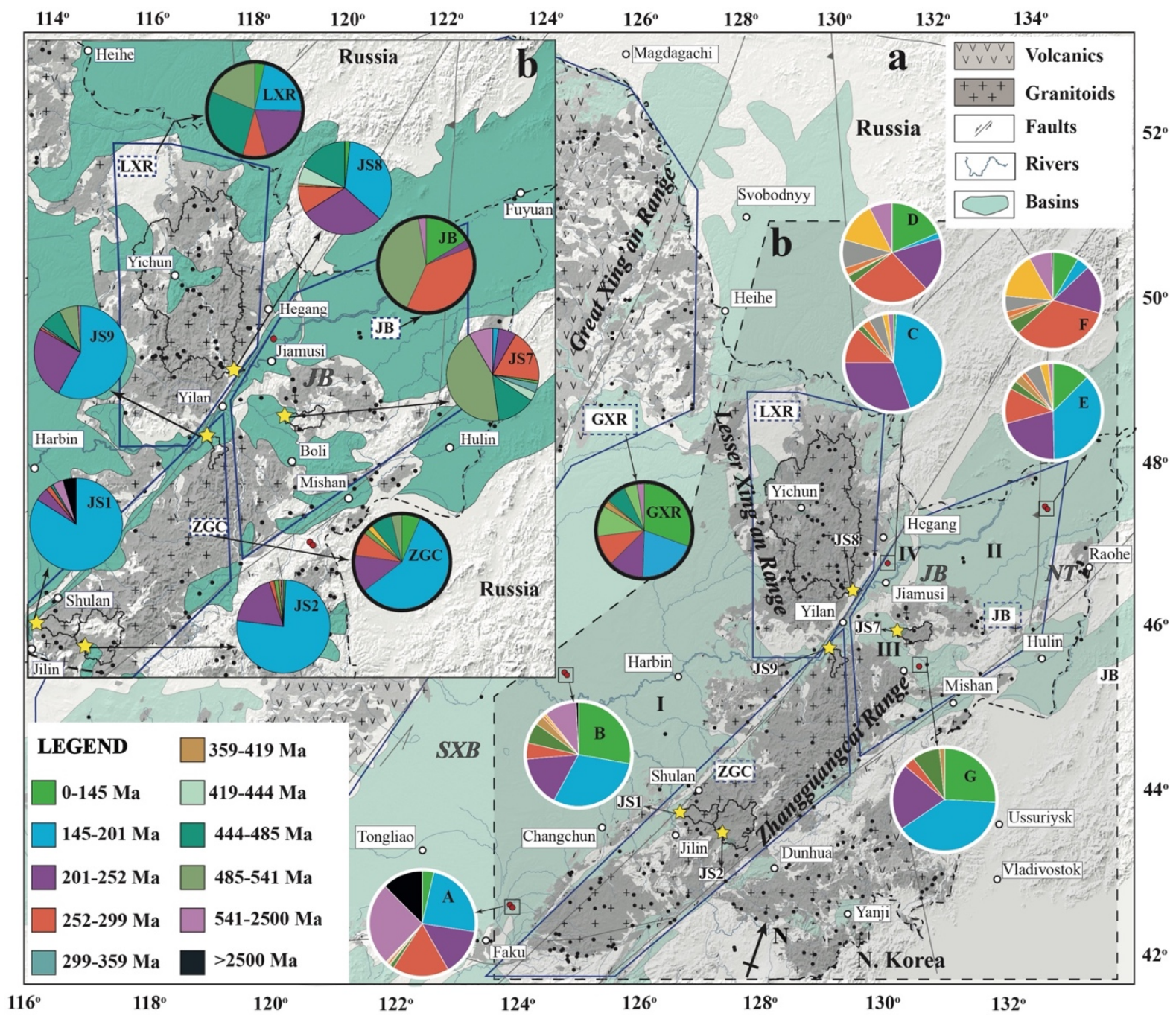

Figure 4.8: Pie-diagrams showing the simplified age spectra of the new detrital zircon U-Pb ages in the river sand samples, the compiled zircon U-Pb ages of the igneous rocks of the exposed basement highs (with black rim), and the compiled detrital age spectra determined in the Cretaceous siliciclastic formations (with white rim; data after Wu et al., 2002, 2003, 2004a,b, 2011, Chen et al., 2009; Ge et al., 2005, 2007; Xu et al., 2008, 2012, 2013; Y. B. Zhang et al., 2005; L. Zhang et al., 2009; Y. L. Zhang et al., 2008, 2010; Yu et al., 2012; Wang, 2017; Sun et al., 2004, 2005, 2013; Wang et al., 2016; Zhou et al., 2005, 2015; Sui et al., 2006, 2007; Miao, 2003; Miao et 
Cretaceous-Cenozoic thermo-tectonic evolution and provenance analysis of the basement and some sedimentary successions northeast of the Songliao Basin, NE China

al., 2004; Liu et al., 2008, 2009; Meng, et al., 2011; Wilde et al., 1997, 2000, 2003; Shi et al., 2003, 2004; She et al., 2012; Cui et al., 2013; Yang et al., 2014, 2015, 2016; Bi et al., 2014, 2016; Dong et al., 2016, 2017; Ge et al., 2018, Ma et al., 2019; Gao et al., 2007; Guo et al., 2016; Wei et al., 2012; Yu et al., 2012. See sources of data in Appendix Table 2). Simplified geological map is after Wu et al. (2011). Black dots indicate the locations of the igneous basement samples. Compilation of detrital zircon U-Pb ages from Cretaceous sediments: A: southern Songliao Basin; B: middle Songliao Basin; C: Early Cretaceous in Hegang Basin; D: Late Cretaceous in Hegang Basin; E: Early Cretaceous in Sanjiang Basin; F: Late Cretaceous in Sanjiang Basin; G: Boli Basin.

\subsubsection{Temporal change in the Cretaceous sediment supply and its geodynamic triggers}

The temporal change in the zircon U-Pb age spectra reflects well the modification of the sediment supply pattern. In this context, the southern Songliao data play a less significant role, as it was strongly influenced by a far-southern source region with Paleoproterozoic ages (North China Craton). The Lower and Upper Cretaceous sediment samples from the central Songliao Basin and eastern satellite basins reveal different $\mathrm{U}-\mathrm{Pb}$ age patterns (Figure 4.9C, D). The most relevant difference is the lack of the Jurassic ages in the Upper Cretaceous samples, except for a minor proportion in the central Songliao Basin (see below). This difference cannot result from simple incision (i.e., the Jurassic igneous units were removed by erosion between Early and Late Cretaceous time), as these age components are present both in the currently exposed basement and in the modern river sediments. A more reliable explanation for the lack of Jurassic zircons is sedimentary burial of the widespread Jurassic igneous units at Late Cretaceous time. To understand the geodynamic framework and implications of this assumption, we have to consider the general geological evolution of the region. 
III: Does U-Pb signatures of river sediment represent the age distributions in the catchments? A study of variegated catchments along the eastern border of the Songliao Basin, NE China
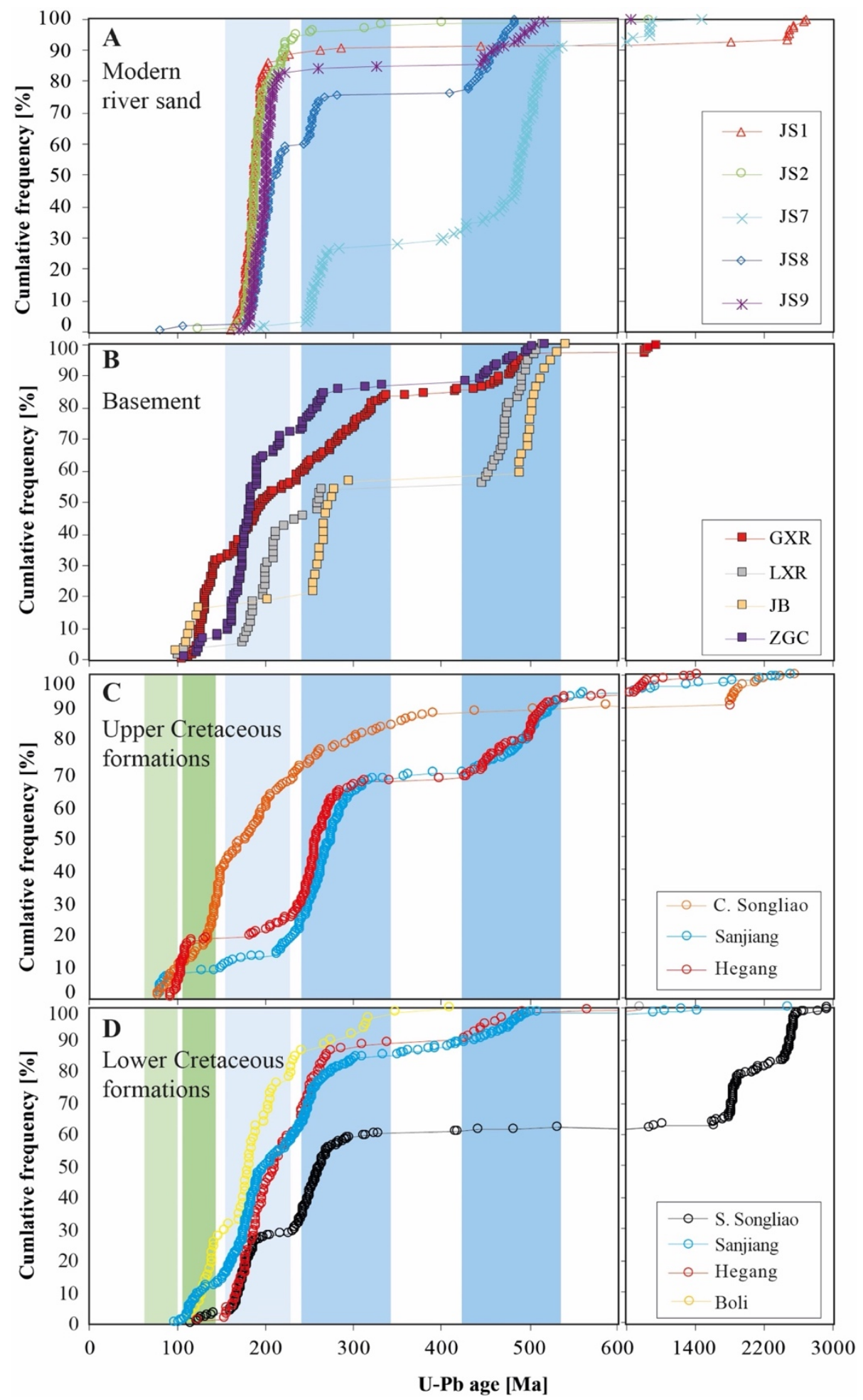

Figure 4.9: Compilation of zircon U-Pb ages from the five modern sand samples of this study (A), from igneous rocks of the basement highs of NE China (B) and from Upper (C) and Lower Cretaceous (D) siliciclastic formations of the basins (see sources of data in Appendix Table A2). Note that the data of the basement reflect mean ages of rock samples, not individual grain ages. Blue belts in A-D represent the durations of the three major magmatic periods (Triassic-Jurassic, Permo-Carboniferous and Early Paleozoic) of the region. Green belts in C and D indicate the sedimentation ages. S. Songliao: South Songliao Basin; C. Songliao: Central Songliao Basin. 
In eastern NE China the roll-back subduction of the Paleo-Pacific plate gradually developed rift basins during Late Jurassic-Early Cretaceous, (Zhou et al., 2009). In the late Early Cretaceous to early Late Cretaceous, at the time of its maximum extent, the currently elevated eastern Lesser Xing'an Range, eastern Jiamusi block and western Zhangguangcai Range were all covered by sedimentary formations (Zhou et al., 2020). During this stage, the southern Songliao Basins received sediment from the North China Craton in the south, from the Great Xing'an Range in the west and Zhangguangcai Range in the east. The Lesser Xing'an Range and Jiamusi block provide minor contributions to the Songliao Basin. The provenance of the eastern satellite basins was dominated by the Zhangguangcai Range and Lesser Xing'an Range. The Jiamusi block and the North China Craton delivered a minor contribution to the sediment budget (Figure 4.10).

In the early Late Cretaceous (ca. $90 \mathrm{Ma}$ ) the Paleo-Pacific plate considerably changed its subduction direction from NNW to WNW at high rates, and the Paleo-pacific plate subducted below the eastern Eurasian continental margin at almost a right angle (Engebretson et al., 1985 and Maruyama et al., 1997). The east NE China area was affected by dextral compressional shear tectonics (Sun et al., 2010). As a consequence, the eastern part of NE China experienced a widespread and significant exhumation from the late Early Cretaceous to Late Cretaceous (ca. 110-80 Ma; Zhou et al., 2020). The thermal/burial history modelling revealed that the eastern margin of the Jiamusi block firstly exhumed at ca. 110-100 Ma and was later followed by the western Jiamusi block and the LXR (Zhou et al., 2020). The minor contribution of Late Triassic-Jurassic ages in the Upper Cretaceous of the eastern basins along with typical JB features such as pronounced Permo-Triassic age component (Figure 9B, C) suggest that in the early Late Cretaceous, the northern ZGC and LXR were still partly buried and the sediment contribution from these regions was subordinate. The most likely primary source of the Upper Cretaceous sedimentary units was the exhumed eastern part of the Jiamusi block. The Late Triassic-Jurassic ages in the Central Songliao Basin, different with the eastern satellite basins (Figure 4.9C) reflect a larger and more complex drainage area, which still includes some igneous units of this age and/or some recycling of Lower Cretaceous strata. In summary of this stage, in the early Late Cretaceous, the regional exhumation greatly influenced the provenance pattern, mostly for the eastern satellite basins. The Jiamusi block became the major source area. The LXR and ZGC provided minor sediment contribution to the eastern basins. The central Songliao Basin received sediment from the NCC in the south, LXR in the north, and JB in the northeast but mostly from the ZGC in the east and the GXR in the west (Figure 4.10). 
III: Does U-Pb signatures of river sediment represent the age distributions in the catchments? A study of variegated catchments along the eastern border of the Songliao Basin, NE China

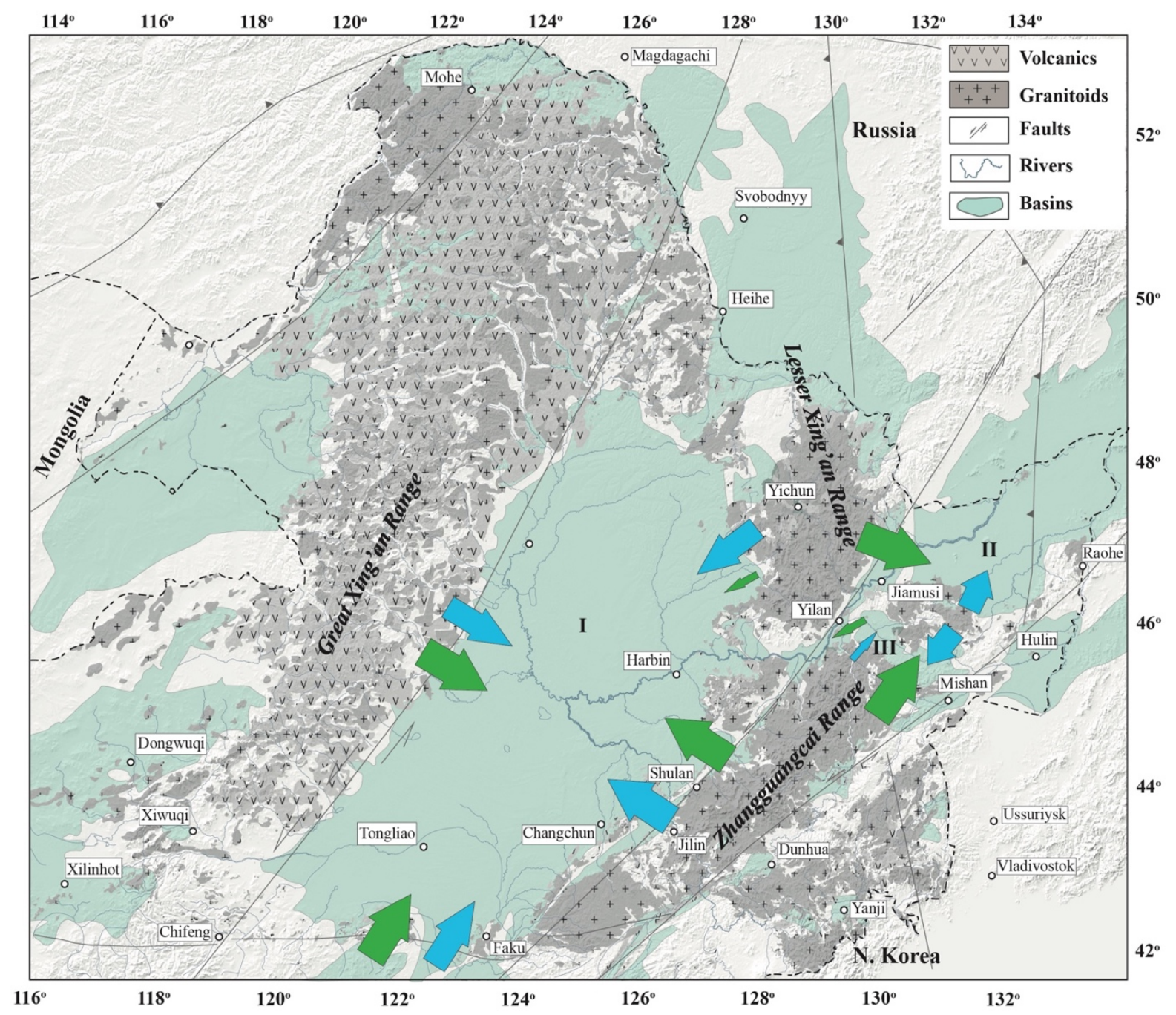

Figure 4.10: General arrows reveal the temporal change in the Cretaceous sediment supply of the study area. Green and blue arrows: sediment supplies from different areas in Early and Late Cretaceous times, respectively. The width of the arrows symbolizes the proportion of the sediment yield.

\subsection{Conclusion}

1. Modern river sand samples from five catchment areas of variable size dewatering predominantly igneous and metasedimentary basement units in NE China were characterized by detrital zircon U-Pb age distributions. The results show strong contrast between the obtained detrital zircon $\mathrm{U}-\mathrm{Pb}$ age spectra and the areal proportions of the potential source units on the available geological maps of the catchments. Differences in fertility and relief-controlled sediment yield cannot explain the huge deviations. Most characteristic is the lack or substantial underrepresentation of zircon ages from the Permo-Carboniferous igneous rocks in the modern sediments. We suggest that these units or a part of them are not Paleozoic in age as indicated on the maps, but actually 
parts of the Jurassic igneous suites. Similarly, some metasedimentary units mapped as Proterozoic have probably much younger sedimentation age.

2. The zircon $\mathrm{U}-\mathrm{Pb}$ age distributions from modern sand can provide useful hints to detect, verify or re-classify the ages of the zircon-bearing units in the catchment. This is especially helpful for largely unknown areas, like in mineral prospection, and for large areas with relatively crude geological maps. The modern sediment age distributions may also provide useful hints for the provenance analysis of ancient sedimentary formations in the same areas, better than the simple map-based evaluation of the areal proportions of basement units.

3. In the Early Cretaceous, the southern Songliao Basins received sediment from the North China Craton in the south, from the Zhangguangcai Range in the east, and the Great Xing' an Range in the west. The Lesser Xing'an Range and Jiamusi block provide minor contributions to the Songliao Basin. The provenance of the eastern satellite basins was dominated by the Zhangguangcai Range and Lesser Xing'an Range. The Jiamusi block and the North China Craton delivered a minor contribution to the sediment budget.

4. In the early Late Cretaceous, the regional exhumation greatly influenced the provenance pattern, mostly for the eastern satellite basins. The Jiamusi block became the major source area. The Lesser Xing'an Range and Zhangguangcai Range provided minor sediment contribution to the eastern basins. The central Songliao Basin received sediment from the North China Craton in the south, Lesser Xing'an Range in the north, and Jiamusi block in the northeast but mostly from the Zhangguangcai Range in the east and the Great Xing' an Range in the west.

\section{Acknowledgements}

This research was funded by the Geoscience Center of the University of Göttingen and the China Scholarship Council (2016094678). All analytical work has been performed at the Geoscience Center Göttingen. Further support was provided by the Taishan Scholars (ts20190918), Qingdao Leading innovation talents (19-3-2-19-zhc) and National Key R\&D Program of China (Grant No. 2017YFC0601300-01). 


\section{Chapter 5 Summary}

In this $\mathrm{PhD}$ thesis, by detailed and widespread field geological survey and sampling, a multiparameter low-temperature thermochronology analysis including apatite fission-track dating, apatite (U-Th)/He and zircon (U-Th)/He and was conducted on the current exhumed Zhangguangcai Range, Lesser Xing'an range and Jiamusi Uplift area. By combining the collected vitrinite reflectance data from the eastern satellite basins, including the Jixi, Boli, Sanjiang and Hulin basin, we can reconstruct the east NE China area's Mesozoic-Cenozoic orogenic and basin's uplift and exhumation history. By sampling the sands which directly contacted with the basaltic lava and sampling granitic rocks with different distances to the regional basaltic lava units, we verified the total thermal reset of the zircons from the sands that experienced the basaltic lava's heating process with (U-Th)/He and Raman spectroscopy. The obtained zircon (U-Th)/He apparent age well represents the basaltic lava's eruption age. Lastly, we studied five modern river catchments of variable size $\left(\sim 500\right.$ to $\left.\sim 40.000 \mathrm{~km}^{2}\right)$, exposed in the Jiamusi block, Zhangguangcai Range and Lesser Xing'an Range with detrital zircon $\mathrm{U}-\mathrm{Pb}$ dating. The areal proportions of the potential source units are compared with our dating result to reveal the modern sediments' provenance features. By including and comparing with the summarized the regional available zircon geochronological ages and zirconium content from the igneous units and detrital zircon $\mathrm{U}-\mathrm{Pb}$ geochronological ages from the Cretaceous sediments from the NE China basin system, we further refined the Songliao Basin and its strongly inverted eastern satellite basins' Cretaceous provenance history. By Summarizing the above knowledge, the geodynamic triggers that influenced the MesozoicCenozoic tectonic evolution of the eastern NE China area were also discussed. The main conclusions gained is as follows:

1. New low-T thermochronological age constraints from 25 igneous rocks projecting the majority basement east of the Songliao basin, NE China revealed mostly younger apparent ages than the major subsidence period of the Early Cretaceous sedimentation in the adjacent basins.

2. According to the thermal modelling the currently exhumed basement areas were covered by Cretaceous successions. The thickness of the missing sequences was calculated by assuming a reliable paleo-heat flow of $60 \mathrm{~mW} / \mathrm{m}^{2}$. The boundary of the Jiamusi Uplift and the Zhangguangcai Range were covered by ca. 1.6-1.7 km sediment, while the central 
Jiamusi Uplift experienced considerably deeper burial: the calculated cover is varying from 2.5 to $4.8 \mathrm{~km}$.

3. During the basin inversion the eastern Jiamusi Uplift and the western Zhangguangcai Range were exhumed first, between 110 and $100 \mathrm{Ma}$ with cooling rates of 2.6 and 1.2 ${ }^{\circ} \mathrm{C} / \mathrm{Myr}$, respectively. Later the cooling rate has slowed down to $0.3-0.5{ }^{\circ} \mathrm{C} / \mathrm{Myr}$. In the central Jiamusi Uplift the exhumation started slightly later, at ca. $90 \mathrm{Ma}$ and with higher cooling rates of ca. $2.4-5.4{ }^{\circ} \mathrm{C} / \mathrm{Myr}$, and continued until ca. $40 \mathrm{Ma}$.

4. Assuming $60 \mathrm{~mW} / \mathrm{m}^{2}$ paleo-heat flow in the western Sanjiang basin the former burial was $2.4 \mathrm{~km}$ in the south and $4.5 \mathrm{~km}$ in the north. In the eastern Boli basin and northern Hulin basin, the models suggest similar thicknesses of the missing sequences: 4.3 and $4.5 \mathrm{~km}$, respectively. However, in the south the Jixi basin revealed a significantly smaller burial of ca. $1.6 \mathrm{~km}$.

5. The calculated thicknesses of the missing sequences revealed a coherent, large-scale pattern, although different constraints and methods were applied for the basins and for the exhumed basement areas. In general, the eastern satellite basins experienced higher post-Early Cretaceous burial and subsequent erosion than the much larger Songliao basin to the west.

6. According to the integrated burial/thermal modelling and combining with previous research results we postulate that the eastern basin group including the Jixi basin, Boli basin, Sanjiang basin and Hulin basin belonged to a single united huge down-warped basin in the eastern Asian continental margin.

7. The current west Zhangguangcai Range and east Mishan Uplift were probably also involved in this united basin. From ca. 110 to $40 \mathrm{Ma}$, the exhumation of the Jiamusi Uplift has gradually destroyed the formerly continuous sedimentary cover and only basin remnants have been preserved. By the end of the major exhumation in the Eocene, both the major uplift area and the basin remnants came to the slow uplift and erosion stage until recent time.

8. (U-Th)/He dating of detrital zircon grains from a sand layer directly below a basalt lava flow in the Huanan region reveals a dominant age component of $9.33 \pm 0.24 \mathrm{Ma}$. This implies, together with the Raman data that the reset of the ZHe thermochronometer was caused by the thermal effect of the basalt lava, which erupted at this time.

9. The result also implies that the basalt in the Huanan area belongs to the Laoyeling volcanic episode.

10. Modern river sand samples from five catchment areas of variable size dewatering predominantly igneous and metasedimentary basement units in NE China were 
characterized by detrital zircon $\mathrm{U}-\mathrm{Pb}$ age distributions. The results show strong contrast between the obtained detrital zircon $\mathrm{U}-\mathrm{Pb}$ age spectra and the areal proportions of the potential source units on the available geological maps of the catchments. Differences in fertility and relief-controlled sediment yield cannot explain the huge deviations. Most characteristic is the lack or substantial underrepresentation of zircon ages from the PermoCarboniferous igneous rocks in the modern sediments. We suggest that these units or a part of them are not Paleozoic in age as indicated on the maps, but actually parts of the Jurassic igneous suites. Similarly, some metasedimentary units mapped as Proterozoic have probably much younger sedimentation age. Thus, the modern sediment age distributions may also provide useful hints for the provenance analysis of ancient sedimentary formations in the same areas, better than the simple map-based evaluation of the areal proportions of basement units.

11. In the Early Cretaceous, the southern Songliao Basins received sediment from the North China Craton in the south, from the Zhangguangcai Range in the east, and the Great Xing' an Range in the west. The Lesser Xing'an Range and Jiamusi block provide minor contributions to the Songliao Basin. The provenance of the eastern satellite basins was dominated by the Zhangguangcai Range and Lesser Xing'an Range. The Jiamusi block and the North China Craton delivered a minor contribution to the sediment budget.

12. In the early Late Cretaceous, the regional exhumation greatly influenced the provenance pattern, mostly for the eastern satellite basins. The Jiamusi block became the major source area of the detrital sediments. The Zhangguangcai Range and Lesser Xing'an Range provided minor sediment contribution to the eastern basins. The central Songliao Basin received sediment from the North China Craton in the south, Lesser Xing'an Range in the north, and Jiamusi block in the northeast but mostly from the Zhangguangcai Range in the east and the Great Xing'an Range in the west.

13. The modelling results of this study revealed a widespread and significant exhumation phase that affecting the eastern part of NE China, starting from the late Early Cretaceous - early Late Cretaceous (ca. 110-80 Ma). This large scaled transformation of the tectonic environment corresponds to the large-scale NW-SE compressional events at the northeastern continental margin of Asia in the Late Cretaceous. The Paleo-Pacific plate (Izanagi-Kula) greatly changed its subduction direction of the plate greatly changed from NNW to WNW with high rates in the early Late Cretaceous (ca. $90 \mathrm{Ma}$ ). It is probable that this movement and tension change in the crust induced the long-lasting uplift in the study area. 
14. The thermal modelling of the exhumed basement blocks in the east NE China indicates a significant reduction of the cooling rate in the Cenozoic, ca. 60-40 Ma. The transition to much slower exhumation might correspond to the slowing of the Pacific plate's subduction rate and the increasing subduction angle in the Eocene. The east Asia continental margin then experienced extensional tectonics, influenced by of the roll-back effect from the subduction of the Pacific plate. 
Cretaceous-Cenozoic thermo-tectonic evolution and provenance analysis of the basement and some sedimentary successions northeast of the Songliao Basin, NE China

\section{Bibliography}

Andersen, T., 2005. Detrital zircons as tracers of sedimentary provenance: limiting conditions from statistics and numerical simulation. Chemical Geology, 216(3-4), 249-270.

Bai, Z.D., Tian, M.Z., Wu, F.D., Xu, D.B., and Li, T.J., 2005. Yanshan, Gaoshan-Two active volcanoes of the volcanic cluster in Arshan, Inner Mongolia. Earthquake Research in China, 19(4), 402-408 (in Chinese with English abstract).

Bai, Z.D., Wang, J.M., Xu, G.L., Liu, L., Xu, D.B., 2008. Quaternary Volcano Cluster of Wulanhada, Right-back-banner, Chabaer, Inner Mongolia. Acta Petrologica Sinica, 24(11), 2585-2594 (in Chinese with English abstract).

Basu, A.R., Wang, J.W., Huang, W.K., Xie, G.H., Mitsunobu, T., 1991. Major element, REE, and $\mathrm{Pb}, \mathrm{Nd}$ and $\mathrm{Sr}$ isotopic geochemistry of Cenozoic volcanic rocks of eastern China: implications for their origin from suboceanic-type mantle reservoirs. Earth and Planetary Science Letters, 105(1-3), 149-169.

BGMRHP., 1993. Bureau of Geology and Mineral Resources of Heilongjiang Province, Regional geology of Heilongjiang Province. Beijing: Geological Publishing House (in Chinese).

Bi, J.H., Ge, W.C., Yang, H., Wang, Z.H., Xu, W.L., Yang, J.H., Chen, H.J., 2016. Geochronology and geochemistry of late Carboniferous-middle Permian I-and A-type granites and gabbro-diorites in the eastern Jiamusi Massif, NE China: Implications for petrogenesis and tectonic setting. Lithos, 266, 213-232.

Bi, J.H., Ge, W.C., Yang, H., Zhao, G.C., Yu, J.J., Zhang, Y.L., Tian, D.X., 2014. Petrogenesis and tectonic implications of early Paleozoic granitic magmatism in the Jiamusi Massif, NE China: geochronological, geochemical and Hf isotopic evidence. Journal of Asian Earth Sciences, 96, 308-331.

Bi, J., Xing, D., Ge, W., Yang, H., Dong, Y., 2018. Age and tectonic setting of meta-acid volcanic rocks from the North Liaohe Group in the Liaodong area: Paleoproterozoic intracontinental rift or active continental margin? Earth Sci. Front., 25(3), 295-308.

Blackburn, T.J., Bowring, S.A., Perron, J.T., Mahan, K.H., Dudas, F.O, Barnhart, K.R., 2012. An exhumation history of continents over billion-year time scales. Science, 335(6064), 73-76.

Blondes, M.S., Reiners, P.W., Edwards, B.R., Biscontini, A., 2007. Dating young basalt eruptions by (U-Th)/He on xenolithic zircons. Geology, 35(1), 17-20. 
Cao, C.R., Zheng, Q.D., 2003. Structural evolution features and its significance of hydrocarbon exploration in relict basin group, eastern Heilongjiang Province. Jour. Jilin Univ.: Earth Sci. Ed 33 (2), 167-172 (in Chinese with English abstract).

Cawood, P.A., Hawkesworth, C.J., Dhuime, B., 2012. Detrital zircon record and tectonic setting. Geology, 40(10), 875-878.

Chen, B., Jahn, B.M., Tian, W., 2009. Evolution of the Solonker suture zone: constraints from zircon $\mathrm{U}-\mathrm{Pb}$ ages, $\mathrm{Hf}$ isotopic ratios and whole-rock $\mathrm{Nd}-\mathrm{Sr}$ isotope compositions of subduction-and collision-related magmas and forearc sediments. Journal of Asian Earth Sciences, 34(3), 245-257.

Chen, D., 2016. Mesozoic-Cenozoic Tectonic Evolution and Low Temperature Thermochronological Study of Eastern Heilongjiang, NE China. Geology (in Chinese with English abstract).

Chen, X., Han, X., 2010. Sedimentary evolution characteristics of 3D seismic areas in Fangzheng fault. Marine Geology Letters, 6 (in Chinese with English abstract).

Cheng, S.Y., 2006. Regional Tectonic Characters and Meso-Cenozoic Basin Evolution in Northeastern China. Doctoral dissertation, Dissertation for Ph.D. degree. China University of geosciences, Beijing (in Chinese with English abstract).

Cheng, Y., Wang, S., Li, Y., Ao, C., Li, Y., Li, J., Zhang, T., 2018. Late CretaceousCenozoic thermochronology in the southern Songliao Basin, NE China: New insights from apatite and zircon fission track analysis. Journal of Asian Earth Sciences 160, 95-106.

Cherniak, D.J, Watson, E.B., 2001. Pb diffusion in zircon. Chemical Geology, 172(1-2), 524.

Cohen, K.M., Harper, D.A.T., Gibbard, P.L, Fan, J.X., 2019. ICS International Chronostratigraphic Chart 2019/05.

Cook, K.L., Royden, L.H., Burchfiel, B.C., Lee, Y.H., Tan, X., 2013. Constraints on Cenozoic tectonics in the southwestern Longmen Shan from low-temperature thermochronology. Lithosphere, 5(4), 393-406.

Cserepes, L., 1989. Numerical mathematics for geophysicist students.358 p., Tankönyvkiadó, Budapest.

Davis, G.A., Darby, B.J., Yadong, Z, Spell, T.L., 2002. Geometric and temporal evolution of an extensional detachment fault, Hohhot metamorphic core complex, Inner Mongolia, China. Geology, 30(11), 1003-1006. 
Dawson, P., Hargreave, M.M., Wilkinson, G.R., 1971. The vibrational spectrum of zircon (ZrSiO4). Journal of Physics C: Solid State Physics, 4(2), 240.

Devroye, L., 1987. A Course in Density Estimation. Birkhauser Boston Inc., Cambridge, MA, USA.

Dickinson, W.R., Gehrels, G.E., 2009. Use of U-Pb ages of detrital zircons to infer maximum depositional ages of strata: a test against a Colorado Plateau Mesozoic database. Earth and Planetary Science Letters, 288(1-2), 115-125.

Dickinson, W.R., 2008. Impact of differential zircon fertility of granitoid basement rocks in North America on age populations of detrital zircons and implications for granite petrogenesis. Earth and Planetary Science Letters, 275(1-2), 80-92.

Dong, Y., Ge, W.C., Yang, H., Xu, W.L., Bi, J.H., Wang, Z.H., 2017. Geochemistry and geochronology of the Late Permian mafic intrusions along the boundary area of Jiamusi and Songnen-Zhangguangcai Range massifs and adjacent regions, northeastern China: Petrogenesis and implications for the tectonic evolution of the Mudanjiang Ocean. Tectonophysics, 694, 356-367.

Dong, Y., Ge, W.C., Yang, H., Xu, W.L., Zhang, Y.L., Bi, J.H., Liu, X.W., 2016. Geochronology, geochemistry, and Hf isotopes of Jurassic intermediate-acidic intrusions in the Xing'an Block, northeastern China: Petrogenesis and implications for subduction of the Paleo-Pacific oceanic plate. Journal of Asian Earth Sciences 118, $11-31$

Donskaya, T.V., Gladkochub, D.P., Mazukabzov, A.M., Ivanov, A.V., 2013. Late PaleozoicMesozoic subduction-related magmatism at the southern margin of the Siberian continent and the 150-million-year history of the Mongol-Okhotsk Ocean. Journal of Asian Earth Sciences, 62, 79-97.

Dunkl, I., 2002. TRACKKEY: a Windows program for calculating and graphical presentation of fission track data. Comput. Geosci 28, 3-12.

Dunkl, I., Székely, B., 2003, April. Component analysis with visualization of fittingPopshare, a freeware program for evaluation of mixed geochronological data. In EGSAGU-EUG Joint Assembly.

Dunk1, I., Farics, É., Józsa, S., Lukács, R., Haas, J, Budai, T., 2019. Traces of Carnian volcanic activity in the Transdanubian Range, Hungary. International Journal of Earth Sciences, 108(5), 1451-1466. 
Eizenhöfer, P.R., Zhao, G., Zhang, J, Sun, M., 2014. Final closure of the Paleo-Asian Ocean along the Solonker suture zone: Constraints from geochronological and geochemical data of Permian volcanic and sedimentary rocks. Tectonics, 33(4), 441-463.

Engebretson, D.C., 1985. Relative motions between oceanic and continental plates in the Pacific basin (Vol. 206). geological Society of America.

Fan Q.C., Zhao, Y.W., Sui, J.L., Li, D.M., Wu, Y., 2012. Studies on Quaternary volcanism stages of Nuomin river area in the Great Xing'an Range: Evidence from petrology, KAr dating and volcanic geology features. Acta Petrologica Sinica, 28(4), 1092-1098 (in Chinese with English abstract).

Fan, Q.C., Liu, R.X., Zhang, G.H., Sui, J., 1998. The genesis and evolution of bimodal volcanic rocks in Wangtian'e volcano, Changbaishan. Acta Petrologica Sinica, 14(3), 305-317 (in Chinese with English abstract).

Fan, Q.C., Sui, J.L., Wang, T.H., Li, N., Sun, Q., 2007. History of volcanic activity, magma evolution and eruptive mechanisms of the Changbai volcanic province. Geological Journal of China Universities, 13(2), 175-190 (in Chinese with English abstract).

Fan, Q.C., Sun, Q., Li, N., Wang, T.H., 2006. Holocene volcanic rocks in Jingbo Lake Region-Diversity of magmatism. Progress in Natural Science, 16(1): 65-71 (in Chinese with English abstract).

Fan, Q.C., Zhao, Y.W., Li, D.M., Wu, Y., Sui, J.L., Zheng, D.W., 2011. Studies on Quaternary volcanism stages of Halaha River and Chaoer River area in the Great Xing'an Range: Evidence from K-Ar dating and volcanic geology features. Acta Petrologica Sinica, 27(10), 2827-2832 (in Chinese with English abstract).

Fan, Q., Hooper, P.R., 1991. The Cenozoic basaltic rocks of eastern China: petrology and chemical composition. Journal of petrology, 32(4), 765-810.

Fang, S., Zhao, X.R., Liu, Z.J., Wang, H.Y., Yang, J.G., 2008. Thrust event of the provenances revealed by zircon fission track ages in Tangyuan Fault-Basin, NE China. Radiation measurements 43, 324-328.

Farley, K.A., 2000. Helium diffusion from apatite: General behavior as illustrated by Durango fluorapatite. Journal of Geophysical Research: Solid Earth 105 (B2), 29032914.

Farley, K.A., Stockli, D.F., 2002. (U-Th)/He dating of phosphates: Apatite, monazite, and xenotime. Reviews in mineralogy and geochemistry 48 (1), 559-577.

Farley, K.A., Wolf, R.A., Silver, L.T., 1996. The effects of long alpha-stopping distances on (U-Th)/He ages. Geochimica et cosmochimica acta 60 (21), 4223-4229. 
Fedo, C.M., Sircombe, K.N, Rainbird, R.H., 2003. Detrital zircon analysis of the sedimentary record. Reviews in Mineralogy and Geochemistry, 53(1), 277-303.

Feng, Z.Q., Jia, J., Liu, Y.J., Wen, Q.B., Li, W.M., Liu, B.Q., Xing, D.Q., Zhang, L., 2015 a. Geochronology and geochemistry of the Carboniferous magmatism in the northern Great Xing'an Range, NE China: constraints on the timing of amalgamation of Xing'an and Songnen blocks. Journal of Asian Earth Sciences 113, 411-426.

Feng, Z.Q., Liu, Y.J., Liu, B.Q., Wen, Q.B., Li, W.M., Liu, Q., 2015b. Timing and nature of the Xinlin-Xiguitu Ocean: constraints from ophiolitic gabbros in the northern Great Xing'an Range, eastern Central Asian Orogenic Belt. International Journal of Earth Sciences (Geol Rundsch) http://dx.doi.org/10.1007/s00531-00015-01185-z.

Fitzgerald, P.G., Baldwin, S.L., Webb, L.E., O'Sullivan, P.B., 2006. Interpretation of (UTh)/He single grain ages from slowly cooled crustal terranes: a case study from the Transantarctic Mountains of southern Victoria Land. Chemical Geology 225 (1-2), 91-120.

Flower, M., Tamaki, K., Hoang, N., 1998. Mantle extrusion: A model for dispersed volcanism and DUPAL-like asthenosphere in East Asia and the western Pacific. Mantle dynamics and plate interactions in East Asia, 27, 67-88.

Flowers, R.M., Ketcham, R.A., Shuster, D.L., Farley, K.A., 2009. Apatite (U-Th)/He thermochronometry using a radiation damage accumulation and annealing model. Geochimica et Cosmochimica acta, 73(8), 2347-2365.

Francis, P., 1993, Volcanoes: a planetary perspective: Clarendon Press, 443 p.

Gao, Y.Z., 2010. Structural features and their relationship with the petroleum and gas in Hulin basin. Master dissertation, Dissertation for master degree. China University of geosciences, Beijing (in Chinese with English abstract).

Gastil, R.G., DeLisle, M., and Morgan, J., 1967. Some effects of progressive metamorphism on zircons. Geol. Soc. Am. Bull. 78, 879-906.

Ge, M.H., Zhang, J.J., Li, L., Liu, K., 2018. A Triassic-Jurassic westward scissor-like subduction history of the Mudanjiang Ocean and amalgamation of the Jiamusi Block in NE China: Constraints from whole-rock geochemistry and zircon U-Pb and Lu-Hf isotopes of the Lesser Xing'an-Zhangguangcai Range granitoids. Lithos, 302, 263 277.

Ge, M.H., Zhang, J.J., Liu, K., Ling, Y.Y., Wang, M, Wang, J.M., 2016. Geochemistry and geochronology of the blueschist in the Heilongjiang Complex and its implications in the late Paleozoic tectonics of eastern NE China. Lithos, 261, 232-249. 
Ge, W.C., Sui, Z.M., Wu, F.Y., Zhang, J.H., Xu, X.C., Cheng, R.Y., 2007. Hf isotopic character- istics and their implications of the Early Paleozoic granites in the northern Da Hinggan Mts., northeastern China. Acta Petrologica Sinica 23, 423-440 (in Chinese with English abstract).

Gehrels, G.E., Dickinson, W.R., Ross, G.M., Stewart, J.H, Howell, D.G., 1995. Detrital zircon reference for Cambrian to Triassic miogeoclinal strata of western North America. Geology, 23(9), 831-834.

Geisler, T., Ulonska, M., Schleicher, H., Pidgeon, R. T., van Bronswijk, W., 2001. Leaching and differential recrystallization of metamict zircon under experimental hydrothermal conditions. Contributions to Mineralogy and Petrology, 141(1), 53-65.

Grimes, C.B., John, B.E., Kelemen, P.B., Mazdab, F.K., Wooden, J.L., Cheadle, M.J., Schwartz, J.J., 2007. Trace element chemistry of zircons from oceanic crust: A method for distinguishing detrital zircon provenance. Geology, 35(7), 643-646.

Guenthner, W.R., Reiners, P.W., Ketcham, R.A., Nasdala, L., Giester, G., 2013. Helium diffusion in natural zircon: Radiation damage, anisotropy, and the interpretation of zircon (U-Th)/He thermochronology. American Journal of Science, 313(3), 145-198.

Guo, F., Fan, W.M., Li, C.W., Miao, L.C., Zhao, L., 2009. Early Paleozoic subduction of the Paleo-Asian Ocean: geochronological and geochemical evidence from the Dashizhai basalts, Inner Mongolia. Science in China Series D: Earth Sciences 52 (7), 940-951.

Guo, J.H., Sun, M., Chen, F.K, Zhai, M.G., 2005. Sm-Nd and SHRIMP U-Pb zircon geochronology of high-pressure granulites in the Sanggan area, North China Craton: timing of Paleoproterozoic continental collision. Journal of Asian Earth Sciences, 24(5), 629-642.

Han, G., Liu, Y., Neubauer, F., Bartel, E., Genser, J., Feng, Z., Zhang, L., Yang, M., 2015. $\mathrm{U}-\mathrm{Pb}$ age and $\mathrm{Hf}$ isotopic data of detrital zircons from the Devonian and Carboniferous sandstones in Yimin area, NE China: new evidences to the collision timing between the Xing'an and Erguna blocks in eastern segment of Central Asian Orogenic Belt. Journal of Asian Earth Sciences 97, 211-228.

Han, G., Liu, Y., Neubauer, F., Genser, J., Zhao, Y., Wen, Q., Zhao, L., 2012. Provenance analysis of Permian sandstones in the central and southern Da Xing'an Mountains, China: constraints on the evolution of the eastern segment of the Central Asian Orogenic Belt. Tectonophysics, 580, 100-113. 
Han, G.Q, Liu, Y.J., Liu, J.J., 2008. Uplifting time of Huanan uplift in the northeastern Heilongjiang. China. Journal of Jilin University (Earth Science Edition) 38 (3), 389397 (in Chinese with English abstract).

Han, X.J., 1998. The Distribution of Heat Flow Data in the Continental Area of Northeast and Statistic Studies. World Geology (4), 04 (in Chinese with English abstract).

HBGMR (Heilongjiang Bureau of Geology and Mineral Resources), 1993. Regional Geology of Heilongjiang Province. Geological Publishing House, Beijing, pp. 347-418 (in Chinese).

He, Z.H., Liu, Z.J., Zhang, X.D., 2009. Subdivisions of structural layers and tectonicsedimentary evolution of eastern basins in Heilongjiang in Late Mesozoic. Global Geology 28 (1), 20-27 (in Chinese with English abstract).

He, Z.H., Liu, Z.J., Chen, X.Y., He, Y.P., Chen, Y.S., 2008. Sedimentary facies characteristics and their evolution of the Early Cretaceous relict basins in eastern Heilongjiang Province. Journal of Palaeogeography 10 (2), 151-158 (in Chinese with English abstract).

Himeno, O., Ohira, H., Liu, Z., Jin, X., Watanabe, K., 2001. Provenance ages of Cretaceous strata in the Songliao Basin, northeast China inferred from fission track data. International Geology Review, 43(10), 945-952.

Hopkinson, T.N., Harris, N.B., Warren, C.J., Spencer, C.J., Roberts, N.M., Horstwood, M. S, Parrish, R. R., 2017. The identification and significance of pure sediment-derived granites. Earth and Planetary Science Letters, 467, 57-63.

Hoskin, P.W.O, Black, L.P., 2000. Metamorphic zircon formationunit by solid-state recrystallization of protolith igneous zircon. Journal of metamorphic Geology, 18(4), 423-439.

Hu, S.L., Wang, S.S., Liu, J.Q., Sang, H.Q., Qiu, J., Jiang, W.Y., 1983. K-Ar Ages and Some Characters of Strontium, Oxygen Isotopes in Cenozoic Wudalianchi Basalts, Northeast China. Petrology Research, 2, 22-31 (in Chinese with English abstract).

Huang, Q.H., Tan, W., Yang, H.C., 1999. Stratigraphic succession and chronosrata of Cretaceous in the Songliao basin. Petroleum Geology and Oilfield Development in Daqing 18, 15-17 (in Chinese with English abstract).

Huang, S.Q., Dong, S.W., Hu, J.M., Shi, W., Chen, X.H., Liu, Z.Q., 2016. The formation and tectonic evolution of the Mongol-Okhotsk belt. Acta Geologica Sinica, 90, 2192-2205 (in Chinese with English abstract). 
Hurford, A.J., Fitch, F.J., Clarke, A., 1984. Resolution of the age structure of the detrital zircon populations of two Lower Cretaceous sandstones from the Weald of England by fission track dating. Geol. Mag., 121, 269-277.

Hurford, A.J., Green, P.F., 1983. The zeta age calibration of fission-track dating. Chemical Geology 41, 285-317.

IMBGMR (Inner Mongolian Bureau of Geology Mineral Resources)., 1991. Regional Geology of Inner Mongolia. Geological Publishing House, 1-725 (in Chinese).

Irmer, G., 1985. On the influence of the apparatus function on the determination of scattering cross sections and lifetimes from optical phonon spectra. Experimentelle Technik der Physik, 33, 501-506.

Jahn, B.M., Wu, F.Y., Chen, B., 2000. Granitoids of the central Asian orogenic belt and continental growth in the Phanerozoic. Transactions of the Royal Society of Edinburgh Earth Science 91, 81-93.

JBGMR (Jilin Bureau of Geology and Mineral Resources)., 1988. Regional geology of Jilin province.

Jia, C.Z., Zheng, M., 2010. Sedimentary history, tectonic evolution of Cretaceous Dasanjiang Basin in Northeast China and the significance of oil and gas exploration of its residual basins [J]. Journal of Daqing Petroleum Institute 6 (in Chinese with English Abstract). Jia, D.C., Hu, R.Z., Lu, Y., Qiu, X.L., 2004. Collision belt between the Khanka block and the North China block in the Yanbian Region, Northeast China. Journal of Asian Earth Sciences 23, 211-219.

Jiang, G.Z., Gao, P., Rao, S., Zhang, L.Y., Tang, X.Y., Huang, F., Wang, J.Y., 2016. Compilation of heat flow data in the continental area of China. Chinese Journal of Geophysics-Chinese edition 59 (8), 2892-2910 (in Chinese with English abstract). Ju, G., 2018. Detrital-zircon geochronology from the Yangjiagou Formation Unit in southern section of Zhangguangcai Range and their geological significance, Master thesis, Jilin University (in Chinese with English abstract).

Ketcham, R.A., 2005. HeFTy: Forward and inverse modeling thermochronometer systems. Computational Tools for Low-Temperature Thermocronometer Interpretation. Mineralogical Society of America, Chantilly, VA.

Ketcham, R.A., Carter, A., Donelick, R.A., Barbarand, J., Hurford, A.J., 2007. Improved modeling of fission-track annealing in apatite. American Mineralogist 92 (5-6), 799810. 
Kinoshita, O., 1995. Migration of igneous activities related to ridge subduction in Southwest Japan and the East Asian continental margin from the Mesozoic to the Paleogene. Tectonophysics, 245(1-2), 25-35.

Kröner, A., Kovach, V., Belousova, E., Hegner, E., Armstrong, R., Dolgopolova, A, Sun, M., 2014. Reassessment of continental growth during the accretionary history of the Central Asian Orogenic Belt. Gondwana Research, 25(1), 103-125.

Li, J. Y., 2006. Permian geodynamic setting of Northeast China and adjacent regions: closure of the Paleo-Asian Ocean and subduction of the Paleo-Pacific Plate. Journal of Asian Earth Sciences, 26(3-4), 207-224.

Li, J.Y., Qu, J.F., Zhang, J., Liu, J.F., Xu, W.L., Zhang, S.H., Guo, R.Q., Zhu, Z.X., Li, Y.P., Li, Y.F., Wang, T., Xu, X.Y., Li, Z.P., Liu, Y.Q., Sun, L.X., Jian, P., Zhang, Y., Wang, L.J., Peng, S.H., Feng, Q.W., Wang, Y., Wang, H.B., Zhang, X.X., 2013. New developments on the reconstruction of Phanerozoic geological history and research of metallogenic geological settings of the Northern China Orogenic Region. Geological Bulletin of China 32, 207-219 (in Chinese with English abstract).

Li, S.Q., Chen, F.K., Siebel, W., Wu, J.D., Zhu, X.Y., Shan, X.L., Sun, X.M., 2012. Late Mesozoic tectonic evolution of the Songliao Basin, NE China: evidence from detrital zircon ages and $\mathrm{Sr}-\mathrm{Nd}$ isotopes. Gondwana Research 22 (3-4), 943-955.

Li, W.M, Liu, Y.J., Zhao, Y.L., Feng, Z.Q., Zhou, J.P., Wen, Q.B., Liang, C.Y., Zhang, D., 2020. Tectonic evolution of the Jiamusi Block, NE China. Acta Petrologica Sinica, 36(3):65-684, doi:10.18654/1000-0569/2020.03.03 (In Chinese with English abstract).

Li, W.M., Takasu, A., Liu, Y.J., Genser, J., Zhao, Y.L., Han, G.Q., Guo, X.Z., 2011a. U-Pb and 40Ar/39Ar age constrains on protolish and high-P/T type metamorphism of the Heilongjiang Complex in the Jiamusi Massif, NE China. Journal of Mineralogical and Petrological Sciences, 106: 326-31.

Li, W.M., Takasu, A., Liu, Y.J., Guo, X.Z., 2010. Newly discovered garnet-barroisite schists from the Heilongjiang Complex in the Huanan Massif, northeastern China. Journal of Mineralogical and Petrological Sciences 105, 86-91.

Li, X.P., Jiao, L.X., Zheng, Q.D., Dong, X., Kong, F.M., Song, Z.J., 2009. U-Pb zircon dating of the Heilongjiang complex at Huanan, Heilongjiang Province. Acta Petrologica Sinica, 25, 1909-1916 (in Chinese with English abstract).

Li, X., Yang, X., Xia, B., Gong, G., Shan, Y., Zeng, Q., Sun, W., 2011c. Exhumation of the Dahinggan Mountains, NE China from the Late Mesozoic to the Cenozoic: New 
evidence from fission-track thermochronology. Journal of Asian Earth Sciences 42 (12), 123-133.

Li, X.F., Chen, Q.M., Zhang, X.H., 2002. The Yitong Graben-the structural features and evolution of a strike-slip fault basin. Petroleum geology and Experiment, 24(1), 19-24 (in Chinese with English abstract).

Li, X.M., Gong, G.L., 2011b. Late Mesozoic-Cenozoic exhumation history of the Lesser Hinggan Mountains, NE China, revealed by fission track thermochronology. Geological Journal 46 (4), 277-287.

Lin, W., Faure, M., Monié, P., Schärer, U, Panis, D., 2008. Mesozoic extensional tectonics in eastern Asia: The South Liaodong Peninsula metamorphic core complex (NE China). The Journal of Geology, 116(2), 134-154.

Lissenberg, C.J., Rioux, M., Shimizu, N., Bowring, S. A, Mével, C., 2009. Zircon dating of oceanic crustal accretion. Science, 323(5917), 1048-1050.

Liu, C.Z., Ge, X.F., Qi, D.Y., 2013. Burial history of Wangfu fault depression in Songliao Basin. Journal of Heilongjiang Institute of Science and Technology 23, 482-6 (in Chinese with English abstract).

Liu, H.F., Liang, H.S., Li, X.Q., Yin, J.G., Zhu, D.F., Liu, L.Q., 2000. The coupling mechanisms of Mesozoic-Cenozoic rift basins and extensional mountain system in eastern China. Earth science frontiers 7 (4), 477-486.

Liu, J.F., Chi, X.G., Dong, C.Y., Zhao, Z., Li, G.R, Zhao, Y.D., 2008. Discovery of Early Paleozoic granites in the eastern Xiao Hinggan Mountains, northeastern China and their tectonic significance. Geological Bulletin of China, 27(4), 534-544.

Liu, J.Q., 1987. Study on geochronology of the Cenozoic volcanic rocks in Northeast China. Acta Petrologica Sinica, 4(2). (in Chinese with English abstract)

Liu, J.Q., 1988. The Cenozoic volcanic episodes in northeast China. Acta Petrologica Sinica, 1(1). (in Chinese with English abstract)

Liu, J.Q., Chen, L.H., Zhong, Y., Lin, W.H., Wang, X.J., 2017. Petrological, K-Ar chronological and volcanic geological characteristics of Quaternary Xunke high-Mg\# andesites from the Lesser Khingan Range. Acta Petrologica Sinica, 33(1), 31-40. (in Chinese with English abstract)

Liu, J., Davis, G. A., Lin, Z, Wu, F., 2005. The Liaonan metamorphic core complex, Southeastern Liaoning Province, North China: A likely contributor to Cretaceous rotation of Eastern Liaoning, Korea and contiguous areas. Tectonophysics, 407(1-2), 65-80. 
Liu, R.X., 1992. The K-Ar age and tectonic environment of Cenozoic rock in China. The age and geochemistry of Cenozoic volcanic rock in China, 1-43 (in Chinese with English abstract).

Liu, R., Fan, Q., Zheng, X., Zhang, M., Li, N., 1998. The magma evolution of Tianchi volcano, Changbaishan. Science in China Series D: Earth Sciences, 41(4), 382-389 (in Chinese with English abstract).

Liu, X.W., Shen N.H., Ge, X.H. 1994. Mesozoic collision tectonics in eastern Jilin and Heilongjiang Provinces, Northeastern China. Journal of Changchun University of Earth Sciences 24 (4):385-389 (in Chinese with English abstract).

Liu, Y.J., Zhang, X.Z., Jin, W., Chi, X.G., Wang, C.W., Ma, Z.H., Zhao, X.F., 2010. Late Paleozoic tectonic evolution in northeast China. Geology in China, 37(4), 943-951 (in Chinese with English abstract).

Liu, Y., Li, W., Feng, Z., Wen, Q., Neubauer, F, Liang, C., 2017. A review of the Paleozoic tectonics in the eastern part of Central Asian Orogenic Belt. Gondwana Research, 43, 123-148.

Lu, S.F., Liu, X.Y., Wang, Z.P., Wang, Y.W., 2005. Denudation thickness and its significance in the deep part of Songliao Basin. Petroleum Geology \& Oilfield Development in Daqing 24 (1), 20-22 (in Chinese with English abstract).

Ludwig, K.R., 2012. Isoplot/Ex, v. 3.75. Berkeley Geochronology Center Special Publication 5,75 .

Lünsdorf, N.K., Lünsdorf, J.O., 2016. Evaluating Raman spectra of carbonaceous matter by automated, iterative curve-fitting. International Journal of Coal Geology, 160, 51-62.

Ma, Y., Liu, Y., Wang, Y., Tang, Z., Qian, C., Qin, T., Zang, Y., 2019. Geochronology and geochemistry of the Carboniferous felsic rocks in the central Great Xing'an Range, NE China: Implications for the amalgamation history of Xing'an and SongliaoXilinhot blocks. Geological Journal, 54(1), 482-513.

Malkowski, M.A., Sharman, G.R., Johnstone, S.A., Grove, M.J., Kimbrough, D.L, Graham, S.A., 2019. Dilution and propagation of provenance trends in sand and mud: Geochemistry and detrital zircon geochronology of modern sediment from central California (USA). American Journal of Science, 319(10), 846-902.

Malusà, M.G., Resentini, A, Garzanti, E., 2016. Hydraulic sorting and mineral fertility bias in detrital geochronology. Gondwana Research, 31, 1-19.

Mapes, R.W., 2009. Past and present provenance of the Amazon River. Doctoral thesis, University of North Carolina at Chapel Hill, 67-73. 
margin of northeastern China. Island Arc 16, 156-172.

Maruyama, S., Isozaki, Y., Kimura, G., Terabayashi, M., 1997. Paleogeographic maps of the Japanese Islands: Plate tectonic synthesis from $750 \mathrm{Ma}$ to the present. Island arc, 6(1), 121-142.

McDougall, I. and Harrison, T.M., 1999. Geochronology and thermochronology by the 40Ar/39Ar Method. Oxford University Press, New York.

Meng, E., Xu, W.L., Pei, F.P., Yang, D.B., Wang, F, Zhang, X.Z., 2011. Permian bimodal volcanism in the Zhangguangcai Range of eastern Heilongjiang Province, NE China: zircon $\mathrm{U}-\mathrm{Pb}-\mathrm{Hf}$ isotopes and geochemical evidence. Journal of Asian Earth Sciences, 41(2), 119-132.

Meng, E., Xu, W.L., Pei, F.P., Yang, D.B., Yu, Y, Zhang, X.Z., 2010. Detrital-zircon geochronology of Late Paleozoic sedimentary rocks in eastern Heilongjiang Province, NE China: implications for the tectonic evolution of the eastern segment of the Central Asian Orogenic Belt. Tectonophysics, 485(1-4), 42-51.

Meng, Q.R., 2003. What drove late Mesozoic extension of the northern China-Mongolia tract? Tectonophysics, 369(3-4), 155-174.

Meng, Q.R., Hu, J.M., Jin, J.Q., Zhang, Y., Xu, D.F., 2003. Tectonics of the late Mesozoic wide extensional basin system in the China-Mongolia border region. Basin Research $15(3), 397-415$.

Moecher, D.P, Samson, S.D., 2006. Differential zircon fertility of source terranes and natural bias in the detrital zircon record: Implications for sedimentary provenance analysis. Earth and Planetary Science Letters, 247(3-4), 252-266.

Nakajima, T., Shirahase, T., Shibata, K., 1990. Along-arc lateral variation of Rb- Sr and KAr ages of cretaceous granitic rocks in Southwest Japan. Contributions to Mineralogy and Petrology, 104(4), 381-389.

Nasdala, L., Irmer, G., Jonckheere, R., 2002. Radiation damage ages: Practical concept or impractical vision? - Reply to two comments on" Metamictisation of natural zircon: Accumulation versus thermal annealing of radioactivity-induced damage", and further discussion. Contributions to Mineralogy and Petrology, 143(6), 758-766.

Nasdala, L., Irmer, G., Wolf, D., 1995. The degree of metamictization in zircons: a Raman spectroscopic study. European Journal of Mineralogy-Ohne Beihefte, 7(3), 471-478.

Nasdala, L., Wenzel, M., Vavra, G., Irmer, G., Wenzel, T., Kober, B., 2001. Metamictisation of natural zircon: accumulation versus thermal annealing of radioactivity-induced damage. Contributions to Mineralogy and Petrology, 141(2), 125-144. 
Pei, F., Xu, W., Yang, D., Zhao, Q., Liu, X, Hu, Z., 2007. Zircon U-Pb geochronology of basement metamorphic rocks in the Songliao Basin. Chinese Science Bulletin, 52(7), 942-948 (in Chinese with English abstract).

Pei, J.L., Sun, Z.M., Liu, J., Liu, J., Wang, X.S., Yang, Z.Y., Zhao, Y., Li, H.B., 2011. A paleomagnetic study from the Late Jurassic volcanics (155 Ma), North China: implications for the width of Mongol-Okhotsk Ocean. Tectonophysics, 510(3-4), 370-380.

Press, W.H., Flannery, B.P., Teukolsky, S.A., Vetterling, W.T., 1996. Numerical recepies in Pascal. 760 p., Cambridge University Press.

QGIS Development Team, 2020. QGIS Geographic Informationunit System. Open Source Geospatial Foundation Project. http://qgis.osgeo.org

Qie, R.Q., 2009. Oil and gas geological condition and prospect evaluation in the peripheral down- faulted basins group of Mesozoic and Cenozoic era, Daqing Exploration Area. Doctoral dissertation, Dissertation for Ph.D. degree. Jilin University, Changchun (in Chinese with English abstract).

Qiu, J.X., Liao, Q.A., Liu, M.H., 1991. Potassium-rich volcanic rocks in WudalianchiKeluo-Erkeshan. China University of Geosciences Press, Wuhan, 85-95 (in Chinese).

Qiu, Z.L., Yang, J.H., Yang, S.F., Yang, S., Li, C., Wang, Y., Yang, X., 2007. Trace element and Hafnium isotopes of Cenozoic basalt-related zircon megacrysts at Muffling, Heilongjiang province. Northeast China. Acta Petrologica Sinica, 23(2), 481-492 (in Chinese with English abstract).

Ratschbacher, L., Hacker, B.R., Calvert, A., Webb, L.E., Grimmer, J.C., McWilliams, M.O., $\mathrm{Hu}$, J., 2003. Tectonics of the Qinling (Central China): tectonostratigraphy, geochronology, and deformation history. Tectonophysics 366 (1-2), 1-53.

Reiners, P.W., 2005. Zircon (U-Th)/He thermochronometry. Reviews in Mineralogy and Geochemistry, 58(1), 151-179.

Reiners, P.W., Spell, T.L., Nicolescu, S., Zanetti, K.A., 2004. Zircon (U-Th)/He thermochronometry: He diffusion and comparisons with 40Ar/39Ar dating. Geochimica et cosmochimica acta, 68(8), 1857-1887.

Ren, F.H., Yang, X.P., Li, Y.C., Wang, Y., Zhou, X.F. 2005. Chronostratigraphic division of the Jixi Group in eastern Heilongjiang Province and its geological significance. Chinese Geology (1), 5 (in Chinese with English abstract). 
Ren, J., Tamaki, K., Li, S., Junxia, Z., 2002. Late Mesozoic and Cenozoic rifting and its dynamic setting in Eastern China and adjacent areas. Tectonophysics, 344(3-4), 175205.

Ren, J., Tamaki, K., Li, S., Z, J.X., 2002. Late Mesozoic and Cenozoic rifting and its dynamic setting in Eastern China and adjacent areas. Tectonophysics 344 (3-4), 175205.

Ren, J.S., Niu, B.G., Wang, J., He, Z.J., Jin, X.C., Xie, L.Z., Yang, F.L. 2013. 1: 5 million international geological maps of Asia. Diqiu Xuebao (Acta Geoscientica Sinica) 34 (1), 24-30 (in Chinese with English Abstract).

Renne, P.R., 2000. K-Ar and 40Ar/39Ar dating. Quaternary geochronology, 77-100.

Rubatto, D., Williams, I.S., Buick, I.S., 2001. Zircon and monazite response to prograde metamorphism in the Reynolds Range, central Australia. Contributions to Mineralogy and Petrology, 140(4), 458-468.

Safonova, I.Y., Utsunomiya, A., Kojima, S., Nakae, S., Tomurtogoo, O., Filippov, A.N., Koizumi, K., 2009. Pacific superplume-related oceanic basalts hosted by accretionary complexes of Central Asia, Russian Far East and Japan. Gondwana Research, 16(3-4), 587-608.

Safonova, I., Seltmann, R., Kroner, A., Gladkochub, D., Schulmann, K., Xiao, W., Sun, M., 2011. A new concept of continental construction in the Central Asian Orogenic Belt. Episodes 34 (3), 186-196.

Sato, K., Vrublevsky, A.A., Rodionov, S.M., Romanovsky, N.P., Nedachi, M., 2002. MidCretaceous Episodic Magmatism and Tin Mineralization in Khingan-Okhotsk Volcano-Plutonic Belt, Far East Russia. Resource Geology, 52(1), 1-14.

Saylor, J.E., Knowles, J.N., Horton, B.K., Nie, J., Mora, A., 2013. Mixing of source populations recorded in detrital zircon $\mathrm{U}-\mathrm{Pb}$ age spectra of modern river sands. The Journal of Geology, 121(1), 17-33.

Şengör, A.M.C., Natal'In, B.A., Burtman, V.S., 1993. Evolution of the Altaid tectonic collage and Palaeozoic crustal growth in Eurasia. Nature, 364(6435), 299-307.

Sengör, A.M.C., Natal'in, B.A., 1996. Paleotectonics of Asia: fragments of a synthesis. In: Yin, A., Harrison, M. (Eds.), The Tectonic Evolution of Asia. Cambridge University Press, Cambridge pp. 486-641.

Sha, J.G., 2002. Major achievements in studying the Early Cretaceous biostratigraphy of eastern Heilongjiang [J]. Earth Science Frontiers 9 (39): 95-101. 
Sha, J.G., Matsukawa, M., Cai, H., Jiang, B., Ito, M., He, C., Gu, Z., 2003. The Upper Jurassic-Lower Cretaceous of eastern Heilongjiang, northeast China: stratigraphy and regional basin history. Cretaceous Research 24 (6), 715-728.

Sha, J.G., Wang, J., Kirillova, G., Pan, Y., Cai, H., Wang, Y., Peng, B., 2009. Upper Jurassic and lower cretaceous of Sanjiang-Middle Amur basin: Non-marine and marine correlation. Science in China Series D: Earth Sciences 52 (12), 1873 (in Chinese with English Abstract).

Shi, L., Zheng, C.Q., Yao, W.G., Li, J., Cui, F.H., Cao, F., Cao, Y., Xu, J.L., Han, X.M., 2015. Geochronological framework and tectonic setting of the granitic magmatism in the Chaihe-Moguqi region, central Great Xing'an Range, China. Journal of Asian Earth Sciences 113, 443-453.

Shuster, D.L., Flowers, R.M., Farley, K.A., 2006. Radiation damage and helium diffusion kinetics in apatite. Geochimica et Cosmochimica Acta, 70(18), A590.

Silverman, B., 1986. Density Estimation for Statistics and Data Analysis. Chapman and Hall, London.

Song, Y., Ren, J., Stepashko, A.A., Li, J., 2014. Post-rift geodynamics of the Songliao Basin, NE China: Origin and significance of T11 (Coniacian) unconformity. Tectonophysics 634, 1-18.

Spencer, C.J., Kirkland, C.L., Roberts, N.M., 2018. Implications of erosion and bedrock composition on zircon fertility: Examples from South America and Western Australia. Terra Nova, 30(4), 289-295.

Spencer, C.J., Roberts, N.M.W., Santosh, M., 2017. Growth, destruction, and preservation of Earth's continental crust. Earth-Science Reviews, 172, 87-106.

Spiegel, C., Kohn, B., Belton, D., Berner, Z., Gleadow, A., 2009. Apatite (U-Th-Sm)/He thermochronology of rapidly cooled samples: the effect of He implantation. Earth and Planetary Science Letters 285 (1-2), 105-114.

Stepashko, A.A., 2006. The Cretaceous dynamics of the Pacific Plate and stages of magmatic activity in northeastern Asia. Geotectonics 40 (3), 225-235.

Stepashko, A.A., 2008. Spreading cycles in the Pacific Ocean. Oceanology 48 (3), 401-408.

Sun, D.Y., Gou, J., Wang, T.H., Ren, Y.S., Liu, Y.J., Guo, H.Y., Hu, Z.C., 2013.

Geochronological and geochemical constraints on the Erguna massif basement, NE China-subduction history of the Mongol-Okhotsk oceanic crust. International Geology Review, 55(14), 1801-1816. 
Sun, D.Y., Wu, F.Y., Gao, S., Lu, X.P., 2005. Confirmation of two episodes of A-type granite emplacement during Late Triassic and Early Jurassic in the central Jilin Province, and their constraints on the structural pattern of Eastern Jilin-Heilongjiang Area, China. Earth Science Frontiers, 12(2), 263-275.

Sun, D.Y., Wu, F.Y., Zhang, Y.B., Gao, S., 2004. The final closing time of the west Lamulun River-Changchun-Yanji plate suture zone: Evidence from the Dayushan granitic pluton, Jilin Province. Journal of Jilin University (Earth Science Edition), 34(2), 174181 (in Chinese with English abstract).

Sun, G., Zheng, S.L., 2000. New proposal on division and correlation of Mesozoic from northeastern China. Journal of Stratigraphy 24 (1), 60-64 (in Chinese with English Abstract).

Sun, X.M., Wang, S.Q., Wang, Y.D., Du, J.Y., Xu, Q.W., 2010. The structural feature and evolutionary series in the northern segment of Tancheng-Lujiang fault zone. Acta Petrologica Sinica 26 (1), 165-176 (in Chinese with English Abstract).

Tang, J., Xu, W.L., Wang, F., Wang, W., Xu, M.J., Zhang, Y.H., 2013. Geochronology and geochemistry of Neoproterozoic magmatism in the Erguna Massif, NE China: petrogenesis and implications for the breakup of the Rodinia supercontinent. Precambrian Research, 224, 597-611.

Tang, J., Xu, W., Wang, F., Ge, W., 2018. Subduction history of the Paleo-Pacific slab beneath Eurasian continent: Mesozoic-Paleogene magmatic records in Northeast Asia. Science China Earth Sciences, 61(5), 527-559.

Tang, K.D., Wang, Y., He, G.Q., 1995. Continental-margin structure of Northeast China and its adjacent areas. Acta Geologica Sinica 69 (1):16-30 (in Chinese with English Abstract).

Tian, Z.Y, Han, P., 1993. Analysis of the structures of Mesozoic and Cenozoic oil gas bearing Basins in northeastern China and the mechanism of their production. Petroleum Exploration and Development, 20(4), 2-4. (in Chinese with English Abstract)

Tian, Z.Y., Han, P., Xu, K.D., 1992. The Mesozoic-Cenozoic East China rift system. Tectonophysics 208 (1-3), 341-363.

U.S. Geological Survey, 2017, Digital Elevation, STRM 1 Arc-Second Global, accessed March 22, 2018 at URL https://earthexplorer.usgs.gov/

Van der Voo, R., Spakman, W., Bijwaard, H., 1999. Mesozoic subducted slabs under Siberia. Nature, 397(6716), 246-249. 
Vermeesch, P., 2012. On the visualisation of detrital age distributions. Chemical Geology, v.312-313, 190-194, doi: 10.1016/j.chemgeo.2012.04.0210

von Eynatten, H., and Dunkl, I., 2012. Assessing the sediment factory: the role of single grain analysis. Earth-Science Reviews, 115(1-2), 97-120.

Wang, C.W., Jin, W., Zhang, X.Z., Ma, Z.H., Chi, X.G., Liu, Y.J., Li, N., 2008. New understanding of the Late Paleozoic tectonics in northeastern China and adjacent areas. Journal of Stratigraphy, 32(2), 119-136 (in Chinese with English Abstract).

Wang, F., Xu, W.L., Gao, F.H., Zhang, H.H., Pei, F.P., Zhao, L., Yang, Y., 2014. Precambrian terrane within the Songnen-Zhangguangcai Range Massif, NE China: Evidence from $\mathrm{U}-\mathrm{Pb}$ ages of detrital zircons from the Dongfengshan and Tadong groups. Gondwana Research, 26(1), 402-413.

Wang, F., Xu, W.L., Ge, W.C., Yang, H., Pei, F.P., Wu, W., 2016b. The offset distance of the Dunhua-Mishan Fault; Constraints from Paleozoic-Mesozoic magmatism within the Songnen-Zhangguangcai Range, Jiamusi, and Khanka massifs. Acta Petrologica Sinica, 32(4), 1129-1140 (in Chinese with English Abstract).

Wang, F., Zhou, X.H., Zhang, L.C., Ying, J.F., Zhang, Y.T., Wu, F.Y., Zhu, R.X., 2006. Late Mesozoic volcanism in the Great Xing'an Range (NE China): timing and implications for the dynamic setting of NE Asia. Earth and Planetary Science Letters, 251(1-2), 179-198.

Wang, J., He, Z.H., Liu, Z.J., 2006. Geochemical characteristics of Cretaceous detrital rocks and their constraint on provenance in Jixi Basin. Global Geology, 25(4), 380-384 (in Chinese with English abstract).

Wang, J.J., 2007. Study on sedimentary facies from upper Jurassic series to Lower Cretaceous series of the Suibing depression of Sanjiang area in Northeast China. Master thesis, Beijing, China University of geosciences.

Wang, P.J., Mattern, F., Didenko, N.A., Zhu, D.F., Singer, B., Sun, X.M., 2016a. Tectonics and cycle system of the Cretaceous Songliao Basin: An inverted active continental margin basin. Earth-Science Reviews 159, 82-102.

Wang, S.T, Liu, B.S., 2014. Characteristics of U--Pb chronology and geochemistry of Neoproterozoic granitic gneiss in Dongfengjingyingsuo of Yichun area. Global Geology, 33(4), 780-786 (in Chinese with English abstract).

Wang, W.T., Liu, Z.J., He, Y.P., Chen, X., 2007. Provenance of Lower Cretaceous clastic rocks in Suibin Depression Heilongjiang Province and its tectonic significance. Acta Sedimentologica Sinica, 25(2), 201 (in Chinese with English abstract). 
Wang, W.T., Liu, Z.J., Chen, X.Y., 2007. Tectonic setting and provenance analysis of Mesozoic--Cenozoic clastic rocks in northern depression of Hulin Basin. Global Geology, 26(1), 14-19 (in Chinese with English abstract).

Wang, X., Xu, D., Lv, X., Wei, W., Mei, W., Fan, X., Sun, B., 2018. Origin of the Haobugao skarn Fe-Zn polymetallic deposit, Southern Great xing'an range, NE China: Geochronological, geochemical, and $\mathrm{Sr}-\mathrm{Nd}-\mathrm{Pb}$ isotopic constraints. Ore Geology Reviews, 94, 58-72.

Wang, Z.W., 2017. Petrology and geochemistry of early Paleozoic igneous rocks in the Lesser Xing'an-Zhangguangcai Ranges: Constrains on the amalgamation history and crustal nature of the massifs. Retrieved from http://ib. jlu. edu. cn/portal/index. aspx. (in Chinese with English abstract).

Wang, Z.W., Xu, W.L., Pei, F.P., Wang, F., Guo, P., 2016. Geochronology and geochemistry of early Paleozoic igneous rocks of the Lesser Xing'an Range, NE China: implications for the tectonic evolution of the eastern Central Asian Orogenic Belt. Lithos, 261, 144-163.

Wei, H.Y., Sun, D.Y., Ye, S.Q., Yang, Y C., Liu, Z.H., Liu, X.M., Hu, Z.C., 2012. Zircon U$\mathrm{Pb}$ ages and its geological significance of the granitic rocks in the Yichun-Hegang region, southeastern Xiao Hinggan Mountains. Earth Science-Journal of China University of Geosciences, 37, 50-59 (in Chinese with English abstract).

Wen, Q.B., Liu, Y.J., Li, J.J., Bai, J.Z., Sun, X.M., Zhao, Y.L., Han, G.Q., 2008b. Provenance analysis and tectonic implications for the Cretaceous sandstones in the Jixi and Boli Basins, Heilongjiang. Sedimentary Geology and Tethyan Geology, 28(3), 52-59 (in Chinese with English abstract).

Wen, Q.B, Liu, Y.J., Han G.Q., 2008a. Mesozoic and Cenozoic tectonic evolution of the basin group in eastern Heilongjiang, China. Global Geology 27 (4): 370-377 (in Chinese with English abstract).

Wen, Q.B., Liu, Y.J., Liu, B., Han, G.Q., Zhao, Y.L., Li, W.M., Liang, C.Y., 2011. Exhumation time of Huanan-uplift of northeastern China constrained by ages of detrital minerals. Geological Bulletin of China 30 (2/3), 250-257 (in Chinese with English abstract).

Wilde S.A., Wu F.Y., Zhang X.Z., 2001.The Mashan Complex: SHRIMP U Pb zircon evidence for a Late Pan-African metamorphic event in NE China and its implication for global continental reconstructions. Geochimica,30(1): 35-50 (in Chinese with English abstract) 
Cretaceous-Cenozoic thermo-tectonic evolution and provenance analysis of the basement and some sedimentary successions northeast of the Songliao Basin, NE China

Wilde S.A., Wu F.Y., Zhang X.Z., 2003. Late Pan-African magmatismin northeastern China: SHRIMP U-Pb zircon evidence from granitoids in the Jiamusi Massif. Precambrian Research,12(1):31-327

Wilde S.A., Zhang X.Z., Wu F.Y., 2000. Extension of a newly identified 500Ma metamorphic ter rane in North East China: Further U-Pb SHRIMP dating of the Mashan Complex, Heilongjiang Province, China. Tectonophysics,328(1-2):115-130

Wilde, S.A., Wu, F.Y., Zhao, G., 2010. The Khanka Block, NE China, and its significance for the evolution of the Central Asian Orogenic Belt and continental accretion. Geological Society, London, Special Publications, 338(1), 117-137.

Windley, B.F., Alexeiev, D., Xiao, W., Kröner, A., Badarch, G., 2007. Tectonic models for accretion of the Central Asian Orogenic Belt. Journal of the Geological Society, 164(1), 31-47.

Wu, F.Y., Jahn, B.M., Wilde, S.A., Lo, C.H., Yui, T.F., Lin, Q., Sun, D.Y., 2003. Highly fractionated I-type granites in NE China (II): isotopic geochemistry and implications for crustal growth in the Phanerozoic. Lithos, 67(3-4), 191-204.

Wu, F.Y., Li, Z., Wen, Z.C., Zhou, N., Zhao, Y.F., Jiang, Y.B., 2002. A novel thiourea-based dual fluorescent anion receptor with a rigid hydrazine spacer. Organic letters, 4(19), 3203-3205.

Wu, F.Y., Sun, D.Y., Ge, W.C., Zhang, Y.B., Grant, M.L., Wilde, S.A., Jahn, B.M., 2011. Geochronology of the Phanerozoic granitoids in northeastern China. Journal of Asian Earth Sciences, 41(1), 1-30.

Wu, F.Y., Sun, D.Y., Li, H.M., Wang, X.L., 2001. The nature of basement beneath the Songliao Basin in NE China: geochemical and isotopic constraints. Physics and Chemistry of the Earth, Part A: Solid Earth and Geodesy, 26(9-10), 793-803.

Wu, F.Y., Yang, J.H., Lo, C.H., Wilde, S.A., Sun, D.Y., Jahn, B.M., 2007. The Heilongjiang Group: a Jurassic accretionary complex in the Jiamusi Massif at the western Pacific margin of northeastern China. Island Arc, 16(1), 156-172.

Wu, G., Chen, Y.C., Sun, F.Y., Liu, J., Wang, G.R., 2015. Geochronology, geochemistry, and Sr-Nd-Hf isotopes of the early Paleozoic igneous rocks in the Duobaoshan area, NE China, and their geological significance. Journal of Asian Earth Sciences 97, 229250.

Xiang, C., Feng, Z., Pang, X., Wu, H., Li, J., 2007. Late stage thermal history of the Songliao Basin and its tectonic implications: Evidence from apatite fission track (AFT) 
analyses. Science in China Series D: Earth Sciences 50 (10), 1479-1487 (in Chinese with English abstract).

Xiao, W.J., Kröner, A., Windley, B., 2009. Geodynamic evolution of Central Asia in the Paleozoic and Mesozoic. International Journal of Earth Sciences 98, 1185-1188.

Xie, R.J., Qin, G., Li, X.Y., 2009. Study on sedimentary facies for Qingshankou Formation in Qianqihao Area of Changling Sag in Songliao Basin [J] Special Oil \& Gas Reservoirs 5 (in Chinese with English abstract).

Xu, W.L., Pei, F.P., Wang, F., Meng, E., Ji, W.Q., Yang, D.B., Wang, W., 2013. Spatialtemporal relationships of Mesozoic volcanic rocks in NE China: constraints on tectonic overprinting and transformations between multiple tectonic regimes. Journal of Asian Earth Sciences 74, 167-193.

Xu, Y.G., Fan, Q.C., 2015. Cenozoic valcanism in Eastern China: Review and perspectives. Bulletin of Mineralogy, Petrology and Geochemistry, 34(4), 682-689. (in Chinese with English abstract)

Xu, Y.G., Zhang, H.H., Qiu, H.N., Ge, W.C., Wu, F.Y., 2012. Oceanic crust components in continental basalts from Shuangliao, Northeast China: derived from the mantle transition zone? Chemical Geology, 328, 168-184.

Xu, W.L., Sun, C.Y., Tang, J., Luan, J.P., Wang, F., 2019. Basement nature and tectonic evolution of the Xing'an Mongolian Orogenic Belt. Earth Science, 44(5): 1620-1646 (in Chinese with English abstract).

Yang, F.P., Chen, F.J., Wang, Y.H., 1995. Apatite fission track analysis in the central depression, Songliao Basin. Petroleum Exploration and Development 22, 20-25 (in Chinese with English abstract).

Yang, H., Ge, W.C., Bi, J.H., Wang, Z.H., Tian, D.X., Dong, Y., Chen, H.J., 2018. The Neoproterozoic-early Paleozoic evolution of the Jiamusi Block, NE China and its East Gondwana connection: Geochemical and zircon $\mathrm{U}-\mathrm{Pb}-\mathrm{Hf}$ isotopic constraints from the Mashan Complex. Gondwana Research, 54, 102-121.

Yang, H., Ge, W.C., Yu, Q., Ji, Z., Liu, X.W., Zhang, Y.L., Tian, D.X., 2016. Zircon U-PbHf isotopes, bulk-rock geochemistry and petrogenesis of Middle to Late Triassic Itype granitoids in the Xing'an Block, northeast China: Implications for early Mesozoic tectonic evolution of the central Great Xing'an Range. Journal of Asian Earth Sciences, 119, 30-48.

Yang, H., Ge, W.C., Zhao, G.C., Bi, J.H., Wang, Z.H., Dong, Y., Xu, W.L., 2017. Zircon U$\mathrm{Pb}$ ages and geochemistry of newly discovered Neoproterozoic orthogneisses in the 
Mishan region, NE China: Constraints on the high-grade metamorphism and tectonic affinity of the Jiamusi-Khanka Block. Lithos, 268, 16-31.

Yang, H., Ge, W.C., Zhao, G.C., Dong, Y., Bi, J.H., Wang, Z.H., Zhang, Y.L., 2014. Geochronology and geochemistry of Late Pan-African intrusive rocks in the JiamusiKhanka Block, NE China: petrogenesis and geodynamic implications. Lithos, 208, 220-236.

Yang, H., Ge, W.C., Zhao, G.C., Dong, Y., Xu, W.L., Ji, Z., Yu, J.J., 2015. Late Triassic intrusive complex in the Jidong region, Jiamusi-Khanka Block, NE China: Geochemistry, zircon U-Pb ages, Lu-Hf isotopes, and implications for magma mingling and mixing. Lithos 224, 143-159.

Yang, Y.T., 2013. An unrecognized major collision of the Okhotomorsk Block with East Asia during the Late Cretaceous, constraints on the plate reorganization of the Northwest Pacific. Earth-Science Reviews 126, 96-115.

Ying, J.F., Zhou, X.H., Zhang, L.C., Wang, F., Zhang, Y.T., 2010. Geochronological and geochemical investigation of the late Mesozoic volcanic rocks from the Northern Great Xing'an Range and their tectonic implications. International Journal of Earth Sciences, 99(2), 357-378.

Yu, J.J., Wang, F., Xu, W.L., Gao, F.H., Pei, F.P., 2012. Early Jurassic mafic magmatism in the Lesser Xing'an-Zhangguangcai Range, NE China, and its tectonic implications: constraints from zircon $\mathrm{U}-\mathrm{Pb}$ chronology and geochemistry. Lithos, 142, 256-266.

Yu, J.J., Zhang, Y.L., Ge, W.C., Yang, H., 2013. Geochronology and geochemistry of the Late Cretaceous granitoids in the northern margin of the Sanjiang basin, NE China and its tectonic implications. Acta Petrologica Sinica 29 (2), 369-385 (in Chinese with English Abstract).

Zhang, F.Q., Chen, H.L., Yang, S.F., Feng, Z.Q., Wu, H.Y., Batt, G.E., Yang, J.G., 2012. Late Mesozoic-Cenozoic evolution of the Sanjiang Basin in NE China and its tectonic implications for the West Pacific continental margin. Journal of Asian Earth Sciences 49, 287-299.

Zhang, F., Chi, Y.L., Wang, D.P., 1999. Dynamic of Cenozoic-Mesozoic Basin Formation on Northeast China-The mantle plume and its adjustment are the primary driving force causing for basin formation. World Geology (4), 4.

Zhang, F.Q., Chen, H.L., Yu, X., Dong, C.W., Yang, S.F., Pang, Y.M., Batt, G.E., 2011. Early Cretaceous volcanism in the northern Songliao Basin, NE China, and its geodynamic implication. Gondwana Research 19 (1), 163-176. 
Zhang, H.H., Xu, Y.G., Ge, W.C., Ma, J.L., 2006. Geochemistry of late Mesozoic-Cenozoic basalts in Yitong-Datun area, Jilin Province and its implication. Acta Petrologica Sinica, 22(6), 1579-1596 (in Chinese with English abstract).

Zhang, X.D., Wang, Y., Li, G.R., 2005. Formation, Evolution and Earth Dynamics of Jurassic and Cretaceous Basins in Northern China. Petroleum Geology \& Oilfield Development in Daqing 5 (in Chinese with English Abstract).

Zhang, X.Z., Guo, Y., Zeng, Z., Fu, Q.L., Pu, J.B., 2015. Dynamic evolution of the Mesozoic-Cenozoic basins in the northeastern China. Earth Science Frontiers 22 (3), 88-98 (in Chinese with English abstract).

Zhang, X.Z., Ma, Z.H., 2010. Evolution of Mesozoic-Cenozoic basins in the eastern Heilongjiang province, northeast China. Geology and Resources 19 (3), 191-196 (in Chinese with English abstract).

Zhang, Y.T., Sun, F.Y., Wang, S., Xin, W., 2018. Geochronology and geochemistry of Late Jurassic to Early Cretaceous granitoids in the northern Great Xing'an Range, NE China: Petrogenesis and implications for late Mesozoic tectonic evolution. Lithos, $312,171-185$.

Zhang, Y.Q., Zhao, Y., Dong, S.W., 2004. Tectonic evolution stages of the Early Cretaceous rift basins in Eastern China and adjacent areas and their geodynamic background. Earth Science Frontiers 11, 123-134.

Zhang, Z.C., Li, Z.N., Li, S.C., Xin, Y., Li, Z.M., Wang, X.Z., 2000. Geochemistry of the Jingpohu Holocene basaltic rocks, Hellongjiang province, and discussion on their deep processes. Acta Petrologica Sinica, 16(3), 327-336 (in Chinese with English abstract).

Zhao, B., Wang, C., Wang, X., Feng, Z., 2013. Late Cretaceous (Campanian) provenance change in the Songliao Basin, NE China: Evidence from detrital zircon $\mathrm{U}-\mathrm{Pb}$ ages from the Yaojia and Nenjiang FormationUnits. Palaeogeography, Palaeoclimatology, Palaeoecology, 385: 83-94.

Zhao, D., Ge, W., Yang, H., Dong, Y., Bi, J., He, Y., 2018. Petrology, geochemistry, and zircon $\mathrm{U}-\mathrm{Pb}-\mathrm{Hf}$ isotopes of Late Triassic enclaves and host granitoids at the southeastern margin of the Songnen-Zhangguangcai Range Massif, Northeast China: Evidence for magma mixing during subduction of the Mudanjiang oceanic plate. Lithos, 312, 358-374. 
Zhao, G., Wilde, S.A., Cawood, P.A., Sun, M., 2001. Archean blocks and their boundaries in the North China Craton: lithological, geochemical, structural and $\mathrm{P}-\mathrm{T}$ path constraints and tectonic evolution. Precambrian Research, 107(1-2), 45-73.

Zhao, L.L., 2011. The evidence of petrology and geochronology on tectonic evolution of Heilongjiang Complex in eastern Heilongjiang Province, China. Ph.D. Dissertation. Changchun: Jilin University (in Chinese with English summary).

Zhao, L., Zhang, X., 2011. Petrological and geochronological evidences of tectonic exhumation of Heilongjiang complex in the eastern part of Heilongjiang Province, China. Acta Petrologica Sinica 27 (4), 1227-1234 (in Chinese with English Abstract).

Zhao, S., Xu, W.L., Tang, J., Li, Y., Guo, P., 2016. Timing of formationunit and tectonic nature of the purportedly Neoproterozoic Jiageda FormationUnit of the Erguna Massif, NE China: Constraints from field geology and $\mathrm{U}-\mathrm{Pb}$ geochronology of detrital and magmatic zircons. Precambrian Research, 281, 585-601.

Zhao, X.Q., 2011. Features of Structure Deformation and Evolution of Mesozoic-Cenozoic basins in Eastern Heilongjiang. Doctoral dissertation, Dissertation for Ph.D. degree. Zhejiang University, Hangzhou (in Chinese with English abstract).

Zhao, Y.W., Fan, Q.C., Bai, Z.D., Sun, Q., Li, N., Sui, J.L., Du, X.X., 2008. Preliminary study on Quaternary volcanoes in the Halaha River and Chaoer River area in Daxing'an Mountain range. Acta Petrologica Sinica, 24(11), 2569-2575 (in Chinese with English abstract).

Zheng, C.Q., Xu, W.L., Wang, D.Y., 1999. The petrology and mineral chemistry of the deepseated xenoliths in Mesozoic basalt in Fuxin district from western Liaoning. Acta Petrologica Sinica, 25(4), 616 (in Chinese with English abstract).

Zhou, C.Y., Wu, F.Y., Ge, W.C., Sun, D.Y., Rahman, A.A., Zhang, J.H., Cheng, R.Y. 2005. Age, geochemistry and petrogenesis of the cumulate gabbro in Tahe, northern Da Hinggan Mountain (in Chinese with English abstract).

Zhou, J.B., Wang, B., Wilde, S.A., Zhao, G.C., Cao, J.L., Zheng, C.Q., Zeng, W.S., 2015. Geochemistry and $\mathrm{U}-\mathrm{Pb}$ zircon dating of the Toudaoqiao blueschists in the Great Xing'an Range, northeast China, and tectonic implications. Journal of Asian Earth Sciences, 97: 197-210.

Zhou, J.B., Wilde, S.A., Zhang, X.Z., Zhao, G.C., Zheng, C.Q., Wang, Y.J., Zhang, X.H., 2009. The onset of Pacific margin accretion in NE China: evidence from the Heilongjiang high-pressure metamorphic belt. Tectonophysics, 478(3-4), 230-246. 
Zhou, J., Liu, Y., Li, W., Wen, Q., Liang, C., Feng, Z., 2019. Eastern extension of the Solonker-Xar Moron-Changchun-Yanji Suture Zone: Constraints from thermochronology of sedimentary and mafic rocks in the Hunchun-Yanji area, Northeast China. Geological Journal, 54(2), 679-697.

Zhou, J.B., Wilde, S.A., 2013. The crustal accretion history and tectonic evolution of the NE China segment of the Central Asian Orogenic Belt. Gondwana Research 23, 13651377.

Zhou, X.H., 2006. Major transformation of subcontinental lithosphere beneath eastern China in the Cenozoic-Mesozoic: review and prospect. Dixue Qianyuan/ Earth Science Frontiers, 13(2), 50-64. (in Chinese with English abstract)

Zhou, X.M., Li, W.X., 2000. Origin of Late Mesozoic igneous rocks in Southeastern China: implications for lithosphere subduction and underplating of mafic magmas. Tectonophysics, 326(3-4), 269-287.

Zhu, C.Y., Zhao, G., Sun, M., Eizenhöfer, P.R., Han, Y., Liu, Q., Liu, D.X., 2017. Subduction between the Jiamusi and Songliao blocks: Geochronological and geochemical constraints from granitoids within the Zhangguangcailing orogen, northeastern China. Lithosphere, 9(4), 515-533.

Zorin, Y.A., Mordvinova, V.V., Turutanov, E.K., Belichenko, B.G., Artemyev, A.A., Kosarev, G.L., Gao, S.S., 2002. Low seismic velocity layers in the Earth's crust beneath Eastern Siberia (Russia) and Central Mongolia: receiver function data and their possible geological implication. Tectonophysics, 359(3-4), 307-327.

Zou, H., Fan, Q., Yao, Y., 2008. U-Th systematics of dispersed young volcanoes in NE China: asthenosphere upwelling caused by piling up and upward thickening of stagnant Pacific slab. Chemical Geology, 255(1), 134-142 (in Chinese with English abstract).

Zou, H., Zindler, A., Xu, X., Qi, Q., 2000. Major, trace element, and Nd, Sr and Pb isotope studies of Cenozoic basalts in SE China: Mantle sources, regional variations and tectonic significance. Chemical Geology, 171: 33-47. 
Cretaceous-Cenozoic thermo-tectonic evolution and provenance analysis of the basement and some sedimentary successions northeast of the Songliao Basin, NE China

\section{Appendix}

\section{Manuscript I: Supplementary data}
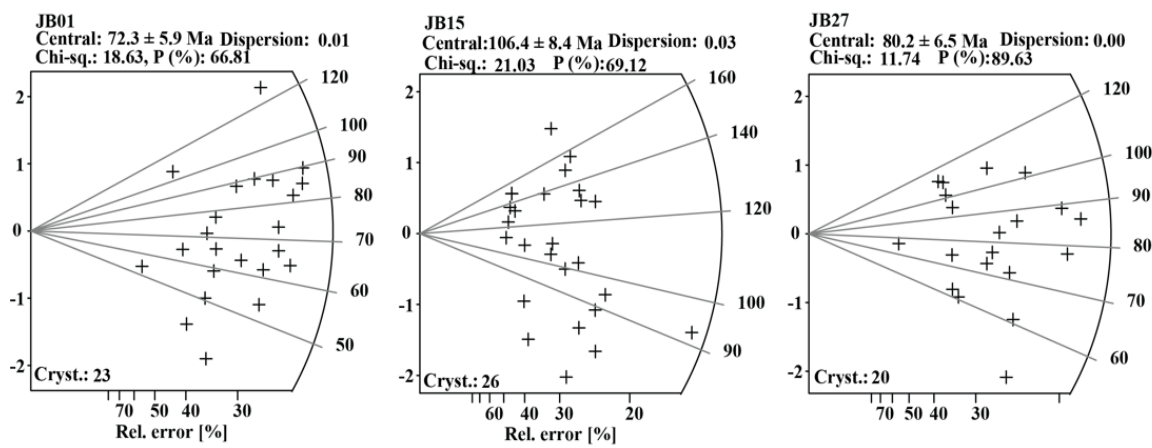

JB29

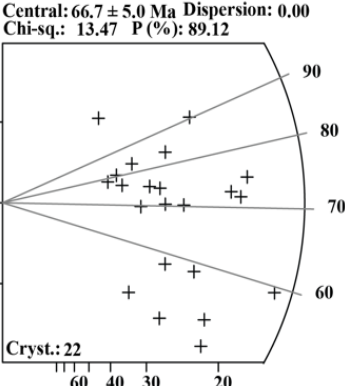

JB17
Central: $82.1 \pm 8.3$ Dispersion: 0.02

JB20
Central: $75.8 \pm 11.5$ Dispersion: 0.00

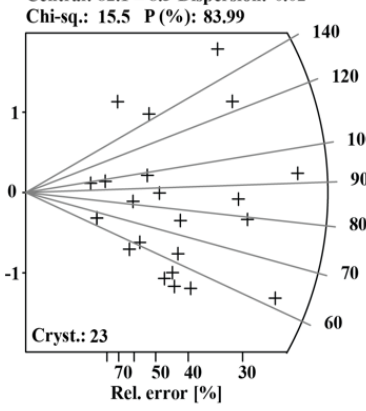

Chi-sq.: $3.78 \quad \mathrm{P}(\%): 58.11$

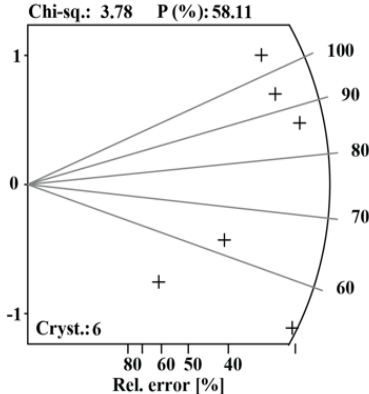

Chi-sq.: $28.29 \quad$ P (\%):24.8

JB30B

Central: $61.1 \pm 4.8 \mathrm{Ma}$ Dispersion: 0.09

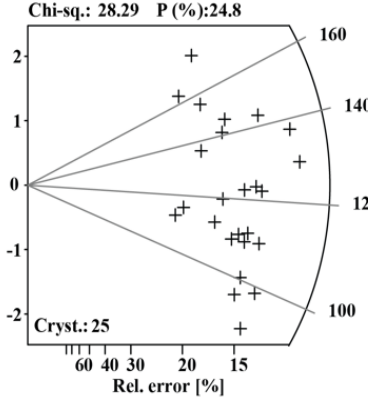

Chi-sq.: 24.15 P (\%): 33.96

Central: $55.3 \pm 5.4$ Ma Dispersion: 0.01

Chi-sq.:14.34 $\quad \mathbf{P}(\%) 85.45$

JB36
Central: $55.7 \pm 3.4$ Ma Dispersion: 0.01

Central: $55.7 \pm 3.4 \mathrm{Ma} \quad$ Dispersion: 0.01

JB39

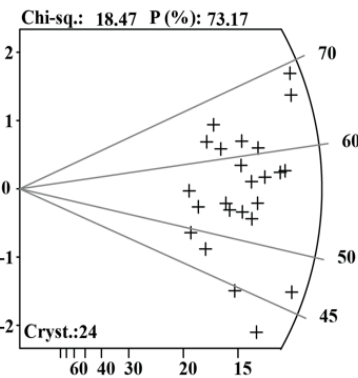

62.1 $4.2 \mathrm{Ma}$ Dispersion: 0.00

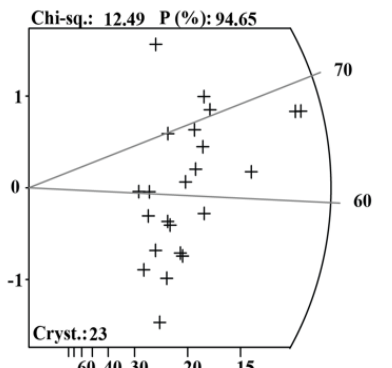

Central: $60.5 \pm 4.2$ Ma Dispersion: 0.01

Chi-sq.: $19.25 \quad P(\%)$ : 68.65

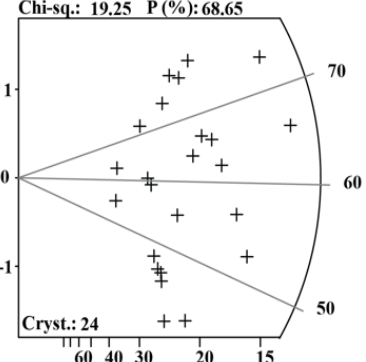

JB53

Central:53.8 $4.3 \mathrm{Ma}$ Dispersion: 0.03
Chi-sq.: 22.6 P (\%):
48.43

Central: $119.5 \pm 9.3 \mathrm{Ma}$ Dispersion: 0.06
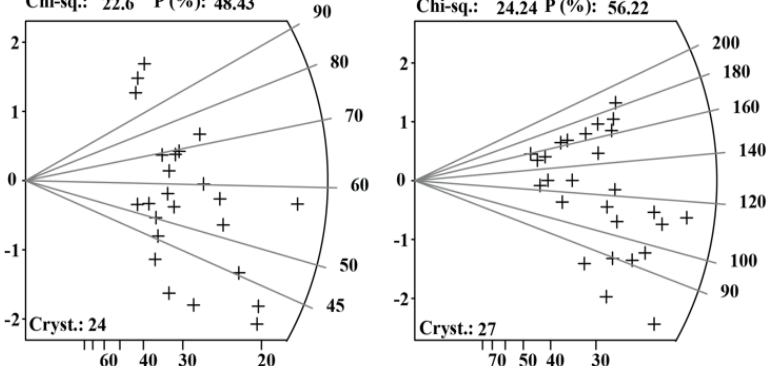

Appendix Figure 2.1: Radial plots generated from the AFT single-grain ages of 14 basement samples. 


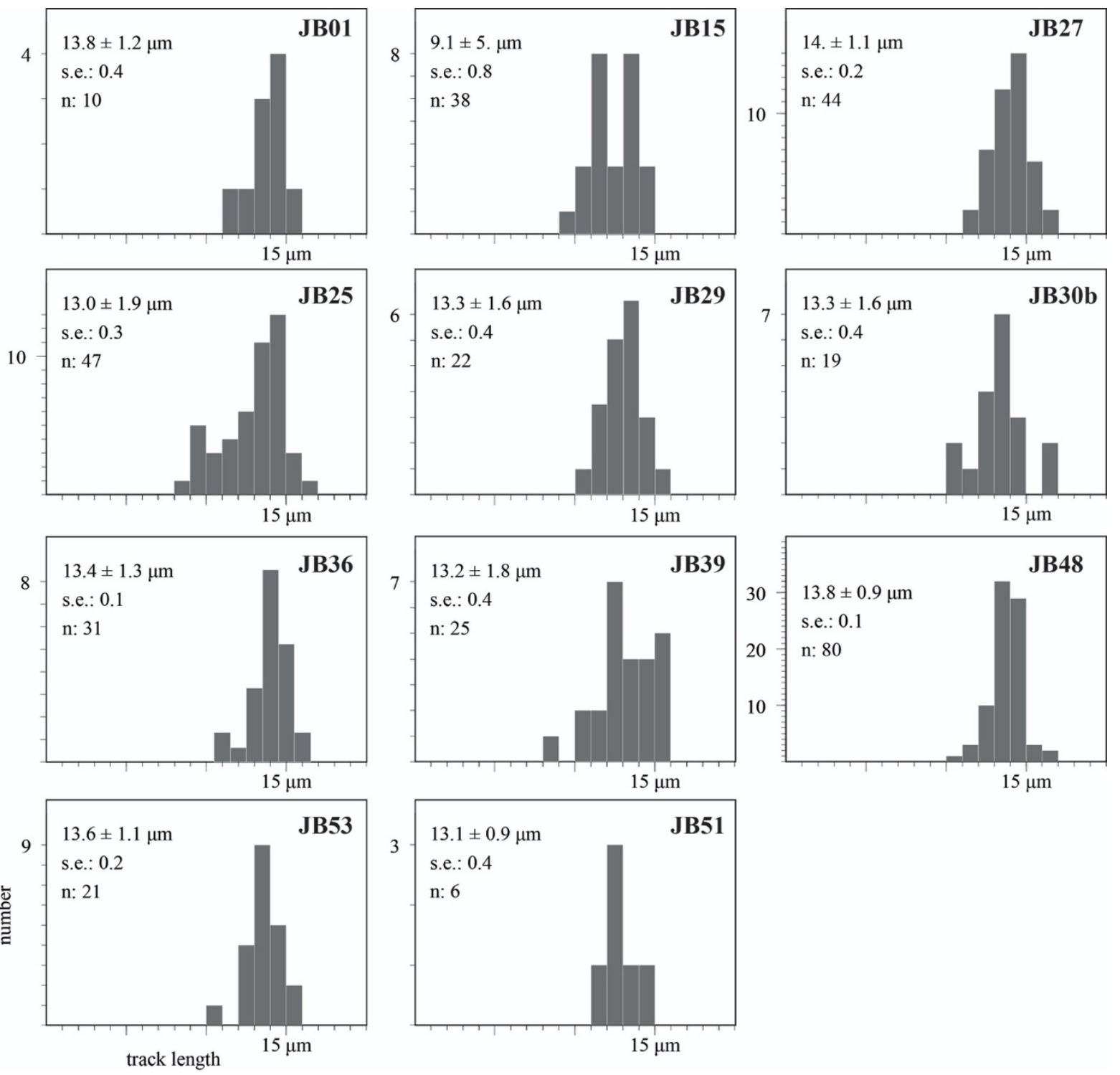

Appendix Figure 2.2: Distribution of confined horizontal fission track lengths measured in apatite of the basement samples. 


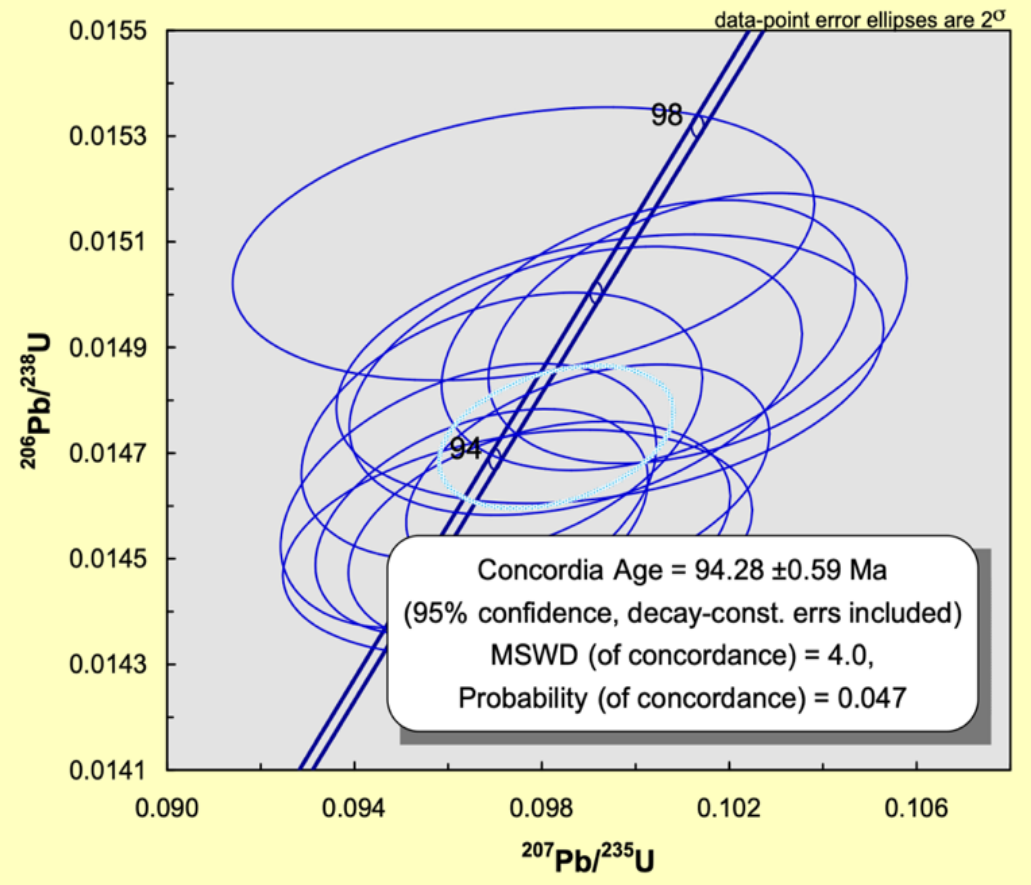

Appendix Figure 2. 3: Concordia plot of laser ablation ICPMS zircon U-Pb data obtained on sample JB27.

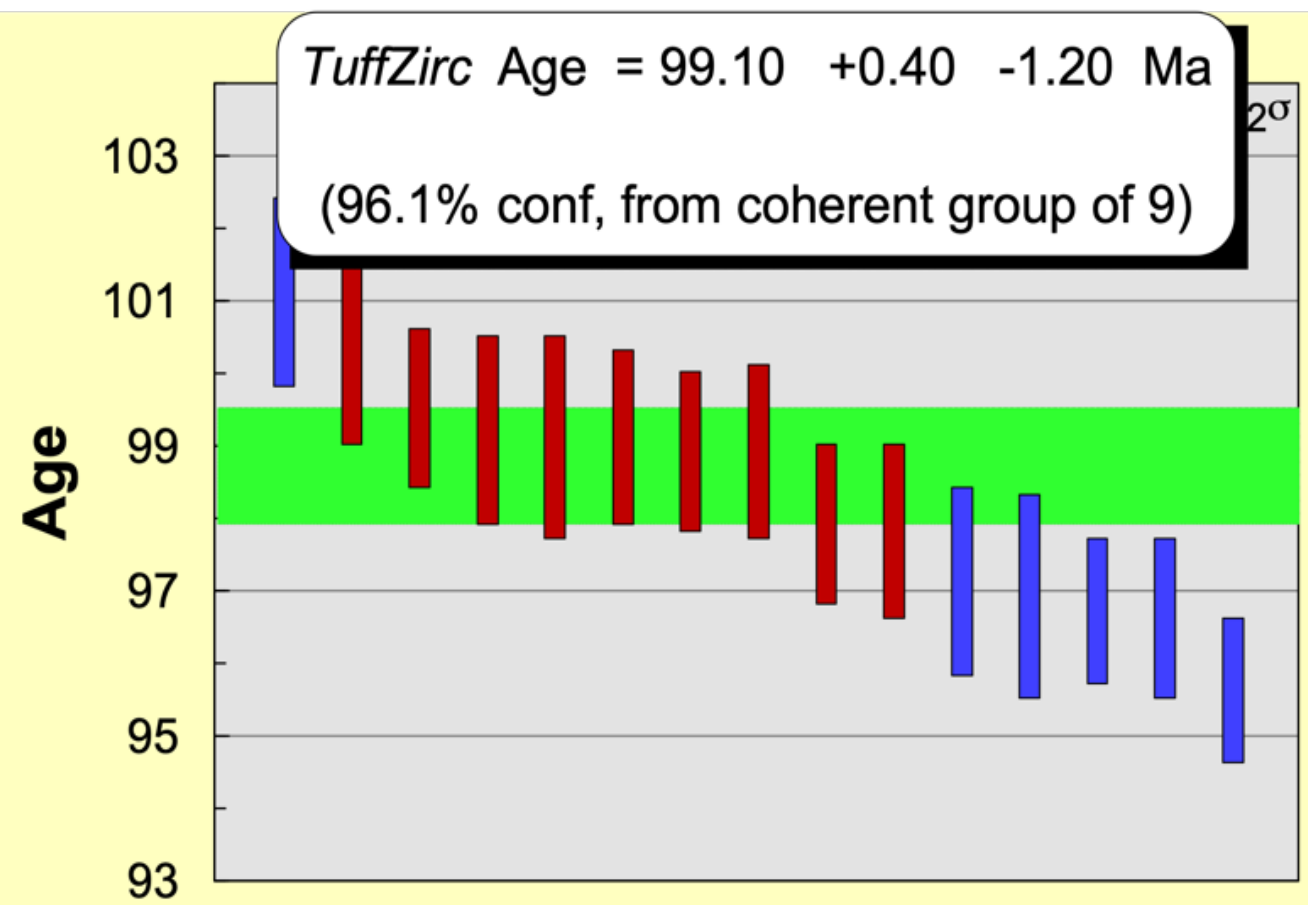

Appendix Figure 2.4: Single-grain U-Pb ages obtained on sample JB28. 
Appendix Table 2.1: Vitrinite reflectance values used for the thermal / subsidence modelling

\begin{tabular}{|c|c|c|c|c|c|c|c|c|}
\hline \multicolumn{3}{|c|}{ Sanjiang basin BinCan1 } & \multicolumn{3}{|c|}{ Sanjiang basin Bin 1} & \multicolumn{3}{|c|}{ Boli basin BoD1 } \\
\hline & Depth & Ro $\%$ & & Depth & $\mathrm{Ro} \%$ & & Depth & Ro $\%$ \\
\hline \multirow{4}{*}{$\begin{array}{c}\text { K1ds } \\
\text { (Dongshan } \\
\text { formation) }\end{array}$} & 352 & 0.7 & \multirow{7}{*}{$\begin{array}{l}\text { K1m (Muling } \\
\text { formation) }\end{array}$} & 480 & 1.06 & \multirow{27}{*}{ K1c(Chengzihe) } & 110 & 1.69 \\
\hline & 562 & 2.15 & & 603 & 1.36 & & 147 & 1.7 \\
\hline & 608 & 0.66 & & 770 & 1.62 & & 189 & 1.71 \\
\hline & 732 & 0.74 & & 886 & 1.72 & & 205 & 1.76 \\
\hline \multirow{8}{*}{$\begin{array}{l}\text { K1m (Muling } \\
\text { formation) }\end{array}$} & 1282 & 0.76 & & 1012 & 1.87 & & 219 & 1.7 \\
\hline & 1316 & 0.66 & & 1016 & 1.82 & & 255 & 1.78 \\
\hline & 1318 & 0.68 & & 1146 & 1.91 & & 310 & 1.85 \\
\hline & 1472 & 0.85 & \multirow{11}{*}{$\begin{array}{l}\text { K1c (Chengzihe } \\
\text { formation) }\end{array}$} & 1203 & 1.95 & & 328 & 1.95 \\
\hline & 1475 & 0.86 & & 1206 & 1.95 & & 356 & 2.42 \\
\hline & 1520 & 0.85 & & 1208 & 1.96 & & 379 & 3.67 \\
\hline & 1642 & 0.94 & & 1230 & 1.99 & & 423 & 2.21 \\
\hline & 1690 & 0.95 & & 1529 & 2.18 & & 493 & 0.83 \\
\hline \multirow{24}{*}{$\begin{array}{c}\text { K1c } \\
\text { (Chengzihe } \\
\text { formation) }\end{array}$} & 1807 & 1.03 & & 1532 & 2.18 & & 496 & 0.87 \\
\hline & 1910 & 1.08 & & 1540 & 2.19 & & 510 & 0.9 \\
\hline & 1998 & 1.16 & & 1541 & 2.19 & & 516 & 1.03 \\
\hline & 2140 & 1.21 & & 1544 & 2.19 & & 519 & 1.05 \\
\hline & 2142 & 1.26 & & 1591 & 2.1 & & 523 & 1.08 \\
\hline & 2142 & 1.25 & & 1877 & 2.27 & & 526 & 1.19 \\
\hline & 2200 & 1.03 & & & & & 529 & 1.32 \\
\hline & 2210 & 1.27 & & & & & 534 & 1.44 \\
\hline & 2261 & 0.63 & & & & & 546 & 2.15 \\
\hline & 2266 & 2.44 & & & & & 606 & 2.2 \\
\hline & 2307 & 1.28 & & & & & 654 & 2.22 \\
\hline & 2320 & 0.62 & & & & & 691 & 2.41 \\
\hline & 2330 & 1.62 & & & & & 755 & 2.53 \\
\hline & 2334 & 2.5 & & & & & 777 & 2.17 \\
\hline & 2389 & 1.3 & & & & & 938 & 2.37 \\
\hline & 2456 & 1.13 & & & & & & \\
\hline & 2462 & 1.94 & & & & & & \\
\hline & 2511 & 1.38 & & & & & & \\
\hline & 2580 & 1.17 & & & & & & \\
\hline & 2761 & 1.38 & & & & & & \\
\hline & 2850 & 2.45 & & & & & & \\
\hline & 2854 & 1 & & & & & & \\
\hline & 2858 & 2.84 & & & & & & \\
\hline & 2905 & 1.51 & & & & & & \\
\hline \multirow{4}{*}{$\begin{array}{l}\text { K1d (Didao } \\
\text { formation) }\end{array}$} & 3269 & 1.78 & & & & & & \\
\hline & 3273 & 1.88 & & & & & & \\
\hline & 3380 & 2.11 & & & & & & \\
\hline & 3380 & 1.93 & & & & & & \\
\hline
\end{tabular}


Cretaceous-Cenozoic thermo-tectonic evolution and provenance analysis of the basement and some sedimentary successions northeast of the Songliao Basin, NE China

Appendix Table 2.1 (continued): Vitrinite reflectance values used for the thermal / subsidence modelling

\begin{tabular}{|c|c|c|c|c|c|}
\hline \multicolumn{3}{|c|}{ Hulin basin HuCan1 } & \multicolumn{3}{|c|}{ Jixi basin Ji2 } \\
\hline & Depth & Ro\% & & Depth & Ro\% \\
\hline \multirow{21}{*}{ K1 } & 1936 & 0.65 & $\begin{array}{l}\text { K1m (Muling } \\
\text { formation) }\end{array}$ & 240 & 0.48 \\
\hline & 2006 & 1.67 & \multirow{20}{*}{$\begin{array}{l}\text { K1c (Chengzihe } \\
\text { formation) }\end{array}$} & 344 & 0.49 \\
\hline & 2265 & 2.16 & & 430 & 0.49 \\
\hline & 2401 & 2.19 & & 528 & 0.61 \\
\hline & 2674 & 2.17 & & 626 & 0.66 \\
\hline & & & & 630 & 0.68 \\
\hline & & & & 630 & 0.69 \\
\hline & & & & 631 & 0.67 \\
\hline & & & & 631 & 0.68 \\
\hline & & & & 634 & 0.69 \\
\hline & & & & 762 & 0.72 \\
\hline & & & & 831 & 0.74 \\
\hline & & & & 837 & 0.74 \\
\hline & & & & 840 & 0.77 \\
\hline & & & & 840 & 0.8 \\
\hline & & & & 952 & 0.79 \\
\hline & & & & 1008 & 0.83 \\
\hline & & & & 1009 & 0.81 \\
\hline & & & & 1009 & 0.81 \\
\hline & & & & 1019 & 0.83 \\
\hline & & & & 1128 & 0.82 \\
\hline
\end{tabular}




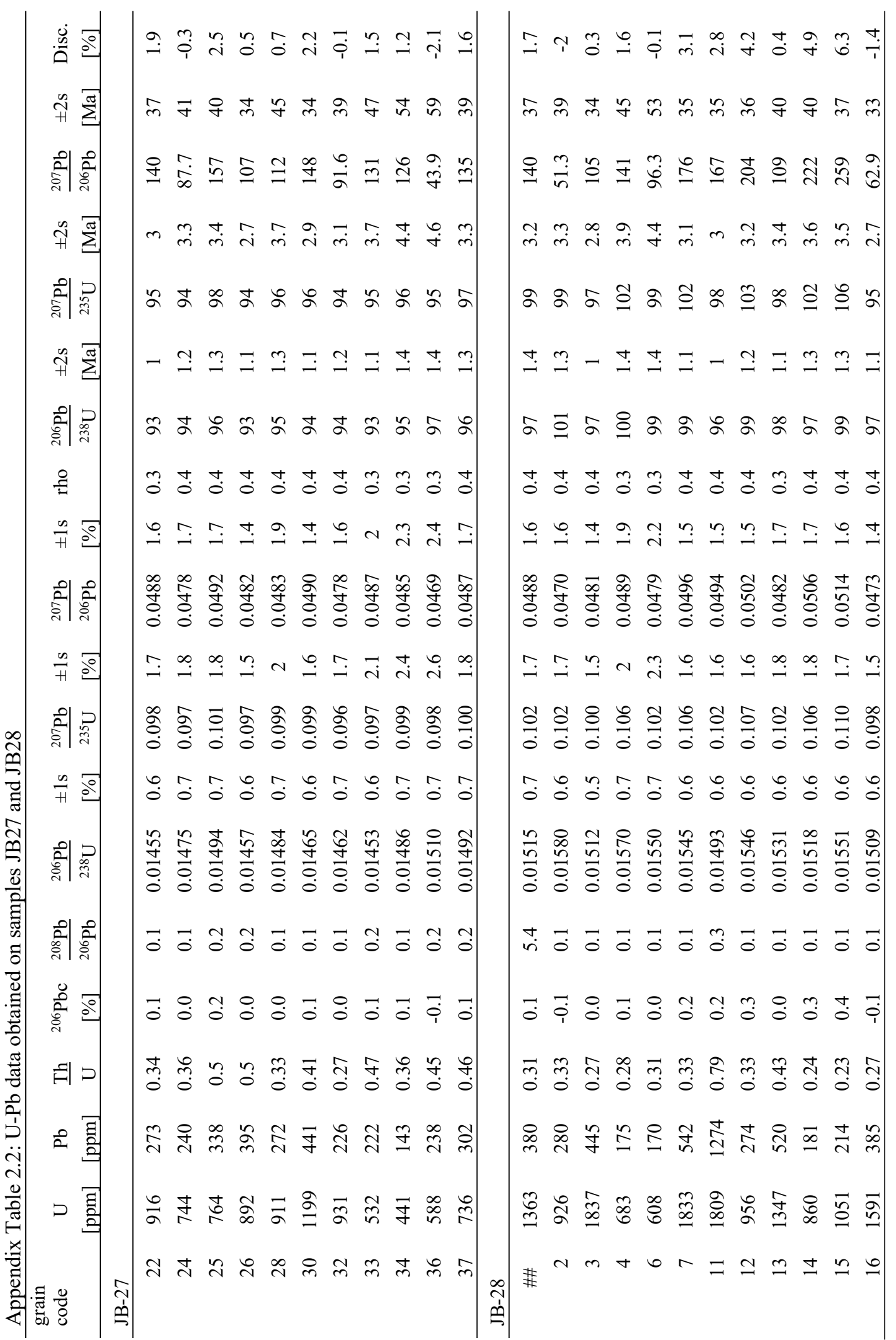


Cretaceous-Cenozoic thermo-tectonic evolution and provenance analysis of the basement and some sedimentary successions northeast of the Songliao Basin, NE China

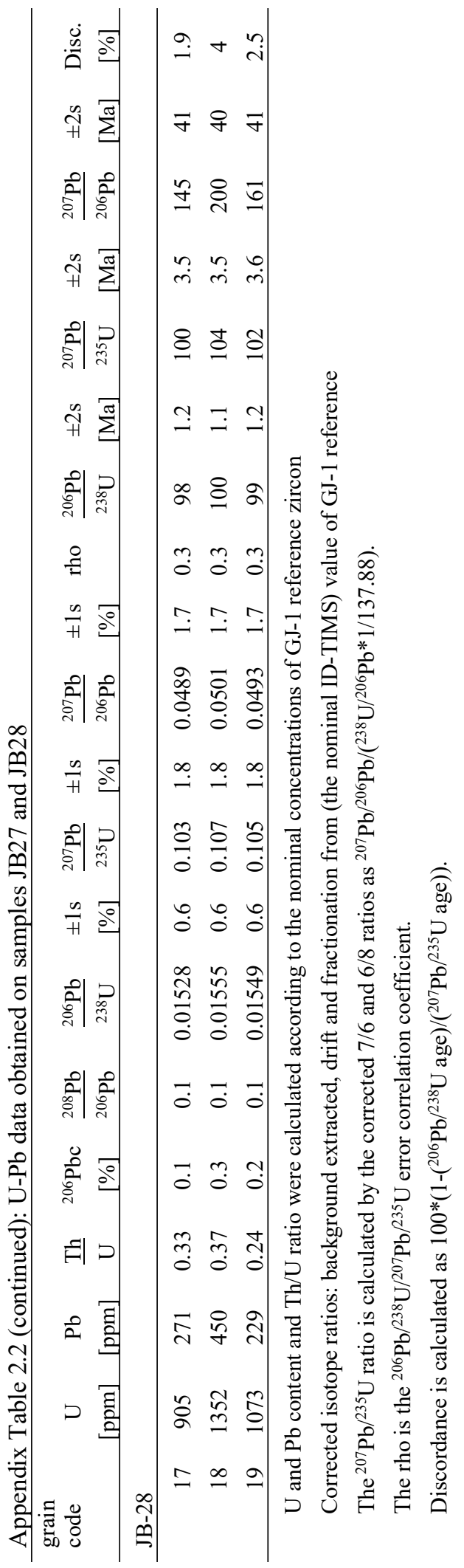


Manuscript III: Supplementary data
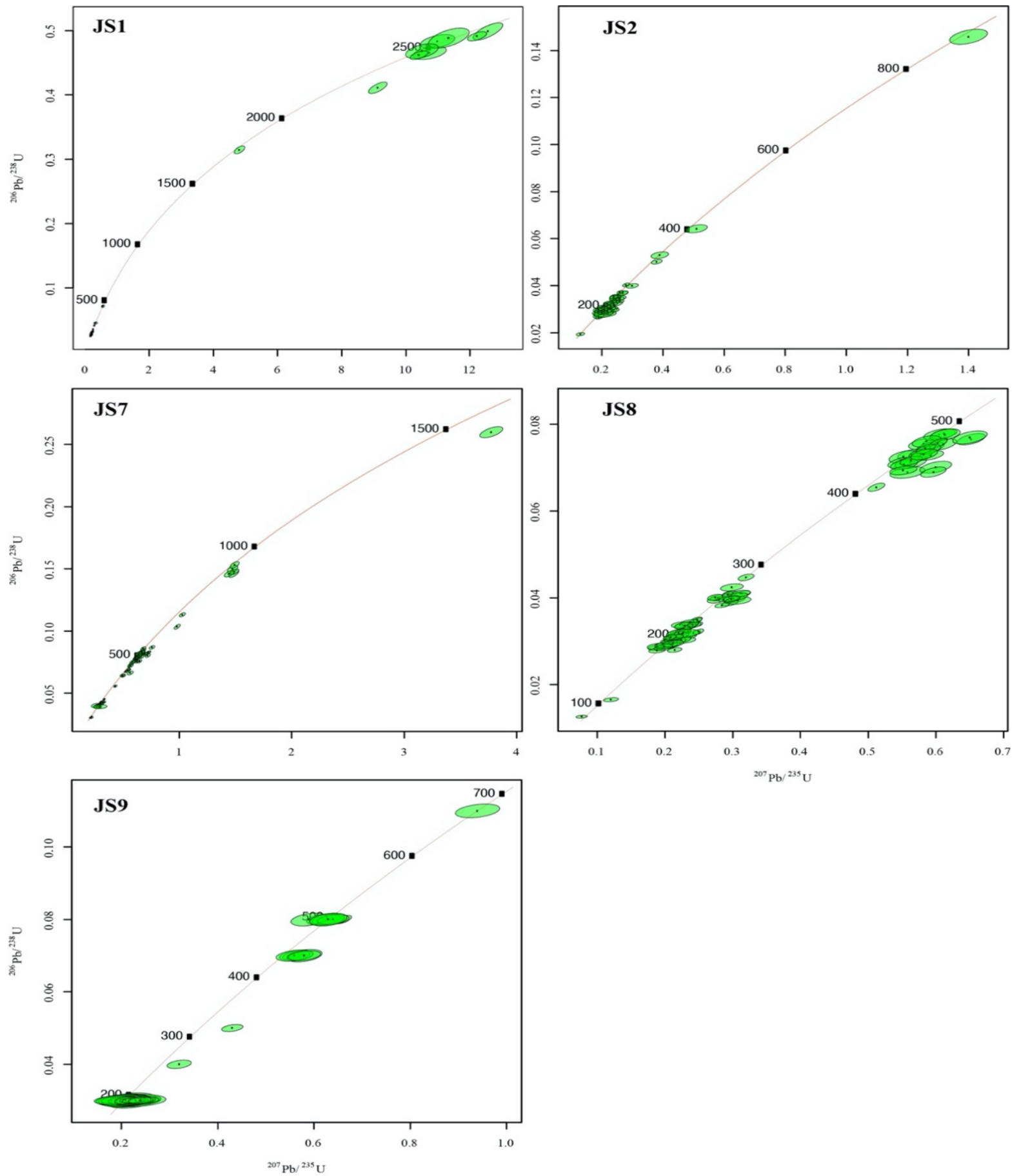

Appendix Figure 4.1: Wetherill zircon U-Pb concordia plots from the modern sediments in this study. 
Cretaceous-Cenozoic thermo-tectonic evolution and provenance analysis of the basement and some sedimentary successions northeast of the Songliao Basin, NE China

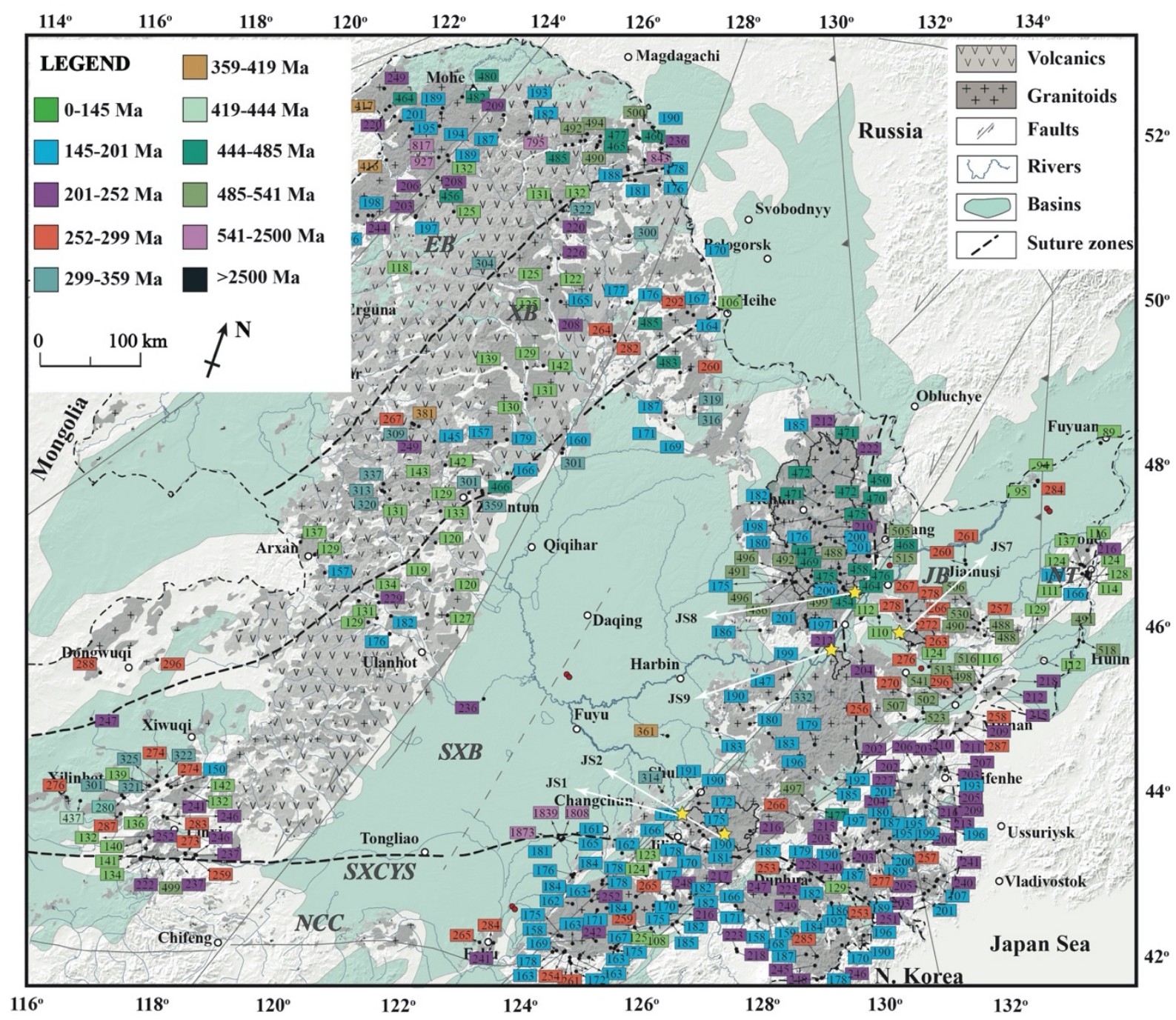

Appendix Figure 4. 2: Compilation of cited igneous rocks' mean zircon U-Pb ages, Cretaceous sediments distributions and sampled detrital zircon river sand sample in this study results shown as pie charts representing age population. Simplified geological map is after Wu et al. (2011). Black dots indicate the cited igneous rock samples' locations. Red dots indicate the cited Cretaceous sediment samples' locations. A, compilation of detrital zircon U-Pb ages from Cretaceous sediments of southern Songliao Basin; B, detrital zircon U-Pb ages from the middle Songliao Basin; $C$, detrital zircon U-Pb ages from eastern Basins. Igneous rocks' mean zircon U-Pb ages and Cretaceous sediments' detrital zircon U-Pb ages are after the same citations shown in Figure 4.6. 


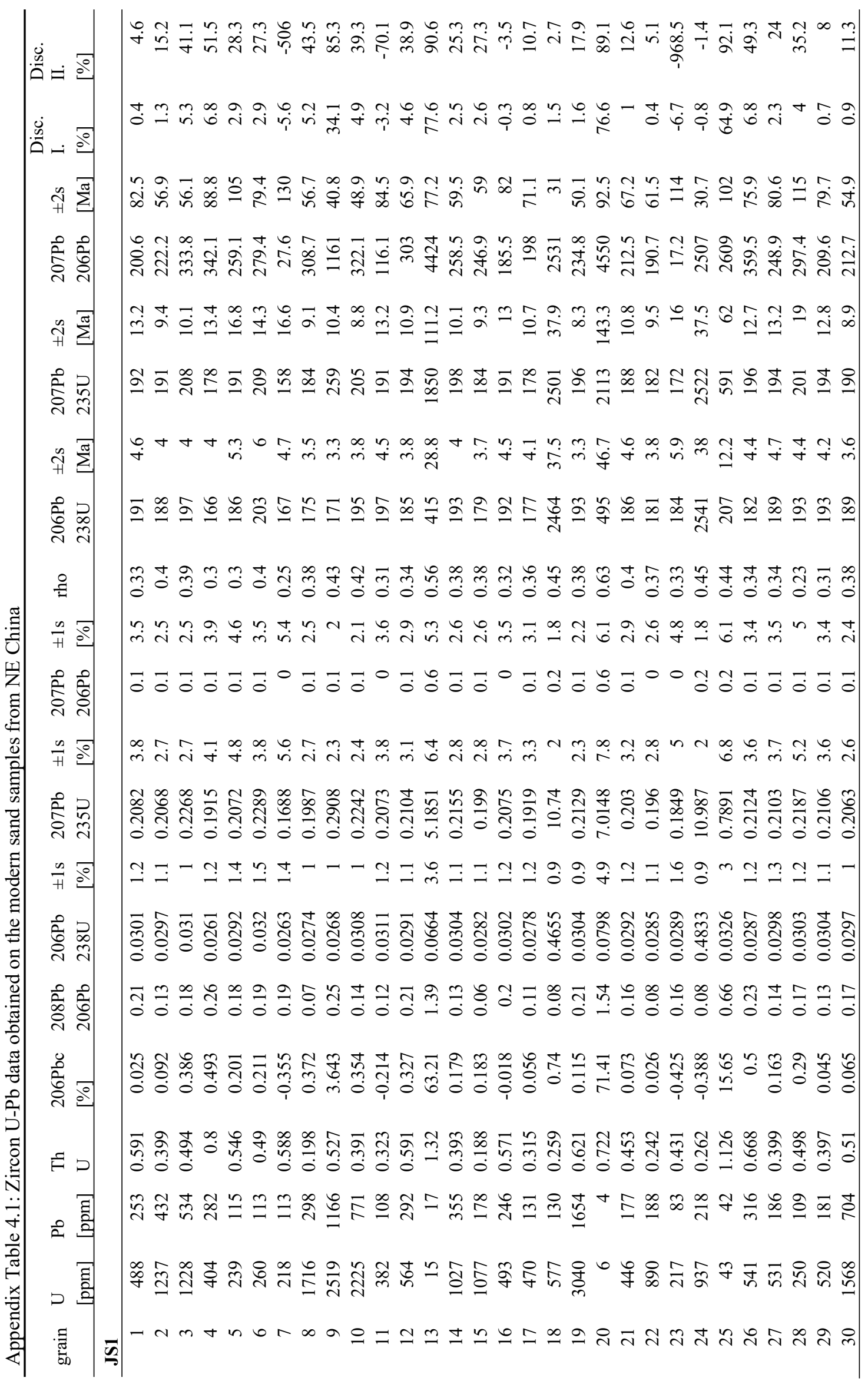




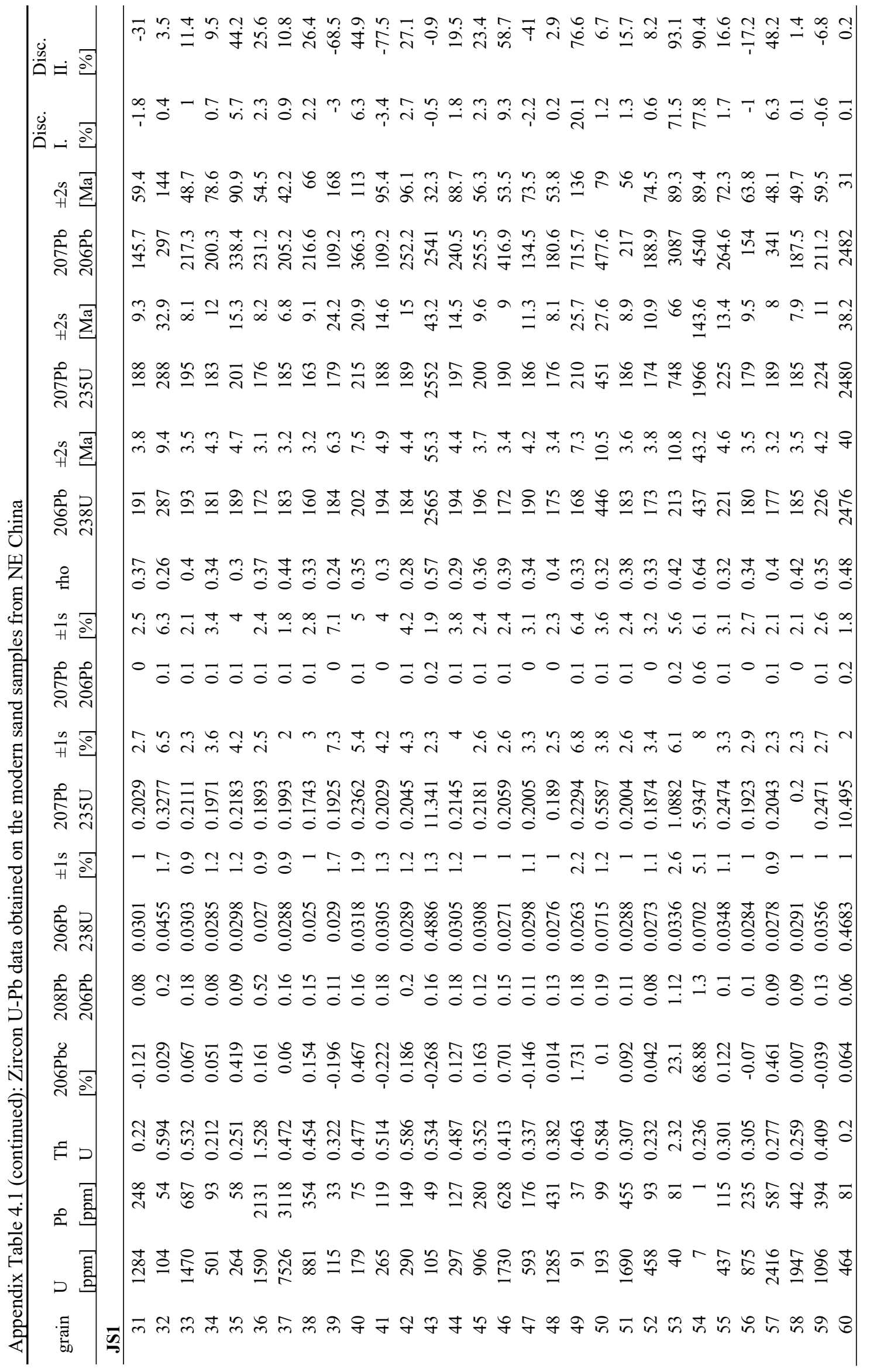




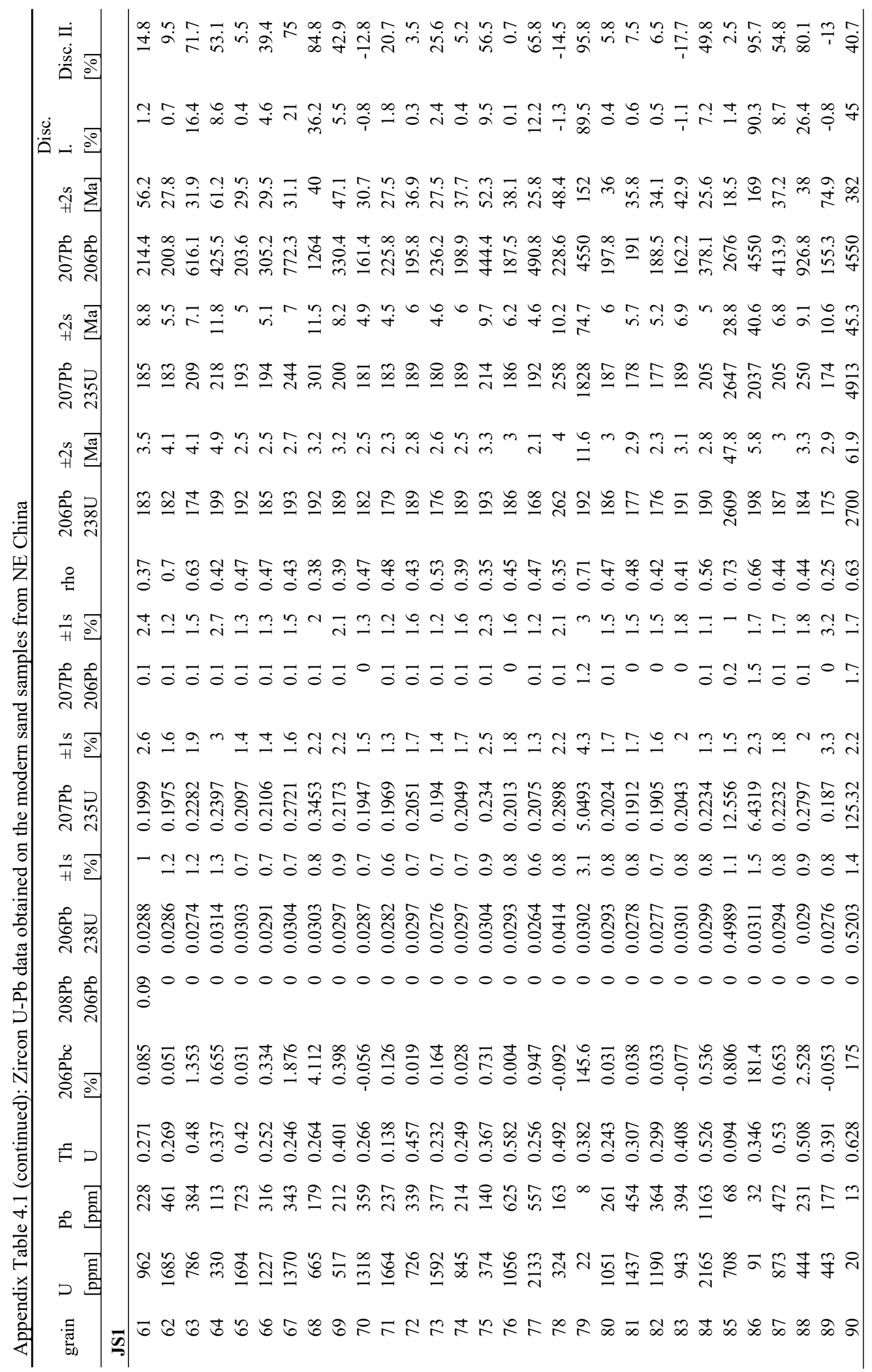




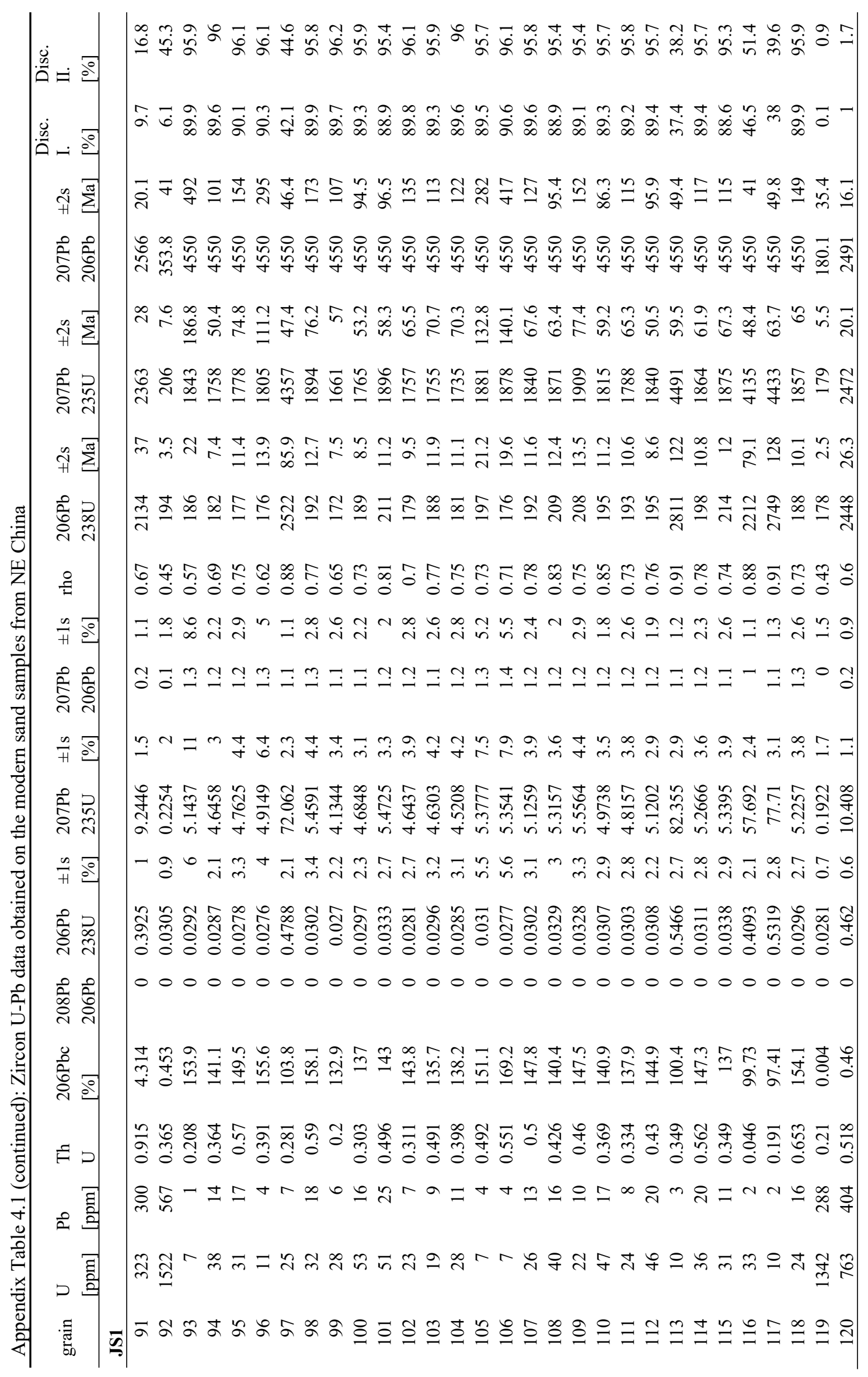




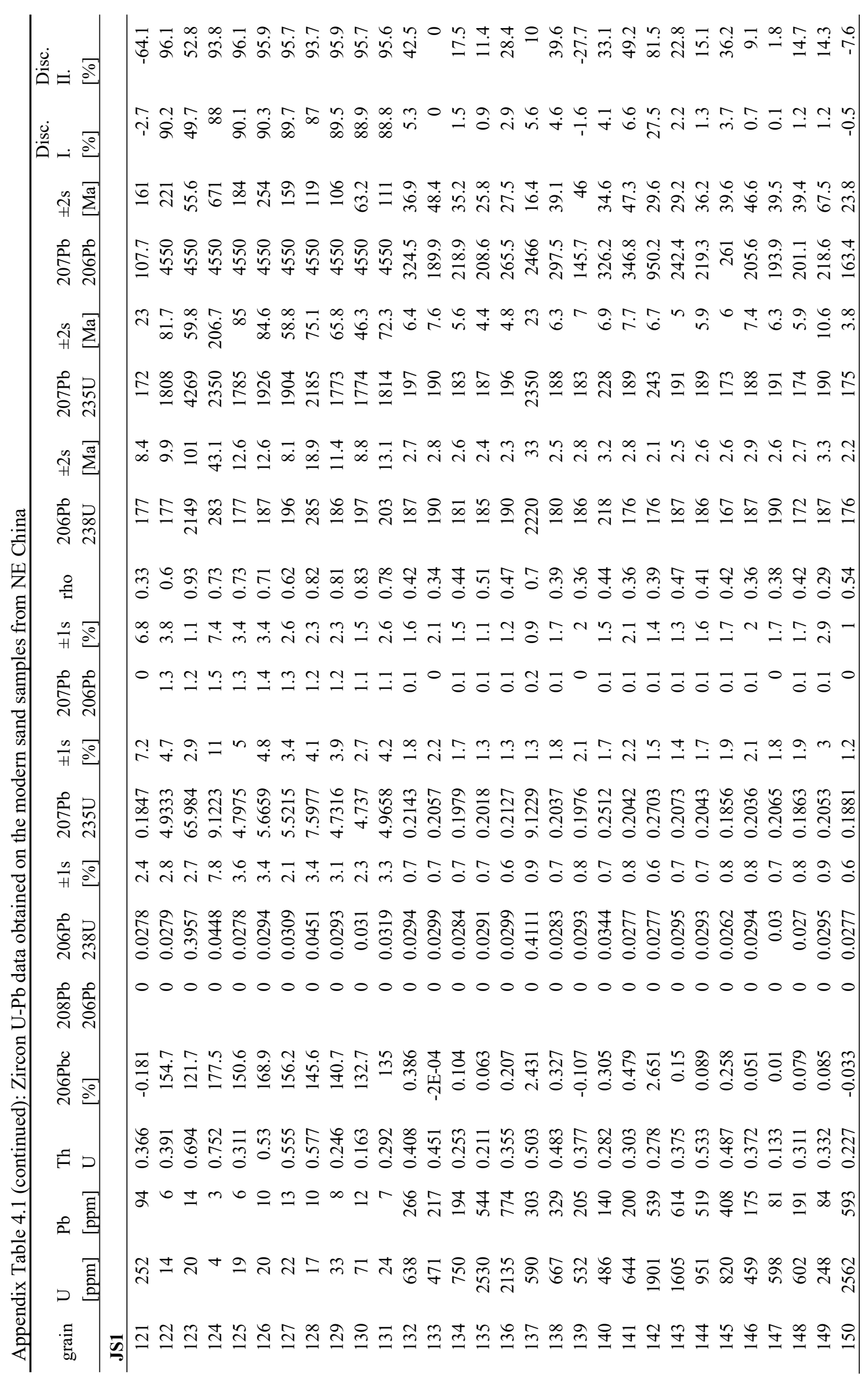




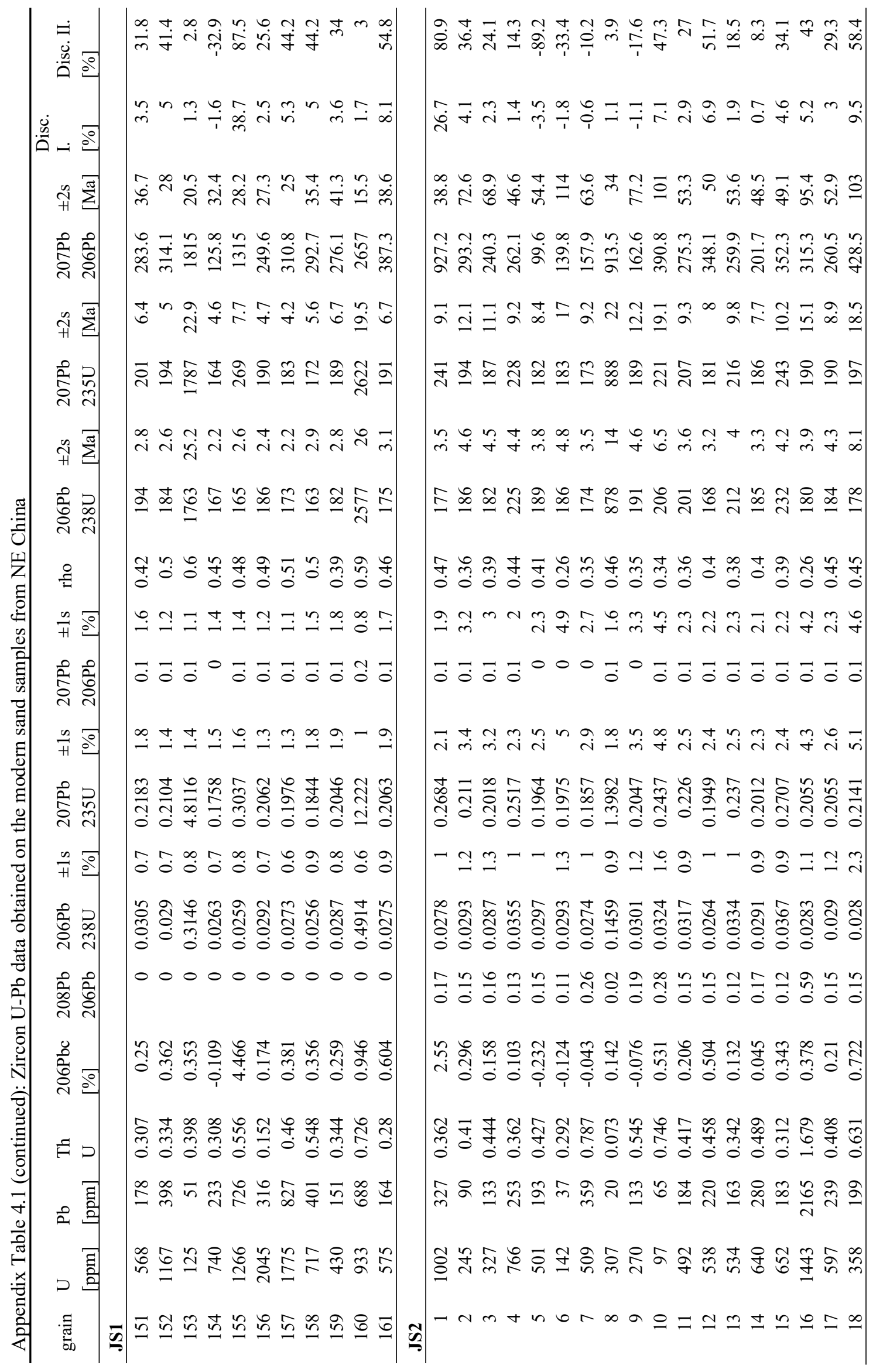




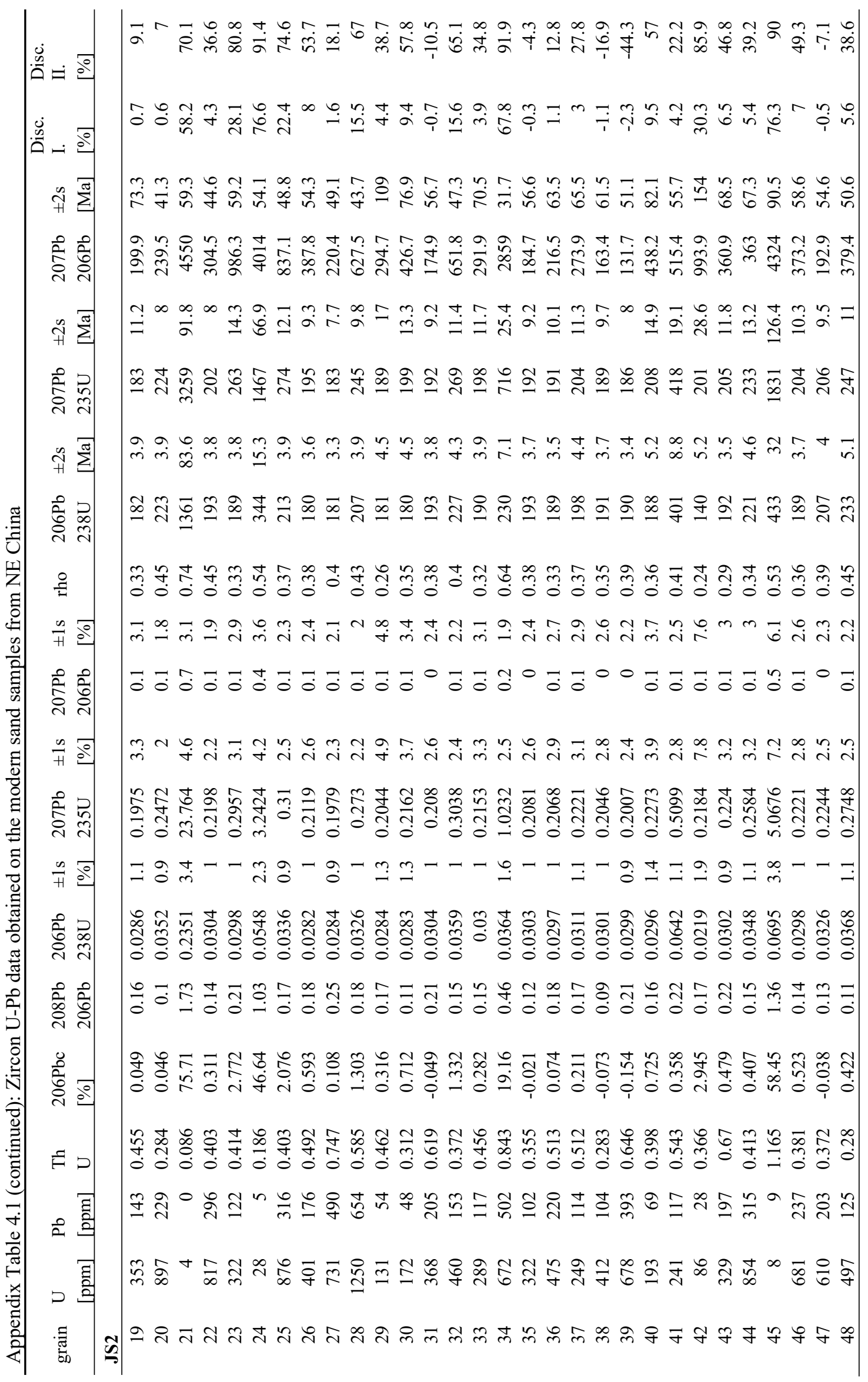




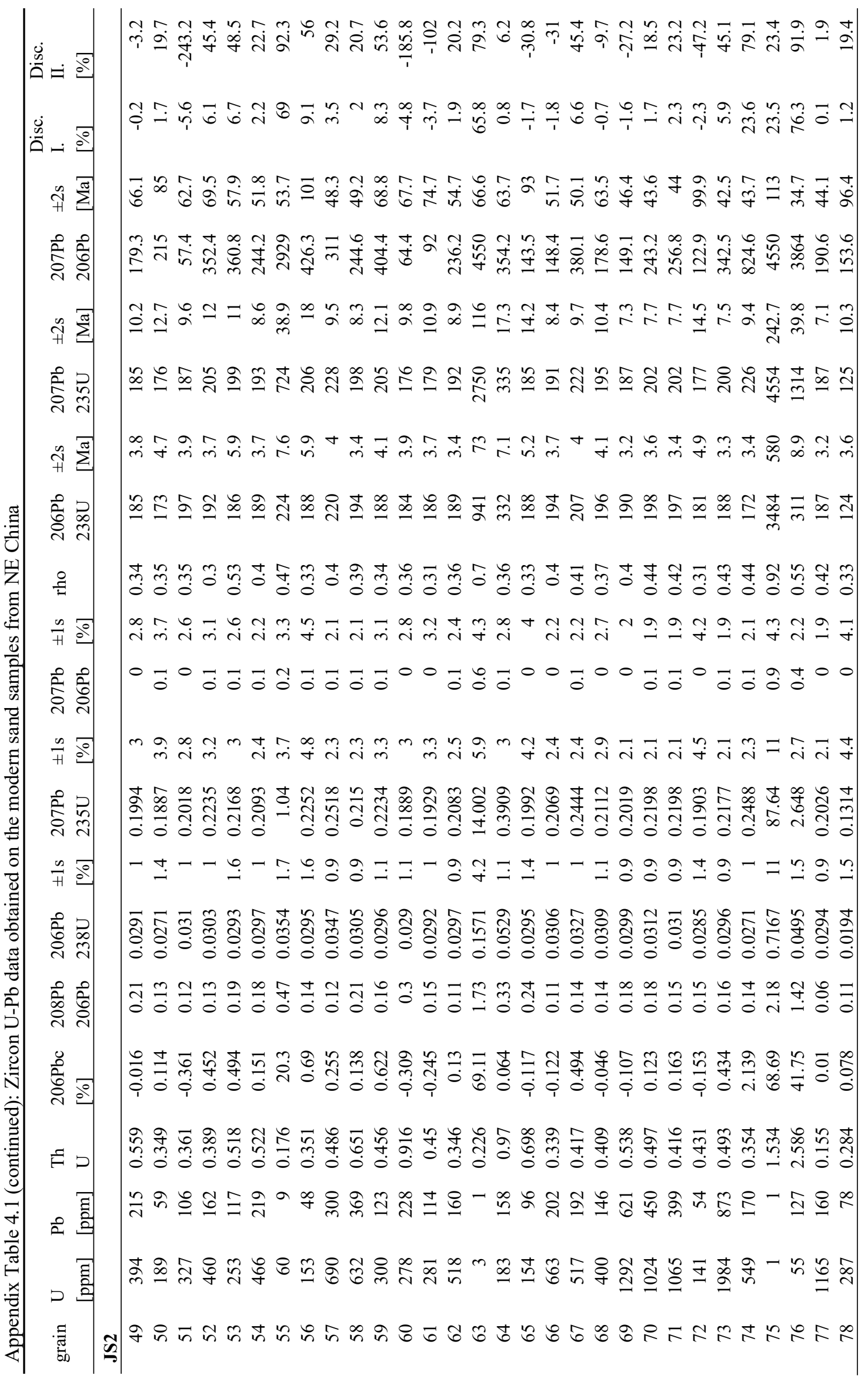




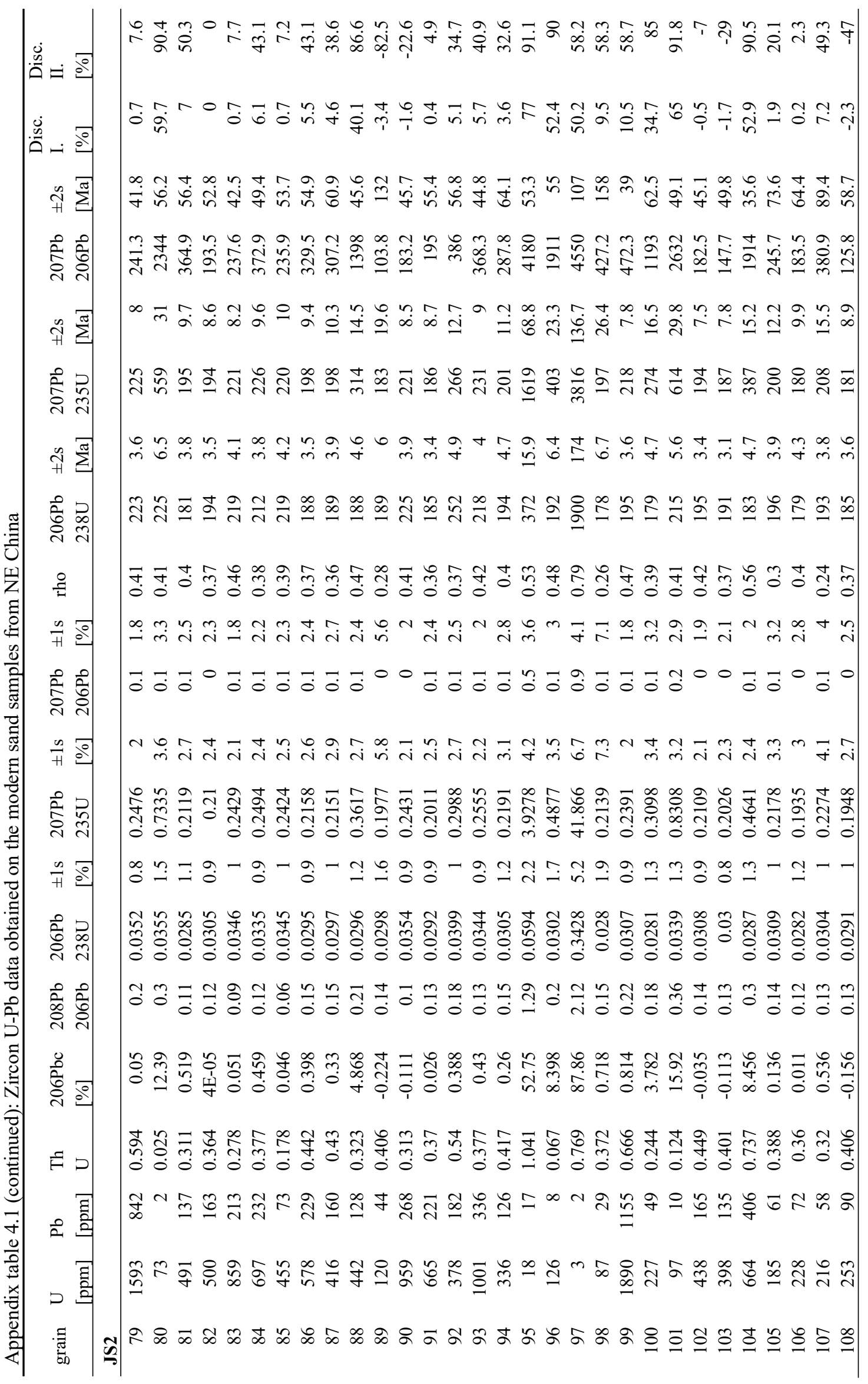




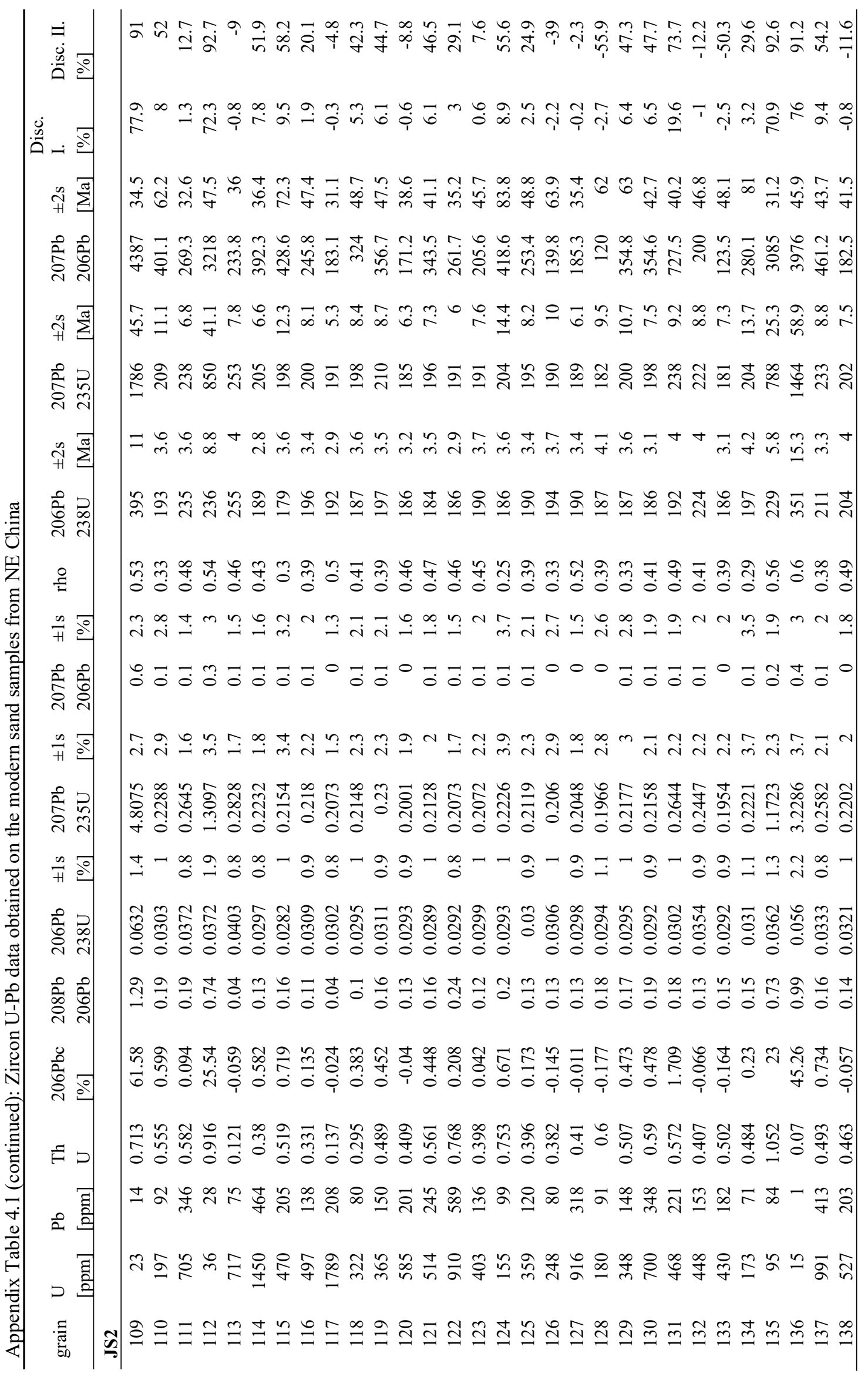




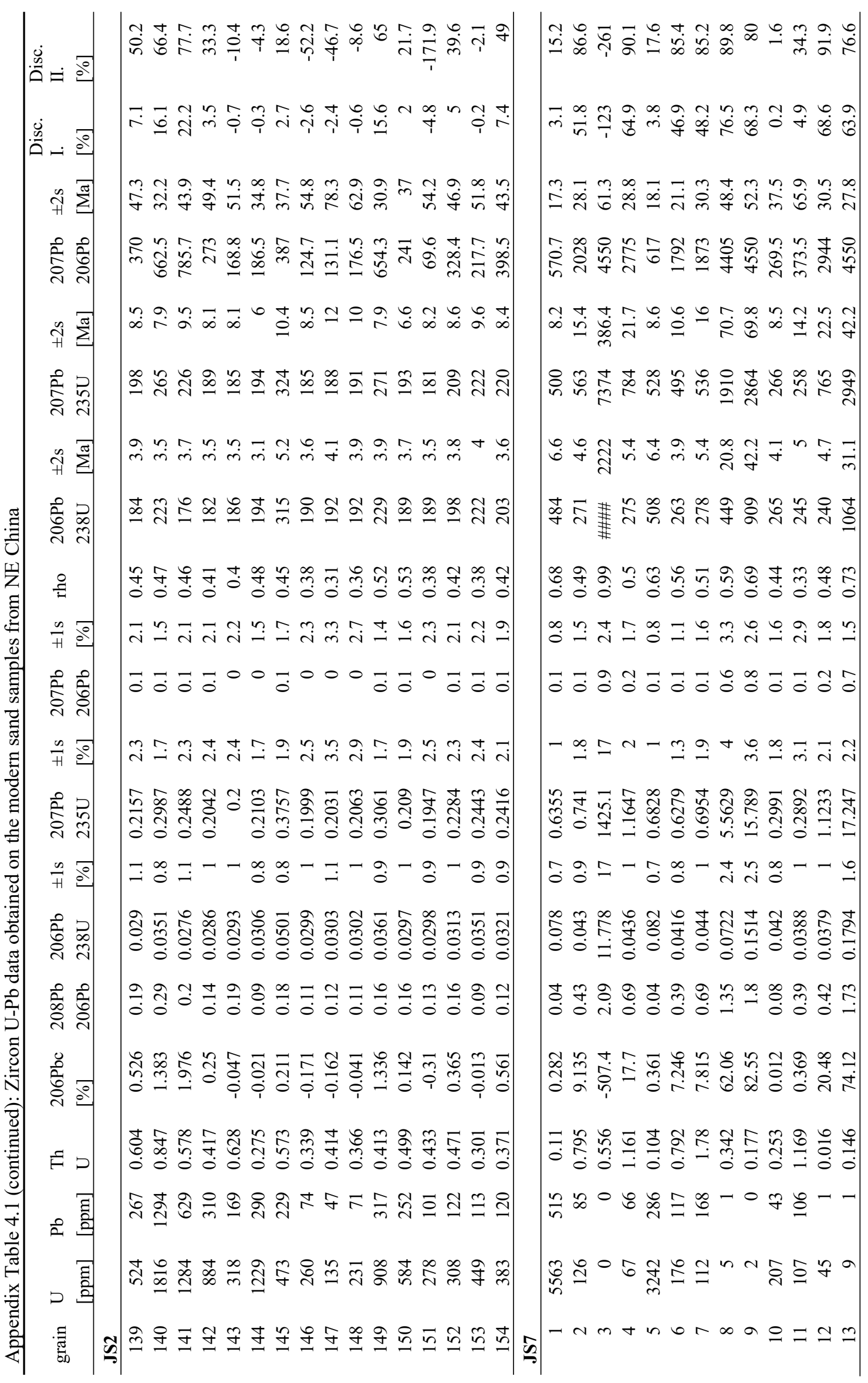


Cretaceous-Cenozoic thermo-tectonic evolution and provenance analysis of the basement and some sedimentary successions northeast of the Songliao Basin, NE China

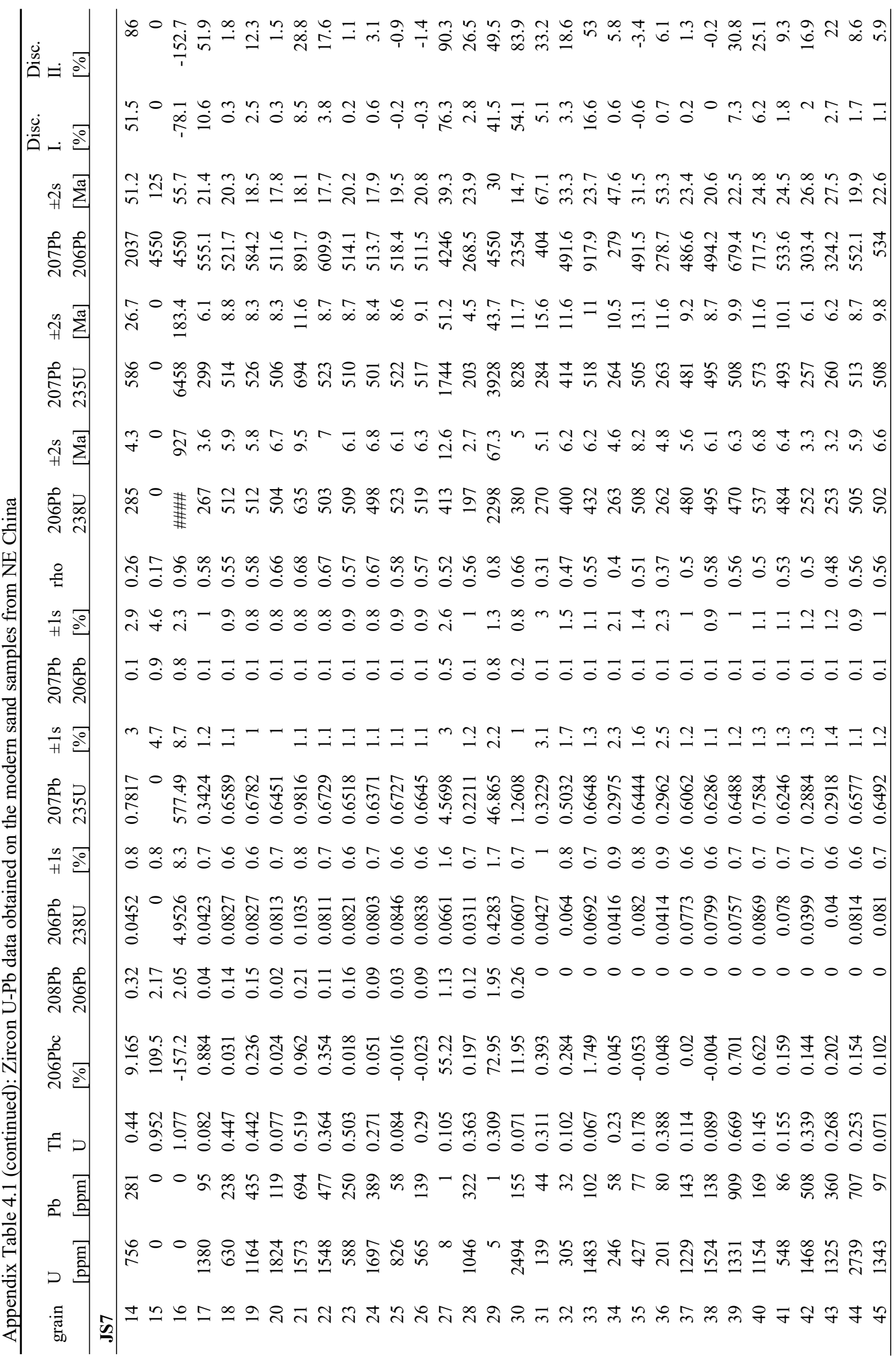




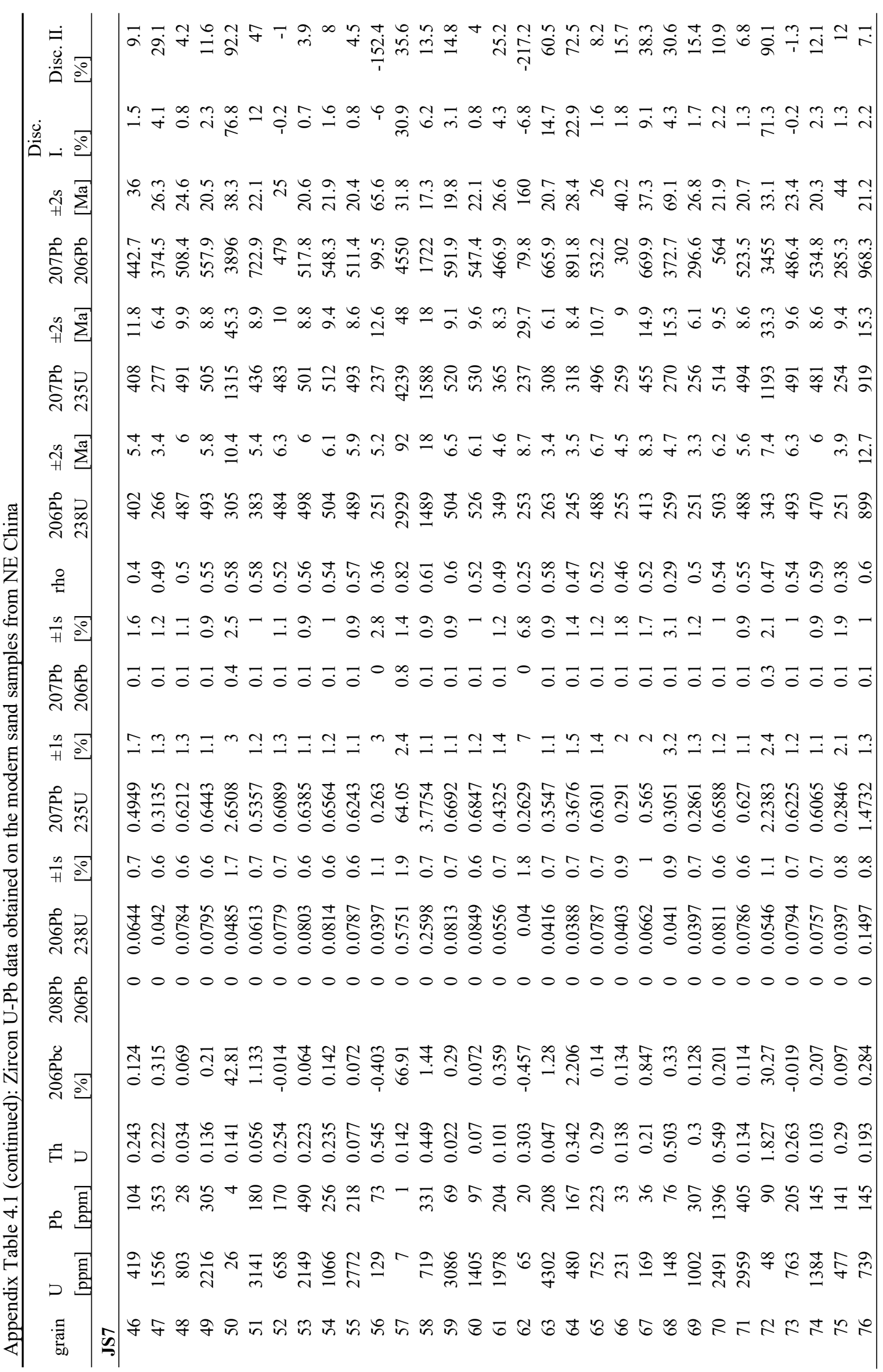


Cretaceous-Cenozoic thermo-tectonic evolution and provenance analysis of the basement and some sedimentary successions northeast of the Songliao Basin, NE China

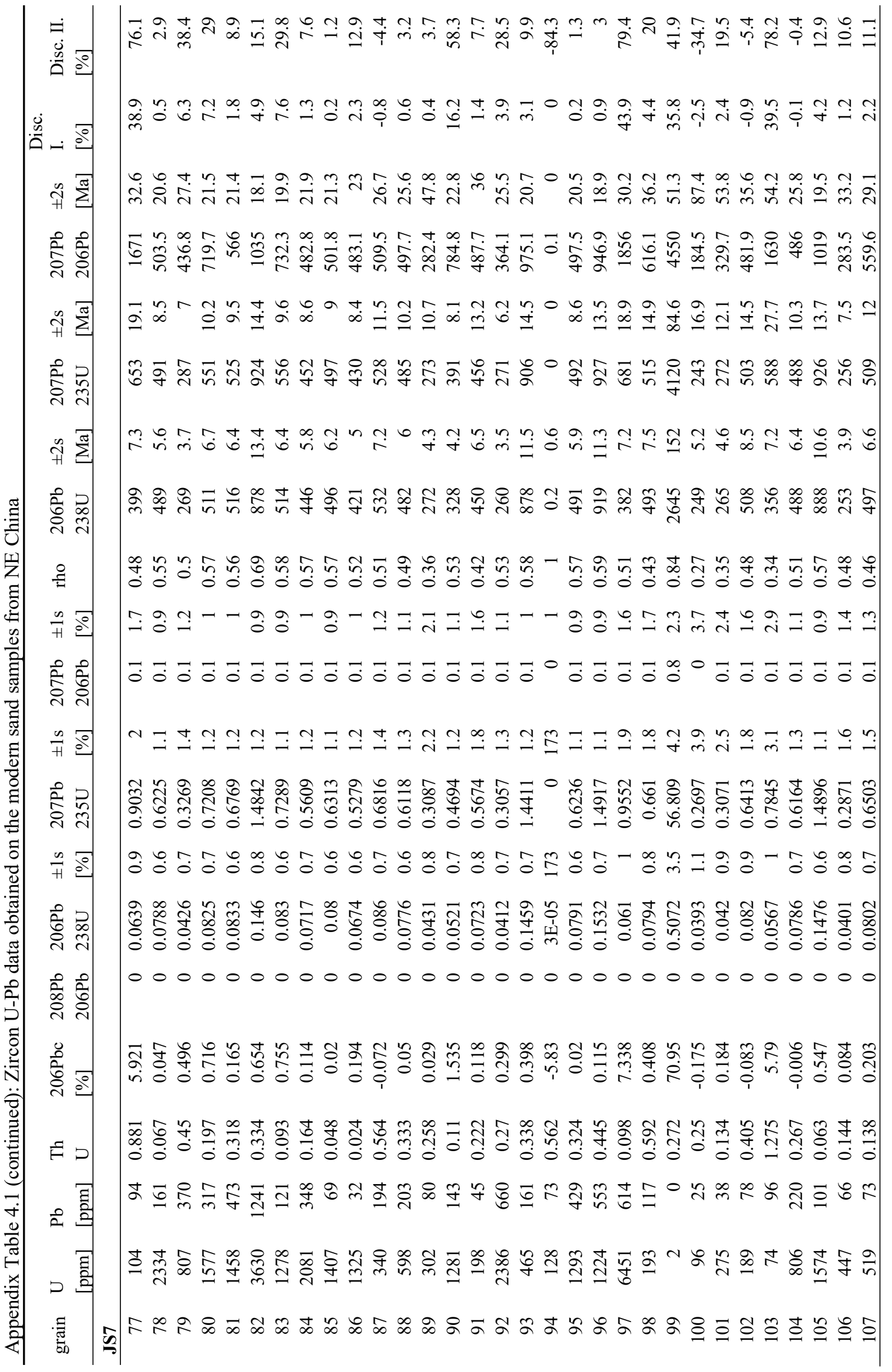




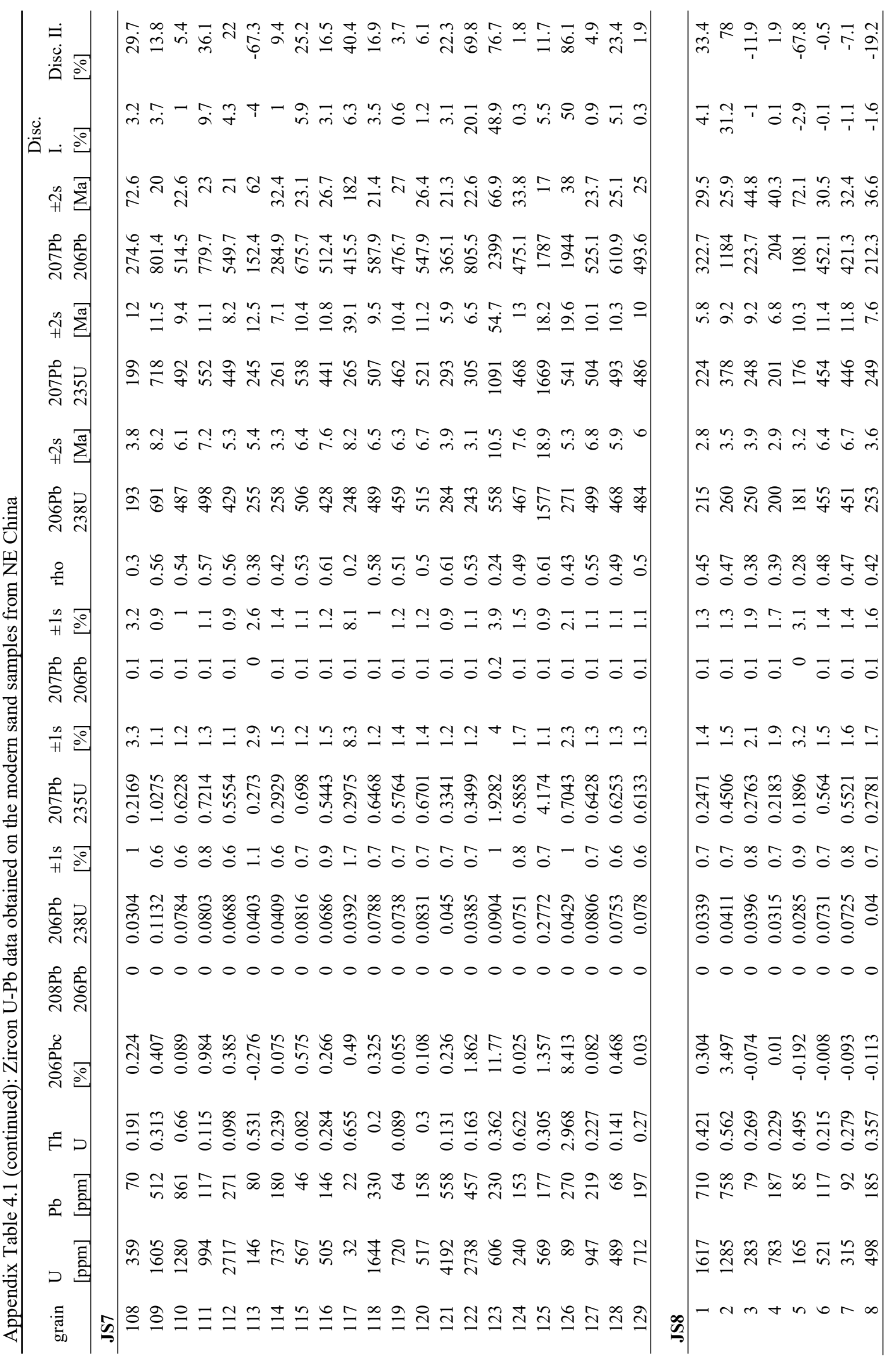


Cretaceous-Cenozoic thermo-tectonic evolution and provenance analysis of the basement and some sedimentary successions northeast of the Songliao Basin, NE China

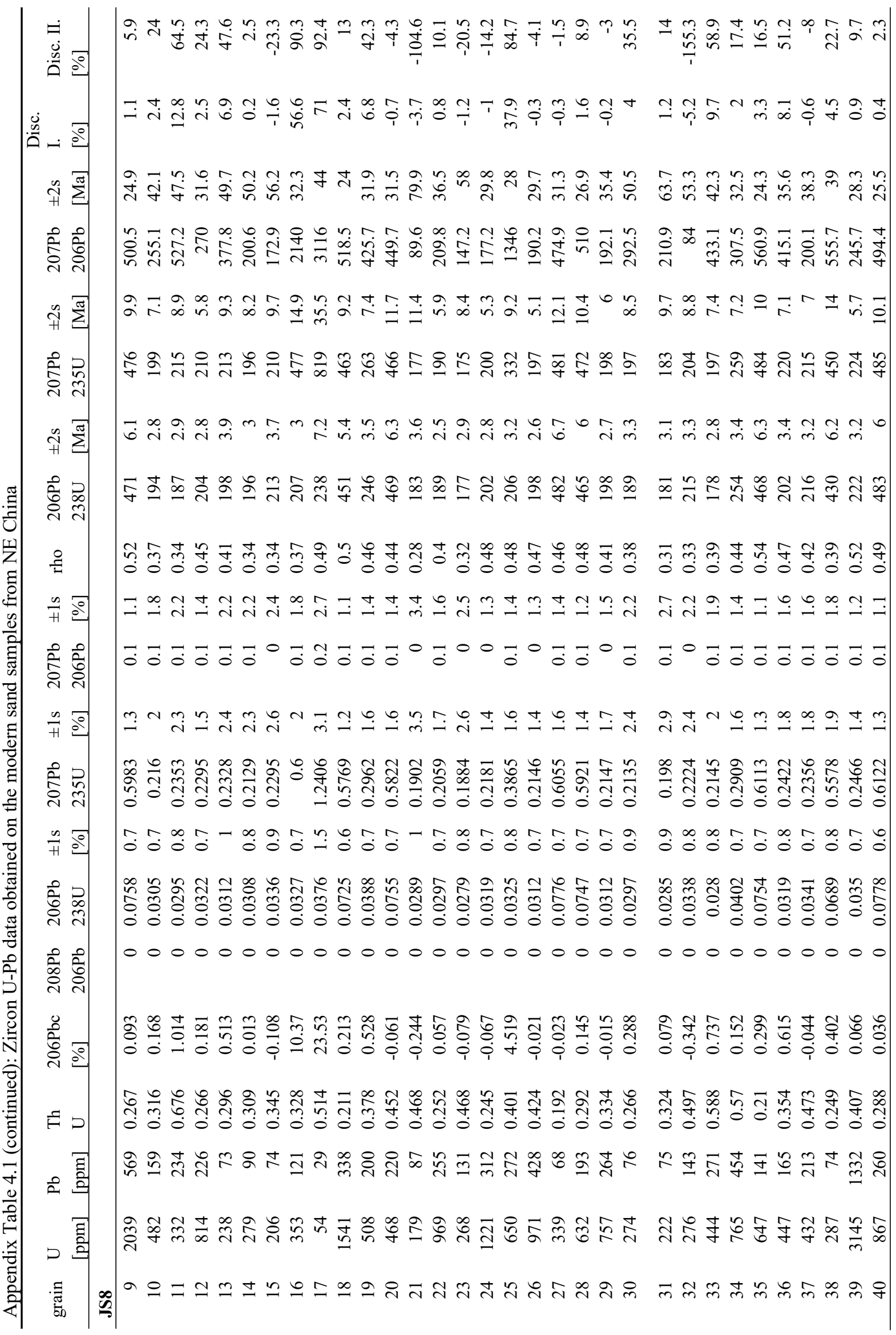




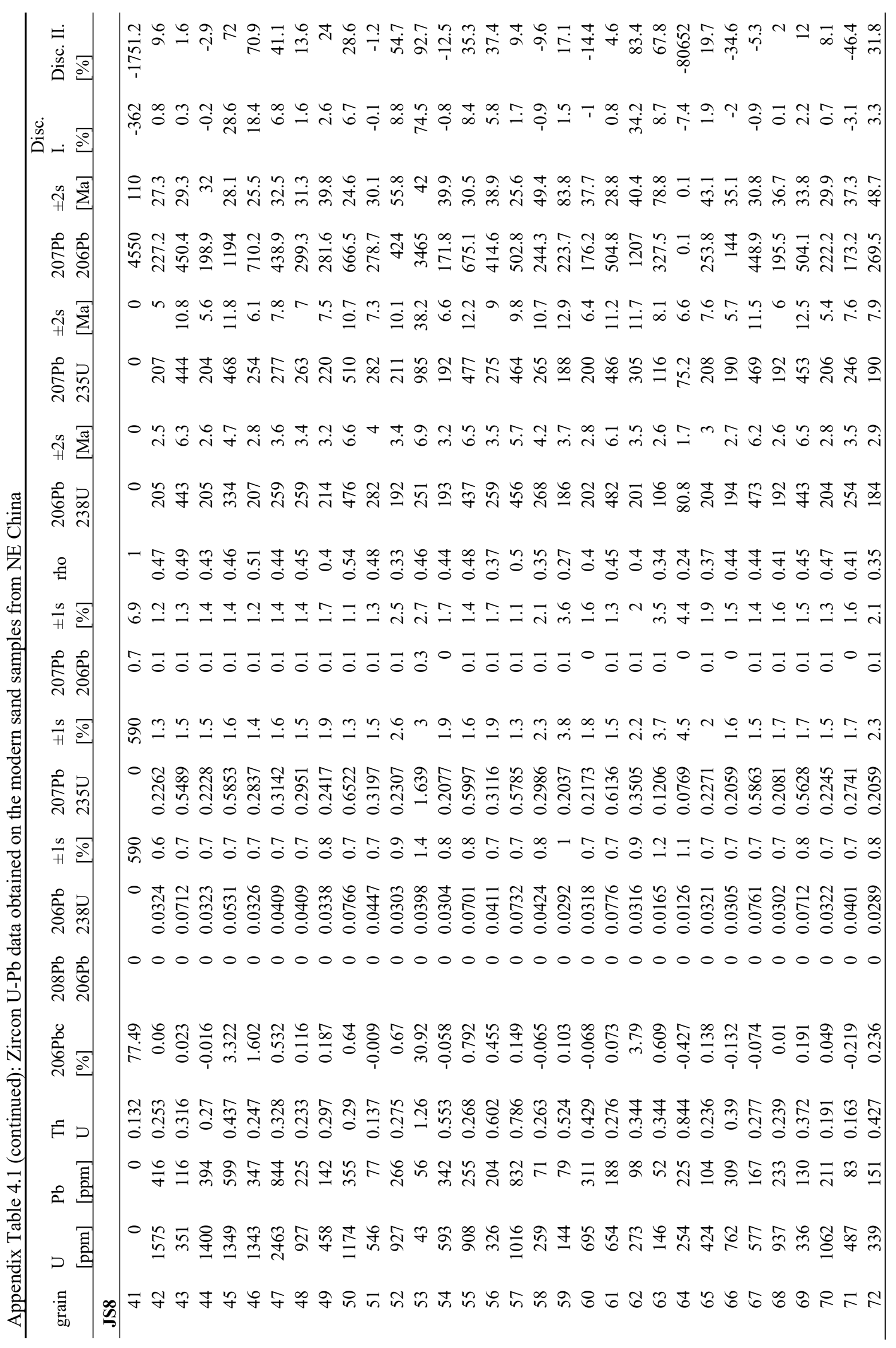




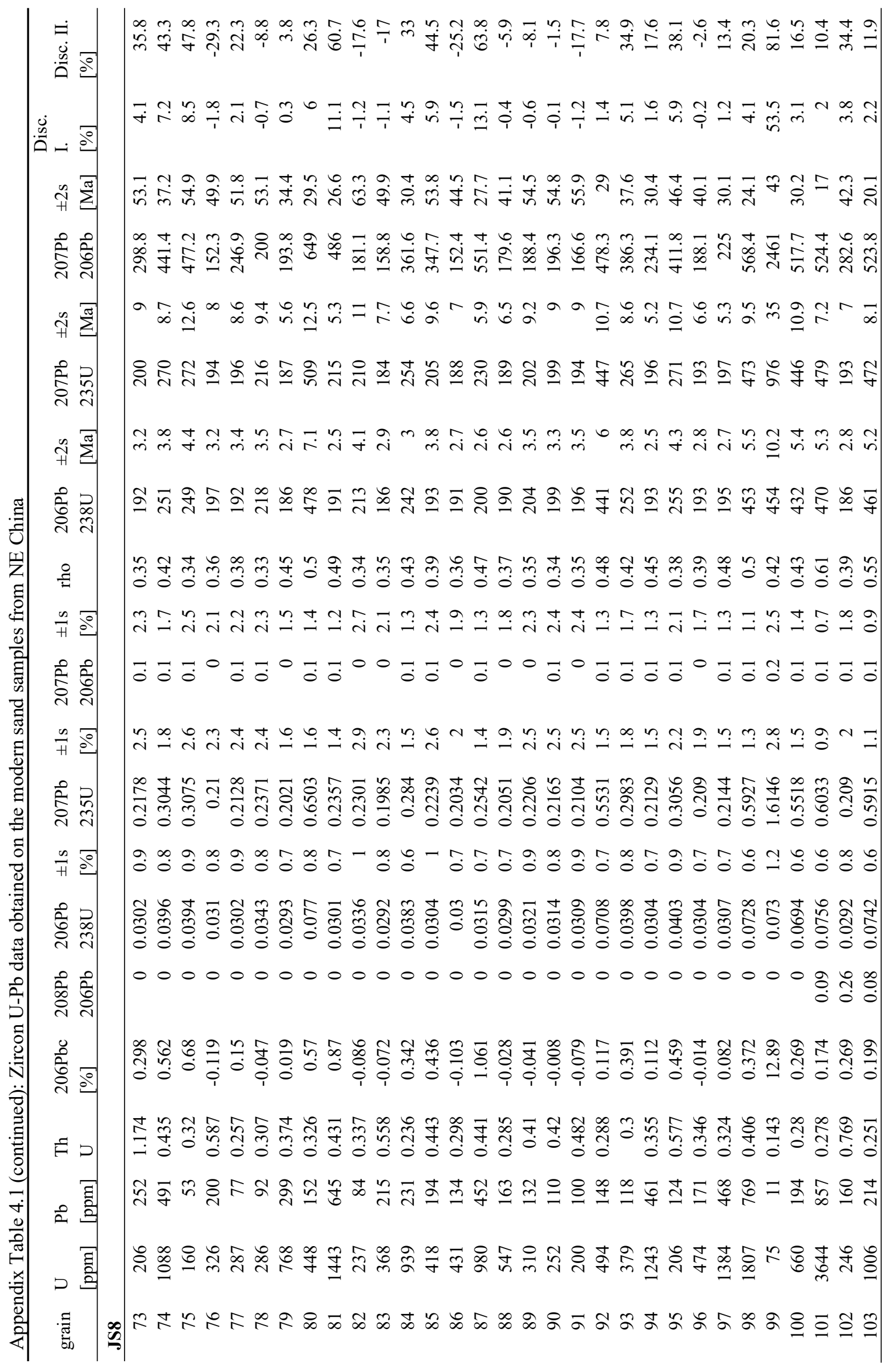




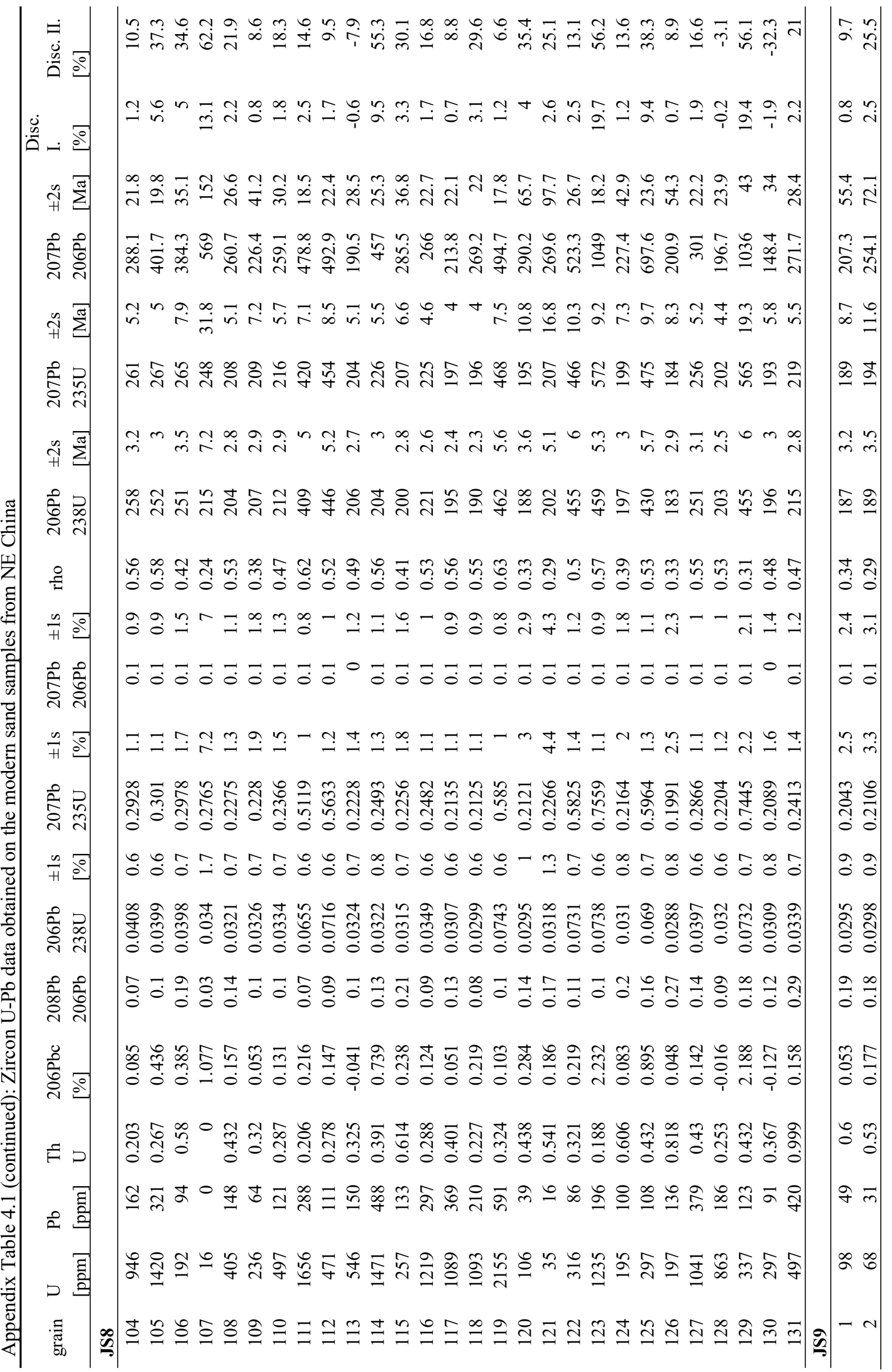




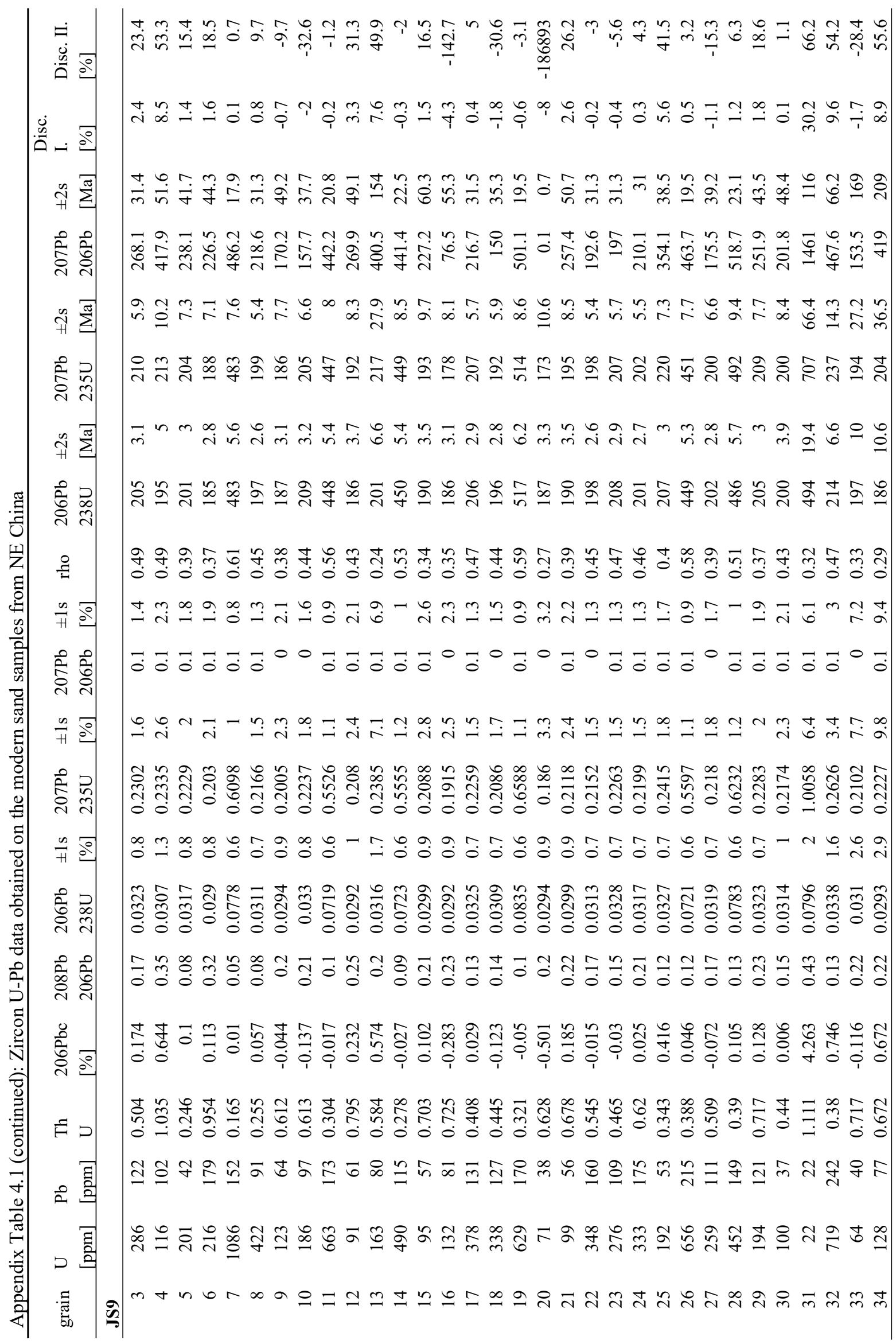




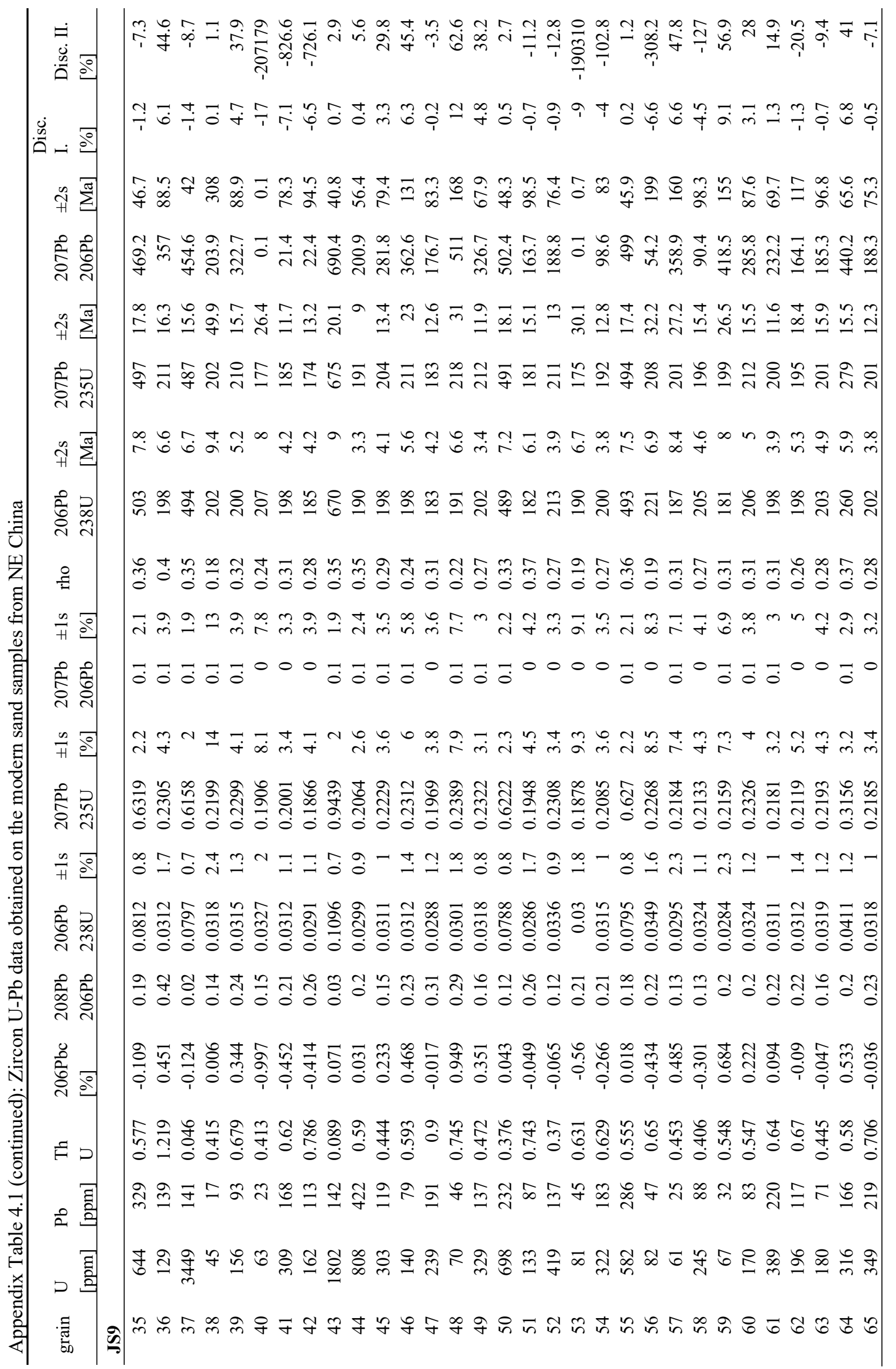



successions northeast of the Songliao Basin, NE China

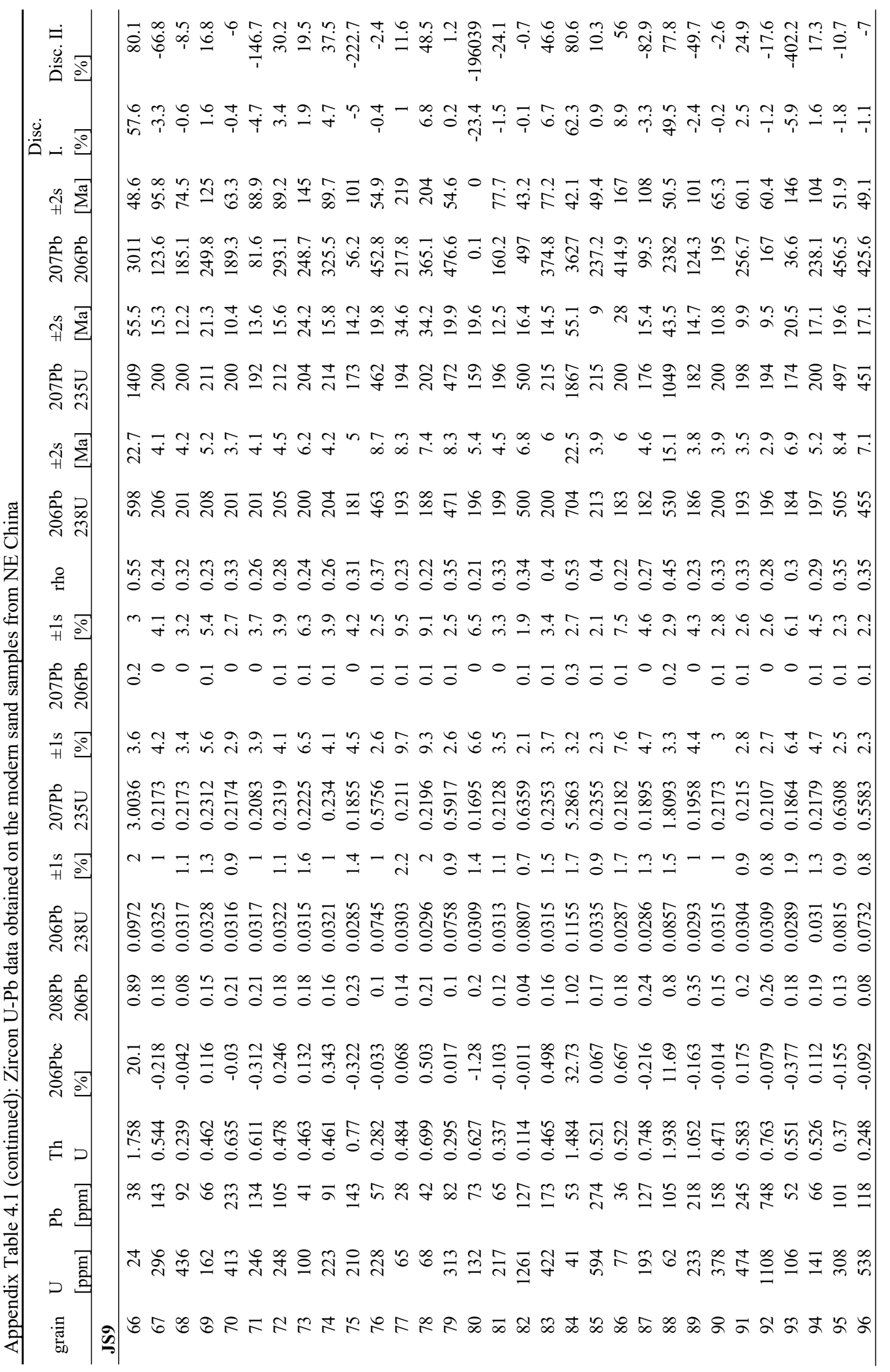




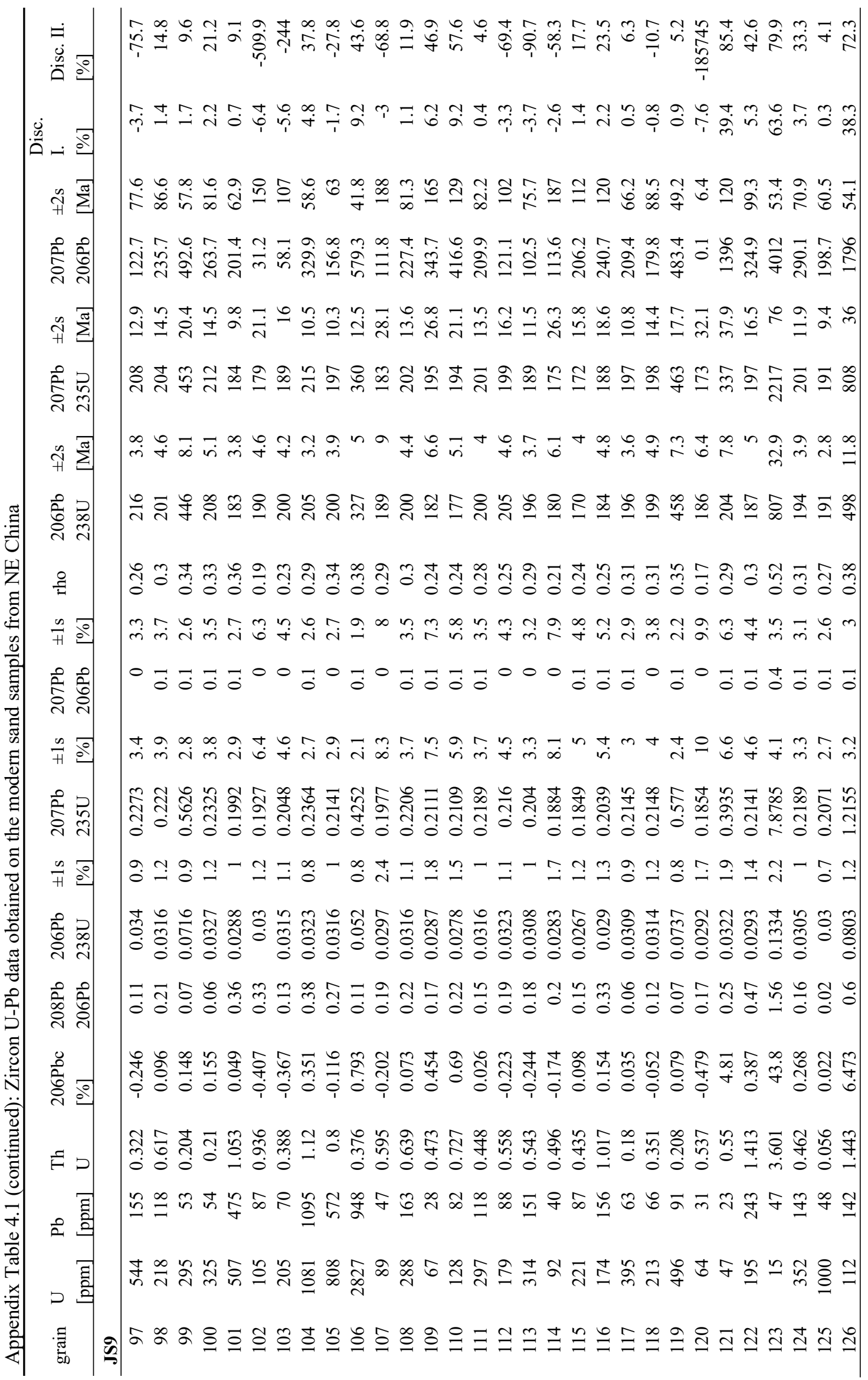


Cretaceous-Cenozoic thermo-tectonic evolution and provenance analysis of the basement and some sedimentary successions northeast of the Songliao Basin, NE China

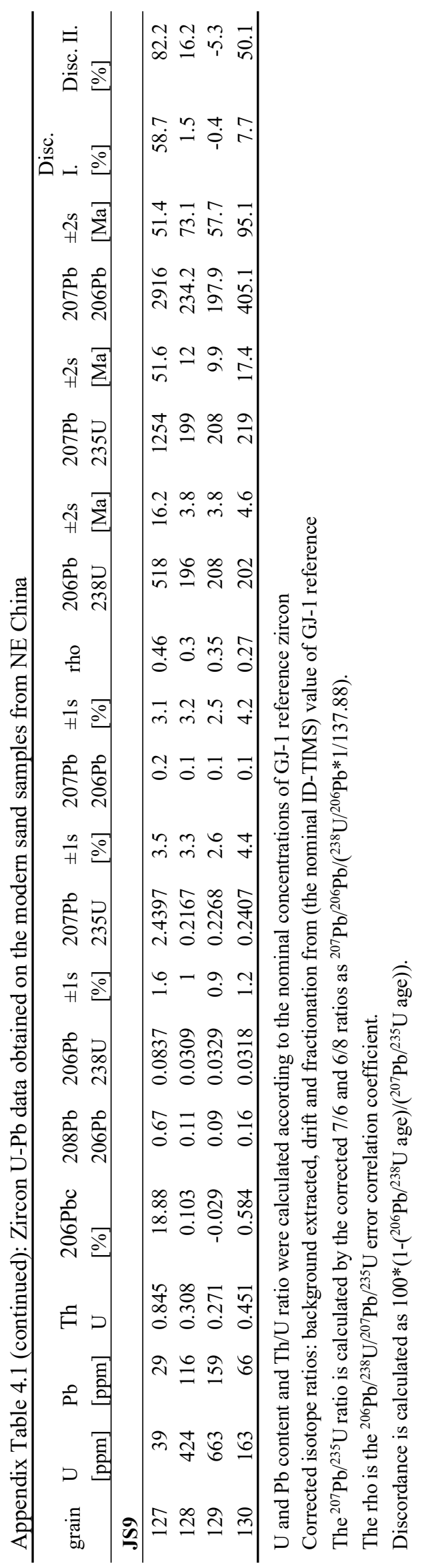


Appendix Table 4.2: Cited Igneous rock Zircon U-Pb ages

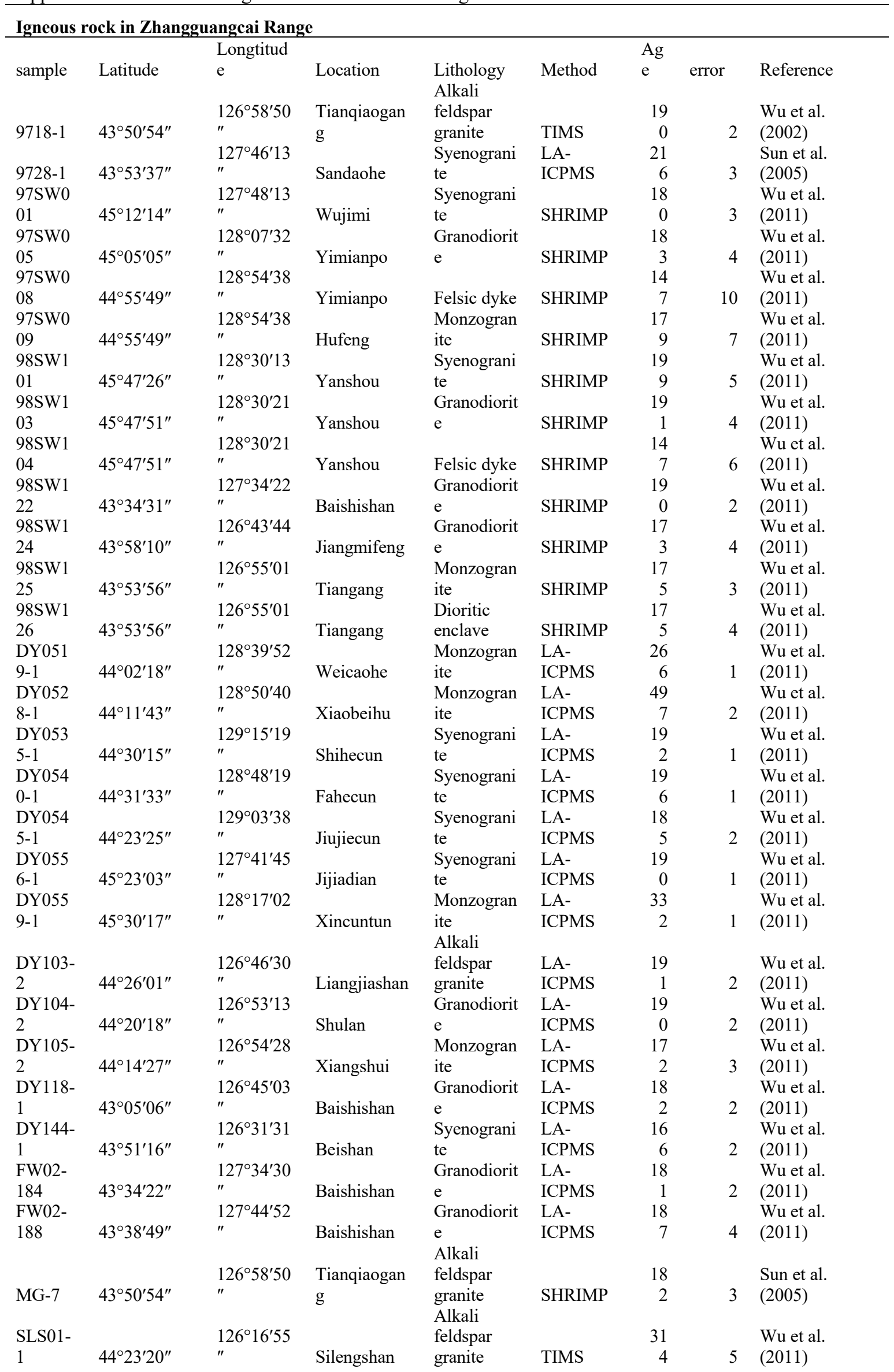


Cretaceous-Cenozoic thermo-tectonic evolution and provenance analysis of the basement and some sedimentary successions northeast of the Songliao Basin, NE China

\begin{tabular}{|c|c|c|c|c|c|c|c|c|}
\hline & & $127^{\circ} 23^{\prime} 05$ & & & & 21 & & Wu et al. \\
\hline P4-5 & $43^{\circ} 15^{\prime} 36^{\prime \prime}$ & $"$ & Piaohechuan & $\begin{array}{l}\text { Pyroxenite } \\
\text { Alkali }\end{array}$ & SHRIMP & 7 & 3 & $(2004 b)$ \\
\hline \multirow{6}{*}{$\begin{array}{l}\text { Ycz-2 } \\
\text { GW045 } \\
30 \\
\text { GW045 } \\
42\end{array}$} & & $128^{\circ} 53^{\prime} 29$ & & feldspar & LA- & 47 & & Chen et al. \\
\hline & $44^{\circ} 08^{\prime} 36^{\prime \prime}$ & & Yingchengzi & granite & ICPMS & 7 & 6 & (2009) \\
\hline & & $126^{\circ} 19^{\prime} 37$ & & Granodiorit & LA- & 17 & & Ge et al. \\
\hline & $43^{\circ} 29^{\prime} 26^{\prime \prime}$ & & Daheishan & e & ICPMS & 0 & 3 & $(2007 b)$ \\
\hline & & $126^{\circ} 18^{\prime} 34$ & & Monzogran & LA- & 17 & & Ge et al. \\
\hline & $43^{\circ} 30^{\prime} 01^{\prime \prime}$ & & Daheishan & $\begin{array}{l}\text { ite } \\
\text { Alkali }\end{array}$ & ICPMS & 8 & 3 & $(2007 b)$ \\
\hline \multirow{5}{*}{$\begin{array}{l}\text { Baishi- } \\
1 \\
99 \mathrm{SW} 1 \\
09\end{array}$} & & $126^{\circ} 05^{\prime} 23$ & & feldspar & & 12 & & Wu et al. \\
\hline & $43^{\circ} 28^{\prime} 50^{\prime \prime}$ & & Baishileizi & granite & TIMS & 3 & 3 & (2002) \\
\hline & & $126^{\circ} 25^{\prime} 22$ & & Leucogabb & & 21 & & Wu et al. \\
\hline & $42^{\circ} 53^{\prime} 52^{\prime \prime}$ & & Hongqiling & ro & SHRIMP & 6 & 5 & $(2004 b)$ \\
\hline & & $126^{\circ} 01^{\prime} 19$ & Qingyangwa & & & 12 & & \\
\hline \multirow[t]{2}{*}{ HP2-2 } & $43^{\circ} 20^{\prime} 46^{\prime \prime}$ & & izi & Gabbro & TIMS & 9 & 1 & Xu et al. (2013) \\
\hline & & $126^{\circ} 01^{\prime} 02$ & Qingyangwa & Monzogran & & 12 & & \\
\hline \multirow[t]{2}{*}{ HP4-1 } & $43^{\circ} 21^{\prime} 37^{\prime \prime}$ & & izi & ite & TIMS & 4 & 4 & Xu et al. (2013) \\
\hline & & $126^{\circ} 19^{\prime} 50$ & & Granodiorit & LA- & 17 & & \\
\hline \multirow[t]{2}{*}{$97103-1$} & $43^{\circ} 06^{\prime} 05^{\prime \prime}$ & & Yima & e & ICPMS & 0 & 1 & Xu et al. (2013) \\
\hline & & $124^{\circ} 48^{\prime} 30$ & Daduanshug & Monzogran & LA- & 17 & & \\
\hline \multirow[t]{2}{*}{$9902-2$} & $43^{\circ} 22^{\prime} 05^{\prime \prime}$ & & ou & & ICPMS & 6 & 3 & Xu et al. (2013) \\
\hline & & $124^{\circ} 47^{\prime} 00$ & & Granodiorit & & 18 & & \\
\hline \multirow[t]{2}{*}{$9903-1$} & $43^{\circ} 19^{\prime} 50^{\prime \prime}$ & & Shichangtun & $\mathrm{e}$ & TIMS & 4 & 2 & Xu et al. (2013) \\
\hline & & $124^{\circ} 47^{\prime} 20$ & & Monzogran & LA- & 16 & & \\
\hline \multirow[t]{2}{*}{$9905-1$} & $42^{\circ} 59^{\prime} 56^{\prime \prime}$ & $"$ & Tiande & ite & ICPMS & 2 & 3 & Xu et al. (2013) \\
\hline & & $125^{\circ} 21^{\prime} 28$ & Xiangshuiyu & $\begin{array}{l}\text { Gt-Mus } \\
\text { monzogran }\end{array}$ & & 18 & & \\
\hline $9909-4$ & $42^{\circ} 57^{\prime} 15^{\prime \prime}$ & & anzi & ite & TIMS & 4 & 3 & Xu et al. (2013) \\
\hline $9923-1$ & $43^{\circ} 07^{\prime} 55^{\prime \prime}$ & $126^{\circ} 28^{\prime} 05$ & Dayushan & $\begin{array}{l}\text { Granodiorit } \\
\text { e } \\
\text { Gt-Mus }\end{array}$ & TIMS & $\begin{array}{r}24 \\
8\end{array}$ & 4 & Xu et al. (2013) \\
\hline \multirow{6}{*}{$\begin{array}{l}\text { DY020- } \\
1 \\
\text { DY018- } \\
1 \\
\text { DY023- } \\
2\end{array}$} & & $125^{\circ} 17^{\prime} 12$ & & monzogran & LA- & 17 & & \\
\hline & $43^{\circ} 17^{\prime} 30^{\prime \prime}$ & & Quanyangou & ite & ICPMS & 8 & 4 & $\mathrm{Xu}$ et al. (2013) \\
\hline & & $126^{\circ} 10^{\prime} 30$ & & Monzogran & LA- & 17 & & \\
\hline & $43^{\circ} 23^{\prime} 35^{\prime \prime}$ & & Quchaihe & ite & ICPMS & 7 & 2 & Xu et al. (2013) \\
\hline & & $125^{\circ} 16^{\prime} 40$ & & Syenograni & LA- & 17 & & \\
\hline & $43^{\circ} 14^{\prime} 48^{\prime \prime}$ & & Qingniushan & te & ICPMS & 8 & 2 & Xu et al. (2013) \\
\hline \multirow{3}{*}{$\begin{array}{l}\text { DY036- } \\
6 \\
\text { DY050 }\end{array}$} & & $124^{\circ} 28^{\prime} 24$ & & & LA- & 17 & & \\
\hline & $42^{\circ} 24^{\prime} 21^{\prime \prime}$ & & Dasanjiazi & Diorite & ICPMS & 8 & 3 & Xu et al. (2013) \\
\hline & & $126^{\circ} 06^{\prime} 01$ & & Syenograni & LA- & 10 & & \\
\hline $2-1$ & $42^{\circ} 42^{\prime} 34^{\prime \prime}$ & & Xujiajie & te & ICPMS & 8 & 1 & Xu et al. (2013) \\
\hline DY050 & & $126^{\circ} 27^{\prime} 20$ & & Syenograni & LA- & 18 & & \\
\hline $4-2$ & $42^{\circ} 45^{\prime} 20^{\prime \prime}$ & & Zhiancun & te & ICPMS & 2 & 3 & Xu et al. (2013) \\
\hline \multirow{2}{*}{$\begin{array}{l}\text { DY050 } \\
6-1\end{array}$} & & $126^{\circ} 31^{\prime} 46$ & Xingnongcu & Syenograni & LA- & 18 & & \\
\hline & $42^{\circ} 47^{\prime} 26^{\prime \prime}$ & & $\mathrm{n}$ & te & ICPMS & 5 & 2 & Xu et al. (2013) \\
\hline \multirow{2}{*}{$\begin{array}{l}\text { DY050 } \\
9-5\end{array}$} & & $126^{\circ} 35^{\prime} 14$ & & & LA- & 18 & & \\
\hline & $42^{\circ} 59^{\prime} 18^{\prime \prime}$ & & Liushuhe & Diorite & ICPMS & 2 & 1 & Xu et al. (2013) \\
\hline \multirow{6}{*}{$\begin{array}{l}\text { DY051- } \\
1 \\
\text { DY053- } \\
2 \\
\text { DY081- } \\
1\end{array}$} & & $125^{\circ} 25^{\prime} 59$ & & Granodiorit & LA- & 17 & & \\
\hline & $42^{\circ} 28^{\prime} 03^{\prime \prime}$ & & Tuanshanzi & $\mathrm{e}$ & ICPMS & 5 & 2 & $\mathrm{Xu}$ et al. (2013) \\
\hline & & $125^{\circ} 29^{\prime} 39$ & & Granodiorit & LA- & 16 & & \\
\hline & $42^{\circ} 27^{\prime} 36^{\prime \prime}$ & & Hudingzi & $\mathrm{e}^{-10}$ & ICPMS & 7 & 3 & Xu et al. (2013) \\
\hline & & $124^{\circ} 45^{\prime} 37$ & & Quartz & & 18 & & \\
\hline & $43^{\circ} 21^{\prime} 22^{\prime \prime}$ & $"$ & Shichangtun & $\begin{array}{l}\text { diorite } \\
\text { Alkali }\end{array}$ & TIMS & 4 & 2 & Xu et al. (2013) \\
\hline DY123- & & $125^{\circ} 57^{\prime} 29$ & Dahongshila & feldspar & LA- & 25 & & \\
\hline 4 & $43^{\circ} 06^{\prime} 40^{\prime \prime}$ & $"$ & $\mathrm{zi}$ & $\begin{array}{l}\text { granite } \\
\text { Alkali }\end{array}$ & ICPMS & 1 & 2 & Xu et al. (2013) \\
\hline DY124- & & $125^{\circ} 50^{\prime} 52$ & Dahongshila & feldspar & LA- & 26 & & \\
\hline & $43^{\circ} 05^{\prime} 57^{\prime \prime}$ & & zi & granite & ICPMS & 0 & 3 & Xu et al. (2013) \\
\hline DY126- & & $125^{\circ} 50^{\prime} 28$ & & Syenograni & LA- & 25 & & \\
\hline & $42^{\circ} 54^{\prime} 26^{\prime \prime}$ & & Qingyang & te & ICPMS & 9 & 3 & Xu et al. (2013) \\
\hline DY141- & & $125^{\circ} 07^{\prime} 58$ & & Monzogran & LA- & 16 & & \\
\hline & $43^{\circ} 10^{\prime} 12^{\prime \prime}$ & & Zumin & & ICPMS & 3 & 1 & Xu et al. (2013) \\
\hline DY143- & & $125^{\circ} 06^{\prime} 22$ & & Monzogran & LA- & 25 & & \\
\hline & $43^{\circ} 02^{\prime} 31^{\prime \prime}$ & $"$ & Anyi & ite & ICPMS & 2 & 2 & Xu et al. (2013) \\
\hline
\end{tabular}




\begin{tabular}{|c|c|c|c|c|c|c|c|c|}
\hline $\begin{array}{l}\text { FW00- } \\
121\end{array}$ & $42^{\circ} 58^{\prime} 11^{\prime \prime}$ & $\begin{array}{l}125^{\circ} 51^{\prime} 48 \\
\prime \\
125^{\circ} 12^{\prime} 14\end{array}$ & Dakangshan & $\begin{array}{l}\text { Quartz } \\
\text { syenite }\end{array}$ & SHRIMP & $\begin{array}{r}26 \\
4 \\
17\end{array}$ & 5 & Xu et al. (2013) \\
\hline MG-12 & $42^{\circ} 55^{\prime} 45^{\prime \prime}$ & $124^{\circ} 48^{\prime} 11$ & Renao & $\begin{array}{l}\text { ite } \\
\text { Monzogran }\end{array}$ & SHRIMP & $\begin{array}{r}17 \\
1 \\
15\end{array}$ & 6 & Xu et al. (2013) \\
\hline MG-13 & $42^{\circ} 59^{\prime} 40^{\prime \prime}$ & $\begin{array}{l}\prime \prime \\
124^{\circ} 36^{\prime} 57\end{array}$ & Tiande & $\begin{array}{l}\text { ite } \\
\text { Quartz }\end{array}$ & SHRIMP & $\begin{array}{r}8 \\
17\end{array}$ & 3 & Xu et al. (2013) \\
\hline MG-15 & $42^{\circ} 36^{\prime} 03^{\prime \prime}$ & $" 124^{\circ} 33^{\prime} 31$ & Fangmu & $\begin{array}{l}\text { diorite } \\
\text { Granodiorit }\end{array}$ & SHRIMP & $\begin{array}{r}5 \\
15\end{array}$ & 6 & Xu et al. (2013) \\
\hline MG-16 & $42^{\circ} 36^{\prime} 34^{\prime \prime}$ & $124^{\circ} 28^{\prime} 24$ & Liushugou & $\mathrm{e}$ & SHRIMP & $\begin{array}{r}8 \\
17\end{array}$ & 4 & Xu et al. (2013) \\
\hline MG-21 & $42^{\circ} 24^{\prime} 21^{\prime \prime}$ & $124^{\circ} 55^{\prime} 44$ & Dasanjiazi & $\begin{array}{l}\text { Diorite } \\
\text { Granodiorit }\end{array}$ & SHRIMP & $\begin{array}{r}4 \\
24\end{array}$ & 3 & Xu et al. (2013) \\
\hline MG-28 & $42^{\circ} 22^{\prime} 19^{\prime \prime}$ & $\begin{array}{l}\prime \prime \\
124^{\circ} 48^{\prime} 10\end{array}$ & Songshuzui & $\begin{array}{l}\text { e } \\
\text { Monzogran }\end{array}$ & SHRIMP & $\begin{array}{r}3 \\
16\end{array}$ & 5 & Xu et al. (2013) \\
\hline MG-32 & $42^{\circ} 30^{\prime} 46^{\prime \prime}$ & $" 125^{\circ} 04^{\prime} 35$ & Helong & $\begin{array}{l}\text { ite } \\
\text { Granodiorit }\end{array}$ & SHRIMP & $\begin{array}{r}3 \\
16\end{array}$ & 4 & Xu et al. (2013) \\
\hline MG-36 & $42^{\circ} 20^{\prime} 46^{\prime \prime}$ & $\begin{array}{l}\prime \prime \\
125^{\circ} 31^{\prime} 18\end{array}$ & Tukouzi & $\begin{array}{l}\text { e } \\
\text { Monzogran }\end{array}$ & SHRIMP & $\begin{array}{r}3 \\
16\end{array}$ & 7 & Xu et al. (2013) \\
\hline MG-38 & $42^{\circ} 29^{\prime} 21^{\prime \prime}$ & $" 125^{\circ} 33^{\prime} 14$ & Hudingzi & $\begin{array}{l}\text { ite } \\
\text { Monzogran }\end{array}$ & SHRIMP & $\begin{array}{r}5 \\
16\end{array}$ & 9 & Xu et al. (2013) \\
\hline MG-40 & $42^{\circ} 26^{\prime} 00^{\prime \prime}$ & $125^{\circ} 49^{\prime} 39$ & Heishantou & $\begin{array}{l}\text { ite } \\
\text { Alkali } \\
\text { feldspar }\end{array}$ & SHRIMP & 3 & 4 & Xu et al. (2013) \\
\hline MG-42 & $42^{\circ} 43^{\prime} 24^{\prime \prime}$ & $125^{\circ} 11^{\prime} 14$ & Loushan & $\begin{array}{l}\text { granite } \\
\text { Monzogran }\end{array}$ & SHRIMP & $\begin{array}{r}5 \\
24 \\
\end{array}$ & 4 & Xu et al. (2013) \\
\hline $\begin{array}{l}\text { MG-64 } \\
\text { MG- }\end{array}$ & $42^{\circ} 32^{\prime} 52^{\prime \prime}$ & $124^{\circ} 40^{\prime} 46$ & Xiaosiping & $\begin{array}{l}\text { ite } \\
\text { Granodiorit }\end{array}$ & SHRIMP & $\begin{array}{r}2 \\
24\end{array}$ & 7 & Xu et al. (2013) \\
\hline $\begin{array}{l}103 \\
\text { MG- }\end{array}$ & $42^{\circ} 25^{\prime} 11^{\prime \prime}$ & $" 124^{\circ} 39^{\prime} 33$ & Jianshanzi & $\begin{array}{l}\mathrm{e} \\
\text { Granodiorit }\end{array}$ & SHRIMP & $\begin{array}{r}3 \\
16\end{array}$ & 5 & Xu et al. (2013) \\
\hline 108 & $42^{\circ} 24^{\prime} 13^{\prime \prime}$ & $"$ & Jianshanzi & $\begin{array}{l}\text { e } \\
\text { Quartz }\end{array}$ & SHRIMP & 3 & 2 & Xu et al. (2013) \\
\hline $\begin{array}{l}\text { MG- } \\
109\end{array}$ & $42^{\circ} 20^{\prime} 33^{\prime \prime}$ & $124^{\circ} 45^{\prime} 41$ & Lazishan & $\begin{array}{l}\text { monzodiori } \\
\text { te } \\
\text { Alkali }\end{array}$ & SHRIMP & $\begin{array}{r}12 \\
3\end{array}$ & 2 & Xu et al. (2013) \\
\hline $\begin{array}{l}\text { MG- } \\
110 \\
\text { MG- }\end{array}$ & $42^{\circ} 20^{\prime} 33^{\prime \prime}$ & $\begin{array}{l}124^{\circ} 45^{\prime} 41 \\
" 124^{\circ} 45^{\prime} 34\end{array}$ & Lazishan & $\begin{array}{l}\text { feldspar } \\
\text { granite } \\
\text { Monzogran }\end{array}$ & SHRIMP & $\begin{array}{r}12 \\
7 \\
25\end{array}$ & 3 & Xu et al. (2013) \\
\hline $\begin{array}{l}119 \\
\text { MG- }\end{array}$ & $42^{\circ} 17^{\prime} 48^{\prime \prime}$ & $\begin{array}{l}" \\
124^{\circ} 54^{\prime} 53\end{array}$ & Jianshanzi & $\begin{array}{l}\text { ite } \\
\text { Granodiorit }\end{array}$ & SHRIMP & $\begin{array}{r}4 \\
16\end{array}$ & 8 & Xu et al. (2013) \\
\hline 139 & $42^{\circ} 19^{\prime} 55^{\prime \prime}$ & $124^{\circ} 52^{\prime} 09$ & Tukouzi & $\begin{array}{l}\text { e } \\
\text { 2-mica } \\
\text { monzogran }\end{array}$ & SHRIMP & 3 & 4 & Xu et al. (2013) \\
\hline 142 & $42^{\circ} 10^{\prime} 19^{\prime \prime}$ & $124^{\circ} 46^{\prime} 52$ & Hongshilazi & $\begin{array}{l}\text { ite } \\
\text { Gt-Mus } \\
\text { monzogran }\end{array}$ & SHRIMP & 2 & 3 & Xu et al. (2013) \\
\hline $\begin{array}{l}143 \\
\text { MG- }\end{array}$ & $42^{\circ} 16^{\prime} 10^{\prime \prime}$ & $" 124^{\circ} 32^{\prime} 18$ & Fangniugou & $\begin{array}{l}\text { ite } \\
\text { Quartz }\end{array}$ & SHRIMP & $\begin{array}{r}1 \\
16\end{array}$ & 20 & Xu et al. (2013) \\
\hline & $42^{\circ} 25^{\prime} 23^{\prime \prime}$ & $\begin{array}{l}\prime \prime \\
126^{\circ} 08^{\prime} 30\end{array}$ & Erlingba & $\begin{array}{l}\text { diorite } \\
\text { Granodiorit }\end{array}$ & $\begin{array}{l}\text { SHRIMP } \\
\text { LA- }\end{array}$ & $\begin{array}{r}9 \\
17\end{array}$ & 3 & Xu et al. (2013) \\
\hline 1 & $42^{\circ} 59^{\prime} 25^{\prime \prime}$ & $125^{\circ} 36^{\prime} 29$ & Shancheshan & $\begin{array}{l}\text { e } \\
\text { Monzogran }\end{array}$ & $\begin{array}{l}\text { ICPMS } \\
\text { LA- }\end{array}$ & $\begin{array}{r}5 \\
16\end{array}$ & 3 & Xu et al. (2013) \\
\hline CH11 & $43^{\circ} 37^{\prime} 47^{\prime \prime}$ & $\begin{array}{l}\prime \prime \\
125^{\circ} 36^{\prime} 13\end{array}$ & Wuxing & $\begin{array}{l}\text { ite } \\
\text { Syenograni }\end{array}$ & $\begin{array}{l}\text { ICPMS } \\
\text { LA- }\end{array}$ & $\begin{array}{r}2 \\
15\end{array}$ & 2 & Xu et al. (2008) \\
\hline X13 & $43^{\circ} 36^{\prime} 05^{\prime \prime}$ & $" 123^{\circ} 25^{\prime} 53$ & Wuxing & $\begin{array}{l}\text { te } \\
\text { Granodiorit }\end{array}$ & ICPMS & $\begin{array}{r}9 \\
28\end{array}$ & 3 & $\begin{array}{l}\text { Xu et al. (2008) } \\
\text { Zhang et al. }\end{array}$ \\
\hline FK51 & $42^{\circ} 30^{\prime} 13^{\prime \prime}$ & $" 123^{\circ} 15^{\prime} 45$ & Faku & $\begin{array}{l}\mathrm{e} \\
\text { Granodiorit }\end{array}$ & SHRIMP & $\begin{array}{r}4 \\
26\end{array}$ & 3 & $\begin{array}{l}\text { (2005) } \\
\text { Zhang et al. }\end{array}$ \\
\hline FK53 & $42^{\circ} 29^{\prime} 49^{\prime \prime}$ & $" 123^{\circ} 29^{\prime} 32$ & Faku & e & SHRIMP & $\begin{array}{r}5 \\
24\end{array}$ & 4 & $\begin{array}{l}\text { (2005) } \\
\text { Zhang et al. }\end{array}$ \\
\hline $\begin{array}{l}\text { FK04-5 } \\
\text { HWC1- }\end{array}$ & $42^{\circ} 29^{\prime} 46^{\prime \prime}$ & $" 127^{\circ} 14^{\prime} 01$ & $\begin{array}{l}\text { Faku } \\
\text { Pingfang }\end{array}$ & $\begin{array}{l}\text { Gabbro } \\
\text { gabbro- }\end{array}$ & $\begin{array}{l}\text { SHRIMP } \\
\text { LA- }\end{array}$ & $\begin{array}{r}1 \\
18\end{array}$ & 6 & (2009) \\
\hline 1 & $45^{\circ} 08^{\prime} 29.0^{\prime \prime}$ & $.7^{\prime \prime}$ & pluton & diorite & ICPMS & 3 & 1 & Yu et al., 2012 \\
\hline $\begin{array}{l}\text { HDL1- } \\
1 \\
\text { HDL1- } \\
2\end{array}$ & $\begin{array}{l}\text { Dongfenglin } \\
\text { chang } \\
\text { Dongfenglin } \\
\text { chang }\end{array}$ & $45^{\circ} 43^{\prime} 56^{\prime \prime}$ & $129^{\circ} 17^{\prime} 21^{\prime \prime}$ & Hongguang & $\begin{array}{l}\text { Meta- } \\
\text { basalt }\end{array}$ & $\begin{array}{r}20 \\
9 \\
21 \\
4\end{array}$ & 3 & $\begin{array}{l}\text { Wu et al. } \\
(2011) \\
\text { Wu et al. } \\
(2011)\end{array}$ \\
\hline
\end{tabular}


Cretaceous-Cenozoic thermo-tectonic evolution and provenance analysis of the basement and some sedimentary successions northeast of the Songliao Basin, NE China

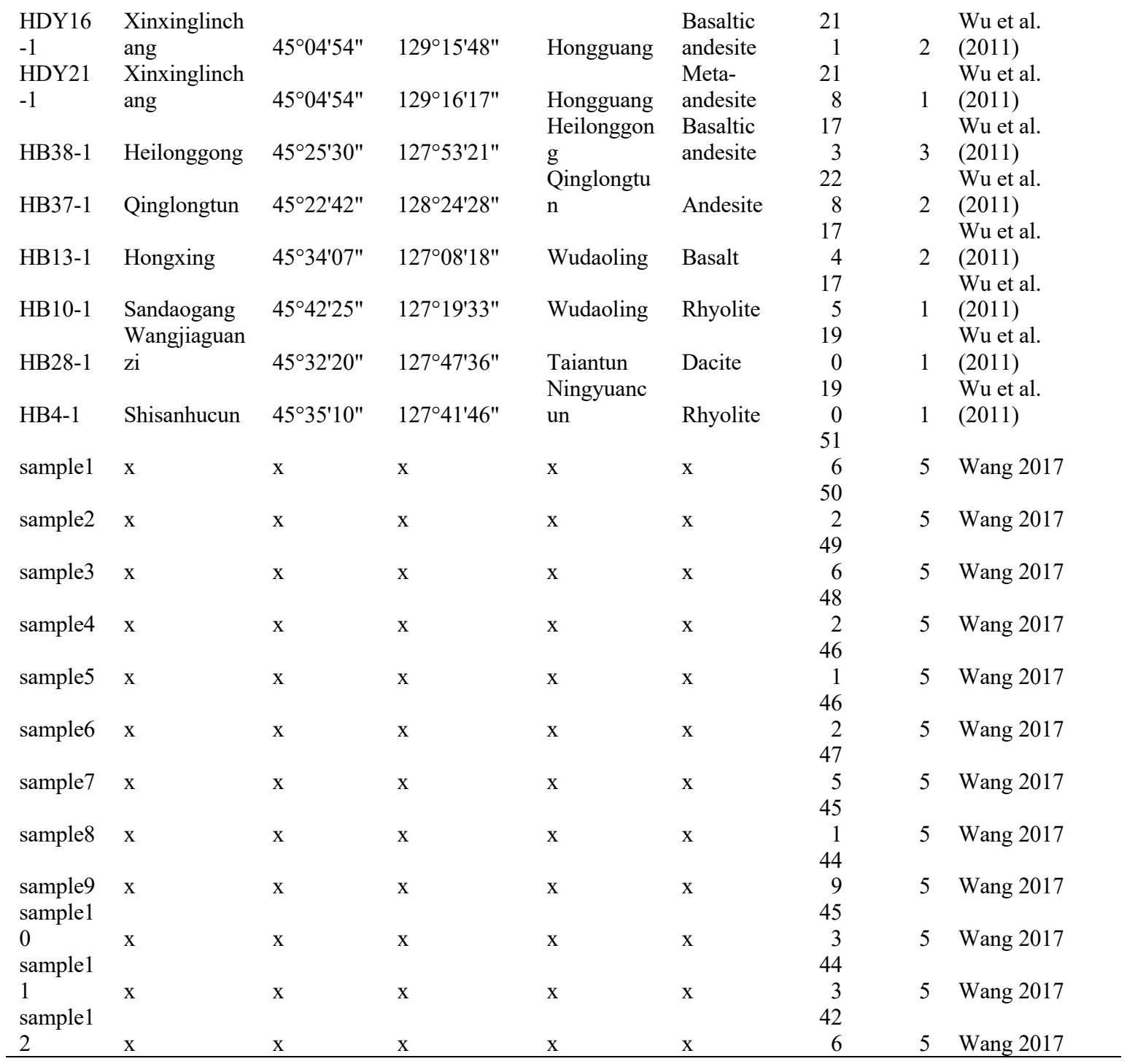

Igenous rock in Grat Xing'an Range

\begin{tabular}{|c|c|c|c|c|c|c|c|c|}
\hline sample & Latitude & $\begin{array}{l}\text { Longtitud } \\
\text { e_1 }\end{array}$ & Location & $\begin{array}{l}\text { Lithology } \\
\text { Granodiorit }\end{array}$ & $\begin{array}{l}\text { Method } \\
\text { LA- }\end{array}$ & $\begin{array}{l}\mathrm{Ag} \\
\mathrm{e} \\
11\end{array}$ & error & $\begin{array}{l}\text { Reference } \\
\text { Wu et al. }\end{array}$ \\
\hline 0066-5 & $50^{\circ} 40^{\prime}$ & $121^{\circ} 36^{\prime}$ & Yitulihe & e & ICPMS & 8 & 1 & $(2011)$ \\
\hline 0071-3 & $50^{\circ} 41^{\prime}$ & $123^{\circ} 10^{\prime}$ & Ganhe & $\begin{array}{l}\text { Monzogran } \\
\text { ite }\end{array}$ & $\begin{array}{l}\text { LA- } \\
\text { ICPMS }\end{array}$ & $\begin{array}{r}30 \\
4\end{array}$ & 5 & $\begin{array}{l}\text { Wu et al. } \\
\text { (2011) }\end{array}$ \\
\hline $0075-7$ & $51^{\circ} 36^{\prime} 23^{\prime \prime}$ & $124^{\circ} 19^{\prime} 26$ & Xinlinzhen & $\begin{array}{l}\text { Granodiorit } \\
\mathrm{e}\end{array}$ & $\begin{array}{l}\text { LA- } \\
\text { ICPMS }\end{array}$ & $\begin{array}{r}13 \\
2\end{array}$ & 3 & $\begin{array}{l}\text { Y.L. Zhang et } \\
\text { al. (2008) }\end{array}$ \\
\hline 0076-9 & $51^{\circ} 37^{\prime} 40^{\prime \prime}$ & $\begin{array}{l}124^{\circ} 09^{\prime} 23 \\
"\end{array}$ & Xinlinzhen & $\begin{array}{l}\text { Granodiorit } \\
\text { e } \\
\text { Alkali }\end{array}$ & $\begin{array}{l}\text { LA- } \\
\text { ICPMS }\end{array}$ & $\begin{array}{r}13 \\
1\end{array}$ & 3 & $\begin{array}{l}\text { Y.L. Zhang et } \\
\text { al. }(2008)\end{array}$ \\
\hline 0116-1 & $51^{\circ} 26^{\prime} 18^{\prime \prime}$ & $122^{\circ} 14^{\prime} 40$ & Niuerhe & $\begin{array}{l}\text { feldspar } \\
\text { granite }\end{array}$ & $\begin{array}{l}\text { LA- } \\
\text { ICPMS }\end{array}$ & $\begin{array}{r}12 \\
5\end{array}$ & 2 & $\begin{array}{l}\text { Wu et al. } \\
\text { (2011) }\end{array}$ \\
\hline GW030 & & $124^{\circ} 23^{\prime} 05$ & & Monzogran & LA- & 31 & & Wu et al. \\
\hline $\begin{array}{l}08 \\
\text { GW030 }\end{array}$ & $51^{\circ} 29^{\prime} 49^{\prime \prime}$ & $\begin{array}{l}" 124^{\circ} 23^{\prime} 05\end{array}$ & Tayuan & ite & $\begin{array}{l}\text { ICPMS } \\
\text { LA- }\end{array}$ & $\begin{array}{r}8 \\
32\end{array}$ & 4 & $\begin{array}{l}\text { (2011) } \\
\text { Wu et al. }\end{array}$ \\
\hline 15 & $51^{\circ} 29^{\prime} 49^{\prime \prime}$ & & Tayuan & Gabbro & ICPMS & 2 & 5 & $(2011)$ \\
\hline GW030 & & $124^{\circ} 16^{\prime} 27$ & & Monzogran & LA- & 22 & & Wu et al. \\
\hline 17 & $51^{\circ} 23^{\prime} 17^{\prime \prime}$ & & Tayuan & ite & ICPMS & 0 & 3 & $(2011)$ \\
\hline GW030 & & $124^{\circ} 47^{\prime} 48$ & & & LA- & 49 & & Ge et al. \\
\hline 35 & $52^{\circ} 21^{\prime} 42^{\prime \prime}$ & $"$ & Tahe & $\begin{array}{l}\text { Gabbro } \\
\text { Alkali }\end{array}$ & ICPMS & 0 & 2 & $(2005 a)$ \\
\hline $\begin{array}{l}\text { GW030 } \\
36\end{array}$ & $52^{\circ} 21^{\prime} 42^{\prime \prime}$ & $124^{\circ} 47^{\prime} 48$ & Tahe & $\begin{array}{l}\text { feldspar } \\
\text { granite }\end{array}$ & $\begin{array}{l}\text { LA- } \\
\text { ICPMS }\end{array}$ & $\begin{array}{r}47 \\
9\end{array}$ & 3 & $\begin{array}{l}\text { Ge et al. } \\
\text { (2005a) }\end{array}$ \\
\hline
\end{tabular}




\begin{tabular}{|c|c|c|c|c|c|c|c|c|}
\hline $\begin{array}{l}\text { GW030 } \\
42\end{array}$ & $52^{\circ} 07^{\prime} 47^{\prime \prime}$ & $125^{\circ} 59^{\prime} 01$ & $\begin{array}{l}\text { Xinghuaduk } \\
\text { ou }\end{array}$ & Gneiss & $\begin{array}{l}\text { LA- } \\
\text { ICPMS }\end{array}$ & $\begin{array}{r}84 \\
3\end{array}$ & 6 & $\begin{array}{l}\text { Wu et al. } \\
\text { (2011) }\end{array}$ \\
\hline GW030 & & $125^{\circ} 59^{\prime} 01$ & Xinghuaduk & Monzogran & LA- & 47 & & Wu et al. \\
\hline 44 & $52^{\circ} 07^{\prime} 47^{\prime \prime}$ & $"$ & ou & ite & ICPMS & 7 & 8 & $(2011)$ \\
\hline GW030 & & $124^{\circ} 50^{\prime} 05$ & & Leucogabb & LA- & 32 & & Zhou et al \\
\hline 57 & $52^{\circ} 26^{\prime} 33^{\prime \prime}$ & & Zhualuogu & ro & ICPMS & 8 & 7 & $(2005)$ \\
\hline GW030 & & $124^{\circ} 50^{\prime} 10$ & & Leucogabb & LA- & 33 & & Zhou et al \\
\hline 61 & $52^{\circ} 26^{\prime} 32^{\prime \prime}$ & & Zhualuogu & ro & ICPMS & 6 & 15 & (2005) \\
\hline GW030 & & $124^{\circ} 42^{\prime} 16$ & & Syenograni & LA- & 49 & & Ge et al. \\
\hline 70 & $52^{\circ} 21^{\prime} 16^{\prime \prime}$ & & Tahe & te & ICPMS & 4 & 9 & (2005a) \\
\hline GW030 & & $124^{\circ} 32^{\prime} 43$ & & Quartz & LA- & 48 & & Ge et al. \\
\hline 85 & $52^{\circ} 18^{\prime} 35^{\prime \prime}$ & & Tahe & monzonite & ICPMS & 5 & 3 & (2005a) \\
\hline GW030 & & $124^{\circ} 24^{\prime} 06$ & & Syenograni & LA- & 49 & & Ge et al. \\
\hline 90 & $52^{\circ} 18^{\prime} 09^{\prime \prime}$ & $"$ & Tahe & $\begin{array}{l}\text { te } \\
\text { Alkali }\end{array}$ & ICPMS & 2 & 5 & $(2005 a)$ \\
\hline GW031 & & $123^{\circ} 39^{\prime} 57$ & & feldspar & LA- & 79 & & Wu et al. \\
\hline 29 & $52^{\circ} 26^{\prime} 40^{\prime \prime}$ & $"$ & Bishui & granite & ICPMS & 5 & 13 & $(2011)$ \\
\hline GW031 & & $123^{\circ} 36^{\prime} 55$ & & Granodiorit & LA- & 79 & & Wu et al. \\
\hline 33 & $52^{\circ} 25^{\prime} 13^{\prime \prime}$ & $"$ & Bishui & e & ICPMS & 2 & 5 & $(2011)$ \\
\hline GW031 & & $123^{\circ} 41^{\prime} 09$ & & Monzogran & LA- & 18 & & Wu et al. \\
\hline 38 & $52^{\circ} 38^{\prime} 27^{\prime \prime}$ & $"$ & Pangu & ite & ICPMS & 2 & 1 & (2011) \\
\hline GW031 & & $123^{\circ} 08^{\prime} 56$ & & & LA- & 20 & & Wu et al. \\
\hline 77 & $52^{\circ} 38^{\prime} 58^{\prime \prime}$ & & Lvlin & Gneiss & ICPMS & 9 & 4 & $(2011)$ \\
\hline GW031 & & $123^{\circ} 08^{\prime} 56$ & & Quartz & LA- & 19 & & $\mathrm{Wu}$ et al. \\
\hline 81 & $52^{\circ} 38^{\prime} 58^{\prime \prime}$ & $"$ & Lvlin & $\begin{array}{l}\text { diorite } \\
\text { Alkali }\end{array}$ & ICPMS & 2 & 3 & (2011) \\
\hline GW031 & & $123^{\circ} 05^{\prime} 00$ & & feldspar & LA- & 18 & & Wu et al. \\
\hline 93 & $52^{\circ} 27^{\prime} 59^{\prime \prime}$ & $"$ & Lvlin & granite & ICPMS & 7 & 2 & $(2011)$ \\
\hline GW032 & & $123^{\circ} 36^{\prime} 04$ & & Monzogran & LA- & 19 & & Wu et al. \\
\hline 07 & $52^{\circ} 49^{\prime} 03^{\prime \prime}$ & $"$ & Xilinji & ite & ICPMS & 3 & 2 & $(2011)$ \\
\hline GW032 & & $122^{\circ} 18^{\prime} 04$ & & Monzogran & LA- & 48 & & Wu et al. \\
\hline 20 & $52^{\circ} 50^{\prime} 59^{\prime \prime}$ & $"$ & Mangui & ite & ICPMS & 2 & 4 & $(2011)$ \\
\hline GW032 & & $121^{\circ} 54^{\prime} 58$ & & Monzogran & LA- & 18 & & Wu et al. \\
\hline 41 & $52^{\circ} 42^{\prime} 02^{\prime \prime}$ & & Fukeshan & ite & ICPMS & 9 & 2 & (2011) \\
\hline GW032 & & $121^{\circ} 53^{\prime} 21$ & & Monzogran & LA- & 18 & & Wu et al. \\
\hline 51 & $52^{\circ} 38^{\prime} 14^{\prime \prime}$ & & Fukeshan & ite & ICPMS & 9 & 2 & $(2011)$ \\
\hline GW032 & & $121^{\circ} 52^{\prime} 29$ & & Monzogran & LA- & 19 & & Wu et al. \\
\hline 55 & $52^{\circ} 28^{\prime} 41^{\prime \prime}$ & & Fukeshan & ite & ICPMS & 4 & 7 & (2011) \\
\hline GW032 & & $122^{\circ} 30^{\prime} 30$ & & Syenograni & LA- & 48 & & Wu et al. \\
\hline 58 & $52^{\circ} 59^{\prime} 24^{\prime \prime}$ & & Mangui & te & ICPMS & 0 & 3 & $(2011)$ \\
\hline GW032 & & $122^{\circ} 03^{\prime} 54$ & & Syenograni & LA- & 18 & & Wu et al. \\
\hline 69 & $52^{\circ} 07^{\prime} 36^{\prime \prime}$ & & Mangui & te & ICPMS & 9 & 2 & $(2011)$ \\
\hline GW032 & & $122^{\circ} 05^{\prime} 33$ & & & LA- & 13 & & Wu et al. \\
\hline 85 & $52^{\circ} 03^{\prime} 27^{\prime \prime}$ & $"$ & Mangui & $\begin{array}{l}\text { Dolerite } \\
\text { Alkali }\end{array}$ & ICPMS & 2 & 2 & (2011) \\
\hline GW032 & & $122^{\circ} 05^{\prime} 33$ & & feldspar & LA- & 92 & & Wu et al. \\
\hline 86 & $52^{\circ} 03^{\prime} 27^{\prime \prime}$ & & Mangui & granite & ICPMS & 7 & 13 & $(2011)$ \\
\hline GW032 & & $121^{\circ} 53^{\prime} 39$ & & Monzogran & LA- & 18 & & Wu et al. \\
\hline 90 & $52^{\circ} 05^{\prime} 41^{\prime \prime}$ & & Mangui & ite & ICPMS & 7 & 3 & $(2011)$ \\
\hline GW040 & & $121^{\circ} 30^{\prime} 15$ & & Syenograni & LA- & 20 & & Wu et al. \\
\hline 38 & $51^{\circ} 20^{\prime} 40^{\prime \prime}$ & & Jinhezhen & te & ICPMS & 3 & 4 & $(2011)$ \\
\hline GW040 & & $121^{\circ} 30^{\prime} 35$ & & Syenograni & LA- & 19 & & Wu et al. \\
\hline 39 & $51^{\circ} 21^{\prime} 51^{\prime \prime}$ & & Jinhezhen & te & ICPMS & 7 & 4 & $(2011)$ \\
\hline GW040 & & $121^{\circ} 49^{\prime} 35$ & & Monzogran & LA- & 45 & & Wu et al. \\
\hline 47 & $51^{\circ} 40^{\prime} 07^{\prime \prime}$ & $"$ & Alongshan & ite & ICPMS & 6 & 7 & $(2011)$ \\
\hline GW040 & & $121^{\circ} 34^{\prime} 42$ & & Monzogran & LA- & 20 & & Wu et al. \\
\hline 54 & $51^{\circ} 37^{\prime} 34^{\prime \prime}$ & & Aluga & ite & ICPMS & 6 & 2 & $(2011)$ \\
\hline GW040 & & $121^{\circ} 53^{\prime} 32$ & & & LA- & 20 & & Wu et al. \\
\hline 61 & $51^{\circ} 50^{\prime} 52^{\prime \prime}$ & & Awuni & Diorite & ICPMS & 8 & 1 & $(2011)$ \\
\hline GW040 & & $121^{\circ} 17^{\prime} 17$ & & Monzogran & LA- & 81 & & Wu et al. \\
\hline 67 & $52^{\circ} 19^{\prime} 49^{\prime \prime}$ & $"$ & Qiqian & ite & ICPMS & 7 & 6 & $(2011)$ \\
\hline GW040 & & $121^{\circ} 19^{\prime} 49$ & & Monzogran & LA- & 19 & & Wu et al. \\
\hline 69 & $52^{\circ} 25^{\prime} 28^{\prime \prime}$ & $"$ & Manguixi & ite & ICPMS & 5 & 2 & $(2011)$ \\
\hline GW040 & & $121^{\circ} 04^{\prime} 57$ & & Syenograni & LA- & 22 & & Wu et al. \\
\hline 77 & $52^{\circ} 30^{\prime} 34^{\prime \prime}$ & $"$ & Manguixi & te & ICPMS & 0 & 3 & $(2011)$ \\
\hline GW040 & & $120^{\circ} 42^{\prime} 58$ & & & LA- & 24 & & Wu et al. \\
\hline 88 & $52^{\circ} 53^{\prime} 40^{\prime \prime}$ & $"$ & Guanhuzhan & Felsic dyke & ICPMS & 9 & 4 & $(2011)$ \\
\hline
\end{tabular}


Cretaceous-Cenozoic thermo-tectonic evolution and provenance analysis of the basement and some sedimentary successions northeast of the Songliao Basin, NE China

\begin{tabular}{|c|c|c|c|c|c|c|c|c|}
\hline $\begin{array}{l}\text { GW040 } \\
92 \\
\text { GW040 }\end{array}$ & $52^{\circ} 40^{\prime} 58^{\prime \prime}$ & $\begin{array}{l}120^{\circ} 51^{\prime} 01 \\
" \\
120^{\circ} 46^{\prime} 41\end{array}$ & Guanhuzhan & $\begin{array}{l}\text { Monzogran } \\
\text { ite }\end{array}$ & $\begin{array}{l}\text { LA- } \\
\text { ICPMS } \\
\text { LA- }\end{array}$ & $\begin{array}{r}46 \\
4 \\
41\end{array}$ & 4 & $\begin{array}{l}\text { Wu et al. } \\
(2011) \\
\text { Wu et al. }\end{array}$ \\
\hline 96 & $52^{\circ} 38^{\prime} 01^{\prime \prime}$ & " & Guanhuzhan & Diorite & ICPMS & 7 & 6 & (2011) \\
\hline GW040 & & $120^{\circ} 57^{\prime} 41$ & Guanhuzhan & Monzogran & LA- & 20 & & Wu et al. \\
\hline 98 & $52^{\circ} 33^{\prime} 39^{\prime \prime}$ & & nan & ite & ICPMS & 1 & 1 & $(2011)$ \\
\hline GW041 & & $120^{\circ} 51^{\prime} 32$ & Guanhuzhan & Monzogran & LA- & 41 & & Wu et al. \\
\hline 05 & $52^{\circ} 01^{\prime} 22^{\prime \prime}$ & & nan & ite & ICPMS & 6 & 4 & (2011) \\
\hline GW041 & & $120^{\circ} 39^{\prime} 56$ & & Monzogran & LA- & 19 & & Wu et al. \\
\hline 14 & $51^{\circ} 19^{\prime} 54^{\prime \prime}$ & & Moerdaoga & ite & ICPMS & 8 & 2 & (2011) \\
\hline GW041 & & $120^{\circ} 34^{\prime} 52$ & & Quartz & LA- & 24 & & Wu et al. \\
\hline 23 & $51^{\circ} 19^{\prime} 51^{\prime \prime}$ & & Kutiankan & diorite & ICPMS & 4 & 4 & (2011) \\
\hline GW041 & & $120^{\circ} 22^{\prime} 03$ & & Monzogran & LA- & 19 & & Wu et al. \\
\hline 26 & $51^{\circ} 19^{\prime} 08^{\prime \prime}$ & & Bajianfang & ite & ICPMS & 6 & 3 & $(2011)$ \\
\hline GW050 & & $125^{\circ} 05^{\prime} 25$ & & Monzogran & LA- & 48 & & Ge et al. \\
\hline 37 & $52^{\circ} 21^{\prime} 11^{\prime \prime}$ & & Chalaban & ite & ICPMS & 1 & 3 & $(2007 a)$ \\
\hline GW050 & & $125^{\circ} 05^{\prime} 53$ & & Monzogran & LA- & 49 & & Ge et al. \\
\hline 49 & $52^{\circ} 25^{\prime} 02^{\prime \prime}$ & & Shijiuzhan & ite & ICPMS & 9 & 2 & (2007a) \\
\hline GW050 & & $125^{\circ} 45^{\prime} 15$ & & Monzogran & LA- & 50 & & \\
\hline 53 & $52^{\circ} 33^{\prime} 12^{\prime \prime}$ & $"$ & Halabaqi & ite & ICPMS & 0 & 2 & Sui et al. (2006) \\
\hline GW050 & & $125^{\circ} 52^{\prime} 33$ & & Monzogran & LA- & 46 & & Ge et al. \\
\hline 56 & $52^{\circ} 23^{\prime} 28^{\prime \prime}$ & & Shibazhan & ite & ICPMS & 0 & 1 & $(2007 a)$ \\
\hline GW050 & & $125^{\circ} 49^{\prime} 53$ & & Granodiorit & LA- & 46 & & \\
\hline 58 & $52^{\circ} 24^{\prime} 21^{\prime \prime}$ & & Halabaqi & e & ICPMS & 1 & 1 & Sui et al. (2006) \\
\hline GW050 & & $126^{\circ} 08^{\prime} 25$ & & Granodiorit & LA- & 19 & & \\
\hline 67 & $52^{\circ} 31^{\prime} 50^{\prime \prime}$ & & Zhengqi & e & ICPMS & 0 & 1 & Sui et al. (2007) \\
\hline GW050 & & $125^{\circ} 38^{\prime} 40$ & & & LA- & 18 & & \\
\hline 99 & $52^{\circ} 02^{\prime} 43^{\prime \prime}$ & & Hanjiayuanzi & Diorite & ICPMS & 8 & 2 & Sui et al. (2007) \\
\hline GW051 & & $125^{\circ} 39^{\prime} 24$ & & Monzogran & LA- & 50 & & Ge et al. \\
\hline 04 & $52^{\circ} 00^{\prime} 42^{\prime \prime}$ & & Hanjiayuanzi & ite & ICPMS & 1 & 2 & $(2007 a)$ \\
\hline 29 & $48^{\circ} 03^{\prime} 30^{\prime \prime}$ & $\begin{array}{l}121^{\circ} 12^{\prime} 27 \\
122^{\circ} 46^{\prime} 19\end{array}$ & Langfeng & $\begin{array}{l}\text { Syenograni } \\
\text { te } \\
\text { Syenograni }\end{array}$ & $\begin{array}{l}\text { LA- } \\
\text { ICPMS } \\
\text { LA- }\end{array}$ & $\begin{array}{r}33 \\
7 \\
30\end{array}$ & 8 & $\begin{array}{l}\text { Wu et al. } \\
\text { (2011) } \\
\text { Wu et al. }\end{array}$ \\
\hline $9411-26$ & $48^{\circ} 00^{\prime} 12^{\prime \prime}$ & & Zhalantun & te & ICPMS & $\begin{array}{r}50 \\
1\end{array}$ & 3 & (2011) \\
\hline 9437 & $48^{\circ} 48^{\prime} 26^{\prime \prime}$ & $121^{\circ} 42^{\prime} 11$ & Xing'an & $\begin{array}{l}\text { Monzogran } \\
\text { ite } \\
\text { Alkali }\end{array}$ & $\begin{array}{l}\text { LA- } \\
\text { ICPMS }\end{array}$ & $\begin{array}{r}30 \\
9\end{array}$ & 4 & $\begin{array}{l}\text { Wu et al. } \\
(2011)\end{array}$ \\
\hline $9801-2$ & $49^{\circ} 05^{\prime} 30^{\prime \prime}$ & $\begin{array}{l}125^{\circ} 12^{\prime} 10 \\
" \\
125^{\circ} 24^{\prime} 45\end{array}$ & $\begin{array}{l}\text { Xiaoshantun } \\
\text { Sizhanlincha }\end{array}$ & $\begin{array}{l}\text { feldspar } \\
\text { granite } \\
\text { Syenograni }\end{array}$ & TIMS & $\begin{array}{r}28 \\
5 \\
28\end{array}$ & 2 & $\begin{array}{l}\text { Wu et al. } \\
(2002) \\
\text { Wu et al. }\end{array}$ \\
\hline $9805-2$ & $49^{\circ} 54^{\prime} 32^{\prime \prime}$ & $125^{\circ} 24^{\prime} 50$ & ng & $\begin{array}{l}\text { te } \\
\text { Syenograni }\end{array}$ & TIMS & $\begin{array}{r}20 \\
2 \\
26\end{array}$ & 4 & $\begin{array}{l}(2002) \\
\text { Wu et al. }\end{array}$ \\
\hline $9806-3$ & $49^{\circ} 58^{\prime} 30^{\prime \prime}$ & $127^{\circ} 18^{\prime} 15$ & $\begin{array}{l}\text { Guguhe } \\
\text { Shangmacha }\end{array}$ & $\begin{array}{l}\text { te } \\
\text { Syenograni }\end{array}$ & TIMS & $\begin{array}{r}4 \\
10\end{array}$ & 5 & $\begin{array}{l}(2002) \\
\text { Wu et al }\end{array}$ \\
\hline $9832-2$ & $50^{\circ} 21^{\prime} 30^{\prime \prime}$ & $\begin{array}{l}" 126^{\circ} 28^{\prime} 10\end{array}$ & ng & $\begin{array}{l}\text { te } \\
\text { Syenograni }\end{array}$ & TIMS & $\begin{array}{r}6 \\
29\end{array}$ & 2 & $\begin{array}{l}(2002) \\
\text { Wu et al. }\end{array}$ \\
\hline 9843-1 & $50^{\circ} 14^{\prime} 05^{\prime \prime}$ & $126^{\circ} 50^{\prime} 00$ & Daheishan & $\begin{array}{l}\text { te } \\
\text { Syenograni }\end{array}$ & TIMS & $\begin{array}{r}2 \\
26\end{array}$ & 4 & $\begin{array}{l}(2002) \\
\text { Wu et al. }\end{array}$ \\
\hline $9849-1$ & $49^{\circ} 33^{\prime} 20^{\prime \prime}$ & & Songmushan & te & TIMS & 0 & 3 & (2002) \\
\hline $\begin{array}{l}\text { FW04- } \\
403\end{array}$ & $49^{\circ} 33^{\prime} 41^{\prime \prime}$ & $123^{\circ} 45^{\prime} 44$ & Longtou & $\begin{array}{l}\text { Monzogran } \\
\text { ite }\end{array}$ & $\begin{array}{l}\text { LA- } \\
\text { ICPMS }\end{array}$ & $\begin{array}{r}12 \\
9\end{array}$ & 2 & $\begin{array}{l}\text { Wu et al. } \\
\text { (2011) }\end{array}$ \\
\hline FW04- & & $123^{\circ} 21^{\prime} 29$ & & Monzogran & $\begin{array}{l}\text { LA- } \\
\text { ICPMS }\end{array}$ & 13 & 1 & Wu et al. \\
\hline $\begin{array}{l}405 \\
\text { FW04- }\end{array}$ & $49^{\circ} 33^{\prime} 03^{\prime \prime}$ & $123^{\circ} 46^{\prime} 04$ & $\begin{array}{l}\text { Dalaibin } \\
\text { Yilinongcha }\end{array}$ & Monzogran & LA- & 13 & & Wu et al. \\
\hline 407 & $49^{\circ} 14^{\prime} 31^{\prime \prime}$ & & ng & ite & ICPMS & 1 & 1 & (2011) \\
\hline FW04- & & $124^{\circ} 04^{\prime} 18$ & & Granodiorit & LA- & 14 & & Wu et al. \\
\hline $\begin{array}{l}412 \\
\text { FW04- }\end{array}$ & $49^{\circ} 35^{\prime} 35^{\prime \prime}$ & $\begin{array}{l}\prime \prime \\
123^{\circ} 45^{\prime} 33\end{array}$ & Yili & $\begin{array}{l}\text { e } \\
\text { Monzogran }\end{array}$ & $\begin{array}{l}\text { ICPMS } \\
\text { LA- }\end{array}$ & $\begin{array}{r}2 \\
13\end{array}$ & 1 & $\begin{array}{l}\text { (2011) } \\
\text { Wu et al. }\end{array}$ \\
\hline 413 & $49^{\circ} 10^{\prime} 38^{\prime \prime}$ & " & Nuomin & $\begin{array}{l}\text { ite } \\
\text { 2-mica }\end{array}$ & ICPMS & 0 & 1 & (2011) \\
\hline $\begin{array}{l}\text { FW04- } \\
414\end{array}$ & $48^{\circ} 15^{\prime} 41^{\prime \prime}$ & $123^{\circ} 27^{\prime} 33$ & Dechang & $\begin{array}{l}\text { monzogran } \\
\text { ite }\end{array}$ & $\begin{array}{l}\text { LA- } \\
\text { ICPMS }\end{array}$ & $\begin{array}{r}16 \\
6\end{array}$ & 2 & $\begin{array}{l}\text { Wu et al. } \\
\text { (2011) }\end{array}$ \\
\hline $\begin{array}{l}\text { FW04- } \\
416\end{array}$ & $48^{\circ} 40^{\prime} 23^{\prime \prime}$ & $123^{\circ} 26^{\prime} 00$ & Sanchahe & $\begin{array}{l}\text { Monzogran } \\
\text { ite }\end{array}$ & $\begin{array}{l}\text { LA- } \\
\text { ICPMS }\end{array}$ & $\begin{array}{r}17 \\
9\end{array}$ & 1 & $\begin{array}{l}\text { Wu et al. } \\
\text { (2011) }\end{array}$ \\
\hline $\begin{array}{l}\text { FW04- } \\
417\end{array}$ & $48^{\circ} 37^{\prime} 57^{\prime \prime}$ & $123^{\circ} 13^{\prime} 27$ & Sanchahe & $\begin{array}{l}\text { Monzogran } \\
\text { ite }\end{array}$ & $\begin{array}{l}\text { LA- } \\
\text { ICPMS }\end{array}$ & $\begin{array}{r}15 \\
7\end{array}$ & 2 & Wu et al. \\
\hline
\end{tabular}




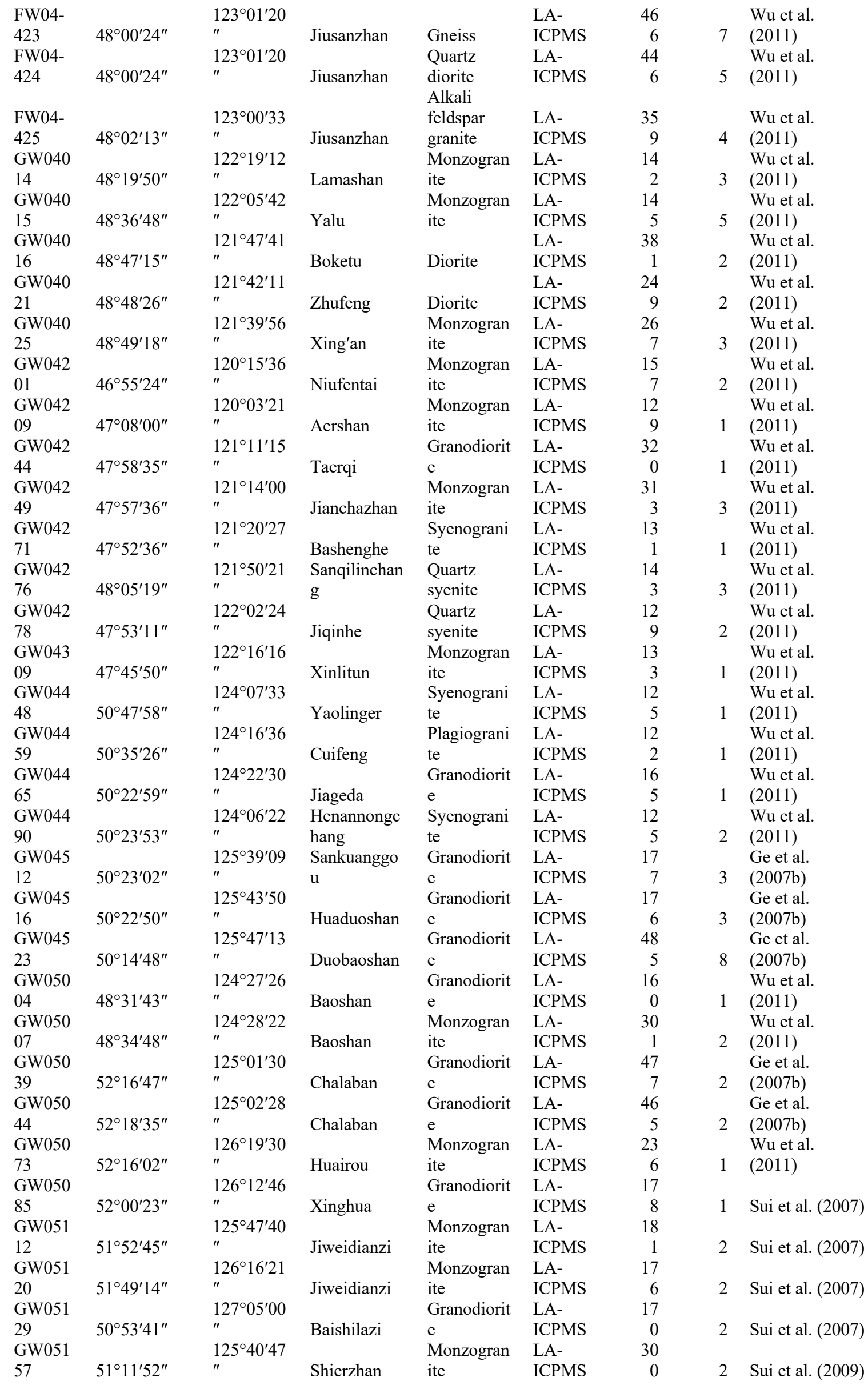


Cretaceous-Cenozoic thermo-tectonic evolution and provenance analysis of the basement and some sedimentary successions northeast of the Songliao Basin, NE China

\begin{tabular}{|c|c|c|c|c|c|c|c|c|}
\hline GW070 & & $126^{\circ} 54^{\prime} 13$ & & Granodiorit & LA- & 31 & & Y.L. Zhang et \\
\hline 05 & $49^{\circ} 02^{\prime} 47^{\prime \prime}$ & & Zhengdashan & e & ICPMS & 9 & 3 & al. (2010) \\
\hline GW070 & & $126^{\circ} 54^{\prime} 15$ & & Monzogran & LA- & 31 & & Y.L. Zhang et \\
\hline 07 & $49^{\circ} 02^{\prime} 51^{\prime \prime}$ & & Zhengdashan & ite & ICPMS & 6 & 4 & al. (2010) \\
\hline GW070 & & $126^{\circ} 54^{\prime} 38$ & & Monzogran & LA- & 31 & & Y.L. Zhang et \\
\hline 09 & $49^{\circ} 05^{\prime} 50^{\prime \prime}$ & & Zhengdashan & ite & ICPMS & 5 & 4 & al. $(2010)$ \\
\hline GW070 & & $126^{\circ} 31^{\prime} 04$ & & Monzogran & LA- & 16 & & Y.L. Zhang et \\
\hline 12 & $48^{\circ} 50^{\prime} 48^{\prime \prime}$ & & Molabushan & ite & ICPMS & 9 & 3 & al. (2010) \\
\hline GW070 & & $126^{\circ} 22^{\prime} 23$ & Chaoyanglin & Monzogran & LA- & 18 & & Y.L. Zhang et \\
\hline 17 & $49^{\circ} 01^{\prime} 58^{\prime \prime}$ & & chang & ite & ICPMS & 7 & 6 & al. (2010) \\
\hline GW070 & & $126^{\circ} 21^{\prime} 44$ & Chaoyanglin & Monzogran & LA- & 17 & & Y.L. Zhang et \\
\hline 19 & $48^{\circ} 56^{\prime} 22^{\prime \prime}$ & & chang & ite & ICPMS & 1 & 4 & $\begin{array}{l}\text { al. (2010) } \\
\text { Wu et al., }\end{array}$ \\
\hline & & $119^{\circ} 47^{\prime} 00$ & & Syenograni & & 13 & & 2003a, Wu et \\
\hline YE-1 & $47^{\circ} 16^{\prime} 30^{\prime \prime}$ & & Yiershi & te & SHRIMP & 7 & 2 & al., 2003b \\
\hline $2002 \mathrm{DL}$ & & $126^{\circ} 38^{\prime} 39$ & & & & 48 & & \\
\hline$-21-32$ & $49^{\circ} 31^{\prime} 16^{\prime \prime}$ & & Daling & Gabbro & SHRIMP & 3 & 4 & Miao (2003) \\
\hline $2002 \mathrm{NJ}$ & & $125^{\circ} 24^{\prime} 24$ & & Monzogran & & 29 & & Miao et al. \\
\hline-2 & $49^{\circ} 21^{\prime} 24^{\prime \prime}$ & & & ite & SHRIMP & 2 & 6 & (2004) \\
\hline $2002 \mathrm{NJ}$ & & $125^{\circ} 40^{\prime} 07$ & & & & 33 & & Miao et al. \\
\hline-7 & $49^{\circ} 15^{\prime} 15^{\prime \prime}$ & $"$ & & Gneiss & SHRIMP & 3 & 7 & (2004) \\
\hline $2002 X$ & & $126^{\circ} 54^{\prime} 29$ & & Granodiorit & & 16 & & \\
\hline KL-2 & $50^{\circ} 13^{\prime} 29^{\prime \prime}$ & & & $\mathrm{e}$ & SHRIMP & 4 & 4 & Miao (2003) \\
\hline $2002 X$ & & $126^{\circ} 47^{\prime} 45$ & & Granodiorit & & 16 & & Miao et al. \\
\hline KL-7 & $50^{\circ} 15^{\prime} 25^{\prime \prime}$ & & & e & SHRIMP & 7 & 4 & (2004) \\
\hline $2002 X T$ & & $124^{\circ} 11^{\prime} 45$ & & & & 20 & & \\
\hline-11 & $50^{\circ} 08^{\prime} 50^{\prime \prime}$ & & Xintian & Felsic dyke & SHRIMP & 8 & 2 & Miao (2003) \\
\hline $2002 Y$ & & $124^{\circ} 18^{\prime} 47$ & & Plagiograni & & 22 & & \\
\hline W-26 & $50^{\circ} 54^{\prime} 47^{\prime \prime}$ & & Guyuan & te & SHRIMP & 6 & 2 & Miao (2003) \\
\hline 05FW0 & & $117^{\circ} 32^{\prime} 30$ & & Monzogran & LA- & 14 & & Wu et al. \\
\hline 64 & $43^{\circ} 13^{\prime} 33^{\prime \prime}$ & & Jingpeng & ite & ICPMS & 1 & 1 & $(2011)$ \\
\hline 05FW0 & & $117^{\circ} 32^{\prime} 30$ & & Monzogran & LA- & 14 & & Wu et al. \\
\hline 65 & $43^{\circ} 13^{\prime} 33^{\prime \prime}$ & & Jingpeng & ite & ICPMS & 0 & 2 & (2011) \\
\hline 05FW0 & & $117^{\circ} 31^{\prime} 54$ & & Quartz & LA- & 13 & & Wu et al. \\
\hline 66 & $43^{\circ} 14^{\prime} 02^{\prime \prime}$ & & Jingpeng & syenite & ICPMS & 4 & 1 & $(2011)$ \\
\hline 05FW0 & & $117^{\circ} 44^{\prime} 55$ & & Monzogran & LA- & 14 & & Wu et al. \\
\hline 80 & $43^{\circ} 15^{\prime} 50^{\prime \prime}$ & & Jingpeng & ite & ICPMS & 0 & 2 & $(2011)$ \\
\hline 05FW0 & & $117^{\circ} 49^{\prime} 12$ & Baiyinbango & Monzogran & LA- & 13 & & Wu et al. \\
\hline 83 & $43^{\circ} 15^{\prime} 08^{\prime \prime}$ & & $\mathrm{u}$ & ite & ICPMS & 1 & 2 & $(2011)$ \\
\hline 05FW0 & & $118^{\circ} 09^{\prime} 03$ & & & LA- & 49 & & $\mathrm{Wu}$ et al. \\
\hline 90 & $43^{\circ} 15^{\prime} 24^{\prime \prime}$ & & Wanbao & Gneiss & ICPMS & 9 & 3 & $(2011)$ \\
\hline 05FW0 & & $118^{\circ} 09^{\prime} 03$ & & Mylonitic & LA- & 23 & & Wu et al. \\
\hline 92 & $43^{\circ} 15^{\prime} 24^{\prime \prime}$ & & Wanbao & granite & ICPMS & 7 & 3 & $(2011)$ \\
\hline 05FW0 & & $118^{\circ} 09^{\prime} 03$ & & Monzogran & LA- & 22 & & Wu et al. \\
\hline 95 & $43^{\circ} 15^{\prime} 24^{\prime \prime}$ & & Wanbao & ite & ICPMS & 2 & 3 & $(2011)$ \\
\hline 05FW0 & & $118^{\circ} 16^{\prime} 37$ & Fangkuangg & & LA- & 27 & & Wu et al. \\
\hline 96 & $43^{\circ} 20^{\prime} 16^{\prime \prime}$ & & ou & Gneiss & ICPMS & 4 & 2 & $(2011)$ \\
\hline 05FW0 & & $118^{\circ} 16^{\prime} 08$ & & & LA- & 26 & & Wu et al. \\
\hline 97 & $43^{\circ} 20^{\prime} 57^{\prime \prime}$ & & Xiahaisugou & Gneiss & ICPMS & 1 & 6 & (2011) \\
\hline 05FW0 & & $118^{\circ} 27^{\prime} 20$ & & & LA- & 25 & & Wu et al. \\
\hline 98 & $43^{\circ} 20^{\prime} 27^{\prime \prime}$ & & Xiahaisugou & Gneiss & ICPMS & 9 & 2 & (2011) \\
\hline 05FW0 & & $118^{\circ} 27^{\prime} 20$ & Yuanbaosha & Monzogran & LA- & 27 & & Wu et al. \\
\hline 99 & $43^{\circ} 20^{\prime} 27^{\prime \prime}$ & & $\mathrm{n}$ & ite & ICPMS & 3 & 3 & (2011) \\
\hline 05FW1 & & $118^{\circ} 26^{\prime} 25$ & & & LA- & 23 & & Wu et al. \\
\hline 02 & $43^{\circ} 20^{\prime} 40^{\prime \prime}$ & & Xiahaisugou & Gneiss & ICPMS & 7 & 2 & $(2011)$ \\
\hline 05FW1 & & $118^{\circ} 24^{\prime} 59$ & & & LA- & 24 & & Wu et al. \\
\hline 10 & $43^{\circ} 17^{\prime} 57^{\prime \prime}$ & & Shuangjing & Diorite & ICPMS & 6 & 2 & $(2011)$ \\
\hline 05FW1 & & $118^{\circ} 24^{\prime} 59$ & & & LA- & 24 & & Wu et al. \\
\hline 11 & $43^{\circ} 17^{\prime} 57^{\prime \prime}$ & & Shuangjing & Gneiss & ICPMS & 7 & 3 & $(2011)$ \\
\hline 05FW1 & & $117^{\circ} 29^{\prime} 47$ & Huanggangli & Syenograni & LA- & 13 & & Wu et al. \\
\hline 16 & $43^{\circ} 26^{\prime} 13^{\prime \prime}$ & & ang & te & ICPMS & 2 & 1 & $(2011)$ \\
\hline 05FW1 & & $117^{\circ} 36^{\prime} 34$ & & Monzogran & LA- & 13 & & Wu et al. \\
\hline 20 & $43^{\circ} 21^{\prime} 43^{\prime \prime}$ & $"$ & Dayingzi & ite & ICPMS & 2 & 1 & $(2011)$ \\
\hline 05FW1 & & $117^{\circ} 39^{\prime} 05$ & Huanggangli & Monzogran & LA- & 14 & & Wu et al. \\
\hline 21 & $43^{\circ} 29^{\prime} 56^{\prime \prime}$ & & ang & ite & ICPMS & 6 & 2 & $(2011)$ \\
\hline 05FW1 & & $117^{\circ} 37^{\prime} 27$ & Huanggangli & Syenograni & LA- & 14 & & Wu et al. \\
\hline 24 & $43^{\circ} 31^{\prime} 09^{\prime \prime}$ & $"$ & ang & te & ICPMS & 1 & 1 & (2011) \\
\hline
\end{tabular}




\begin{tabular}{|c|c|c|c|c|c|c|c|c|}
\hline 05FW1 & & $117^{\circ} 54^{\prime} 44$ & & & LA- & 25 & & Wu et al. \\
\hline 33 & $43^{\circ} 45^{\prime} 27^{\prime \prime}$ & & Donghuang & Gabbro & ICPMS & 2 & 5 & $(2011)$ \\
\hline 05FW1 & & $117^{\circ} 50^{\prime} 39$ & & Syenograni & LA- & 28 & & Wu et al. \\
\hline 37 & $43^{\circ} 46^{\prime} 22^{\prime \prime}$ & & Banshantu & te & ICPMS & 3 & 2 & $(2011)$ \\
\hline 05FW1 & & $118^{\circ} 01^{\prime} 08$ & & Granodiorit & LA- & 24 & & Wu et al. \\
\hline 40 & $43^{\circ} 55^{\prime} 42^{\prime \prime}$ & $"$ & Xinlin & $\mathrm{e}$ & ICPMS & 1 & 2 & $(2011)$ \\
\hline 05FW1 & & $118^{\circ} 16^{\prime} 28$ & Chaoyanggo & Monzogran & LA- & 13 & & Wu et al. \\
\hline 41 & $44^{\circ} 09^{\prime} 55^{\prime \prime}$ & & $\mathrm{u}$ & ite & ICPMS & 2 & 1 & $(2011)$ \\
\hline 05FW1 & & $118^{\circ} 10^{\prime} 03$ & Chaoyanggo & Monzogran & LA- & 14 & & Wu et al. \\
\hline 47 & $44^{\circ} 07^{\prime} 36^{\prime \prime}$ & $"$ & $\mathrm{u}$ & ite & ICPMS & 2 & 3 & $(2011)$ \\
\hline 05FW1 & & $118^{\circ} 10^{\prime} 03$ & Chaoyanggo & Dioritic & LA- & 15 & & Wu et al. \\
\hline 48 & $44^{\circ} 07^{\prime} 36^{\prime \prime}$ & & $\mathrm{u}$ & enclave & ICPMS & 0 & 4 & $(2011)$ \\
\hline 05FW1 & & $117^{\circ} 40^{\prime} 55$ & Mishengmia & Quartz & LA- & 30 & & Wu et al. \\
\hline 50 & $44^{\circ} 15^{\prime} 20^{\prime \prime}$ & & o & diorite & ICPMS & 3 & 3 & (2011) \\
\hline 05FW1 & & $117^{\circ} 51^{\prime} 33$ & Qianjinchan & Granodiorit & LA- & 27 & & Wu et al. \\
\hline 55 & $44^{\circ} 09^{\prime} 46^{\prime \prime}$ & & g & e & ICPMS & 4 & 1 & $(2011)$ \\
\hline 05FW1 & & $117^{\circ} 55^{\prime} 18$ & Qianjinchan & Granodiorit & LA- & 27 & & Wu et al. \\
\hline 61 & $44^{\circ} 08^{\prime} 25^{\prime \prime}$ & $"$ & $\mathrm{~g}$ & $\mathrm{e}$ & ICPMS & 5 & 2 & (2011) \\
\hline 05FW1 & & $117^{\circ} 40^{\prime} 04$ & Daqingmuch & Monzogran & LA- & 27 & & Wu et al. \\
\hline 62 & $44^{\circ} 11^{\prime} 36^{\prime \prime}$ & & ang & ite & ICPMS & 4 & 4 & (2011) \\
\hline 05FW1 & & $117^{\circ} 43^{\prime} 05$ & & Granodiorit & LA- & 13 & & Wu et al. \\
\hline 63 & $44^{\circ} 04^{\prime} 54^{\prime \prime}$ & & Beidashan & $\mathrm{e}$ & ICPMS & 9 & 1 & $(2011)$ \\
\hline 05FW1 & & $117^{\circ} 34^{\prime} 07$ & & Monzogran & LA- & 24 & & Wu et al. \\
\hline 67 & $43^{\circ} 51^{\prime} 58^{\prime \prime}$ & & Zhuanshanzi & ite & ICPMS & 6 & 2 & $(2011)$ \\
\hline 05FW1 & & $117^{\circ} 32^{\prime} 24$ & & Syenograni & LA- & 13 & & Wu et al. \\
\hline 71 & $43^{\circ} 57^{\prime} 15^{\prime \prime}$ & & Beidashan & te & ICPMS & 6 & 2 & $(2011)$ \\
\hline 05FW1 & & $117^{\circ} 06^{\prime} 27$ & & Quartz & LA- & 30 & & Wu et al. \\
\hline 74 & $43^{\circ} 58^{\prime} 41^{\prime \prime}$ & & Meilindaba & diorite & ICPMS & 1 & 1 & (2011) \\
\hline 05FW1 & & $117^{\circ} 08^{\prime} 56$ & & Monzogran & LA- & 32 & & Wu et al. \\
\hline 76 & $43^{\circ} 56^{\prime} 59^{\prime \prime}$ & & Dusheyetu & ite & ICPMS & 1 & 1 & (2011) \\
\hline 05FW1 & & $117^{\circ} 07^{\prime} 23$ & & Monzogran & LA- & 28 & & Wu et al. \\
\hline 78 & $43^{\circ} 45^{\prime} 03^{\prime \prime}$ & & Telegute & ite & ICPMS & 0 & 3 & $(2011)$ \\
\hline 05FW1 & & $117^{\circ} 07^{\prime} 23$ & & Dioritic & LA- & 28 & & Wu et al. \\
\hline 80 & $43^{\circ} 45^{\prime} 03^{\prime \prime}$ & & Telegute & dyke & ICPMS & 7 & 3 & (2011) \\
\hline G0206- & & $122^{\circ} 29^{\prime} 13$ & & Monzodiori & LA- & 12 & & Ge et al. \\
\hline 1 & $46^{\circ} 29^{\prime} 24^{\prime \prime}$ & & Yonghetun & te & ICPMS & 7 & 2 & $(2005 b)$ \\
\hline G0206- & & $122^{\circ} 29^{\prime} 13$ & & & LA- & 12 & & Ge et al. \\
\hline 2 & $46^{\circ} 29^{\prime} 24^{\prime \prime}$ & & Yonghetun & Porphyrite & ICPMS & 8 & 3 & $(2005 b)$ \\
\hline G0208- & & $122^{\circ} 07^{\prime} 29$ & & Monzogran & LA- & 13 & & Ge et al. \\
\hline 1 & $46^{\circ} 29^{\prime} 41^{\prime \prime}$ & & Qingshan & ite & ICPMS & 8 & 3 & $(2005 b)$ \\
\hline G0208- & & $122^{\circ} 07^{\prime} 29$ & & Monzogran & LA- & 13 & & Ge et al. \\
\hline 3 & $46^{\circ} 29^{\prime} 41^{\prime \prime}$ & & Qingshan & ite & ICPMS & 3 & 3 & $(2005 b)$ \\
\hline G0211- & & $121^{\circ} 28^{\prime} 55$ & & Monzogran & LA- & 17 & & Ge et al. \\
\hline 1 & $46^{\circ} 13^{\prime} 34^{\prime \prime}$ & & Dashizhai & ite & ICPMS & 6 & 13 & $(2005 b)$ \\
\hline G0211- & & $121^{\circ} 28^{\prime} 55$ & & Monzogran & LA- & 18 & & Ge et al. \\
\hline & $46^{\circ} 13^{\prime} 34^{\prime \prime}$ & & Dashizhai & ite & ICPMS & 2 & 3 & $(2005 b)$ \\
\hline G0213- & & $121^{\circ} 28^{\prime} 55$ & & Monzogran & LA- & 17 & & Ge et al. \\
\hline 4 & $46^{\circ} 13^{\prime} 34^{\prime \prime}$ & $"$ & Jingyang & $\begin{array}{l}\text { ite } \\
\text { Alkali }\end{array}$ & ICPMS & 6 & 4 & $(2005 b)$ \\
\hline G0215- & & $121^{\circ} 15^{\prime} 23$ & & feldspar & LA- & 12 & & Ge et al. \\
\hline 4 & $46^{\circ} 36^{\prime} 07^{\prime \prime}$ & $"$ & Suolun & $\begin{array}{l}\text { granite } \\
\text { Alkali }\end{array}$ & ICPMS & 6 & 2 & $(2005 b)$ \\
\hline G0217- & & $121^{\circ} 29^{\prime} 14$ & & feldspar & LA- & 22 & & Ge et al. \\
\hline 1 & $46^{\circ} 26^{\prime} 46^{\prime \prime}$ & $"$ & Chagan & $\begin{array}{l}\text { granite } \\
\text { Alkali }\end{array}$ & ICPMS & 9 & 3 & $(2005 b)$ \\
\hline G0217- & & $121^{\circ} 29^{\prime} 14$ & & feldspar & LA- & 23 & & Ge et al. \\
\hline 2 & $46^{\circ} 26^{\prime} 46^{\prime \prime}$ & & Chagan & granite & ICPMS & 6 & 2 & $(2005 b)$ \\
\hline GW041 & & $121^{\circ} 14^{\prime} 23$ & Wulanmaod & Syenograni & LA- & 13 & & Wu et al. \\
\hline 58 & $46^{\circ} 24^{\prime} 42^{\prime \prime}$ & $"$ & $\mathrm{u}$ & te & ICPMS & 1 & 1 & (2011) \\
\hline GW041 & & $121^{\circ} 05^{\prime} 32$ & & Monzogran & LA- & 12 & & Wu et al. \\
\hline 62 & $46^{\circ} 21^{\prime} 14^{\prime \prime}$ & $"$ & Shabutai & $\begin{array}{l}\text { ite } \\
\text { Alkali }\end{array}$ & ICPMS & 9 & 2 & (2011) \\
\hline GW041 & & $120^{\circ} 53^{\prime} 55$ & & feldspar & LA- & 13 & & Wu et al. \\
\hline 90 & $46^{\circ} 36^{\prime} 30^{\prime \prime}$ & & Jilasitai & granite & ICPMS & 5 & 2 & (2011) \\
\hline GW043 & & $122^{\circ} 12^{\prime} 34$ & & Syenograni & LA- & 12 & & Wu et al. \\
\hline 14 & $47^{\circ} 22^{\prime} 25^{\prime \prime}$ & $"$ & Fengshou & te & ICPMS & 0 & 2 & (2011) \\
\hline
\end{tabular}


Cretaceous-Cenozoic thermo-tectonic evolution and provenance analysis of the basement and some sedimentary successions northeast of the Songliao Basin, NE China

\begin{tabular}{|c|c|c|c|c|c|c|c|c|}
\hline $\begin{array}{l}\text { GW043 } \\
60\end{array}$ & $46^{\circ} 48^{\prime} 21^{\prime \prime}$ & $\begin{array}{l}122^{\circ} 33^{\prime} 00 \\
"\end{array}$ & $\begin{array}{l}\text { Caishichang } \\
\text { xi }\end{array}$ & $\begin{array}{l}\text { Monzogran } \\
\text { ite } \\
\text { Alkali }\end{array}$ & $\begin{array}{l}\text { LA- } \\
\text { ICPMS }\end{array}$ & $\begin{array}{r}12 \\
0\end{array}$ & 1 & $\begin{array}{l}\text { Wu et al. } \\
\text { (2011) }\end{array}$ \\
\hline $\begin{array}{l}\text { GW043 } \\
64\end{array}$ & $46^{\circ} 54^{\prime} 43^{\prime \prime}$ & $122^{\circ} 08^{\prime} 29$ & Shenshan & $\begin{array}{l}\text { feldspar } \\
\text { granite } \\
\text { Alkali }\end{array}$ & $\begin{array}{l}\text { LA- } \\
\text { ICPMS }\end{array}$ & $\begin{array}{r}11 \\
9\end{array}$ & 1 & $\begin{array}{l}\text { Wu et al. } \\
\text { (2011) }\end{array}$ \\
\hline $\begin{array}{l}\text { GW043 } \\
69\end{array}$ & $46^{\circ} 40^{\prime} 58^{\prime \prime}$ & $\begin{array}{l}121^{\circ} 13^{\prime} 11 \\
" 116^{\circ} 25^{\prime} 24\end{array}$ & Suolun & $\begin{array}{l}\text { feldspar } \\
\text { granite }\end{array}$ & $\begin{array}{l}\text { LA- } \\
\text { ICPMS }\end{array}$ & $\begin{array}{r}13 \\
4 \\
43\end{array}$ & 2 & $\begin{array}{l}\text { Wu et al. } \\
\text { (2011) }\end{array}$ \\
\hline MX01 & $43^{\circ} 51^{\prime} 06^{\prime \prime}$ & $116^{\circ} 11^{\prime} 12$ & Xilingele & $\begin{array}{l}\text { Gneiss } \\
\text { Alkali } \\
\text { feldspar }\end{array}$ & SHRIMP & 7 & 3 & Shi et al. (2003) \\
\hline $\begin{array}{l}\text { MX16 } \\
\text { 21DW- }\end{array}$ & $43^{\circ} 52^{\prime} 24^{\prime \prime}$ & $\begin{array}{l}\prime \prime \\
116^{\circ} 26^{\prime} 33\end{array}$ & Xilinhot & $\begin{array}{l}\text { granite } \\
\text { Granodiorit }\end{array}$ & SHRIMP & $\begin{array}{r}6 \\
24\end{array}$ & 2 & Shi et al. (2004) \\
\hline $\begin{array}{l}25 \\
21 \mathrm{NMG}\end{array}$ & $44^{\circ} 51^{\prime} 41^{\prime \prime}$ & $" 116^{\circ} 30^{\prime} 02$ & $\begin{array}{l}\text { Hegenshan } \\
\text { Dongfangho }\end{array}$ & $\begin{array}{l}\text { ic dyke } \\
\text { Monzogran }\end{array}$ & SHRIMP & $\begin{array}{r}7 \\
28\end{array}$ & 2 & Miao (2003) \\
\hline $\begin{array}{l}-96 \\
21 \mathrm{NMG}\end{array}$ & $45^{\circ} 26^{\prime} 18^{\prime \prime}$ & $" 117^{\circ} 27^{\prime} 32$ & ng & $\begin{array}{l}\text { ite } \\
\text { Monzogran }\end{array}$ & SHRIMP & $\begin{array}{r}8 \\
29\end{array}$ & 6 & Miao (2003) \\
\hline-105 & $45^{\circ} 40^{\prime} 29^{\prime \prime}$ & $117^{\circ} 49^{\prime} 48$ & Baolige & $\begin{array}{l}\text { ite } \\
\text { Quartz }\end{array}$ & $\begin{array}{l}\text { SHRIMP } \\
\text { LA- }\end{array}$ & $\begin{array}{r}6 \\
32\end{array}$ & 7 & $\begin{array}{l}\text { Miao (2003) } \\
\text { J.F. Liu et al. }\end{array}$ \\
\hline $42-79$ & $44^{\circ} 16^{\prime} 14^{\prime \prime}$ & $117^{\circ} 33^{\prime} 04$ & Jinxing & $\begin{array}{l}\text { diorite } \\
\text { Quartz }\end{array}$ & $\begin{array}{l}\text { ICPMS } \\
\text { LA- }\end{array}$ & $\begin{array}{r}2 \\
32\end{array}$ & 2 & $\begin{array}{l}\text { (2009) } \\
\text { J.F. Liu et al. }\end{array}$ \\
\hline $38-72$ & $44^{\circ} 07^{\prime} 50^{\prime \prime}$ & $" 123^{\circ} 10^{\prime} 53$ & Daqihundi & $\begin{array}{l}\text { diorite } \\
\text { Quartz }\end{array}$ & $\begin{array}{l}\text { ICPMS } \\
\text { LA- }\end{array}$ & $\begin{array}{r}5 \\
23\end{array}$ & 3 & $\begin{array}{l}(2009) \\
\text { Gao et al. }\end{array}$ \\
\hline T6-1 & $45^{\circ} 29^{\prime} 07^{\prime \prime}$ & $"$ & Drill hole & diorite & $\begin{array}{l}\text { ICPMS } \\
\text { Basaltic }\end{array}$ & $\begin{array}{r}6 \\
18\end{array}$ & 3 & $(2007)$ \\
\hline ER18-1 & Shanghulin & $50^{\circ} 44^{\prime} 02^{\prime \prime}$ & $120^{\circ} 11^{\prime} 57^{\prime \prime}$ & Wanbao & $\begin{array}{l}\text { andesite } \\
\text { Pyroxene }\end{array}$ & $\begin{array}{r}2 \\
16\end{array}$ & 2 & $\begin{array}{l}\text { Xu et al., } 2013 \\
\text { Meng et al., }\end{array}$ \\
\hline MZ2-1 & Western & $49^{\circ} 17^{\prime} 44^{\prime \prime}$ & $117^{\circ} 31^{\prime} 30^{\prime \prime}$ & Shangkuzi & andesite & $\begin{array}{r}6 \\
14\end{array}$ & 2 & 2011 \\
\hline $\begin{array}{l}\text { ER17-1 } \\
\text { ZKX24 }\end{array}$ & Eastern & $50^{\circ} 44^{\prime} 45^{\prime \prime}$ & $120^{\circ} 11^{\prime} 19^{\prime \prime}$ & Shangkuli & $\begin{array}{l}\text { Rhyolite } \\
\text { Trachydac }\end{array}$ & $\begin{array}{r}3 \\
14\end{array}$ & 4 & $\begin{array}{l}\text { Xu et al., } 2011 \\
\text { Meng et al., }\end{array}$ \\
\hline-04 & Well & $49^{\circ} 21^{\prime} 36^{\prime \prime}$ & $117^{\circ} 33^{\prime} 28^{\prime \prime}$ & Shangkuli & $\begin{array}{l}\text { ite } \\
\text { Dacitic }\end{array}$ & $\begin{array}{r}2 \\
14\end{array}$ & 1 & $\begin{array}{l}2011 \\
\text { Meng et al., }\end{array}$ \\
\hline MZ1-1 & Western & $49^{\circ} 17^{\prime} 33^{\prime \prime}$ & $117^{\circ} 31^{\prime} 36^{\prime \prime}$ & $\begin{array}{l}\text { Shangkuli } \\
\text { Tamulanto }\end{array}$ & $\begin{array}{l}\text { ignimbrite } \\
\text { Olivne }\end{array}$ & $\begin{array}{r}1 \\
12\end{array}$ & 1 & $\begin{array}{l}2011 \\
\text { Meng et al., }\end{array}$ \\
\hline $\begin{array}{l}\text { MZ21-1 } \\
\text { ZKX24 }\end{array}$ & Dashimo & $49^{\circ} 26^{\prime} 42^{\prime \prime}$ & $117^{\circ} 02^{\prime} 31^{\prime \prime}$ & $\mathrm{u}$ & $\begin{array}{l}\text { basalt } \\
\text { Basaltic }\end{array}$ & $\begin{array}{r}9 \\
12\end{array}$ & 2 & $\begin{array}{l}2011 \\
\text { Meng et al., }\end{array}$ \\
\hline-00 & $\begin{array}{l}\text { Well } \\
\text { Genheqiaobe }\end{array}$ & $49^{\circ} 19^{\prime} 16^{\prime \prime}$ & $117^{\circ} 32^{\prime} 22^{\prime \prime}$ & $\begin{array}{l}\text { Shangkuzi } \\
\text { Tamulango }\end{array}$ & $\begin{array}{l}\text { andesite } \\
\text { Basaltic }\end{array}$ & $\begin{array}{r}3 \\
12\end{array}$ & 2 & 2011 \\
\hline ER3-1 & i & $50^{\circ} 19^{\prime} 57^{\prime \prime}$ & $120^{\circ} 15^{\prime} 01^{\prime \prime}$ & $\begin{array}{l}\mathrm{u} \\
\text { Tamulanto }\end{array}$ & $\begin{array}{l}\text { andesite } \\
\text { Basaltic }\end{array}$ & $\begin{array}{r}5 \\
12\end{array}$ & 2 & Xu et al., 2011 \\
\hline $\begin{array}{l}\text { ER19-2 } \\
\text { ZKD2- }\end{array}$ & Shanghulin & $50^{\circ} 42^{\prime} 37^{\prime \prime}$ & $120^{\circ} 12^{\prime} 52^{\prime \prime}$ & $\begin{array}{l}\mathrm{u} \\
\text { Tamulanto }\end{array}$ & $\begin{array}{l}\text { andesite } \\
\text { Basaltic }\end{array}$ & $\begin{array}{r}7 \\
12\end{array}$ & 1 & Xu et al., 2011 \\
\hline 1 & Well & $50^{\circ} 46^{\prime} 32^{\prime \prime}$ & $120^{\circ} 11^{\prime} 35^{\prime \prime}$ & $\mathrm{u}$ & $\begin{array}{l}\text { andesite } \\
\text { Trachydac }\end{array}$ & $\begin{array}{r}8 \\
12\end{array}$ & 3 & $\begin{array}{l}\text { Xu et al., } 2011 \\
\text { Meng et al., }\end{array}$ \\
\hline MZ20-1 & Dashimo & $49^{\circ} 25^{\prime} 27^{\prime \prime}$ & $117^{\circ} 04^{\prime} 48^{\prime \prime}$ & $\begin{array}{l}\text { Shangkuzi } \\
\text { Tamulanto }\end{array}$ & ite & $\begin{array}{r}7 \\
12\end{array}$ & 3 & 2011 \\
\hline ER16-1 & Eastern & $50^{\circ} 45^{\prime} 57^{\prime \prime}$ & $120^{\circ} 10^{\prime} 37^{\prime \prime}$ & $\mathrm{u}$ & Rhyolite & $\begin{array}{r}4 \\
12\end{array}$ & 1 & $\begin{array}{l}\text { Xu et al., } 2011 \\
\text { Meng et al., }\end{array}$ \\
\hline MZ5-3 & Western & $49^{\circ} 20^{\prime} 06^{\prime \prime}$ & $117^{\circ} 30^{\prime} 33^{\prime \prime}$ & Shangkuzi & Dacite & $\begin{array}{r}5 \\
12\end{array}$ & 1 & $\begin{array}{l}2011 \\
\text { Meng et al., }\end{array}$ \\
\hline MZ7-1 & Western & $49^{\circ} 21^{\prime} 16^{\prime \prime}$ & $117^{\circ} 34^{\prime} 22^{\prime \prime}$ & Shangkuli & $\begin{array}{l}\text { Andesite } \\
\text { Trachyand }\end{array}$ & $\begin{array}{r}5 \\
12\end{array}$ & 2 & 2011 \\
\hline ER1-1 & Genhe & $49^{\circ} 59^{\prime} 57^{\prime \prime}$ & $120^{\circ} 06^{\prime} 50^{\prime \prime}$ & Meiletu & $\begin{array}{l}\text { esite } \\
\text { Trachydac }\end{array}$ & $\begin{array}{r}8 \\
12\end{array}$ & 2 & Xu et al., 2011 \\
\hline ER9-1 & Eastern & $50^{\circ} 47^{\prime} 12^{\prime \prime}$ & $119^{\circ} 52^{\prime} 54^{\prime \prime}$ & Shangkuli & $\begin{array}{l}\text { ite } \\
\text { Pyroxene }\end{array}$ & $\begin{array}{r}5 \\
12\end{array}$ & 1 & $\begin{array}{l}\text { Xu et al., } 2011 \\
\text { Meng et al., }\end{array}$ \\
\hline MZ10-1 & $\begin{array}{l}\text { Western } \\
\text { Genheqiaobe }\end{array}$ & $49^{\circ} 23^{\prime} 56^{\prime \prime}$ & $117^{\circ} 25^{\prime} 21^{\prime \prime}$ & $\begin{array}{l}\text { Shangkuzi } \\
\text { Tamulango }\end{array}$ & andesite & $\begin{array}{r}5 \\
11\end{array}$ & 2 & 2011 \\
\hline ER5-1 & $\mathrm{i}$ & $50^{\circ} 26^{\prime} 14^{\prime \prime}$ & $120^{\circ} 00^{\prime} 54^{\prime \prime}$ & $\mathrm{u}$ & Andesite & 4 & 3 & Xu et al., 2011 \\
\hline
\end{tabular}

\section{Jiamusi Block}

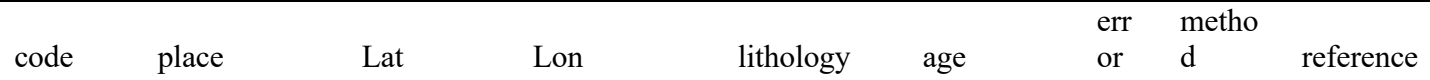




\begin{tabular}{|c|c|c|c|c|c|c|c|c|}
\hline & & & & & & & $\begin{array}{l}\text { LA- } \\
\text { ICPM }\end{array}$ & \\
\hline HQ3-1 & Qitaihe & $45^{\circ} 48^{\prime} 57^{\prime \prime}$ & $130^{\circ} 57^{\prime} 04^{\prime \prime}$ & Rhyolite & 124 & 3 & $\begin{array}{l}\text { S } \\
\text { LA- } \\
\text { ICPM }\end{array}$ & Xu et al., 2013 \\
\hline HM1-1 & Peide & $45^{\circ} 39^{\prime} 47^{\prime \prime}$ & $131^{\circ} 52^{\prime} 01^{\prime \prime}$ & Rhyolite & 116 & 1 & $\begin{array}{l}\mathrm{S} \\
\mathrm{LA}-\end{array}$ & Xu et al., 2013 \\
\hline HY4-1 & $\begin{array}{l}\text { Qinglongsha } \\
\mathrm{n}\end{array}$ & $46^{\circ} 27^{\prime} 24^{\prime \prime}$ & $130^{\circ} 07^{\prime} 25^{\prime \prime}$ & Dacite & 110 & 2 & $\begin{array}{l}\text { ICPM } \\
\text { S } \\
\text { LA- } \\
\text { ICPM }\end{array}$ & Xu et al., 2013 \\
\hline HN18 & Huanan & $46^{\circ} 19^{\prime} 39^{\prime \prime}$ & $130^{\circ} 58^{\prime} 23^{\prime \prime}$ & Rhyolite & 100 & 1 & $\begin{array}{l}\text { S } \\
\text { LA- }\end{array}$ & Sun et al., 2013 \\
\hline HY1-1 & $\begin{array}{l}\text { Dongfangho } \\
\text { ng }\end{array}$ & $46^{\circ} 26^{\prime} 51^{\prime \prime}$ & $129^{\circ} 48^{\prime} 11^{\prime \prime}$ & $\begin{array}{l}\text { Andesite } \\
\text { Gneissic }\end{array}$ & 112 & 1 & $\begin{array}{l}\text { ICPM } \\
\text { S }\end{array}$ & Xu et al., 2013 \\
\hline $\begin{array}{l}\text { 97SAW } \\
027\end{array}$ & Chaihe & $44^{\circ} 41^{\prime} 40^{\prime \prime}$ & $129^{\circ} 41^{\prime} 39^{\prime \prime}$ & $\begin{array}{l}\text { monzogran } \\
\text { ite }\end{array}$ & 254 & 4 & $\begin{array}{l}\text { SHRI } \\
\text { MP }\end{array}$ & $\begin{array}{l}\text { Wu et al., } \\
2001 \mathrm{a}\end{array}$ \\
\hline $\begin{array}{l}\text { 97SAW } \\
028 \\
07 \text { SW0 }\end{array}$ & Chushan & $45^{\circ} 07^{\prime} 27^{\prime \prime}$ & $130^{\circ} 02^{\prime} 30^{\prime \prime}$ & $\begin{array}{l}\text { Gneissic } \\
\text { granodiorit } \\
\text { e }\end{array}$ & 256 & 5 & $\begin{array}{l}\text { SHRI } \\
\text { MP }\end{array}$ & $\begin{array}{l}\text { Wu et al., } \\
\text { 2001a }\end{array}$ \\
\hline 97SW0 & Ximashan & $45^{\circ} 12^{\prime} 35^{\prime \prime}$ & $130^{\circ} 28^{\prime} 30^{\prime \prime}$ & Gt granite & 507 & 12 & $\begin{array}{l}\text { SHRI } \\
\text { MP }\end{array}$ & \\
\hline $\begin{array}{l}97 \mathrm{SW0} \\
34\end{array}$ & Ximashan & $45^{\circ} 12^{\prime} 35^{\prime \prime}$ & $130^{\circ} 28^{\prime} 30^{\prime \prime}$ & $\begin{array}{l}\text { Granulite } \\
\text { Gneissic }\end{array}$ & 500 & 9 & $\begin{array}{l}\text { SHRI } \\
\text { MP }\end{array}$ & $\begin{array}{l}\text { Wilde et al. } \\
(2000)\end{array}$ \\
\hline $\begin{array}{l}\text { 98SW1 } \\
19\end{array}$ & Qingshan & $45^{\circ} 28^{\prime} 52^{\prime \prime}$ & $130^{\circ} 34^{\prime} 26^{\prime \prime}$ & $\begin{array}{l}\text { granodiorit } \\
\text { e }\end{array}$ & 270 & 4 & $\begin{array}{l}\text { SHRI } \\
\text { MP }\end{array}$ & $\begin{array}{l}\text { Wu et al., } \\
2001 \mathrm{a}\end{array}$ \\
\hline DM1 & Dongmashan & $45^{\circ} 10^{\prime} 18^{\prime \prime}$ & $130^{\circ} 40^{\prime} 24^{\prime \prime}$ & $\begin{array}{l}\text { Granitic } \\
\text { gneiss }\end{array}$ & 523 & 8 & $\begin{array}{l}\text { SHRI } \\
\text { MP } \\
\text { SHRI }\end{array}$ & $\begin{array}{l}\text { Wilde et al. } \\
\text { (2003) } \\
\text { Wilde et al. }\end{array}$ \\
\hline M1 & Liumao & $45^{\circ} 15^{\prime} 48^{\prime \prime}$ & $130^{\circ} 48^{\prime} 12^{\prime \prime}$ & Granulite & 502 & 8 & $\begin{array}{l}\text { MP } \\
\text { SHRI }\end{array}$ & $\begin{array}{l}\text { (1997) } \\
\text { Wilde et al. }\end{array}$ \\
\hline M3 & Liumao & $45^{\circ} 15^{\prime} 48^{\prime \prime}$ & $130^{\circ} 48^{\prime} 12^{\prime \prime}$ & Felsic dyke & 502 & 10 & $\begin{array}{l}\text { MP } \\
\text { SHRI }\end{array}$ & $\begin{array}{l}\text { (1997) } \\
\text { Wilde et al. }\end{array}$ \\
\hline M5 & Liumao & $45^{\circ} 15^{\prime} 48^{\prime \prime}$ & $130^{\circ} 48^{\prime} 12^{\prime \prime}$ & Pegmatite & 501 & 18 & $\begin{array}{l}\text { MP } \\
\text { SHRI }\end{array}$ & $\begin{array}{l}(2003) \\
\text { Wilde et al. }\end{array}$ \\
\hline M7 & Liumao & $45^{\circ} 15^{\prime} 48^{\prime \prime}$ & $130^{\circ} 48^{\prime} 12^{\prime \prime}$ & $\begin{array}{l}\text { Metadiorite } \\
\text { Gneissic }\end{array}$ & 498 & 7 & MP & (1997) \\
\hline M9B & Shichang & $45^{\circ} 09^{\prime} 46^{\prime \prime}$ & $130^{\circ} 41^{\prime} 14^{\prime \prime}$ & $\begin{array}{l}\text { granodiorit } \\
\text { e }\end{array}$ & 267 & 2 & $\begin{array}{l}\text { SHRI } \\
\text { MP } \\
\text { LA- }\end{array}$ & $\begin{array}{l}\text { Wu et al., } \\
2001 \mathrm{a}\end{array}$ \\
\hline 12GW0 & & N45 25 & & Syenograni & & & ICPM & Yang et al. \\
\hline 26 & & 58.6 & E131 1048.9 & te & 541 & 5 & $\begin{array}{l}\mathrm{S} \\
\text { LA- }\end{array}$ & 2014 \\
\hline 12GW0 & & N46 18 & & Granodiorit & & & ICPM & \\
\hline 51 & & 10.0 & E131 5311.5 & $\mathrm{e}$ & 530 & 5 & $\begin{array}{l}\text { S } \\
\text { LA- }\end{array}$ & Bi et al. (2014a) \\
\hline $\begin{array}{l}11 \mathrm{GW0} \\
10\end{array}$ & & $\begin{array}{l}\text { N45 } 35 \\
04.7\end{array}$ & E131 4854.4 & $\begin{array}{l}\text { Quartz } \\
\text { monzonite }\end{array}$ & 516 & 5 & $\begin{array}{l}\text { ICPM } \\
\text { S } \\
\text { LA- }\end{array}$ & $\begin{array}{l}\text { Yang et al. } \\
2014\end{array}$ \\
\hline $\begin{array}{l}12 \mathrm{GW0} \\
31\end{array}$ & & $\begin{array}{l}\text { N45 } 31 \\
11.7\end{array}$ & E131 2853.5 & $\begin{array}{l}\text { Quartz } \\
\text { monzonite }\end{array}$ & 513 & 5 & $\begin{array}{l}\text { ICPM } \\
\text { S } \\
\text { LA- }\end{array}$ & $\begin{array}{l}\text { Yang et al. } \\
2014\end{array}$ \\
\hline $\begin{array}{l}11 \mathrm{GW0} \\
39\end{array}$ & & $\begin{array}{l}\text { N46 } 33 \\
00.4\end{array}$ & E131 4317.4 & $\begin{array}{l}\text { Monzogran } \\
\text { ite }\end{array}$ & 506 & 5 & $\begin{array}{l}\text { ICPM } \\
\text { S } \\
\text { LA- }\end{array}$ & Bi et al. (2014a) \\
\hline $\begin{array}{l}11 \mathrm{GW} 0 \\
11\end{array}$ & & $\begin{array}{l}\text { N45 } 30 \\
41.1\end{array}$ & E131 4341.3 & $\begin{array}{l}\text { Monzogran } \\
\text { ite }\end{array}$ & 498 & 5 & $\begin{array}{l}\text { ICPM } \\
\text { S } \\
\text { LA- }\end{array}$ & $\begin{array}{l}\text { Yang et al. - } \\
2014\end{array}$ \\
\hline $\begin{array}{l}11 \mathrm{GW} 0 \\
34\end{array}$ & & $\begin{array}{l}\text { N46 } 15 \\
14.5\end{array}$ & E131 4701.9 & $\begin{array}{l}\text { Syenograni } \\
\text { te }\end{array}$ & 490 & 5 & $\begin{array}{l}\text { ICPM } \\
\text { S } \\
\text { LA- }\end{array}$ & Bi et al. (2014a) \\
\hline $\begin{array}{l}11 \mathrm{GW} 0 \\
29\end{array}$ & & $\begin{array}{l}\text { N46 } 09 \\
07.3\end{array}$ & E131 5735.2 & $\begin{array}{l}\text { Monzogran } \\
\text { ite }\end{array}$ & 488 & 5 & $\begin{array}{l}\text { ICPM } \\
\mathrm{S}\end{array}$ & Bi et al. (2014a) \\
\hline
\end{tabular}


Cretaceous-Cenozoic thermo-tectonic evolution and provenance analysis of the basement and some sedimentary successions northeast of the Songliao Basin, NE China

\begin{tabular}{|c|c|c|c|c|c|c|c|}
\hline $\begin{array}{l}11 \mathrm{GW} 0 \\
32\end{array}$ & $\begin{array}{l}\text { N46 } 13 \\
30.8\end{array}$ & E131 5102.8 & $\begin{array}{l}\text { Monzogran } \\
\text { ite }\end{array}$ & 488 & 5 & $\begin{array}{l}\text { LA- } \\
\text { ICPM } \\
\text { S }\end{array}$ & Bi et al. (2014a) \\
\hline 12GW0 & N45 25 & & & & & $\begin{array}{l}\text { LA- } \\
\text { ICPM }\end{array}$ & Yang et al. \\
\hline 29 & 40.5 & E131 2751.4 & Diorite & 296 & 5 & $\begin{array}{l}\text { S } \\
\text { LA- }\end{array}$ & $(2015 a)$ \\
\hline 15GW0 & N46 26 & & Granodiorit & & & ICPM & Dong et al. \\
\hline 73 & 08.4 & E130 3025.7 & e & 278 & 5 & $\begin{array}{l}\text { S } \\
\text { LA- }\end{array}$ & $(2017 b)$ \\
\hline 15GW2 & N46 14 & & Alkali & & & ICPM & Dong et al. \\
\hline 35 & 20.8 & E130 4556.9 & granite & 276 & 5 & $\begin{array}{l}\text { S } \\
\text { LA- }\end{array}$ & (2017b) \\
\hline 15GW0 & N46 23 & E1303008 5 & Monzogran & 272 & 5 & $\begin{array}{l}\text { ICPM } \\
\text { S }\end{array}$ & Dong et al. \\
\hline & & E130 3908.5 & & $2 / 2$ & 5 & LA- & \\
\hline 15GW2 & N46 37 & & Monzogran & & 5 & ICPM & Dong et al. \\
\hline & 58.4 & E130 3/ 40.6 & & 267 & 5 & LA- & \\
\hline $15 \mathrm{GW} 2$ & N46 30 & & Monzogran & & & ICPM & Dong et al. \\
\hline 65 & 46.3 & E130 3831.8 & ite & 266 & 5 & $\begin{array}{l}\text { S } \\
\text { LA- }\end{array}$ & (2017b) \\
\hline 15GW2 & N46 31 & & Monzogran & & & ICPM & Dong et al. \\
\hline & & E130 3844.4 & & 263 & 5 & $\begin{array}{l}\text { S } \\
\text { LA- }\end{array}$ & \\
\hline $11 \mathrm{GW} 0$ & N47 05 & & Monzogran & & & ICPM & Bi et al. \\
\hline 41 & 00.2 & E131 4232.9 & ite & 261 & 5 & $\begin{array}{l}\text { S } \\
\text { LA- }\end{array}$ & (2014b) \\
\hline 10GW2 & N47 02 & & Granodiorit & & & ICPM & Bi et al. \\
\hline 51 & 02.5 & E131 4312.7 & $\mathrm{e}$ & 260 & 5 & $\begin{array}{l}\text { S } \\
\text { LA- }\end{array}$ & $(2014 b)$ \\
\hline 11GW0 & N46 20 & & Granodiorit & & & ICPM & Yang et al. \\
\hline 22 & 19.1 & E131 5730.8 & e & 257 & 5 & & $(2015 a)$ \\
\hline 13HYL & N46 02 & & Syenograni & & & ICPM & \\
\hline 3 & 46.5 & E129 4641.8 & te & 204 & 5 & $\begin{array}{l}\mathrm{S} \\
\mathrm{LA}-\end{array}$ & Guo et al. -2016 \\
\hline $\begin{array}{l}15 \mathrm{GW} 2 \\
40\end{array}$ & $\begin{array}{l}\text { N46 } 05 \\
570\end{array}$ & & Granodiorit & 123 & & ICPM & Dong et al. \\
\hline
\end{tabular}

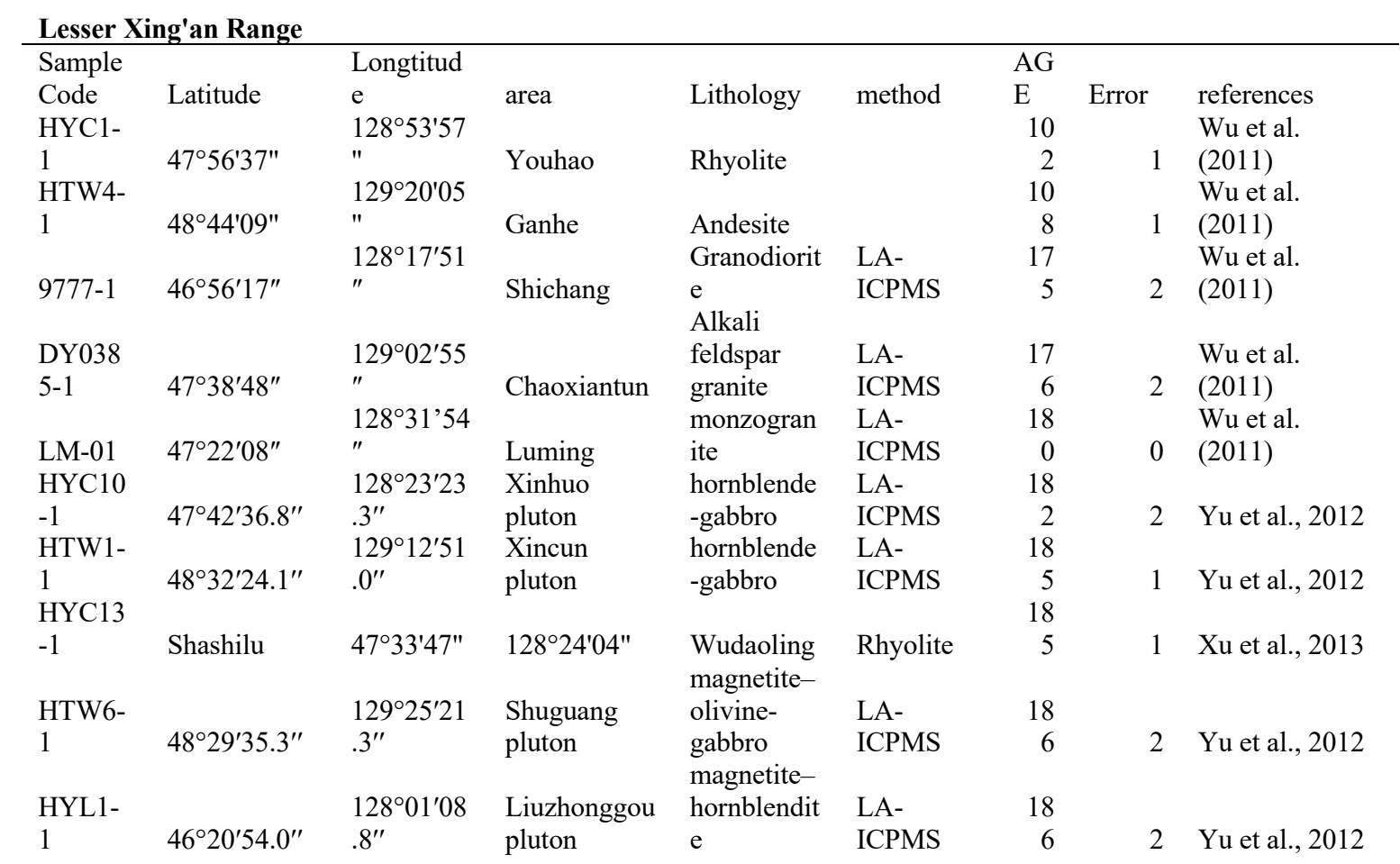




\begin{tabular}{|c|c|c|c|c|c|c|c|c|}
\hline HYC2- & & & & & & 18 & & \\
\hline 1 & Qingshan & $47^{\circ} 56^{\prime} 37^{\prime \prime}$ & $128^{\circ} 53^{\prime} 57^{\prime \prime}$ & Taiantun & Rhyolite & 7 & 2 & Xu et al., 2013 \\
\hline & & $128^{\circ} 49^{\prime} 51$ & & Syenograni & & 19 & & Wu et al. \\
\hline $9767-2$ & $46^{\circ} 31^{\prime} 05^{\prime \prime}$ & & Milin & te & TIMS & 7 & 2 & $(2002)$ \\
\hline 00SW2 & & $128^{\circ} 58^{\prime} 00$ & & Granodiorit & & 19 & & Wu et al. \\
\hline 25 & $47^{\circ} 41^{\prime} 50^{\prime \prime}$ & & Hongqi & $\mathrm{e}$ & SHRIMP & 8 & 4 & $(2011)$ \\
\hline & & $128^{\circ} 53^{\prime} 15$ & & Granodiorit & LA- & 20 & & Wu et al. \\
\hline $9766-1$ & $46^{\circ} 55^{\prime} 42^{\prime \prime}$ & & Langxiang & $\mathrm{e}$ & ICPMS & 0 & 2 & $(2011)$ \\
\hline DY038 & & $129^{\circ} 14^{\prime} 40$ & & Granodiorit & LA- & 20 & & Wu et al. \\
\hline $0-1$ & $47^{\circ} 27^{\prime} 22^{\prime \prime}$ & & Xiaoxilin & $\mathrm{e}$ & ICPMS & 0 & 3 & $(2011)$ \\
\hline & & $128^{\circ} 47^{\prime} 14$ & & Monzogran & LA- & 20 & & Wu et al. \\
\hline 9773-1 & $46^{\circ} 43^{\prime} 00^{\prime \prime}$ & & Tuanjie & ite & ICPMS & 1 & 3 & $(2011)$ \\
\hline 00SW2 & & $129^{\circ} 24^{\prime} 36$ & & Monzogran & & 20 & & Wu et al. \\
\hline 31 & $47^{\circ} 24^{\prime} 15^{\prime \prime}$ & & Dafeng & ite & SHRIMP & 1 & 4 & $(2011)$ \\
\hline HTW1- & & $129^{\circ} 12^{\prime} 51$ & Xincun & hornblende & LA- & 20 & & \\
\hline 1a & $48^{\circ} 32^{\prime} 24.1^{\prime \prime}$ & & pluton & -gabbro & ICPMS & 4 & 1 & Yu et al., 2012 \\
\hline & $47^{\circ} 35^{\prime} 27.18$ & $129^{\circ} 14^{\prime} 23$ & Yichun- & & LA- & 20 & & \\
\hline P40-1 & $"$ & $.1 "$ & Hegang & Granite & ICPMS & 9 & 1 & Wei et al., 2012 \\
\hline & & $129^{\circ} 14^{\prime} 23$ & & & LA- & 21 & & Wu et al. \\
\hline P40-1 & $47^{\circ} 35^{\prime} 28^{\prime \prime}$ & $"$ & Taiqing & Monzonite & ICPMS & 0 & 2 & $(2011)$ \\
\hline & $47^{\circ} 24^{\prime} 52.98$ & $129^{\circ} 40^{\prime} 57$ & Yichun- & & LA- & 21 & & \\
\hline P24-4 & $"$ & $.48 "$ & Hegang & Granite & ICPMS & 0 & 2 & Wei et al., 2012 \\
\hline & $47^{\circ} 20^{\prime} 54.12$ & $129^{\circ} 36^{\prime} 21$ & Yichun- & & LA- & 21 & & \\
\hline P31-4 & $"$ & $.6 "$ & Hegang & Granite & ICPMS & 1 & 1 & Wei et al., 2012 \\
\hline HTW6- & & $129^{\circ} 25^{\prime} 21$ & Shuguang & $\begin{array}{l}\text { magnetite- } \\
\text { olivine- }\end{array}$ & LA- & 21 & & \\
\hline $1 \mathrm{~b}$ & $48^{\circ} 29^{\prime} 35.3^{\prime \prime}$ & $.3^{\prime \prime}$ & pluton & gabbro & ICPMS & 2 & 1 & Yu et al., 2012 \\
\hline & & $129^{\circ} 17^{\prime} 56$ & Yichun- & & LA- & 21 & & \\
\hline $1015-01$ & $47^{\circ} 29^{\prime} 9.42^{\prime \prime}$ & $.46 "$ & Hegang & Granite & ICPMS & 2 & 2 & Wei et al., 2012 \\
\hline & & & & Alkali & & & & \\
\hline & & $129^{\circ} 47^{\prime} 03$ & & feldspar & LA- & 22 & & Sun et al. \\
\hline $9780-2$ & $48^{\circ} 16^{\prime} 28^{\prime \prime}$ & & Qingshui & granite & ICPMS & 2 & 5 & (2004) \\
\hline & $47^{\circ} 22^{\prime} 50.52$ & $129^{\circ} 59^{\prime} 27$ & Yichun- & Granodiorit & LA- & 23 & & \\
\hline P10-1 & $"$ & & Hegang & e & ICPMS & 4 & 2 & Wei et al., 2012 \\
\hline & $47^{\circ} 22^{\prime} 50.52$ & $129^{\circ} 59^{\prime} 27$ & Yichun- & Granodiorit & LA- & 24 & & \\
\hline P10-2 & $"$ & $.3 "$ & Hegang & e & ICPMS & 4 & 2 & Wei et al., 2012 \\
\hline & $47^{\circ} 22^{\prime} 32.88$ & $130^{\circ} 03^{\prime} 52$ & Yichun- & & LA- & 26 & & \\
\hline 1002-01 & $"$ & $.32 "$ & Hegang & Diorite & ICPMS & 0 & 1 & Wei et al., 2012 \\
\hline & $47^{\circ} 24^{\prime} 30.72$ & $129^{\circ} 49^{\prime} 10$ & Yichun- & & LA- & 26 & & \\
\hline P18-9 & $"$ & & Hegang & Granite & ICPMS & 0 & 1 & Wei et al., 2012 \\
\hline & & $129^{\circ} 47^{\prime} 17$ & Yichun- & & LA- & 26 & & \\
\hline $1009-01$ & $47^{\circ} 34^{\prime} 52.5^{\prime \prime}$ & $.58 "$ & Hegang & Granite & ICPMS & 1 & 1 & Wei et al., 2012 \\
\hline & $47^{\circ} 23^{\prime} 57.84$ & $129^{\circ} 54^{\prime} 22$ & Yichun- & & LA- & 26 & & \\
\hline 1006-01 & $"$ & .14 & Hegang & Granite & ICPMS & 2 & 2 & Wei et al., 2012 \\
\hline & $47^{\circ} 24^{\prime} 56.46$ & $129^{\circ} 43^{\prime} 27$ & Yichun- & & LA- & 26 & & \\
\hline $1007-01$ & $"$ & $.96 "$ & Hegang & Granite & ICPMS & 4 & 1 & Wei et al., 2012 \\
\hline DY038 & & $129^{\circ} 08^{\prime} 22$ & & Granodiorit & LA- & 44 & & Wu et al. \\
\hline $1-3$ & $47^{\circ} 22^{\prime} 40^{\prime \prime}$ & & Xiaoxilin & e & ICPMS & 7 & 4 & (2011) \\
\hline & & $129^{\circ} 25^{\prime} 27$ & & & LA- & 45 & & Wang et al., \\
\hline 14HT22 & $48^{\circ} 14^{\prime} 58^{\prime \prime}$ & & Wuying & granite & ICPMS & 0 & 2 & 2016 \\
\hline 14HYC & & $129^{\circ} 32^{\prime} 50$ & & & LA- & 45 & & Wang et al., \\
\hline 1 & $46^{\circ} 48^{\prime} 11^{\prime \prime}$ & & Chenming & Granite & ICPMS & 4 & 2 & 2016 \\
\hline 14HYC & & $129^{\circ} 28^{\prime} 31$ & & & LA- & 45 & & Wang et al., \\
\hline 9 & $47^{\circ} 00^{\prime} 15^{\prime \prime}$ & & Chenming & Rhyolite & ICPMS & 8 & 2 & 2016 \\
\hline $13 \mathrm{HYC}$ & & $129^{\circ} 27^{\prime} 31$ & & & LA- & 46 & & Wang et al., \\
\hline & $47^{\circ} 04^{\prime} 49^{\prime \prime}$ & & Chenming & Rhyolite & ICPMS & 0 & 2 & 2016 \\
\hline 14HYC & & $129^{\circ} 30^{\prime} 46$ & & monzogran & LA- & 46 & & Wang et al., \\
\hline 2 & $46^{\circ} 49^{\prime} 36^{\prime \prime}$ & & Chenming & ite & ICPMS & 4 & 4 & 2016 \\
\hline $14 \mathrm{HYC}$ & & $130^{\circ} 08^{\prime} 32$ & & monzodiori & LA- & 46 & & Wang et al., \\
\hline 16 & $47^{\circ} 11^{\prime} 46^{\prime \prime}$ & & Chenming & & ICPMS & 8 & 3 & 2016 \\
\hline & & $129^{\circ} 08^{\prime} 22$ & & monzogran & LA- & 46 & & Wang et al., \\
\hline 14HT9 & $47^{\circ} 38^{\prime} 24^{\prime \prime}$ & & Meixi & & ICPMS & 9 & 2 & 2016 \\
\hline & & $129^{\circ} 27^{\prime} 53$ & & & LA- & 47 & & Wang et al., \\
\hline $14 \mathrm{HT} 8$ & $47^{\circ} 46^{\prime} 16^{\prime \prime}$ & $"$ & Meixi & Rhyolite & ICPMS & 0 & 3 & 2016 \\
\hline & & $129^{\circ} 31^{\prime} 12$ & & $\begin{array}{l}\text { Alkali } \\
\text { feldspar }\end{array}$ & & 47 & & \\
\hline YC113 & $48^{\circ} 29^{\prime} 41^{\prime \prime}$ & & Tangwanghe & granite & ICPMS & 1 & 3 & Liu et al. (2008) \\
\hline
\end{tabular}


Cretaceous-Cenozoic thermo-tectonic evolution and provenance analysis of the basement and some sedimentary successions northeast of the Songliao Basin, NE China

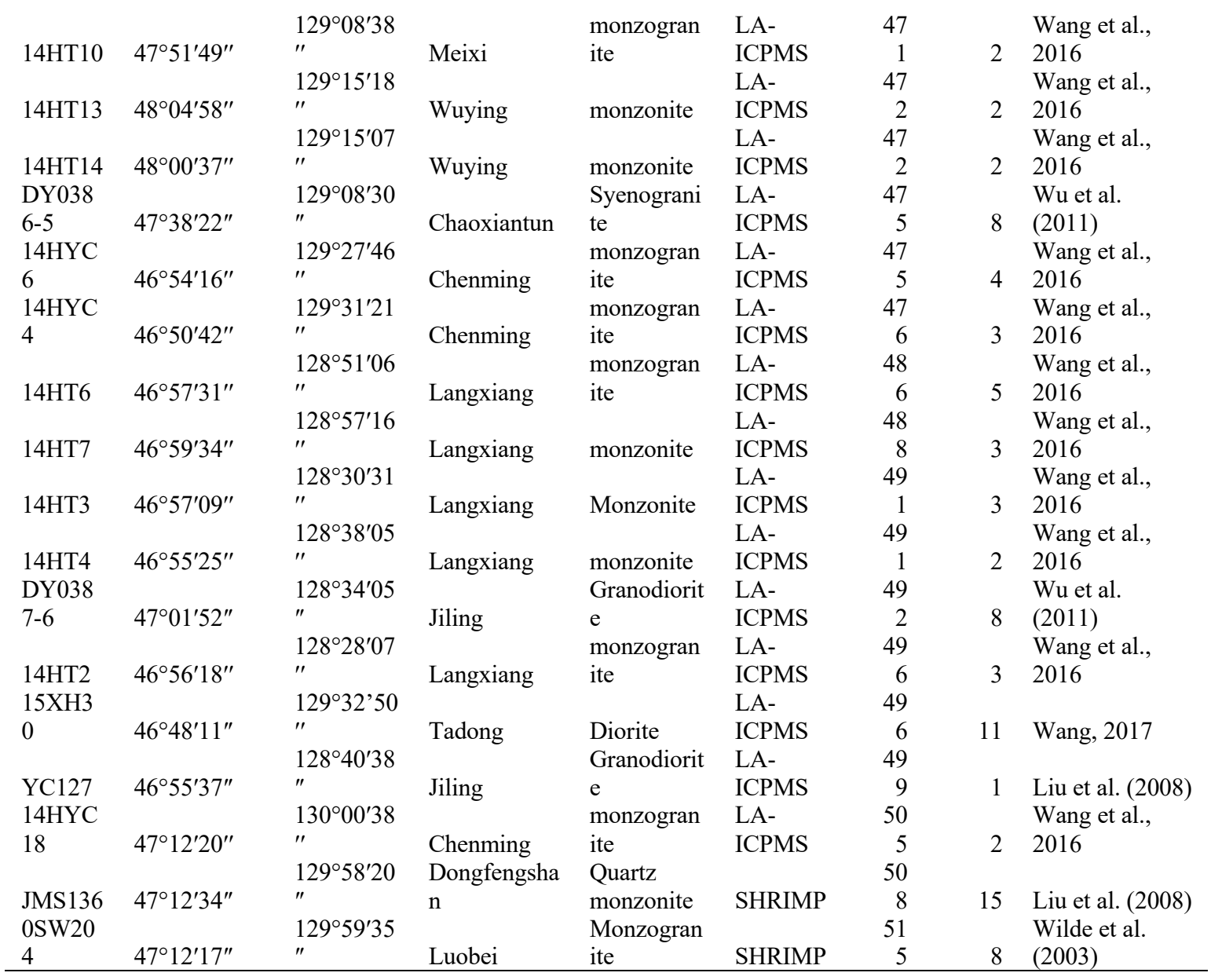


Appendix Table 4.3: Cited whole-rock geochemistry zirconium contents from igneous rock units

\begin{tabular}{|c|c|c|c|c|c|}
\hline $\begin{array}{l}\text { Sample } \\
\text { code }\end{array}$ & Location & Age(Ma) & $\begin{array}{l}\text { error } \\
\text { (Ma) }\end{array}$ & $\begin{array}{c}\mathrm{Zr} \\
(\mathrm{ppm})\end{array}$ & references \\
\hline $13 \mathrm{GW} 273$ & GXR & 210 & 2 & 129.0 & Yang et al., 2016 \\
\hline 13GW348 & GXR & 244 & 3 & 91.5 & Yang et al., 2016 \\
\hline $13 \mathrm{GW} 210$ & GXR & 212 & 2 & 107.0 & Yang et al., 2016 \\
\hline $13 \mathrm{GW} 219$ & GXR & 216 & 2 & 108.0 & Yang et al., 2016 \\
\hline $13 \mathrm{GW} 222$ & GXR & 225 & 2 & 131.0 & Yang et al., 2016 \\
\hline $13 \mathrm{GW} 228$ & GXR & 214 & 3 & 96.5 & Yang et al., 2016 \\
\hline $13 \mathrm{GW} 234$ & GXR & 230 & 2 & 92.6 & Yang et al., 2016 \\
\hline 13GW237 & GXR & 226 & 3 & 93.7 & Yang et al., 2016 \\
\hline $13 \mathrm{Gw} 255$ & GXR & 206 & 2 & 99.4 & Yang et al., 2016 \\
\hline $13 \mathrm{GW} 272$ & GXR & 151 & 1 & 64.5 & Dong et al., 2016 \\
\hline $13 \mathrm{GW} 276$ & GXR & 177 & 2 & 34.6 & Dong et al., 2016 \\
\hline $13 \mathrm{GW} 280$ & GXR & 180 & 1 & 53.2 & Dong et al., 2016 \\
\hline 13GW284 & GXR & 171 & 1 & 34.0 & Dong et al., 2016 \\
\hline 13GW289 & GXR & 171 & 2 & 51.1 & Dong et al., 2016 \\
\hline 13GW297 & GXR & 170 & 2 & 43.9 & Dong et al., 2016 \\
\hline granite-1 & GXR & 139 & 2 & 170.0 & Wang et al., 2018 \\
\hline DHS-N3 & GXR & 161 & 3 & 149.0 & Zhang et al., 2018 \\
\hline DHS-N1 & GXR & 133 & 3 & 138.0 & Zhang et al., 2018 \\
\hline DHS-N2 & GXR & 132 & 3 & 144.0 & Zhang et al., 2018 \\
\hline DHS-N4 & GXR & 131 & 3 & 159.0 & Zhang et al., 2018 \\
\hline TW05 & GXR & 345 & 3 & 134.9 & Ma et al., 2019 \\
\hline Tw28 & GXR & 321 & 3.5 & 136.5 & Ma et al., 2019 \\
\hline TW25 & GXR & 310 & 4 & 173.1 & Ma et al., 2019 \\
\hline ER7-1 & GXR & 851 & 6 & 202.0 & Tang et al., 2013 \\
\hline ER27-1 & GXR & 792 & 3 & 133.0 & Tang et al., 2013 \\
\hline ER24-1 & GXR & 792 & 4 & 160.0 & Tang et al., 2013 \\
\hline 11ER23-1 & GXR & 792 & 7 & 236.0 & Tang et al., 2013 \\
\hline ER13-1 & GXR & 737 & 5 & 216.0 & Tang et al., 2013 \\
\hline JF04 & GXR & 306 & 8 & 50.0 & Feng et al., 2015 \\
\hline JF05 & GXR & 308 & 7 & 52.0 & Feng et al., 2015 \\
\hline TY02 & GXR & 315 & 2 & 126.0 & Feng et al., 2015 \\
\hline TY05 & GXR & 312 & 3 & 176.0 & Feng et al., 2015 \\
\hline PM002-18 & GXR & 130 & 3 & 213.0 & Dong et al., 2014 \\
\hline D0570-5-2 & GXR & 131 & 1 & 251.0 & Dong et al., 2014 \\
\hline D9832 & GXR & 162 & 2 & 10.0 & Ji et al., 2018 \\
\hline D9843 & GXR & 154 & 1 & 30.0 & Ji et al., 2018 \\
\hline D9845 & GXR & 157 & 1 & 35.0 & Ji et al., 2018 \\
\hline D9849 & GXR & 161 & 1 & 50.0 & Ji et al., 2018 \\
\hline D09-06 & GXR & 511 & 2 & 96.0 & Zhou et al., 2015 \\
\hline D09-07 & GXR & 492 & 1 & 258.0 & Zhou et al., 2015 \\
\hline
\end{tabular}


Cretaceous-Cenozoic thermo-tectonic evolution and provenance analysis of the basement and some sedimentary successions northeast of the Songliao Basin, NE China

\begin{tabular}{|c|c|c|c|c|c|}
\hline D09-8 & GXR & 511 & 5 & 291.0 & Zhou et al., 2015 \\
\hline D09-8A & GXR & 517 & 17 & 287.0 & Zhou et al., 2015 \\
\hline 05MZL10 & GXR & 164 & 3 & 321.0 & Ying et al., 2010 \\
\hline 05MZL16 & GXR & 149.5 & 2 & 113.0 & Ying et al., 2010 \\
\hline 05TH08 & GXR & 129.7 & 1.6 & 299.0 & Ying et al., 2010 \\
\hline 05GH10 & GXR & 123.8 & 1.3 & 305.0 & Ying et al., 2010 \\
\hline 10GW240 & Jiamusi & 283.7 & 2.2 & 13.6 & Yu et al., 2013 \\
\hline 11GW070 & Jiamusi & 277.6 & 1.6 & 37.8 & Yu et al., 2013 \\
\hline 13GW148 & Jiamusi & 507 & 4 & 242.0 & Bi master 2015 \\
\hline 13GW150 & Jiamusi & 493 & 3 & 139.0 & Bi master 2015 \\
\hline 11GW037 & Jiamusi & 510 & 3 & 48.6 & Bi master 2015 \\
\hline $11 \mathrm{Gw} 039$ & Jiamusi & 506 & 3 & 75.2 & Bi master 2015 \\
\hline 13GW156 & Jiamusi & 497 & 8 & 161.0 & Bi master 2015 \\
\hline 11GW035 & Jiamusi & 493 & 4 & 175.0 & Bi master 2015 \\
\hline 12GW051 & Jiamusi & 530 & 5 & 210.0 & Bi master 2015 \\
\hline $11 \mathrm{Gw} 032$ & Jiamusi & 488 & 3 & 105.0 & Bi master 2015 \\
\hline 11GW034 & Jiamusi & 490 & 3 & 156.0 & Bi master 2015 \\
\hline 11GW029 & Jiamusi & 488 & 3 & 112.0 & Bi master 2015 \\
\hline 15GW073 & Jiamusi & 278 & 2 & 50.0 & Dong et al., 2017 \\
\hline $15 G W 235$ & Jiamusi & 303 & 3 & 12.0 & Dong et al., 2017 \\
\hline 15GW075 & Jiamusi & 272 & 2 & 19.0 & Dong et al., 2017 \\
\hline $15 \mathrm{GW} 248$ & Jiamusi & 267 & 3 & 60.0 & Dong et al., 2017 \\
\hline $15 \mathrm{GW} 261$ & Jiamusi & 263 & 3 & 33.0 & Dong et al., 2017 \\
\hline 15GW265 & Jiamusi & 266 & 2 & 35.0 & Dong et al., 2017 \\
\hline $18 \mathrm{gw} 240$ & Jiamusi & 123 & 3 & 108.0 & Dong et al., 2016 \\
\hline $11 \mathrm{GW} 010$ & Jiamusi & 516 & 7 & 101.0 & Yang et al., 2014 \\
\hline 11Gw011 & Jiamusi & 498 & 3 & 209.0 & Yang et al., 2014 \\
\hline 11GW017 & Jiamusi & 499 & 6 & 213.0 & Yang et al., 2014 \\
\hline 12GW007 & Jiamusi & 501 & 4 & 56.0 & Yang et al., 2014 \\
\hline 12GW026 & Jiamusi & 541 & 7 & 247.0 & Yang et al., 2014 \\
\hline $\begin{array}{l}12 \mathrm{GW} 031 \\
\text { graodiorite- }\end{array}$ & Jiamusi & 513 & 6 & 110.0 & Yang et al., 2014 \\
\hline 01 & Jiamusi & 54 & 2 & 55.0 & Wang ZH, 2016 \\
\hline 2029 & Jiamusi & 275.9 & 1.8 & 168.0 & Hua et al., 2016 \\
\hline 4228 & Jiamusi & 298.8 & 3.6 & 188.0 & Hua et al., 2016 \\
\hline 12GW019 & Jiamusi & 213 & 2 & 5.0 & Yang et al., 2015 \\
\hline 13GW010 & Jiamusi & 204 & 2 & 6.0 & Yang et al., 2015 \\
\hline 12GW015 & Jiamusi & 208 & 2 & 9.0 & Yang et al., 2015 \\
\hline 13GW018 & Jiamusi & 211 & 2 & 11.0 & Yang et al., 2015 \\
\hline 12GW016 & Jiamusi & 209 & 2 & 9.0 & Yang et al., 2015 \\
\hline 13GW017 & Jiamusi & 211 & 2 & 21.0 & Yang et al., 2015 \\
\hline 12GW001 & Jiamusi & 213 & 2 & 15.0 & Yang et al., 2015 \\
\hline 13GW012 & Jiamusi & 210 & 2 & 25.0 & Yang et al., 2015 \\
\hline 13GW124 & Jiamusi & 270 & 2 & 163.0 & Bi et al., 2016 \\
\hline
\end{tabular}




\begin{tabular}{|c|c|c|c|c|c|}
\hline 13Gw110 & Jiamusi & 275 & 2 & 121.0 & Bi et al., 2016 \\
\hline 13GW104 & Jiamusi & 272 & 3 & 529.0 & Bi et al., 2016 \\
\hline 13GW564 & Jiamusi & 267 & 2 & 135.0 & Bi et al., 2016 \\
\hline 13GW554 & Jiamusi & 301 & 2 & 80.3 & Bi et al., 2016 \\
\hline 13GW560 & Jiamusi & 302 & 3 & 58.4 & Bi et al., 2016 \\
\hline 13GW096 & Jiamusi & 282 & 2 & 90.7 & Bi et al., 2016 \\
\hline 13GW094 & Jiamusi & 287 & 3 & 94.6 & Bi et al., 2016 \\
\hline 13Gw090 & Jiamusi & 281 & 2 & 99.8 & Bi et al., 2016 \\
\hline 13GW086 & Jiamusi & 302 & 4 & 95.5 & Bi et al., 2016 \\
\hline 13Gw039 & Jiamusi & 293 & 2 & 119.0 & Bi et al., 2016 \\
\hline ZS pluton & Jiamusi & 256 & 2 & 20.0 & Dong et al., 2016 \\
\hline TP pluton & Jiamusi & 259 & 3 & 34.0 & Dong et al., 2016 \\
\hline H15-08-01 & Jiamusi & 181 & 1 & 35.0 & Ge et al., 2018 \\
\hline H15-11-01 & Jiamusi & 178 & 1 & 30.0 & Ge et al., 2018 \\
\hline H15-14-01 & Jiamusi & 191 & 1 & 35.0 & Ge et al., 2018 \\
\hline H15-16-01 & Jiamusi & 195 & 1 & 24.0 & Ge et al., 2018 \\
\hline H15-34-01 & Jiamusi & 210 & 1 & 8.0 & Ge et al., 2018 \\
\hline H15-35-01 & Jiamusi & 220 & 1 & 10.0 & Ge et al., 2018 \\
\hline H15-37-01 & Jiamusi & 251 & 1 & 15.0 & Ge et al., 2018 \\
\hline H15-38-01 & Jiamusi & 242 & 1 & 26.0 & Ge et al., 2018 \\
\hline H15-39-01 & Jiamusi & 246 & 1 & 25.0 & Ge et al., 2018 \\
\hline h15-40-01 & Jiamusi & 241 & 1 & 28.0 & Ge et al., 2018 \\
\hline 15GW004 & Jiamusi & 272 & 3 & 80.0 & Yang et al., 2019 \\
\hline 15Gw013 & Jiamusi & 273 & 3 & 50.0 & Yang et al., 2019 \\
\hline 15GW026 & Jiamusi & 260 & 2 & 10.0 & Yang et al., 2019 \\
\hline 15GW036 & Jiamusi & 264 & 2 & 90.0 & Yang et al., 2019 \\
\hline 14GW516 & Jiamusi & 279 & 5 & 231.0 & Bi et al., 2016 \\
\hline 13GW186 & Jiamusi & 279 & 2 & 211.0 & Bi et al., 2016 \\
\hline T03 & LXR & 264 & 4 & 280.0 & Cui et al., 2013 \\
\hline T04 & LXR & 268 & 1 & 346.0 & Cui et al., 2013 \\
\hline Hsw2-3 & LXR & 175 & 1 & 349.0 & Xu mj, 2013 \\
\hline hsw2-6 & LXR & 239 & 3 & 100.0 & Xu mj, 2013 \\
\hline hsw6-4 & LXR & 183 & 2 & 55.0 & Xu mj, 2013 \\
\hline hsw6-12 & LXR & 185 & 2 & 101.0 & Xu mj, 2013 \\
\hline 131 & LXR & 310 & 6 & 288.0 & Qu et al., 2015 \\
\hline 9780 & LXR & 222 & 5 & 326.0 & Sun et al., 2004 \\
\hline JMS136 & LXR & 500 & 3 & 383.3 & Liu JF, 2008 \\
\hline JMS136 & LXR & 508 & 15 & 398.0 & Liu JF, 2008 \\
\hline YC127 & LXR & 498 & 1 & 261.0 & Liu JF, 2008 \\
\hline YC113 & LXR & 471 & 3 & 361.0 & Liu JF, 2008 \\
\hline 14HYC18-1 & LXR & 505 & 2 & 364.0 & Wang et al., 2016 \\
\hline 14HYC16-1 & LXR & 468 & 3 & 378.0 & Wang et al., 2016 \\
\hline 13HYC6-1 & LXR & 460 & 2 & 280.0 & Wang et al., 2016 \\
\hline
\end{tabular}


Cretaceous-Cenozoic thermo-tectonic evolution and provenance analysis of the basement and some sedimentary successions northeast of the Songliao Basin, NE China

\begin{tabular}{|c|c|c|c|c|c|}
\hline 14HT2-1 & LXR & 496 & 3 & 131.0 & Wang et al., 2016 \\
\hline 14HT4-1 & LXR & 491 & 2 & 284.0 & Wang et al., 2016 \\
\hline 14HT5-1 & LXR & 488 & 2 & 243.0 & Wang et al., 2016 \\
\hline 14HT6-1 & LXR & 486 & 5 & 227.0 & Wang et al., 2016 \\
\hline 14НT7-1 & LXR & 488 & 3 & 260.0 & Wang et al., 2016 \\
\hline 14HT8-1 & LXR & 470 & 3 & 135.0 & Wang et al., 2016 \\
\hline 14HT9-1 & LXR & 469 & 2 & 149.0 & Wang et al., 2016 \\
\hline 14HT10-1 & LXR & 471 & 2 & 254.0 & Wang et al., 2016 \\
\hline 14HT14-1 & LXR & 503 & 4 & 315.0 & Wang et al., 2016 \\
\hline 14HT13-01 & LXR & 472 & 2 & 364.0 & Wang et al., 2016 \\
\hline 14HT22-1 & LXR & 450 & 2 & 244.0 & Wang et al., 2016 \\
\hline 1 & LXR & 432 & 1 & 157.0 & Wei Lianxi, 2013 \\
\hline \multirow[t]{2}{*}{2} & LXR & 431 & 1 & 151.0 & $\begin{array}{l}\text { Wei Lianxi, } 2013 \\
\text { Wang and Liu }\end{array}$ \\
\hline & LXR & 850 & & 248.0 & 2014 \\
\hline 15YL14-1 & LXR & 182 & 2 & 172.0 & Zhu et al., 2017 \\
\hline 15YL28-1 & LXR & 185 & 2 & 125.0 & Zhu et al., 2017 \\
\hline 15YL18-4 & LXR & 182.7 & 2 & 199.0 & Zhu et al., 2017 \\
\hline 15YL10-1 & LXR & 185 & 2 & 152.0 & Zhu et al., 2017 \\
\hline 15YL38-1 & ZGC & 163 & 2 & 170.0 & Zhu et al., 2017 \\
\hline 15YL36-5 & $\mathrm{ZGC}$ & 191 & 2 & 152.0 & Zhu et al., 2017 \\
\hline 15YL40-1 & ZGC & 191 & 2 & 149.0 & Zhu et al., 2017 \\
\hline 11GW03 & ZGC & 289 & 3 & 126.0 & Yu qian, 2013 \\
\hline 9718 & $\mathrm{ZGC}$ & 182 & 3 & 299.0 & Sun et al., 2005 \\
\hline $9728-1$ & ZGC & 216 & 3 & 184.0 & Sun et al., 2005 \\
\hline D2251 & $\mathrm{ZGC}$ & 850 & 2 & 273.0 & Wang, Liu 2014 \\
\hline 1111 & $\mathrm{ZGC}$ & 443 & 5 & 39.0 & Pei et al., 2014 \\
\hline JS20 & $\mathrm{ZGC}$ & 360 & 2 & 152.0 & Wang et al., 2015 \\
\hline 12JS01 & $\mathrm{ZGC}$ & 360 & 2 & 171.0 & Wang et al., 2015 \\
\hline 12JS4-1 & ZGC & 361 & 3 & 153.0 & Wang et al., 2015 \\
\hline 11LK19-1 & ZGC & 342 & 4 & 162.0 & Wang et al., 2015 \\
\hline JS4-1 & $\mathrm{ZGC}$ & 340 & 2 & 683.0 & Wang et al., 2015 \\
\hline 11HNA7 & ZGC & 516 & 5 & 60.0 & Wang, 2017 \\
\hline \multirow[t]{5}{*}{$16 \mathrm{PH}$} & ZGC & 502 & 3 & 47.0 & Wang, 2017 \\
\hline & ZGC & 502 & 5 & 52.0 & Wang, 2017 \\
\hline & $\mathrm{ZGC}$ & 496 & 4 & 179.0 & Wang, 2017 \\
\hline & ZGC & 482 & 4 & 258.0 & Wang, 2017 \\
\hline & ZGC & 475 & 4 & 155.0 & Wang, 2017 \\
\hline HB1-1 & ZGC & 294 & 6 & 396.0 & Meng et al., 2011 \\
\hline HMD4-1 & $\mathrm{ZGC}$ & 286 & 5 & 347.0 & Meng et al., 2011 \\
\hline HYS1-1 & ZGC & 291 & 5 & 374.0 & Meng et al., 2011 \\
\hline \multirow[t]{3}{*}{ HYS2-1 } & ZGC & 291 & 5 & 333.0 & Meng et al., 2011 \\
\hline & $\mathrm{ZGC}$ & 248 & 4 & 160.0 & Sun et al., 2004a \\
\hline & ZGC & 182 & 3 & 250.0 & Sun et al., 2005a \\
\hline
\end{tabular}




\begin{tabular}{llllll} 
& ZGC & 188 & 4 & 185.0 & Sun et al., 2005a \\
16GW114 & ZGC & 215 & 1 & 10.0 & Zhao et al., 2018 \\
16GW121 & ZGC & 217 & 1 & 15.0 & Zhao et al., 2018 \\
16GW126 & ZGC & 219 & 1 & 20.0 & Zhao et al., 2018 \\
16GW110 & ZGC & 221 & 1 & 25.0 & Zhao et al., 2018 \\
16GW124 & ZGC & 221 & 1 & 30.0 & Zhao et al., 2018 \\
$9757-4$ & ZGC & 213 & 2 & 428.0 & Wu et al., 2002 \\
$9767-2$ & ZGC & 197 & 2 & 92.0 & Wu et al., 2002 \\
$9718-1$ & ZGC & 191 & 9 & 299.0 & Wu et al., 2002 \\
baishi-1 & ZGC & 123 & 3 & 324.0 & Wu et al., 2002 \\
9780 & ZGC & 196 & 4 & 378.0 & Wu et al., 2002 \\
DW2 & ZGC & 229 & 4 & 785.0 & Wu et al., 2002 \\
9715 & ZGC & 190 & 2 & 255.0 & Wu et al., 2002 \\
\hline
\end{tabular}

